
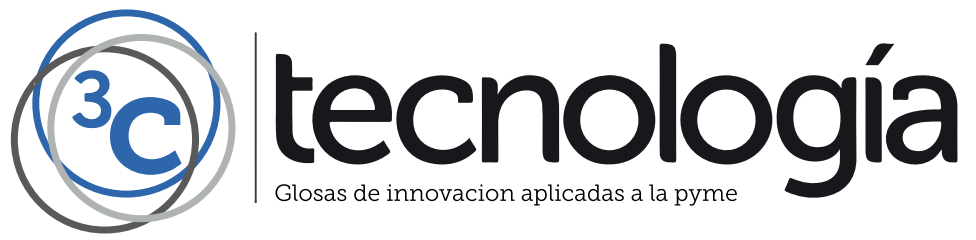

Edición Especial

Noviembre 2019

Special Issue November 2019

ISSN: 2254-4143

Intelligent Disaster Management and Green Computing in the Big Data Era: Policies,

Perspectives, and Prospects

5th International Conference on Green Computing and Engineering Technologies

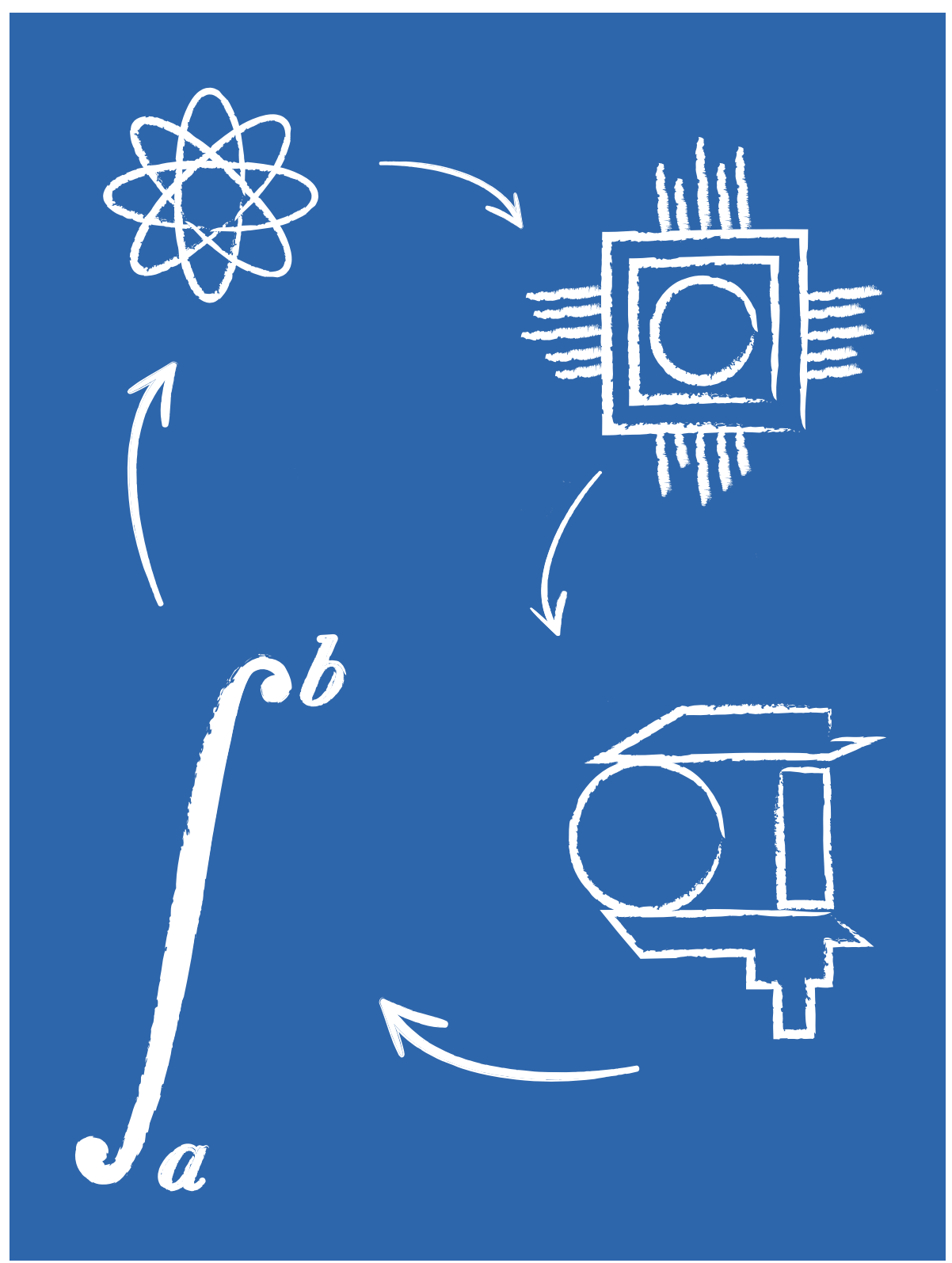




\section{C Tecnología. Glosas de innovación aplicadas a la pyme.}

Periodicidad trimestral. Quarterly periodicity.

Edición Especial. Special Issue.

Intelligent Disaster Management and Green Computing in the Big Data Era: Policies, Perspectives, and Prospects.

5th International Conference on Green Computing and Engineering Technologies.

Hotel Diwan, 31 Boulevard Hassan Seghir, Casablanca 20000, Morocco.

17-19 Septiembre, 2019. September 17-19, 2019.

\section{Guest Editors:}

Prof. Jason Levy. University of Hawaii, U.S.A. jlevy@hawaii.edu

Dr. Bishwajeet Kumar Pandey. Director-Gyancity Research Lab. gyancity@gyancity.com

Tirada nacional e internacional. National and internacional circulation.

Artículos revisados por el método de evaluación de pares de doble ciego.

Articles reviewed by the double blind peer evaluation method.

ISSN: 2254-4143

$\mathrm{N}^{\mathrm{o}}$ de Depósito Legal: A 268-2012

DOI: http://dx.doi.org/10.17993/3ctecno.2019.specialissue3

Edita:

Área de Innovación y Desarrollo, S.L.

C/ Els Alzamora 17, Alcoy, Alicante (España)

Tel: 965030572

info@3ciencias.com _www.3ciencias.com

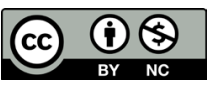

Todos los derechos reservados. Se autoriza la reproducción total o parcial de los artículos citando la fuente y el autor. This publication may be reproduced by mentioning the source and the authors. Copyright (C) Área de Innovación y Desarrollo, S.L. 


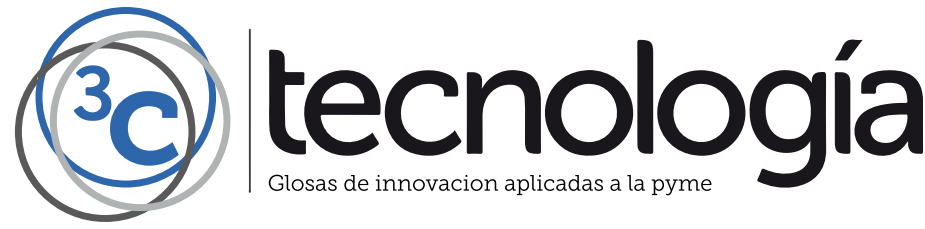




\section{CONSEJO EDITORIAL EDITORIAL BOARD}

Director

Director

Editores adjuntos

Assistant editors

Editores asociados

Associate editors
Víctor Gisbert Soler

María J. Vilaplana Aparicio

Maria Vela Garcia

David Juárez Varón

F. Javier Cárcel Carrasco

\section{CONSEJO DE REDACCIÓN DRAFTING BOARD}

Dr. David Juárez Varón. Universidad Politécnica de Valencia (España)

Dr. Martín León Santiesteban. Universidad Autónoma de Occidente (México)

Dr. F. Javier Cárcel Carrasco. Universidad Politécnica de Valencia (España)

Dr. Alberto Rodríguez Rodríguez. Universidad Estatal del Sur de Manabi (Ecuador)

\section{CONSEJO ASESOR ADVISORY BOARD}

Dra. Ana Isabel Pérez Molina. Universidad Politécnica de Valencia (España)

Dr. Julio C. Pino Tarragó. Universidad Estatal del Sur de Manabi (Ecuador)

Dr. Jorge Francisco Bernal Peralta. Universidad de Tarapacá (Chile)

Dr. Roberth O. Zambrano Santos. Instituto Tecnológico Superior de Portoviejo (Ecuador)

Dr. Sebastián Sánchez Castillo. Universidad de Valencia (España)

Dra. Sonia P. Ubillús Saltos. Instituto Tecnológico Superior de Portoviejo (Ecuador)

Dr. Jorge Alejandro Silva Rodríguez de San Miguel. Instituto Politécnico Nacional (México) 


\section{CONSEJO CIENTÍFICO TÉCNICO TECHNICAL SCIENTIFIC BOARD}

Área téxtil

Textile area

Área financiera

Financial area

Organización de empresas y RRHH

Organization of companies and $H R$

Estadística; Investigación operativa

Statistics; Operative investigation

Economía y empresariales

Economy and business

Sociología y Ciencias Políticas

Sociology and Political Science

Derecho

Law

Ingeniería y Tecnología

Engineering and Technology

Tecnologías de la Información y la

Comunicación

Technology of the information and communication

Ciencias de la salud

Health Sciences
Dr. Josep Valldeperas Morell

Universidad Politécnica de Cataluña (España)

Dr. Juan Ángel Lafuente Luengo

Universidad faime I (España)

Dr. Francisco Llopis Vañó

Universidad de Alicante (España)

Dra. Elena Pérez Bernabeu

Universidad Politécnica de Valencia (España)

Dr. José Joaquín García Gómez

Universidad de Almería (España)

Dr. Rodrigo Martínez Béjar

Universidad de Murcia (España)

Dra. María del Carmen Pastor Sempere

Universidad de Alicante (España)

Dr. David Juárez Varón

Universidad Politécnica de Valencia (España)

Dr. Manuel Llorca Alcón

Universidad Politécnica de Valencia (España)

Dra. Mar Arlandis Domingo

Hospital San Juan de Alicante (España) 


\section{OBJETIVO EDITORIAL}

La Editorial científica 3Ciencias pretende transmitir a la sociedad ideas y proyectos innovadores, plasmados, o bien en artículos originales sometidos a revisión por expertos, o bien en los libros publicados con la más alta calidad científica y técnica.

\section{NUESTRO PÚBLICO}

- Personal investigador.

- Doctorandos.

- Profesores de universidad.

- Oficinas de transferencia de resultados de investigación (OTRI).

- Empresas que desarrollan labor investigadora y quieran publicar alguno de sus estudios.

\section{COBERTURA TEMÁTICA}

3C Tecnología es una revista de carácter científico-social en la que se difunden trabajos originales que abarcan la Arquitectura y los diferentes campos de la Ingeniería, como puede ser Ingeniería Mecánica, Industrial, Informática, Eléctrica, Agronómica, Naval, Física, Química, Civil, Electrónica, Forestal, Aeronáutica y de las Telecomunicaciones.

\section{INFORMACIÓN PARA AUTORES}

Toda la información sobre el envío de originales se puede encontrar en el siguiente enlace: 


\section{PUBLISHING GOAL}

3Ciencias wants to transmit to society innovative projects and ideas. This goal is reached thought the publication of original articles which are subdue to peer review or thorough the publication of scientific books.

\section{OURTARGET}

- Research staff.

- PhD students.

- Professors.

- Research Results Transfer Office.

- Companies that develop research and want to publish some of their works.

\section{TEMATIC COVERAGE}

3C Tecnología is a scientific-social journal in which original works that cover Architecture and the different fields of Engineering are disseminated, such as Mechanical, Industrial, Computer, Electrical, Agronomic, Naval, Physics, Chemistry, Civil, Electronics, Forestry, Aeronautics and Telecommunications.

\section{INSTRUCTIONS FOR AUTHORS}

All information about sending originals can be found at the following link: https://www.3ciencias.com/en/regulations/instructions/ 


\section{INDIZADO POR \\ INDEXED BY}

Plataforma de evaluación de revistas
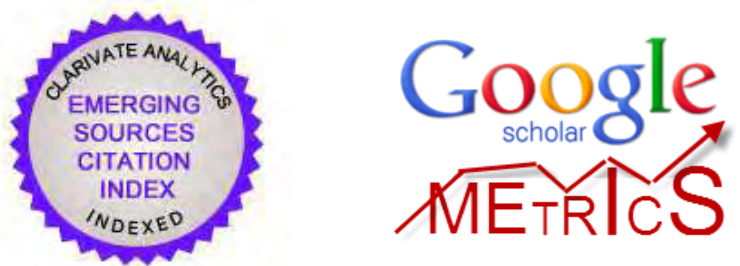

MIAR

Matriu d'Informació

per a l'Avaluació de Revistes

Bases de datos internacionales selectivas

\section{$\checkmark$ EBSCOhost}

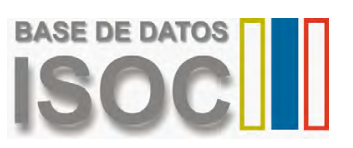

Business Source Premier OAJ $\begin{aligned} & \text { Open Academic } \\ & \text { Journals Index }\end{aligned}$
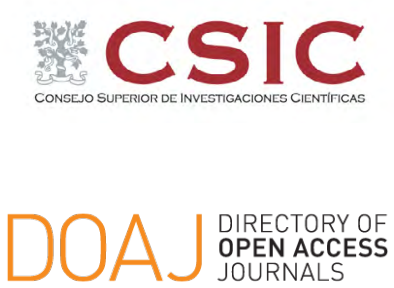

(

JOURNALS
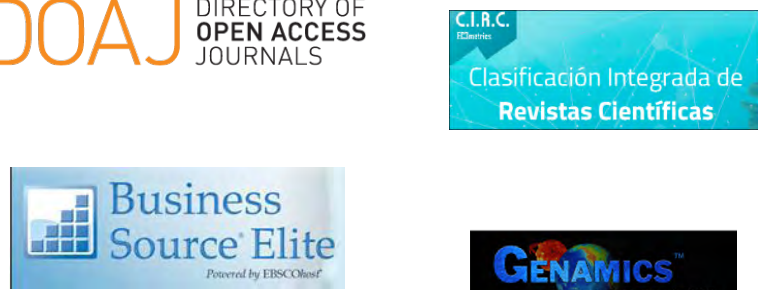

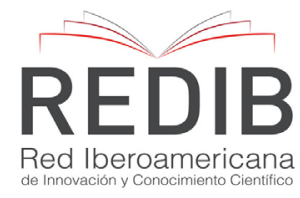

Gevalics

research from your desktop Genamics JournalSeek 
Directorios selectivos

\section{latindex}

Hemerotecas selectivas

\section{- Dialnet}

Buscadores de literatura científica en acceso abierto

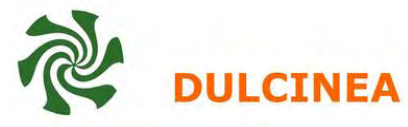


/SUMMARY/ 
Prologue: Intelligent Disaster Management and Green Computing in the Big Data Era: Policies, Perspectives and Prospects

Technologies for Effective Disaster Management Systems: A State of the Art Survey of Current Challenges and Opportunities

Bishwajeet Pandey, Jason Levy, Yousef Abubaker Mohamed Ahmed Al-Abiary, Bhagwan Das, Arifa Bhutto \& Arjumand Bano

Blockchain based auditable medical transaction scheme for organ transplant services

Gasim Alandjani

Cloud query processing analysis: encryption and decryption

Zainalabideen Ali, Azana Hafizah Binti Mohd Aman \& Rosilah Hassan

Simulation analysis for QoS in Internet of Things wireless network

Ghaith Mojib, Azana Hafizah Mohd Aman, Mahdi Khalaf \& Rosilah Hassan 77

Applications of unmanned aerial vehicles: a review

Haque Nawaz, Husnain Mansoor Ali \& Shafiq-ur-Rehman Massan

Towards a new SDN NFV approach for the management of MPLS infrastructures

Faycal Bensalah \& Najib El Kamoun

107

Ecosystem for healthcare services and management system

Azana Hafizah Mohd Aman, Syed Abdul Mutalib Al Junid, Hasimi Salehudin, Adil Hidayat, Rosilah Hassan \& Syed Mohamed Aljunid

3D modeling for Wildlife Encyclopedia using Blender

Sallar Khan, Sallar Channa, Syed Abbas Ali, Muhammad Haaris Khan, Arhum Hayat Qazi \& Kamran Mengal

Determining the effectiveness of proposed customized financial software in a Public Sector University

Muneer A. Shaikh, Rizwan Hassan, Mujawar Malik \& Ali Akbar Shah 
Design and tuning of digital power line carrier to improve network line parameters at high voltage transmission lines

Mukhtiar Hussain Khowaja, Irfan Ahmed Halepoto \& Shakeela Memon

Achieving high input power factor for DCM Buck PFC converter by variable Duty-Cycle Control

A. Hakeem Memon, M. Osama Nizamani, Anwar A. Memon, Zubair A. Memon

\& Amir M. Soomro

Critical conduction Mode Buck-Buck/Boost converter with high efficiency

A. Hakeem Memon, Mansoor A. Memon, Zubair A. Memon \& Ashfaque A. Hashmani

Conducting traffic surveillance for motor vehicle taxation

Anwar A.Memon, Arslan R. Memon \& A. Hakeem Memon

Combining the ethics and science of disaster management: key issues, policy considerations and best practices

Jason Levy \& Bishwajeet Pandey

Occupational Health \& Safety implementation framework for Pakistani construction industry in Sindh Province

Maryam Khokhar, Yumei Hou, Inayatullah Sethar, Waqas Amin \& Mohammad Shakib

Airline digital click stream event processing for enriching the airline business

Md. Alauddin, Ting Choo Yee \& Ian Tan Kim Teck

Solar Energy Status and Potential Assessment across Karachi, Pakistan

Sabir Ali Kalhoro, Muhammad Shahid, Rizwan Ali Lashari, Muhammad

Waleed, Engr. Tufail Ahmed \& Darakhshan Ara

Study on Enhancing the Energy Efficiency through Real-Time Smart

Energy Management Systems for Achieving Green ICT Campus

Kesava Rao Alla, Zainuddin Hassan \& Soong Der Chen 

/PROLOGUE/ 


\title{
INTELLIGENT DISASTER MANAGEMENT AND GREEN COMPUTING IN THE BIG DATA ERA: POLICIES, PERSPECTIVES AND PROSPECTS
}

\author{
J. Levy \\ B. Pandey \\ University of Hawaii \\ Gynacity Corporation
}

Intelligent disaster management and green computing constitute rapidly expanding research areas spanning the fields of soft computing, environmental technologies, computer science, engineering and information management. The explosion of Open and Big Data have given rise to new opportunities for understanding and solving formerly intractable environmental and disaster management challenges. The use of Big Data has now been mainstraimed into all recent trends in computing and engineering as well different disciplinary fields such as computational biology, disaster response, healthcare, social networks, finance, transportation and telecommunications. This special issue provides a unique and powerful vehicle for disseminating the latest research dealing with intelligent disaster management and green computing research, development, applications and its intelligence. The rise of Big and Open Data-and the ease with which scientists, communities, thought leaders and decision makers can access it-redefining how governments, civil society and the private sector operate. References to Big and Open Data have grown exponentially over in the past several years, and examples of big data abound, giving rise to a new philosophy of 'open-source environmental governance and disaster management', that promotes a linkage between the principles of the disaster science, green computing and open-source and open-content movements.

This set of distinguished eighteen papers strengthens interdisciplinary linkages between the fields of green computing and disaster science investigates current gaps in environmental technologies and and the opening of new research directions in the era of Big and Open Data era. Rather than separating the engineering technologies from its 'real world' impact, those contributing to this special issue have demonstrated attention to the issues of societal resilience, environmental governance and disaster risk reduction and that their work informs. Accordingly, this special issue helps 
engineering and science academics and practitioners to better understand the complex relationships related to the following key issues: transformative green computing and community resilience; disaster risk reduction and peace-building, human rights, big data and civil society activities; soft computing and social vulnerability; and environmental group decision and negotiation support. In summary, this crossdisciplinary and international collection of papers examines the most challenging societal-technologic dilemmas, with a special emphasis on crafting comprehensive, sustainable and intelligent solutions to effectively transform them with the power of Open and Big Data.

In the first paper Das et al. (2019) discuss leading edge technologies for intelligent and effective disaster management systems. In this state of the art survey, current disaster technologies the authors not only identify challenges and opportunities of existing systems but also predict areas for future growth. They note that disasters constitute devastating phenomena that may result in the large scale loss of human life. The paper addresses not only damage to critical infrastructure but also how technologies can address the large scale destruction of critical socio-technical sytems as well as how to reduce impacts to the natural and built environment. The authors show that innovative new emergency management technologies can protect human lives and ensure a more disaster resilient future. The authors discuss new technologies for disaster resistant coastal mega-cities including the Internet of Things (IoT), Big Data, as well as advances in Soft Computing and Deep Learning. The authors discuss how the Internet of things (IoT) is comprised of numerous smart devices and communication technologies. The IoT devices interchange critical information through wireless or wired network connections. The strengths and weaknesses of possible solutions for Effective Disaster Management using Multi-Technologies are discussed. Key conclusions are highlighted to promote more efficient and effective disaster management. A comprehensive literature review of current challenges and opportunities in the field are discussed with a focus on computational cybernetics and disaster risk reduction.

In the second paper, Gasim Alandjani (2019) provides a discussion of Blockchainbased medical transaction schemes for organ transplant services. Dr. Alandjani notes 
that according to the American Transplant Foundation, over one hundred thousand people in the United States are on the waiting list to receive an organ as of early March, 2019. He quotes poignant statistics dealing with the frequency with which new names are added to the transplant list list and highlights the fact that many people each day in the US die due to a lack of organ availability. It is emphasized that according to the US Department of health $(\mathrm{DoH})$ in the US alone, over a thousand new patients are added onto waiting list for organ transplantation in the US. There is a large demand for transplanting not only corneas and kidneys but a wide range of organs and human tissue including intestines, liver, bone marrow and lungs (Decoded Science, 2019). Specific data cited in the paper show that kidneys make up about three-quarters of the global unlawful trade in organs (Whoin, 2019).

Alandjani notes that the Internet of Things have brought fundamental and innovative changes to the way society works and lives. He notes that the introduction of machine to machine communication (M2M) can provide services such as setting off alarms, acting as personal assistant for reminders, and keeping track of daily activities etc. The author proposes the use of Blockchain for tracking all transactions without the compromising secrecy of data. This is achieved by keeping its integrity intact for medical-legal requirements and to prevent the risk of fraud. A Blockchain based scheme is proposed to allow auditable medical transactions to prevent organ trafficking and to support the tracking of legitimate organ donors and recipients. This research has contributed to the field of Smart Health services based on Blockchain. It is expected that this research can help to safeguard the rights of medical professionals and patients.

In the third paper, Ali, Aman and Hassan (2019) discuss encryption and decryption approaches for cloud query processing. The authors note that data query services which use cloud technologies are increasing in popularity for challenges that demand scalability and cost-efficient solutions. They also emphases the challenges faced by cloud consumers. For example how to best keep confidential data safe and secure? The need to encrypt sensitive data for security and confidentiality purposes is discussed. A wide range of papers are discussed to provide a survey of the field, such as classification approaches for identifying confidential data in order to enhance 
the efficiency of query processing over the cloud (Hussein and Sulaiman, 2016). In particular it is shown that properly encrypting data facilitates the protection of private information. The AES and RSA encryption methods are discussed with a particular focus on encryption method performance. Key technologies are highlighted including the use of Microsoft SQL Server as a cloud database simulation system and the use of Visual Studio platform to simulate the local processing of queries. A range of performance evaluation parameters are discussed for encryption and decryption. The architecture of the proposed method contains three key components: the local side; Encryption and Decryption methods (AES and RSA); and the cloud side. The three type of queries discussed are to insert data, retrieve data, and drop data. The authors suggest a combination of multiple encryption methods to improve encryption time and encryption security.

In the fourth paper Mojib, Aman, Khalaf and Hassan (2019) provide simulation analyses for QOS within the context of an Internet of Things (IOT) wireless network. The authors discuss the use of wireless network protocols for connecting smart devices such as 6LoWPAN, RPL, CoAP, MQTT, and AMQP and for transferring messages in an IoT network. The parameters considered for this paper are throughput (Aman et al., 2016), end-to-end delay (Rosilah, 2017) and jitter. They review an analysis of the RPL Routing Standard for Low Power and Lossy Networks (Parasuram, Culler, \& Katz, 2016) and a performance evaluation of RPL routing protocol in 6lowpan (Xie et al., 2014). One of the key contributions of this paper involves a comparison of the IPv6 protocol wireless network with the Low Power Wide Area Network (6LoWPAN) and Low Power and Lossy Network Routing (RPL) for IoT communications using the Contiki:cooja simulator. The considered QoS parameters are throughput, endto-end delay, and jitter.The authors show that the 6LoWPAN demonstrated superior results compared better QoS compared to RPL. It is shown that the link layer of 6LoWPAN and RPL could support the participation of "tiny things".

In the fifth paper, Haque Nawaz, Husnain Mansoor Ali and Shafiq-ur-Rehman provide an overview of Unmanned Aerial Vehicles (UAV) applications. The authors note how autonomous unnamed aerial vehicle systems are capable of performing important and timely missions. The paper presents the a wide range of UAV 
applications in a range of case studies varying from agriculture to military uses. For example, agricultural farming can be improved by using UAVs technology. The authors discuss how UAVs can be used to enhace methodologies of cultivation, to improve soil analysis and the monitoring of crops. The authors also fous on how irrigation system reconnaissance could be carried out by UAVs to improve production yields building on the work of Zhang and Kovacs (2012)2012. For example, the authors discuss the use of UAVs in the crop cycle to create 3-D mappings for soil analyses and to identify bacterial or fungal infections. The innovative use of UAVs also allows for improved irrigation and nitrogen level management (Lu et al., 2017).

In the sixth paper, Bensalah and El-Kamoun (2019) discuss a novel SDN Network Feature Virtualization (NFV) approach for managing MPLS Infrastructure. The paper addresses the integration of NFV and SDN in different environments such as cloud computing, wide area networks, $5 \mathrm{G}$ and telemedicine. The authors note that NFV allows for software components to quickly install, control and manipulate network functions. By integrating cloud and virtualization technologies NFV efficiently creates new network services while optimizing flexibility, scalability and automation. Moreover, NFV technology reduces vendor dependency and allows new features to be rapidly deployed. The authors put forth a novel solution for the virtualization of network services in order to ensure fast network access while ensuring high service quality. Results show that NFV achieves significant impovements in flexibility and cost reduction for next-generation networks. In this paper we have proposed a new architecture for virtualization of MPLS infrastructures by combining SDN and NFV approaches. Results suggest that the proposed architecture succesfully manages network services and equipment to meet subscriber QoS requirements in a timely manner. There are a number of reasons for this unparalleled flexibility and cost reduction. A key reason for these remarkable achievements is that a single gateway can instantiate multiple virtual routing tables, each of which is subject to a routing policy that meets users' QoS requirements.

In the seventh paper Aman, Al Junid, Salehudin, Hidayat, Hassan, and Aljunid (2009) propose an Intelligent Ecosystem for Healthcare Service and Management (IEHSM). This tool respresents a unique reformulation and extension of previous 
approaches in order to achieve a valuable integration of healthcare management systems, health databases as well as disease control and elimination tools. The authors emphasize the optimization of disease prevention through the use of Big Data analytics, cloud computing, machine learning and information centric networking. Based on the Casemix system, the IEHSM framework is capable of aggregating key information about patients and associated procedures based on the type and variety of treatments. In this way the authors put forth a robust and cognitive ecosystem for the management of healthcare services. In this way the authors address several key objectives: to provide a novel and valuable model for the improvement of public health; the intelligent adaptation of disease prevention models; the use of big data analytics and artificial intelligence for healthcare management; and the development of an engaging and sustainable patient and doctor-friendly system.

In the eighth paper, Khan, Channa, Ali, Khan, Qazi, and Mengal discuss the use of three-dimensionsl (3-D) wildlife modeling to benefit wildlife researchers, students, and experts. The authors use a 3D creation software blender in order to develop live 3D models of different species. This approach is not only user friendly but also provides an attractive way for users to control and retrieve desired information about different species from various ecosystems and regions around the world. 3D processing is an emerging and growing need in the multimedia domain. The first step in their orginal methodology involves "model creation". Here, a background image is chosen for the desired 3D model and an image axis is established using the software blender 3D. Next the desired body is created with the help of a "tool cube" in order to resize, scale and extend the shape. The second step in their methodology involves "unwrapping the model" followed by specific modeling steps. In conclusion, the authors successfully develop the 3D recreation of pictures and put forth a new method for deforming and articulating an object from a 2D image to a 3D model. Finally, the original use of the 3D blender software is used to transform the display of $2 \mathrm{D}$ to $3 \mathrm{D}$ images through the successful alteration of three-dimensional meshes.

Ninth, Shaikh, Hassan, Malik, and Shah (2019) examine the effectiveness of customized financial software. They carry out a thorough review of open source and licensed software applications in accounting, business and finance applications 
including Oracle, SPSS, Peachtree, SAAS and Microsoft excel. A major focus of the paper deals with powerful enterprise resource planning (ERP) software such as SAP. For example, SAP ERP incorporates the key business processes and functions of an organization including Operations, Financials (i.e. Management Accounting and Financial Supply Chain Management) and Human Capital Management (Training, Payroll, etc). Operations within SAP ERP include a wide range of fields from Sales \& Distribution, Materials Management, Production Planning, and Logistics Execution to Quality Management. The system flow of the novel financial software includes linking details of the account with voucher entries (i.e. the transactions created made by the user). After the process of recording transactions, the software retreives the transaction details and records the flow of information from sender to receiver. Next the transaction requests approval of transactions by a unit head, with each transactions assigned with a unique identifier followed by the printing of the cheques With the completion of this process, the cheque book is updated automatically by the software. The proposed software also provides data analysis tools including an income report that shows the variations in the withdrawal of the transactions. On the other hand, the remaining budget is updated to the account sheets.

The tenth paper involves the design and tuning of digital power line carriers to improve network line parameters with a particular focus on (high voltage) transmission lines. This paper, authored by Khowaja, Halepoto, and Memon (2019) involves the designed, configuration, and simulation of a Digital Power Line Carrier (DPLC) over a 3 -phase $500 \mathrm{kV} / 220 \mathrm{kV}$ high voltage transmission line. The authors employ the Micom software and configure the DPLC for fast and efficient data transmission. In particular data transmission involved distances that exceeded $700 \mathrm{~km}$. Key objectives included the need to reduce noise by using different enhanced digital techniques and advanced indoor/outdoor equipment. As a case study the existing network of the National Transmission and Dispatching Center was used Pakistan. Two two remote stations between $500 \mathrm{kV}$ Jamshoro and NKI Karachi were employed for in situ line condition measurents with respect to attenuation and noise. Line spectrum results show that in the $\mathrm{Rx}(116 \mathrm{KHz}$ to $124 \mathrm{KHz})$ band high noise leves exist $(-3.951 \mathrm{~dB}$ and analog line gain of $10.45 \mathrm{~dB}$.) To ameliorate this noise level, the DPLC was 
reconfigured and after synchronising both DPLGs of $500 \mathrm{kV}$ Jamshoro and NKI Karachi, there was a significant improvement in line parameters including noise, attenuation and BER. When DPLC was used for data transmission the system was 99.6\% error free when running for half an hour.

The eleventh paper, authored by Memon, Nizamani, Memon, Memon and Soomro (2019) discuss achieving a high input power factor for a DCM Buck Power Factor Correction ( $\mathrm{PFC}$ ) converter. Such converters are commonly employed for a broad range of $\mathrm{AC} / \mathrm{DC}$ applications. However, the authors note that there is a significant downside: traditional Discontinuous Conduction Mode (DCM) Buck Power PFC operates on a constant duty-cycle control (CDCG) scheme. As a result its input power factor $(\mathrm{PF})$ is low. To deal with this challenge, the authors propose a variable-dutycycle control (VDCG) method. Another approach is also employed: the fitting dutycycle method was shown to improve circuit implementation easier. As a result, the $\mathrm{PF}$ was improved to approximately unity. Finally, rigorous simulation results were employed to verify and validate the analysis and technique. In summary, a high power factor was achieved through the use of a variable duty-cycle control scheme and the implementation of a proposed circuit. Simulation results are presented for the verification of the analysis.

Twelfth, Memon, Memon, Memon, and Hashmani (2019) examine a high efficiency critical conduction Mode Buck-Buck/Boost converter. A novel approach is put forth to overcome the low efficiency of the buck converter when the on-time is constant, which results in higher conduction and switching losses (due to increased levels of the rms and peak values of the inductor current. The proposed methodology focuses on improving efficiency through a powerful Variable On-Time Control (VOTC) strategy to create a buck-buck/boost topology with numerous advantages. The new system has not only a simpler structure but also reduces losses and has lower component costs. A saber simulator is employed for validity testing. The simulation results confirm that the the new approach offers a promising tool for increasing the efficiency of the buck converter. 
In the thirteenth paper in this special issue Memon, Memon and Memon (2019) examine a traffic surveillance problem. The authors expore how to improve surveillance for the purposes of motor vehicle taxation with specific reference to excise taxation is the Sind government. The Sind excise taxation department collects revenue from vehicles operating under the purview of the government of Sind. Currently a tiring and cumbersome manual system is used to check payments of individual vehicles. It is proposed to develop a online automatic portal that addresses the key issues of tax defaulters. Accordingly, the authors address the optimal solution for detecting defaulters using a new technology known as Automatic Vehicle Number Plate Recognition (AVNPR). This tool face recognition and image processing to meet key goals. For example, license number plate numbers and characters are automatically read by image processing algotrithms. The proposed system has great promise for increasing the payment of vehicle taxes by delinquent motorists.

In the fourteenth paper, Levy and Pandey (2019) explore how to best combine the ethics and science of Disaster Management. They note that the scientific discourse about disasters has historically focused predominantly upon the characteristics of the physical hazards themselves and the costs of mitigation actions to reduce the risks of these physical threats. While this physical science approach involves important geologists, hydrologists and other experts, the importance of community resilience and social vulnerabilities has become increasingly recognized in the social sciences. This research uses statistical tools including binary logistic regression to analyze ethical considerations in flood disaster management issues with a focus on Asia's more devastating floods. The authors conclude that it is important that values and ethical considerations are made explicit during the disaster planning process so that they are consistent with the ethical judgments that underly the emergency management decision process. In summary the authors note that during the disaster planning phase, there will be innumerable technical and political issues, each with its own ethical components. What humans and assets do we protect, and to what level of safety? How do we set disaster budgets and priorities? The way these questions are answered reflects the ethical perspectives and moral analysis strategies of planning groups. In this paper the role of both ethical and scientific decisions in grave flood management challenges are comprehensively considered. 
In the fifteenth paper, Khokhar et.al. (2019) discuss the occupational hazards of construction companies. The principal objective of their research is to investigate occupational health and safety $(\mathrm{OH} \& \mathrm{~S})$ training to be delivered effectively to the workers of the construction companies. It has also been investigated that how the construction workers been trained during OH\&S training.

In the sixteen paper, Alauddin, Yee, and Teck (2019) propose a new way of promoting airline business with the help of both social network and mobile applications. In the proposed method, authors are using BigQuery to process huge volume of online customers' data. The proposed method is to understand the airline ecommerce online visitors effectively by analysing the event data stream collected from various digital properties.

In the seventeenth paper, Kalhoro, Waleed, Shahid, Ahmed, Lashari and Ara (2019) investigate the future of Renewable energy production in Pakistan. They observed the solar irradiation trend and the fluctuation for the hourly, daily, monthly and yearly durations. The Solar irradiation is available in the form of energy only need to explore it. They are using the python software for the solar irradiation trend observation for the Karachi.

In the eighteenth paper, Alla, Hassan and Chen (2019) discuss ongoing trends among the most Higher Education Institutions (HEI) to achieve a Green ICT Campus as part of its responsibility for building a sustainable environment. Efficient energy distribution is one of the key factors to achieve the maximum benefits of producing clean and green energy. Authors focuses on studying the current practices in energy usage in MHEI and proposing various techniques to reduce the consumption of energy usage to achieve Green ICT Campus through the Smart Grid including suggesting for alternate energy production. 


\section{REFERENCES}

Alandjani. G. (2019). Blockchain-based medical transaction schemes for organ transplant services. 3C Tecnología. Glosas de innovación aplicadas a la pyme. Special Issue, November 2019, 41-63. doi: http://dx.doi.org/10.17993/3ctecno.2019. specialissue3.41-63

Ali, Z., Aman, A.H.B.M., \& Hassan, R. (2019). Cloud Query Processing Analysis: Encryption and Decryption. 3C Tecnología. Glosas de innovación aplicadas a la pyme. Special Issue, November 2019, 65-75. doi: http:/ / dx.doi.org/10.17993/3ctecno.2019. specialissue3.65-75

Aman, A.H.M, Al Junid, S.A.M., Salehudin, H. Hidayat, A. Rosilah, H., \& Aljunid, S.M. (2019). Ecosytem for Healthcare Services and Management System. 3C Tecnología. Glosas de innovación aplicadas a la pyme. Special Issue, November 2019, 121 131. doi: http://dx.doi.org/10.17993/3ctecno.2019.specialissue3.121-131

Aman, A.H.M., Hashim, A.H.A, Abdullah, A., Ramli, H.A.M, \& Islam, S. (2016). Parametric comparison of multicast support for network mobility management: A qualitative analysis. International fournal of Multimedia and Ubiquitous Engineering, 11(9), 203-210.

Bensalah, F., \& El Kamoun, N. (2019). Towards a new SDN NFV approach for the management of MPLS Infrastructures. 3C Tecnología. Glosas de innovación aplicadas a la pyme. Special Issue, November 2019, 107-119. doi: http://dx.doi. org/10.17993/3ctecno.2019.specialissue3.107-119

Das, B., Butto, A., Bano, A., Pandey, B., Levy, J., \& Ahmed Al-Abiary, Y.A.M. (2019). Technologies for Effective Disaster Management Systems: A State of the Art Survey of Current Challenges and Opportunities. 3C Tecnología. Glosas de innovación aplicadas a la pyme. Special Issue, November 2019, 29-39. doi: http://dx.doi. org/10.17993/3ctecno.2019.specialissue3.29-39

Decoded Science. (2019, March 7). Retrieved from: https:/ /www.decodedscience. org/organ-harvesting-human-trafficking-black-market/56966 
Hussein, A., \& Sulaiman, R. (2016). A Classification Method for Identifying Confidential Data to Enhance Efficiency of Query Processing over Cloud. Fournal of Theoretical and Applied Information Technology, 93(2), 412-420.

Khan, S., Channa, S., Ali, S.A., Khan, M.H., Qazi, A.H., \& Mengal, K. (2019). 3D Modeling for Wildlife Encyclopedia Using Blender. 3C Tecnología. Glosas de innovación aplicadas a la pyme. Special Issue, November 2019, 133-147. doi: http:// dx.doi.org/10.17993/3ctecno.2019.specialissue3.133-147

Khowaja, M.H., Halepoto, I.A., \& Memon, S. (2019). Design and tuning of a digital power line carrier to improve network line parameters at high voltage transmission lines. 3C Tecnología. Glosas de innovación aplicadas a la pyme. Special Issue, November 2019, 167-183. doi: http://dx.doi.org/10.17993/3ctecno.2019. specialissue3.167-183

Levy, J., \& Pandey. B. (2019) Combining the Ethics and Science of Disaster Management: Key Issues, Policy Considerations and Best Practices. 3C Tecnología. Glosas de innovación aplicadas a la pyme. Special Issue, November 2019, 233-251. doi: http://dx.doi.org/10.17993/3ctecno.2019.specialissue3.233-251

Liu, P., Ghen, A.Y., Huang, Y.N., Han, J.Y., Lai, J.S., Kang, S.-G., ... Tsai, M.H. (2014). A review of rotorcraft Unmanned Aerial Vehicle (UAV) developments and applications in civil engineering. Smart Structures and Systems, 13(6), 1065-1094. https://doi.org/10.12989/SSS.2014.13.6.1065

Memon, A.A., Memon, A.R., \& Memon, A.H. (2019). Conducting traffic surveillance for motor vehicle taxation. 3C Tecnología. Glosas de innovación aplicadas a la pyme. Special Issue, November 2019, 221-231. doi: http://dx.doi. org/10.17993/3ctecno.2019.specialissue3.221-231

Memon, A.H., Nizamani, M. O., Memon, A.A., Memon, Z.A., \& Soomro, A.M. (2019). Achieving high input power factor for DCM Buck PFC converter by variable duty-cycle control. 3C Tecnología. Glosas de innovación aplicadas a la pyme. Special Issue, November 2019, 185-199. doi: http://dx.doi.org/10.17993/3ctecno.2019. specialissue3.185-199 
Memon, A.H., Mansoor, A. M., Memon, Z.A., \& Hashmani, A.A. (2019). Critical Conduction Mode Buck-Buck/Boost Converter with High Efficiency. 3C Tecnología. Glosas de innovación aplicadas a la pyme. Special Issue, November 2019, 201219. doi: http://dx.doi.org/10.17993/3ctecno.2019.specialissue3.201-219

Mojib, G., Aman, A.H.M., Khalaf, M., \& Hassan, R. (2019). Simluation analysis for QoS in Internet of Things wireless network. 3C Tecnología. Glosas de innovación aplicadas a la pyme. Special Issue, November 2019, 77-83. doi: http://dx.doi. org/10.17993/3ctecno.2019.specialissue3.77-83

Nawaz, H., Ali, H.N., \& Rehham-ur-Shafiq, A. (2019). Applications of unmanned aerial vehicles: a review. 3C Tecnología. Glosas de innovación aplicadas a la pyme. Special Issue, November 2019, 85-105. doi: http://dx.doi.org/10.17993/3ctecno.2019. specialissue3.85-105

Parasuram, A., Culler, D., \& Katz, R. (2016). An Analysis of the RPL Routing Standard for Low Power and Lossy Networks. Technical Report No. UCB/ EECS-2016-10698.

Rosilah, H., \& Rana, J. (2017). End-to-end (e2e) Quality of Service (QoS) for IPv6 Video Streaming. 19th International Conference on Advanced Communication Technology (ICACT), 1-4, South Korea.

Who.in. (2019, March 09). Retrieved from: https://www.who.int: https://www.who. int/bulletin/volumes/85/12/06-039370/en/

Xie, H., Zhang, G., Su, D., Wang, P., \& Zeng, F. (2014). Performance evaluation of RPL routing protocol in 6lowpan. Proceedings of the IEEE International Conference on Software Engineering and Service Sciences, ICSESS, 625-628. doi: https:// doi.org/10.1109/ICSESS.2014.6933646

Zhang, G., \& Kovacs, J.M. (2012). The application of small unmanned aerial systems for precision agriculture: A review. Precision Agriculture, 13(6), 693-712. doi: https://doi.org/10.1007/s11119-012-9274-5 


$$
\text { /1/ }
$$




\section{TECHNOLOGIES FOR EFFECTIVE DISASTER MANAGEMENT SYSTEMS: A STATE OF THE ART SURVEY OF CURRENT CHALLENGES AND OPPORTUNITIES}

\author{
Bishwajeet Pandey \\ Gyancity Research Lab, India. \\ E-mail: gyancity@gyancity.com \\ Jason Levy \\ Gyancity Research Lab, India \\ E-mail: jlevy@hawaii.edu
}

Yousef Abubaker Mohamed Ahmed

Al-Abiary

UniSZA, Malaysia

E-mail: yousefelebiary@unisza.edu.my

\author{
Bhagwan Das \\ Department of Electronic Engineering, \\ Quaid-e-Awam University of
} Engineering, Science and Technology,

Nawabshah, Sindh, Pakistan.

E-mail: engr.bhagwandas@hotmail.com

Arifa Bhutto

Insittute of Information and

Communication Technology,

University of Sindh, Pakistan.

E-mail: arifa.bhutto@usindh.edu.pk

Arjumand Bano

Insittute of Information and

Communication Technology,

University of Sindh, Pakistan.

E-mail: arjumand@usindh.edu.pk

Recepción: 26/07/2019 Aceptación: 18/09/2019 Publicación: 06/11/2019

\section{Citación sugerida:}

Pandey, B., Levy, J., Al-Abiary, Y.A.M.A., Das, B., Bhutto, B. y Bano, A. (2019). Technologies for effective disaster management systems: a state of the art survey of current challenges and opportunities. 3C Tecnología. Glosas de innovación aplicadas a la pyme. Edición Especial, Noviembre 2019, 29-39. doi: http://dx.doi.org/10.17993/3ctecno.2019. specialissue3.29-39

\section{Suggested citation:}

Pandey, B., Levy, J., Al-Abiary, Y.A.M.A., Das, B., Bhutto, B. \& Bano, A. (2019). Technologies for effective disaster management systems: a state of the art survey of current challenges and opportunities. 3 C Tecnología. Glosas de innovación aplicadas a la pyme. Special Issue, November 2019, 29-39. doi: http://dx.doi.org/10.17993/3ctecno.2019. specialissue 3.29-39 


\section{ABSTRACT}

Disasters constitute devastating phenomena that result in the large scale loss of human life and critical infrastructure, often severely disrupting critical societal sytems and the built environment. Robust emergency management can protect human lives and ensure for resilient and resistant cities. Effective disaster management systems are essential to protect human lives and to promote the development of less brittle and vulnerable critical infrastructure systems. The use of leading edge technologies for Effective Disaster Management systems are discussed and analyzed. Early technologies for Disaster Management systems include Sirens, Amateur and Community Radio, and Short Message Services (SMS). More recent approaches inlude Satellite Radio, Information and Communication (ICT) Devices, the Internet of Things (IoTs), Big Data and Deep Learning. The strengths and weaknesses of possible solutions for Effective Disaster Management using Multi-Technologies are herein discussed. Key conclusions are highlighted to promote more efficient and effective disaster management.

\section{KEYWORDS}

Effective Disaster Management (EDM), Disaster Response, Multi-Technologies, Internet of Things (IoTs). 


\section{INTRODUCTION}

A disaster is a severe disruption that often occurs in a short span of time. Natural disasters are usually considered to constitute geological events that yield large losses to humans, natural systems or infrastructure. These natural disasters include storms (Hurricanes, Tornadoes, and Tropical), floods, Earthquakes, Wildfires and etc. In natural disasters, emergency decision makers and their respective response units initiate the disaster response and recovery phases to protect lives and critical assets. Other types of disasters are health-related, intentional and na-tech disasters. Disaster examples can include environmental pollution crises, industrial catastrophes, wars and terrorist attacks. The nature of the disaster must be considered in order to provide disaster risk reduction. Disaster risk management and sustainable hazard mitigation and resilience planning are essential. Disaster management has several definitions, as proposed by various researchers. This work focuses on Effective Disaster Management (EDM). EDM can be described as providing systems, technologies and tools to thoroughly organize and manage the information from various disciplines in order to protect human lives and critical assets and key resources. The EDM can also be well described as Effective Disaster Response (EDR). This involves responding to crises and supporting survivors after a disaster strikes. A wide number of technological tools and practices of available for EDM and EDR. EDM can offer a robust technological solution in terms of Information and Communication Technologies (ICTs) and other technologies.

\section{PREVIOUS WORK}

There are many systems, technologies and innovations that have been proposed recently for disaster management and in the recent past. Each disaster management system was designed and developed to meet specific goals and criteria. The strengths of weaknesses of these systems are now discussed below.

Spencer (2019) discusses how entertainment and leisure are related to goods and service via ICT. ICT helps to increase provide new services, products and breakthroughs for productivity growth. Spencer (2019) discussed the case of Caribbean Tourism based 
on ICT in order to market tourist destinations and attractions. This can be done by updating social media and websites to include travel advisories and visitor safety information. The information is available on social media handles using Twitter, Facebook, and Instagram for real-time updates. Lee, Park and Lee (2019) have proposed to study the implementation of citizens' adoption of digital government services.

Alazawi, Altowaijri, Mehmood and Abdljabar (2011) discussed the importance of emergency response systems. The study notes that the impact of disasters can be reduced by implementing the Telecommunications and ICT systems to reduce the human losses and as well the disruption of critical infrastructure systems. This study discusses an innovative emergency response system for disasters by capitalizing on Intelligent Transportation Systems (ITS) including VANETs (Vehicular Ad hoc Networks), mobile and Cloud computing technologies. In this way an intelligent disaster management system can be proposed. The collects information from the point of accident and generates an action plan to reduce disaster damage. In an ICT, the disaster can be controlled via Vehicular Ad hoc Networks (VANETs) as well as by Machine to Machine Communication technologies (Drake, 2009). The author also describes that in disaster management the Cloud Computing has emerged as an innovative solutions in several models of business continuity planning and disaster recovery. These ICT disaster management systems are able to collect information from different locations to make appropriate decisions. Cloud computing is a centralized system to collect and store information via server services. Users pay to avail these services instead of using, buying and installing the software or hardware (Chee \& Franklin Jr., 2010). In the Figure 1 a disaster management architecture based on different layers is put forth. This is based in part on a real-time environment and an intelligent layer to support incident response. M2M, VANET and other technologies are also are proposed to support disaster management. 


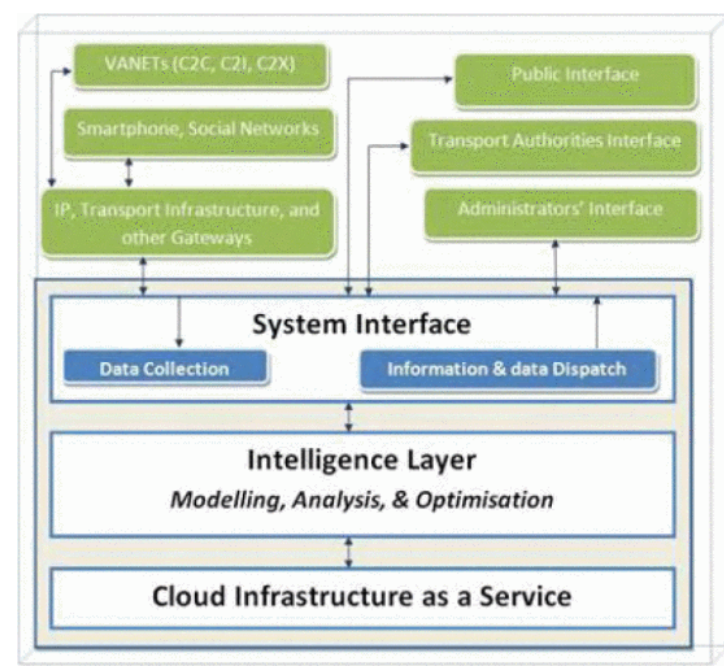

Figure 1. Disaster Management Architecture. Source: (Alazawi et al., 2011).

Islam, Sheikh, and Islam (2018) discussed a disaster management scheme based on a cognitive radio ad hoc network (GRAHN). A new solution for disaster management is provided based on a multi-layer perceptron (MLP) based disaster detection scheme. This system proposes the use of WSN and a real-time GUI to provide shared situation awareness to rescue survivors and enable better decision making.

Park et al. (2018) discuss an augmented reality (AR) based Smart Building and Town Disaster Management System. It allows for rapid guidance and supports initial response via AR. Fajardo and Oppus (2010) discussed a rescue system which was designed using an Android application known as "MyDisasterDroid". The system offers the best routes for volunteers so that they can reach the disaster zone as rapidly as possible so that the maximum number of lives can be saved. This system of disaster management is designed and developed via a Genetic Algorithm (GA) which allows for the optimization of the system by managing routes and volunteer information.

\section{MULTI-TECHNOLOGY}

This paper highlights the timely and important use of Multi-technologies for providing Effective Disaster Management. The proposed innovations can help to 
reduce the impact and likelihood of disasters in order to reduce disaster losses. Based on the information discussed above it is shown that a wide range of systems have been proposed. It is shown that the most promising solutions include GIS, mobile system, IoT based systems and Android-based approaches. ITU communications motivates researchers to use ICT systems including leading edge devices, communication systems and geospatial approaches to provide maximal safety for volunteers during a disaster and to mitigate disaster threats (Domnori, Cabri, \& Leonardi, 2011).

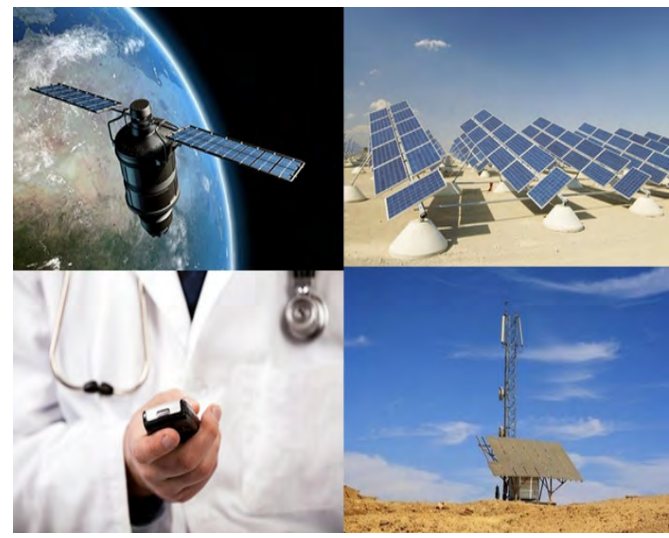

Figure 2. A Demonstration of Multi-Technologies for Disaster Management. Source: (Thomas, 2018).

A sophisticated communication system design is often used to address disaster management related issues. The phases of emergency management are shown in Figure 3.

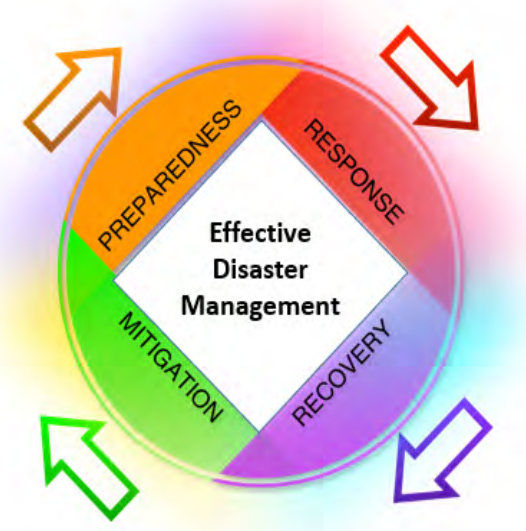

Figure 3. Multiple Phases of Effective Disaster Management. Source: (Carter, 2008). 


\section{CONCLUSION AND FUTURE SCOPE}

In this paper, the use of Multi-technologies for Effective Disaster Management systems are proposed. The Multi-Technologies include ICT, IoT and others. A multistage approach for Effective Disaster Management has been put forth. Disasters constitute an unexpected, abrupt or gradual phenomena that results in a large scale loss of human life, often disrupting critical societal sytems and the built environment. Robust emergency management and timely evacuations from the affected area can protect human lives. Effective disaster management systems are essential to protect human lives and critical infrastructure systems. A wide range of technologies for Effective Disaster Management (EDM) are put forth. The use of leading edge technologies for Effective Disaster Management systems are discussed and analyzed. Early technologies for Disaster Management systems include Sirens, Amateur and Community Radio, and Short Message Services. More recent approaches inlude Satellite Radio, Information and Communication (ICT) Devices, Internet of Things (IoTs), Big Data and others. The strengths and weaknesses of possible solutions for Effective Disaster Management using Multi-Technologies are discussed. Key conclusions are highlighted to promote more efficient and effective disaster management.

\section{REFERENCES}

Alamdar, F., Kalantari, M., \& Rajabifard, A. (2016). Towards multi-agencysensor information integration for disaster management. Computers, Environment and Urban Systems, 56, 68-85. doi: https://doi.org/10.1016/j.compenvurbsys.2015.11.005

Alazawi, Z., Altowaijri, S., Mehmood, R. \& Abdljabar, M.B. (2011, August). Intelligent disaster management system based on cloud-enabled vehicular networks. In 2011 11th International Conference on ITS Telecommunications (361-368). IEEE. 
Ali, K., Nguyen, H. X., Shah, P., Vien, Q. T., \& Ever, E. (2019). Internet of Things (IoT) Considerations, Requirements, and Architectures for Disaster Management System. In Performability in Internet of Things ( 111-125). Springer, Cham.

Banerjee, A., Basak, J., Roy, S., \& Bandyopadhyay, S. (2019). Towards a Collaborative Disaster Management Service Framework using Mobile and Web Applications: A Survey and Future Scope. In Emergency and Disaster Management: Concepts, Methodologies, Tools, and Applications ( 324-346). IGI Global.

Beydoun, G., Dascalu, S., Dominey-Howes, D., \& Sheehan, A. (2018). Disaster Management and Information Systems: Insights to Emerging Challenges. Information Systems Frontiers, 20(4), 649-652. doi: https://doi. org/10.1007/s10796-018-9871-6

Garter, W. N. (2008). Disaster management: A disaster manager's handbook. Mandaluyong City, Philippines: ADB.

Garreño, M. L., Gardona, O. D., \& Barbat, A. H. (2007). A disaster risk management performance index. Natural Hazards, 41(1), 1-20. doi: https://doi. org/10.1007/s1 1069-006-9008-y

Ghee, B.J. \& Franklin Jr., C. (2010). Cloud computing: technologies and strategies of the ubiquitous data center. CRC Press.

Comfort, L. K. (2005). Risk, security, and disaster management. Annual Review of Political Science, 8, 335-356. doi: https://doi.org/10.1146/annurev. polisci.8.081404.075608

Das, S., \& Mukhopadhyay, P. (2018). Multi-hazard disaster resilient housing with bamboo-based system. Procedia engineering, 212, 937-945. doi: https://doi. org/10.1016/j.proeng.2018.01.121

Domnori, E., Cabri, G., \& Leonardi, L. (2011, October). Multi-agent approach for disaster management. In P2P, Parallel, Grid, Cloud and Internet Computing (3PGCIC), 2011 International Conference on (311-316). IEEE. 
Drake, R. (2009). The hierarchy of emergency preparedness. In Safeguarding homeland security, 31-40. Springer, New York, NY.

Erdelj, M., Król, M., \& Natalizio, E. (2017). Wireless sensor networks and multiUAV systems for natural disaster management. Computer Networks, 124, 72-86. doi: https://doi.org/10.1016/j.comnet.2017.05.021

Fajardo, J.T. \& Oppus, G.M. (2010). A mobile disaster management system using the android technology. WSEAS Transactions on Communications, 9(6), 343-353.

Faulkner, B. (2001). Towards a framework for tourism disaster management. Tourism management, 22(2), 135-147. doi: https://doi.org/10.1016/S0261-5177(00)000480

Grossman, R. I. (2018). Disaster Management. Radiology, 288(1), 180413. doi: https://doi.org/10.1148/radiol.2018180413

Huang, G., Shen, Z., \& Mardin, R. (2019). Overview of Urban Planning and Water-Related Disaster Management. In Urban Planning and Water-related Disaster Management (1-10). Springer, Cham.

Islam, N., Sheikh, G.S. \& Islam, Z. (2018). A cognitive radio ad hoc networks based disaster management scheme with efficient spectrum management, collaboration and interoperability. arXiv preprint arXiv:1810.05090.

Janssen, M., Lee, J., Bharosa, N., \& Cresswell, A. (2010). Advances in multiagency disaster management: Key elements in disaster research. Information Systems Frontiers, 12(1), 1-7. doi: https://doi.org/10.1007/s10796-009-9176-x

Kaur, H., Gupta, S., Parkash, S., \& Thapa, R. (2018). Application of geospatial technologies for multi-hazard mapping and characterization of associated risk at local scale. Annals of GIS, 24(1), 33-46. doi: https://doi.org/10.1080/19475683. 2018.1424739 
Krishna, G. H., Chandra, V. S., Boyidi, S., Jaisankar, G., Anusha, G., Sridhar, B., ... \& Sridevi, T. (2019). Disaster Management Emergency Responsive Mechanism Using GIS and Networking with Android Technology. In Proceedings of International Conference on Remote Sensing for Disaster Management ( 729738). Springer, Cham.

Lee, T.D., Park, H. \& Lee,J. (2019). Collaborative accountability for sustainable public health: A Korean perspective on the effective use of ICT-based health risk communication. Government Information Quarterly.

Li, J., \& Zlatanova, S. (2007). Geomatics solutions for disaster management (p. 444). A. G. Fabbri (Ed.). Berlin, Heidelberg, New York: Springer.

Mukherjee, A., Dey, N., Kausar, N., Ashour, A. S., Taiar, R., \& Hassanien, A. E. (2019). A disaster management specific mobility model for flying ad-hoc network. In Emergency and Disaster Management: Concepts, Methodologies, Tools, and Applications (279-311). IGI Global.

O’Brien, G., O’Keefe, P., Rose, J., \& Wisner, B. (2006). Climate change and disaster management. Disasters, 30(1), 64-80. doi: https://doi.org/10.1111/ j.1467-9523.2006.00307.x

Oloruntoba, R., Sridharan, R., \& Davison, G. (2018). A proposed framework of key activities and processes in the preparedness and recovery phases of disaster management. Disasters, 42(3), 541-570. doi: https://doi.org/10.1111/disa.12268

Park, S., Park, S. H., Park, L. W., Park, S., Lee, S., Lee, T., ... \& Park, S. (2018). Design and Implementation of a Smart IoT Based Building and Town Disaster Management System in Smart City Infrastructure. Applied Sciences, 8(11), 2239. doi: https://doi.org/10.3390/app8112239

Prusty, A. R., \& Mohanty, A. (2019). Prospect of Low Power Sensor Network Technology in Disaster Management for Sustainable Future. In Emergency and Disaster Management: Concepts, Methodologies, Tools, and Applications ( 834-856). IGI Global. 
Spencer, A. (2019). ICT and Caribbean Tourism. In Travel and Tourism in the Caribbean (95-114). Palgrave Macmillan, Cham.

Thomas, D. S. (2018). The Role of Geographic Information Science \& Technology in Disaster Management. In Handbook of Disaster Research (311-330). Springer, Cham. 


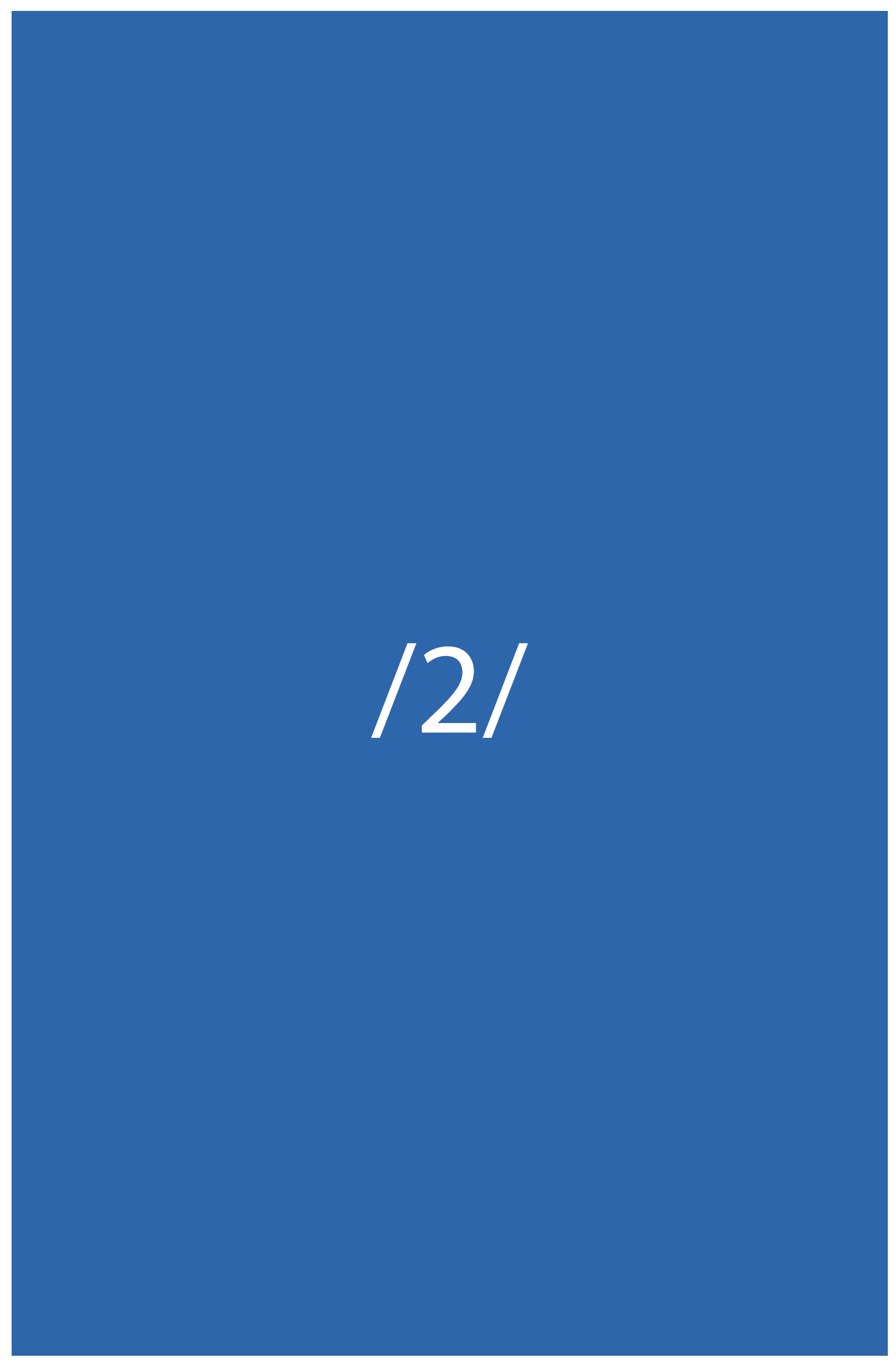




\section{BLOCKCHAIN BASED AUDITABLE MEDICAL TRANSACTION SCHEME FOR ORGAN TRANSPLANT SERVICES}

Gasim Alandjani

Assistant Professor, CSE Department, Yanbu University College, Royal Commission Yanbu (Saudi Arabia). E-mail: alandjanig@rcyci.edu.sa

Recepción: 26/07/2019 Aceptación: 18/09/2019 Publicación: 06/11/2019

\section{Gitación sugerida:}

Alandjani, G. (2019). Blockchain based auditable medical transaction scheme for organ transplant services. 3C Tecnología. Glosas de innovación aplicadas a la pyme. Edición Especial, Noviembre 2019, 41-63. doi: http://dx.doi.org/10.17993/3ctecno.2019. specialissue 3.41-63

\section{Suggested citation:}

Alandjani, G. (2019). Blockchain based auditable medical transaction scheme for organ transplant services. 3 C Tecnología. Glosas de innovación aplicadas a la pyme. Special Issue, November 2019, 41-63. doi: http://dx.doi.org/10.17993/3ctecno.2019.specialissue3.41-63 


\section{ABSTRACT}

Internet of Things have brought exciting changes in the social norms, work environments and the prospects for future generations. These devices (Things) have already changed the way our networks are used for communication. With the introduction of machine to machine communication (M2M), where devices communicate without human involvement to perform routine day to day tasks. These tasks on one hand, include services that provide convenience to the device owners such as setting off alarms, acting as personal assistant for reminders, keeping track of daily activities etc. On the other hand, there are certain tasks where these devices perform Transactions on behalf of the owners i.e. financial transactions/ online ordering etc. These transactional tasks have significant legal implications if some problem / dispute arises due to such action performed by these devices on behalf of the owners. To ensure that these interactions take place under observation of the owners and to keep track of their occurrence, there is a need to keep record of all such communication. We propose use of Blockchain for tracking all these transactions without compromising secrecy of data by keeping its integrity intact for medico-legal requirements and prevent risk of fraud.

\section{KEYWORDS}

IoT Security, Blockchain, Organ Donation, Smart Health, Nodes, Mining, UPRL, IDoT, M-IOT, P2P. 


\section{INTRODUCTION}

Since the introduction of bitcoin cryptocurrency by Satoshi Nakamoto (2019) and implementation of its underlying technology called Blockchain, many diverse applications of Blockchain have been proposed by the researchers. Apart from the traditional use of Blockchain that provides distributed, secure, trustable and anonymous ecosystem to allow cryptocurrency transactions, its use in the field of medical record management, counterfeit drugs detection and fraud prevention is a new area of research. As the economic disparity between the developed and developing countries is increasing day by day, there is a continuous upsurge in the demand of organs from third world countries to the advanced countries. This has increased the potential of human organ trafficking and poaching for financial benefits. Despite, efforts by the governments to formalize the laws regarding organ donation to prevent mistreatment of donors, there is a dire need of a secure, traceable and distributed organ management and distribution system. In this paper, a Blockchain based scheme is proposed to allow auditable medical transactions to prevent organ trafficking and tracking of legitimate organ donors \& recipients. This will open a new field of Smart Health services based on Blockchain to safeguard the rights of medical professionals and patients. With the advancement in science and technology, new techniques have been introduced and humanity is getting benefit from these latest innovations especially in medical field there came a revolution when transplantation of human body part took place in recent history. Organ transplantation has been used as a novel medical procedure that allows grafting of an organ from donor's body to replace a damaged or missing organ of the recipient. Due to its effectiveness and importance as a lifesaving technique, there is an ever-increasing number of patients waiting for transplant operations. Patients are no more on the mercy of fate to live their lives with organ disabilities. Now they can easily change them with healthy body parts of another person. With this level of advancement, it has become a routine task in some prominent hospitals to transplant organs. According to the American Transplant Foundation, 113,000 people in the United States are on the waiting list to receive an organ as of March 2019. Every 12 minutes a new name is added to the list and an average of 21 persons per day die due to a lack of organ availability. 
According to the Department of health $(\mathrm{DoH})$ approximately 2,000 new waiting patients are added into waiting list for organ transplantation in US only, Corneas, kidneys, intestines, liver, bone marrow and lung, are the most common transplant needs now a days (Decoded Science, 2019). WHO is working on this but the most authentic data is from The U.S. DoH \& Human Services related to complete Organ translation process starting from its procurement from black market, selling to targeted customers and then eventually its transplantation Network have publish a report, according to this report there are approximately 121,333 organ transplant are awaiting and kidney is having a very high number with awaiting 100,402 patients of kidney recipients. Legally only 30,970 transplants took place in 2015 more and less the same number was issued for 2014. WHO have reported about illegal import of organs by many developed countries all the way from under developed countries, USA is one of them and as per internet statistics patients are able to get transplant of different organs starting from range of $\$ 70$ to till $\$ 160,000.00$ as per nature and demand of organ. More than 120650 patients waiting for organ transplant in USA. There always more demand for fresh new organs which has created a perfect condition for corrupt medics to exploit organs from those who are less privileged and then sell them to needy people who have much and ultimately in this whole process they get huge margin of profit (List25, 2019). According to the WHO, an estimated 10,000 black market operations are being carried out by illegal purchase of kidneys. Even in this current era of modern technologies still in some part of the world many people have become victims of forcefully/involuntary organ donation with the help of black market of pharmaceuticals. There are many international organizations working to eliminate this illegal traffic of organs which include Organ failure solutions, ESOT and Organs watch, the average male organ donor is about 28.9 years old having a low average annual income of $\$ 480$ on the recipient side the average age for a male is about 48.1 years and an annual average income of $\$ 53,000$. Considering current situation, Medical experts have a view that based in long queue due to lengthy procedure for organs retrieval from dead bodies, there is a need to legalized organ donation by implementing strict and transparent policy in place. Lack of legal framework on organ donation and poor law enforcement helps black market where they offer little incentives to needy people and take away their 
organs. A great number of patients go to China, India or Pakistan for surgery can pay up to $\$ 200,000$ for a kidney to traffickers who harvest organs from vulnerable, desperate people, sometimes for as little as $\$ 5,000$. Estimates state that kidneys make up $75 \%$ of the global unlawful trade in organs and because of the rising rates of diabetes, high blood pressure and heart problems the demand for kidneys far outstrip supply (Whoin, 2019). According to the Bulletin of the World Health Organization, Volume 85, Number 12, December 2007, 955-962, Many websites are online that allow patients traveling abroad to purchase organs for transplants. The transplant package range in China was as follows: Kidney (\$70 000), Liver $(\$ 120000)$, Pancreas (\$110 000), Kidney and Pancreas (\$ 160000$)$ while on average, same package of Kidney transplant in Pakistan costed around US\$17000 (Decoded Science, 2019). As there are many black markets in every walk of life so is the case with human organs and there exist a black market where you can buy livers, lungs, Kidney and even hearts based on worldwide failure rate there is more demand for kidney in black market as compared to any other organ. According to the World Health Organization, this is the reason that approximately 7,000 kidneys are illegally harvested sent to their required destination by traffickers as per their black-market network. The prices for the same organ vary from country to country based on its demand and supply conditions. If we calculate worldwide data for price of human kidney then an average buyer spends $\$ 150,000$ to purchase it from black market depending on his access to any particular black market. On the other side the average donor only gets an average amount of $\$ 5,000$. This huge difference in prices facilitate the middlemen (commonly known as "organ brokers") to get huge margin of profit during this transaction. In this black-market business, the profits are enormous, and money is used to lure many brokers and even doctors and supporting paramedical staff and eventually they just cannot resist. In 2010 WHO estimated about 11,000 organs were obtained on the black market. WHO based on statistical data and associated findings also claims that organs are being sold in black market and continuous supply for organs is available which make to sell organ in almost every hour 24/7/365. 


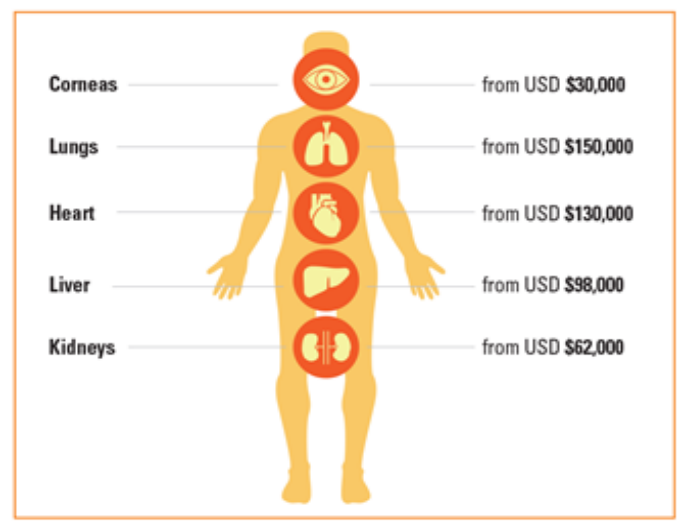

Figure 1. International black-market rates for organs.

On a world map you can find many geographic locations where human organs are being sold to potential recipients.

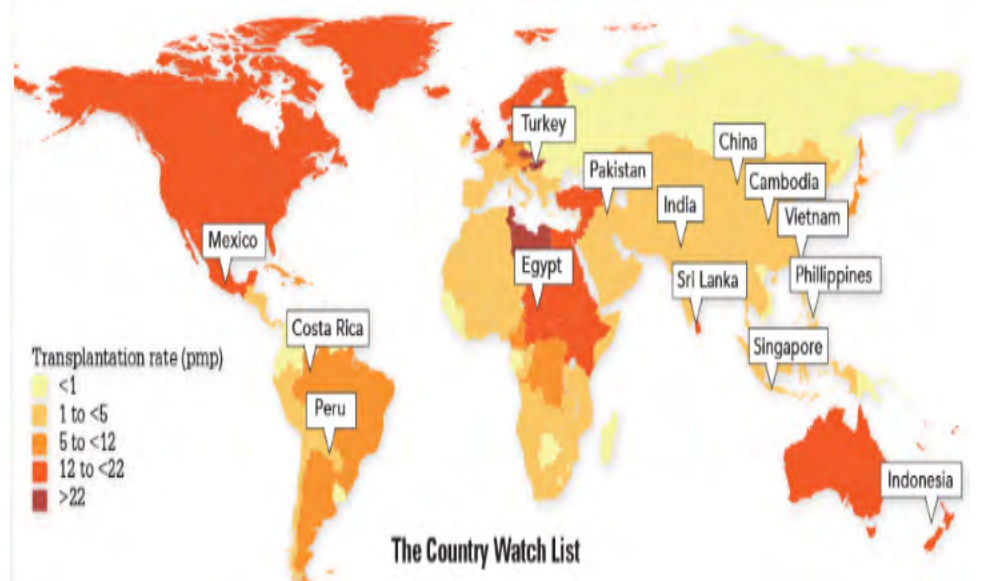

Figure 2. Global distribution of Living donor transplantation Activity -2017. Source: (Global Distribution, 2018).

Many international conferences are hosted by WHO and the February 2017 Summit was one of them. This summit was organized on topic of Organ Trafficking in Vatican City, this summit also shared research and findings on the state of the organ trade. Even with this much technology advancement still the extent of organ trafficking and their transplantation with success and failure rate is not precisely known. Which further complicate human trafficking due to demands of their organs in black market. 
In order to effectively combat organ trafficking there is need to increase its visibility by complete tracking record of organs starting from donor till recipients, every step should be documented with some reference number, fully hashed with time stamp and unchangeable. This will help to reduce this kind of organized crimes, there should be effective engagement of public-private partnerships including healthcare and insurance companies for complete success to get rid of these kind of crimes (Alarming Facts, 2019).

The solution lies in secure, track able recipient/donor profiles and historical integral information system. Which ultimately means ensuring security of patient's medical data and personal information is of utmost importance for any application in medical domain. Consider a patient with wearable sensors that record any change in the patient health-such as-high blood pressure, heart attack, faintness, blood sugar level etc. The sensors send the information to cloud storage, where analytical procedures are built, and other data related to the patient such as his medical history is already saved. Real-time data from the sensors and the historical data from the cloud is used to conduct classification and predication of the patient's case. These findings are sent to a monitoring doctor that can get alert of the changes in condition of that particular patient. It works in a reverse order to keep track of all the all phases during from start till current status of transaction. Before going to implement Blockchain solution we present Blockchain internal architecture, its working and essential components which play important role in building a secure Blockchain solution for organ donation through a track able, secure and unchangeable solution.

\section{BLOCKCHAIN HISTORY AND ARCHITECTURE}

The history of Blockchain Technology started with in 2008 when Nakamoto introduced E-currency platform which is commonly known as cryptocurrency for Bitcoin. In technical terms it is considered as a distributed database for storing a constantly developing detail of records stored in the form of list in the same database also known as blocks. A Blockchain is redundant yet verified list of records which manipulate as result of different transactions in a peer-to-peer network of nodes, 
with the condition that each node will be having a copy of all records in the form of a mirror image of the whole database. Blockchain devices connect to each other in sequential list of blocks since each block except first block which is also known as the Genesis Block in blockchain terminology, contains information about and also a link to the previous block and considered as a hash of the previous block. Every block in a Blockchain is also containing a time stamped which in a way differentiate them from other blocks. Blockchain provides a decentralized peer-to-peer platform for tracking all transaction related to any process without the need of a trusted third party. Using Blockchain for medical domain is a relatively new area of research. In this paper, we propose using Blockchain for tracking organ donation process for secure, safe and auditable operation. Following series of figures (3-6) are explaining step by step procedure starting from formation of block its entry in the chain and then its functionality.

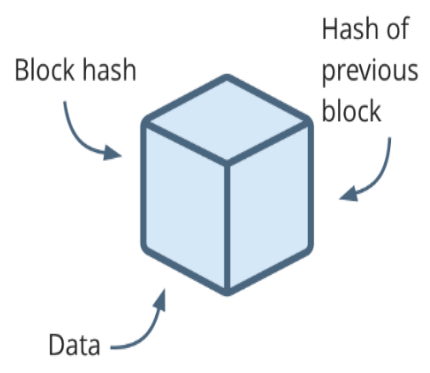

Figure 3. Formation of a Block.

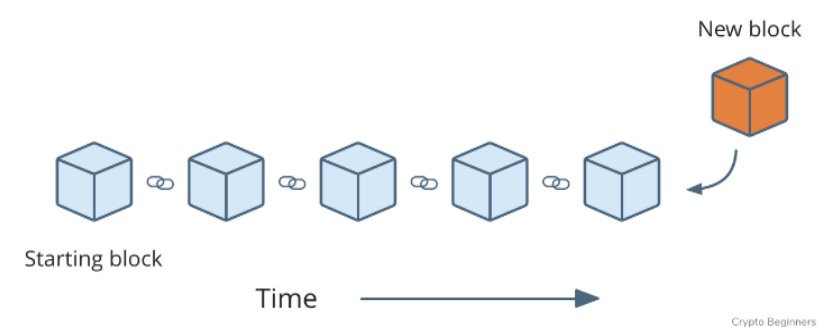

Figure 4. Adding of Blocks in a chain series. 


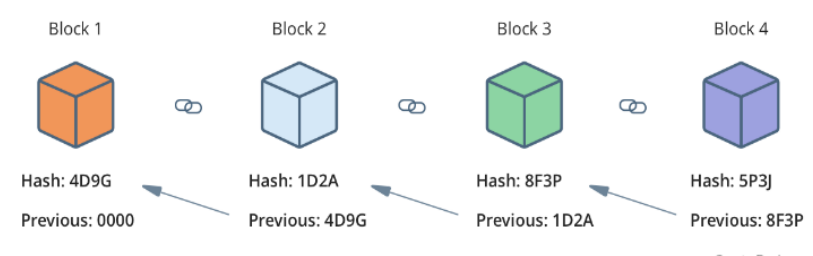

Figure 5. Block Addition with Hash Numbers.

Above figure 5 is showing how blocks are connected to other blocks and keeping its own hash tag and pointing to hash tag of previous block it will reject the entry into block if hash is not matched as given in Figure 6 below.

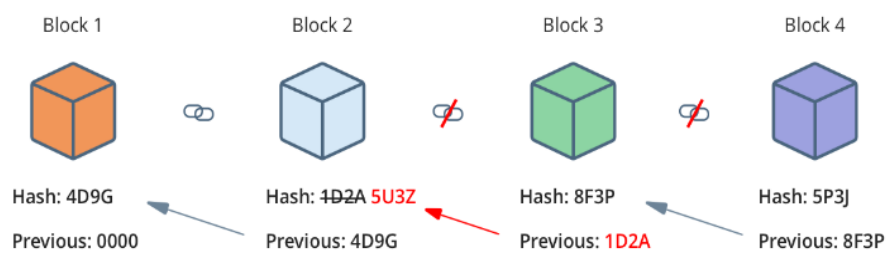

Figure 6. Denial of Block based on incorrect hash Number.

Blockchain works as distributed ledger using blocks of data. Each block contains multiple transactions by hashing them and each transaction will have the network timestamps on it. When a new block is created it will be added to the previous written blocks and the process goes on and on to complete the chain of blocks. Then all blocks and details of all previous transaction are stored in the user disc storage named node. The information held inside of nodes will be used to verify new transaction so new nodes will be added to the user chain or will be aborted. This technique is called mining which insures proof-of-work feature (Diawar, 2019) Blockchain technology can be utilized in many fields of life i.e. Supply chain, Real Estates, Automobiles, Digital identity, Governance etc. Let's consider a use-case of Blockchain in healthcare services. 


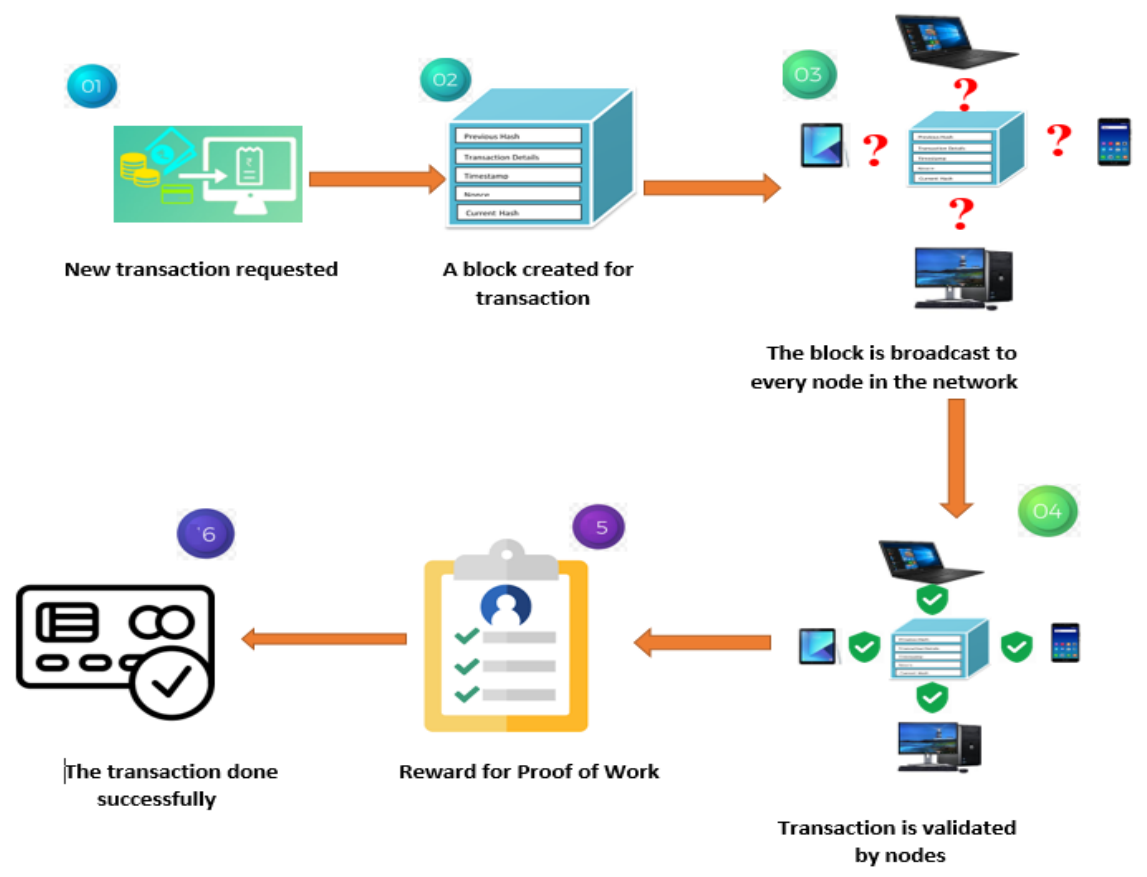

Figure 7. Complete Workflow diagram of Blockchain.

\section{USE OF BLOCKCHAIN IN SERVICES}

Blockchain technology is incorporated in various domains due to its compelling benefits in improving systems efficiency, transparency, safety and integrity. A wide range of domains are utilizing Blockchain approach including health, financial, manufacturing, business, governmental, and educational domains. With respect to healthcare domain, several applications and ongoing systems are utilizing Blockchain for improving medical record management, enhancing insurance claim process, and accelerating clinical research (Ivan, 2016). Adopting Blockchain for storing patient's health record data and management of medical records will enable patients to control access to their healthcare data. This will eliminate the need to acquiring copies of the healthcare data or sending data to another healthcare provider. Numerous companies are involved in adopting Blockchain technology such as Healthcare Data Gateways (Snow, Deery, Kirby, \& Johnston, 2015). Guardtime, a well-known company, is using a Blockchain-based system to secure 1 million 
health records in Estonia (Williams-Grut Technology Behind Bitcoin, 2019). Due to the transparency and immutability of Blockchain technology, it is used in some of the governmental services. For example, Danish political party deployed the first Blockchain voting application for internal elections in which every vote is recorded in a secure environment and stakeholders can participate and observe other votes (Millet, 2019; Ojo, n/d). In financial domain, numerous applications have been introduced for employing Blockchain technology. One of the most popular Blockchain-based application in financial area is cryptocurrency. It guarantees a secure environment for financial transactions in virtual currencies such as Bitcoin, Ripple, Litecoin, and Monoro. Various Blockchain applications are related to stock markets services such as securities exchange, smart contracts, trading and settlement, and payments and remittance. Generally, these applications aim to simplify and speed up the traditional process. Even in educational domain, Blockchain technology is used in different scenarios. Several educational institutions have adopted Blockchain for various problems. For example, the National University of La Plata (UNLP) developed a Blockchain-based framework that verifies students' academic achievements and accordingly issues the diploma. In 2015, a school in San Francisco started to utilize Blockchain in order to assist employers to validate the academic credentials. Shahbaz Pervez (2018) explains that in current technological era, everything revolves around technology and technology rotates around cloud applications and communication over internet. Security of data and associated applications is of great importance which can result into drastic results if there is any negligence from programmers over the security issues, SDLC cycle.

\subsection{USE OF BLOCKCHAIN IN HEALTH INDUSTRY}

Today's healthcare industry is awfully multifaceted with a range of stakeholders, which is a public private partnership of government agencies and private organizations including insurance companies, pharmaceutical manufacturer and end users of these medical products. There is a huge gap between healthcare providers and end users because of non-transparent information exchange which ultimately affects the entire healthcare including medical system. In the healthcare industry, collaboration 
for stakeholders is always difficult based on their particular business goals, intentions and even approached to address all these issues and their solutions. The goals are not properly aligned which result into fragmentation and unproductive services for patients. Based on varied stakeholders and their business goals, conflict of interest is inevitable, there is a great need that healthcare system should have effective collaboration, transparent processes and track able communication channels. But in real world still there need to fix some data handling and communication flaws with appropriate flow of information and its process audits which are extremely costly and eventually resulting in slowing down of healthcare services. Governments and health Insurance companies are major stakeholders which participate in drafting and implementing healthcare policies with the help of paramedics. Blockchain helps in several ways to ensure the integrity of data with proper tracking details of all transactions right from start of Blockchain enabled UPRL. Government agencies and international organization working in health sector, including WHO could have the liberty to access real-time data from any hospital for research purposes and to study different used cases based on this data which would help to determine the health conditions of people living in specific area and even in a broader case over all national health condition of a country. It will also help government agencies in tracking of any infectious disease, their causes based on lifestyle of people and to provide better health services with effective and more transparent way. This will also help the insurance companies to solve the long-awaited problem by tracking all transactional records which will ultimately prevent frauds, which is costing US only about $\$ 68$ billion per year ( The National Heath Care Anti-Fraud Association, 2018). Use of Blockchain technology enables scientists, research organization, Universities and even pharma companies. Through this technology they will get better access to data without having fear for compromise on security of data and privacy of patients which will eventually contribute for research. Paramedic's staff including doctors and other medical staff including doctors and nurses will also get advantage of Blockchainbased systems in performing their day to day routine tasks with more efficiency and peace of mind. By accessing Universal Patient Record ledger, will reduce ambiguities related to recovery or reaction of any medicine on any particular patient or group of patients in some particular situation. If the UPRL is also connected with latest 
technology gadgets including wearable technology and Medical IoT (M-IOT) devices, healthcare professionals can easily record first response, set action plans and emergency procedures with less error, by reducing number of casualties.

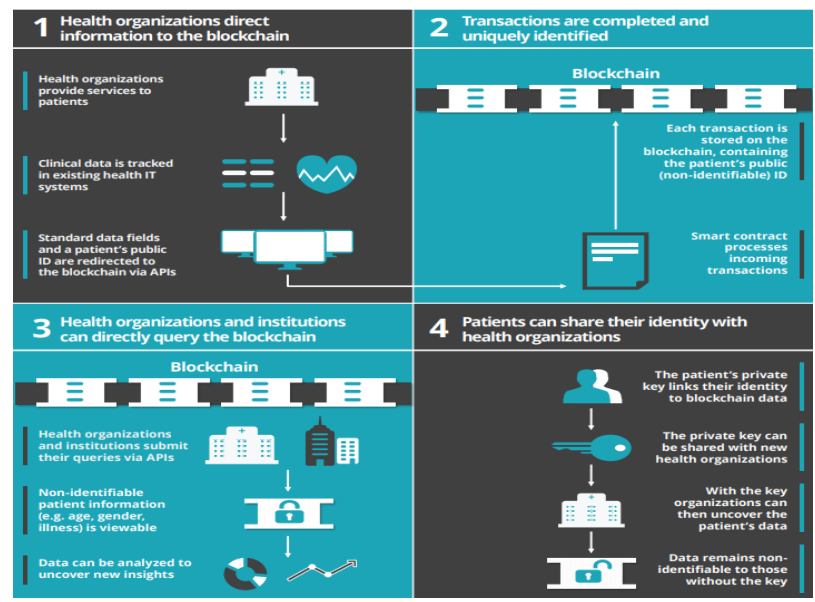

Figure 8. Illustrative Healthcare Blockchain Ecosystem. [10]

Above Figure 8 is showing overall Blockchain enabled healthcare ecosystem in four stages, starting from healthcare organizations, through secure storage and ensuring integrity of data and to end users by ensuring secure and temper free communication from start to end of a medical process for a patient.

As far as cost is concerned, Use of Blockchain based services will also help in decreasing response time and overhead costs by eliminating paperwork which unnecessarily consume lot of time of doctors and nurses in paper work and administration tasks (i.e. starting from patient entry till discharge) reduction in these tasks will eventually help patients for gaining more attention of doctors, they can also utilize this time in some innovative work for betterment of patients. With the use of Blockchain, all stakeholders including patients, their relative's and even hospital staff will be having more confidence on doctors, hospitals and even overall healthcare system related to originality of medicines and other medical products by placing a complete tracking system in Blockchain enabled network. Patients enjoy liberty of having access to their personal information by monitoring medical history by accessing laboratory reports and doctors' recommendations for curing from a specific medical condition. This will 
also ensure transparency of whole process and ultimately it will turn health insurance companies and governments into a patient-centric, traceable and more transparent system. It will also prevent fraud, especially in international market by introducing blockchain based supply chain management system. This is the most important issue that we are going to address in this research, resulting in fraud prevention in organ donation through transparent and traceable system of Blockchain.

\section{PROPOSED SYSTEM: USE OF BLOCKCHAIN IN ORGAN DONATION}

Based on its practical outcomes, trust in results, integrity and almost foolproof security in Blockchain there is an enormous increase in the use of Blockchain technology in healthcare. The importance of Organ donation cannot be ignored in healthcare system. It is a process of giving of an organ and tissue to support someone that needs transplant. Which ultimately can protect or transform the life of a person. The process of organ donation needs to be efficient, secure, distributed, trackable and immutable that can only be achieved if Blockchain technology carefully used for the processes.

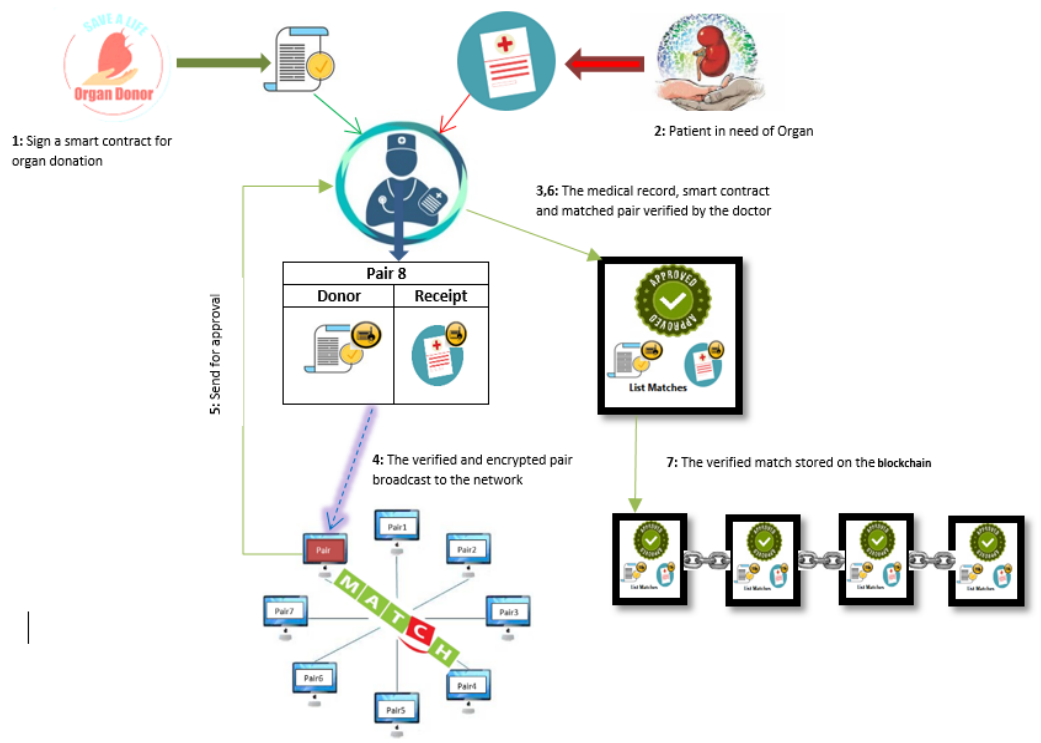

Figure 9. Use of Blockchain in Organ donation Process. 
A typical use-case for organ donation and matching process is depicted in Figure 9. The donor and receipt record can be seen as a global database, based on Blockchain technology, secured with cryptographic tools. Using the Blockchain technology in organ donation, the matching process increases chances of promptly finding an appropriate match, while being completely secure. Confidentiality and privacy can be achieved using the encryption tools and techniques. Also, the authenticity can be done using the approved digital certificates issued by authorized healthcare bodies.

The use case functions in real-time and is distributed. The process of organ donation as shown in diagram (Figure 9) starts with the donor sign a smart contact for organ donation and the patient/receipt files a request for transplant. Both the documents are verified and hashed from authorized healthcare doctor, the doctor make a verified mismatching pair and broadcast over the network pair. The network finds a match and send the match to doctor for approval, if the match is perfect the doctor give the approval and next step is to generate the hash and if doctor generate a hash, the verified matched pair will then become the part of Blockchain which cannot be altered or tempered at any later stage. Doctor and healthcare professionals receive all the information needed to arrange the operation logistics.

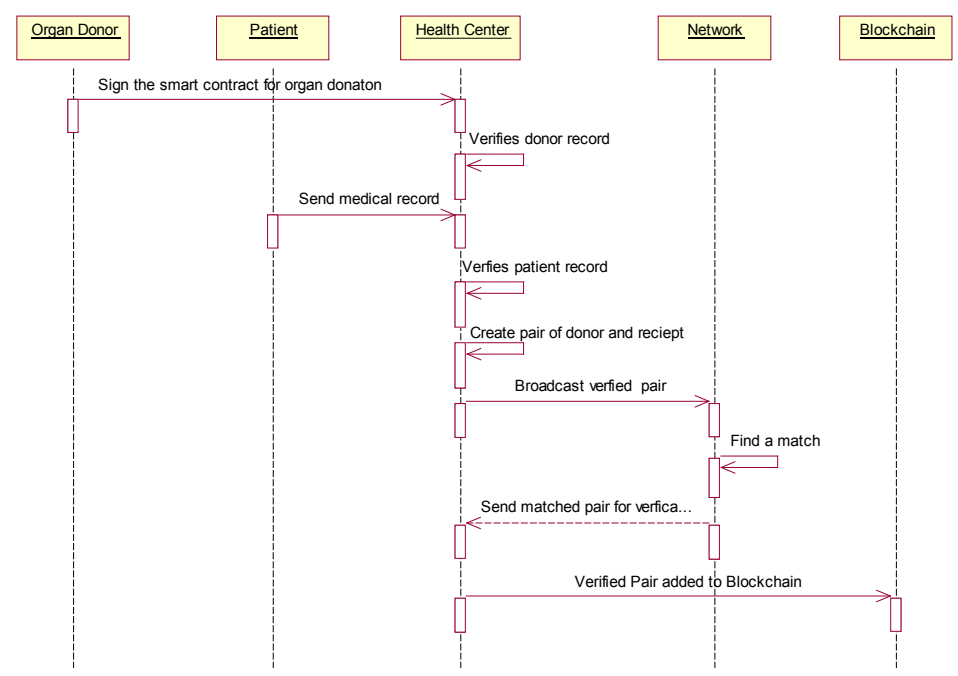

Figure 10. Sequence Diagram for Organ donation system. 
The interaction and exchange of information among Organ donor, patient and healthcare unit all are secure using the smart contact and hash tagging capabilities of Blockchain technology. The verified matched pair when broadcasted to Blockchain, this action become immutable and hence give all the involved parties the integrity, security and conformance of available information. The health unit here can act as a miner All the steps have been completed in a predefined sequence which have been shown in above sequence diagram in Figure 10 which initiates process from the agreement between Organ donor and patient (which is also known as receipt of organ), one both entities agree and sign document then its forwarded to healthcare unit for verification of medical records and sample matching process. If samples are not compatible then the request will be discarded and with the note from medical experts not to proceed with this process based on their expert opinion supported by technical details on this particular case, but if the samples are compatible and are best fit for the patient then request will be forwarded to network and with digital signatures and after approval of that request it will become part of Blockchain which finalize it and no further modification can be done after this step. Collaboration between different entities which are part of this organ donor process have been shown in in a collaborative diagram as shown in Figure 11 which is where medical experts verifies medical records of donor as well as for patient and create pair of donor and recipient, After creation of this pair and verification they broadcast it on network for finding best possible match shows the initiation of collaboration process by organ donor, which signs a contract with Health Center for organ donation.

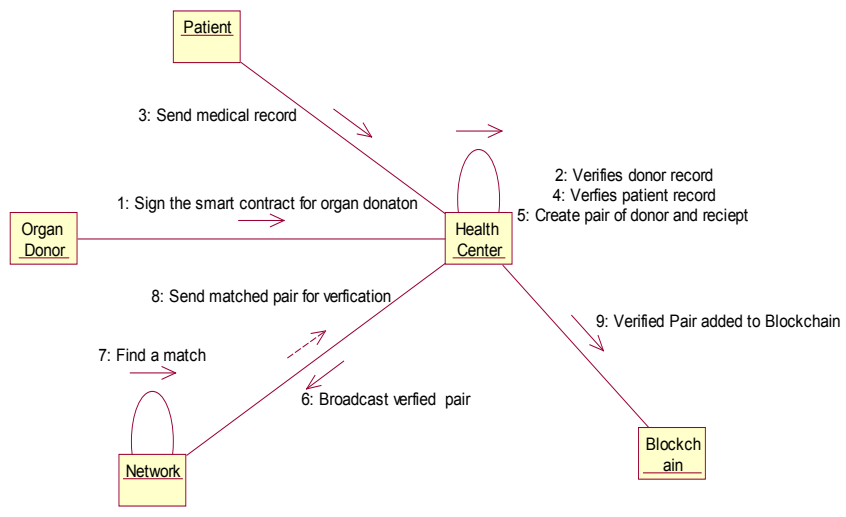

Figure 11. Collaboration diagram for Organ Donation System. 
Once they get best fit match, they further send that match for verification and after successful verification from health center this will send to Blockchain to make it part of Blockchain now this record will be considered unchangeable with integrity intact for all kind of transactions on this process.

\section{RELATED WORK}

Significant work has been done in the context of Blockchain and security. This section surveys Blockchain-based security solutions by addressing some security issues and provides an understanding for current research trends. Furthermore, some recent research work has been carried out to make Blockchain technology appropriate for IoT enabled medical equipment and hardware and software-based security issues. The physical issues are related to computational power and memory. The softwarebased issues are related to privacy, defense against malware, authentication and the regularization of governmental /organizational policies as per international technological norms, and monitoring. Main issue which is considered as one of the biggest limitations in creating a decentralized topological design is mutual trust of all the entities participating in this process. The main idea behind Blockchain is its beauty of decentralization which means it's not solely dependent on any single authority, and is not prone for having a single point of failure by attacking that particular target with the intention to target integrity of data, since complete mirror image of data is stored in all nodes of a peer to peer $(\mathrm{P} 2 \mathrm{P})$ network. Which ultimately making it difficult for attackers to fulfill their goals. However, if an attacker somehow manages to get control of several nodes in a P2P Blockchain network, with mining access permission to mining nodes, then possibility to compromise integrity of data in the attacked Blockchain. A Blockchain is considered as a distributed database for storing an uninterruptedly growth of listed records called blocks. The public key is used to identify a Blockchain user. Each Create, Read, Update or Delete operation which is also known as CRUD operation on an IoT enabled Systems, which can be registered as a transactional update/ record in a Blockchain based blocks of record. The distributed and autonomous liberty of a Blockchain make it an ideal component in IoT security enabled environment. The main limitation for resource limitation 
in IoT devices their low processing and storage capabilities due to nature of their routine tasks. There is no Blockchain-based IoT security solution available with a claim to foolproof security against threats and all kind of attacks by fulfilling all security needs in proposed standard security procedures. As of now there is no such system currently in operations, all these are just theoretical findings which might be implemented in future. Whereas a foolproof operational security model for an IoT system can be combination of standard information security procedures and Blockchain-based security.

As per normal practice is going on there are many known and unknown security threats while distributing medical information which include the forgery, no tracking of records updates. (Chen, 2018). Proposed blockchain based medical information sharing model to cope with such security threats and constructed a medical information sharing model based on blockchain by implementation to verify satisfaction for security requirements for medical information. Which confirmed that the blockchain based medical information sharing model can provide the reliability and traceability of medical information for prevention of forgery and modification in transaction or alteration of medical information. (Kuo, Kim, \& Ohno-Machado, 2017) summarize existing Blockchain protocols and application domains of Blockchain technologies in Internet of Things (IoT) networks. The application domains of Blockchain technologies in IoT discussed in this paper are: Internet of Vehicles, Internet of Energy, Internet of Cloud, and Edge computing. The authors also classify the threat models that are considered by the Blockchain protocols in IoT networks, into five main categories, namely, identity-based attacks, manipulation-based attacks, cryptanalytic attacks, reputation-based attacks, and service-based attacks. The study also outlines both open questions and research challenges that could improve the capabilities and effectiveness of Blockchain for the IoT. The paper has summarized research for Blockchain-based IoT security and privacy in terms of Blockchain model, security model, Goal, Performance and Complexity. To implement Hyper-Ledger Fabric in a smart-IoT environment to assess the validity of the communicating devices whether normal or malicious i.e., to assure users of the integrity of the data from any device. There is history of well- 
known attacks such as DDoS attack. Shen (2019) have proposed a security solution for IoT-eHealth system by presenting a context-aware and self-adaptive security model to mitigate the traditional problems, including limited context with optimal autonomous response. The IoT-eHealth multivariate and complex concepts have been simplified using Ontology technique. The system structure shows procedure from context collection till feedback. The system comprises of three layers Device Layer, Security Management Layer and Cloud Layer (Waqas, 2019). At Device Layer Local Context Manager collects device native context. Context Manager Parse, refine and transform the monitored context in in Security Management Layer. Context Agents are utilities to capture communication pattern for in/out-bound of devices. Context Analyzer with support of Machine Learning models analyzes the possible risks. Alert Generator converts any security context to an alert that will be responding by Context Adapter for optimal security according to Adaptation Rules. Evaluator will assess all the selected mechanism using a score to decide for new optimal security configuration, which can be communicated by Messenger. The proposed architecture aims to fulfill the following objectives: Holistic security, SelfAdaptation and context awareness, Open connectivity and Minimize decision delays. The proposed model can manage and deal with dynamic and multifaceted traits of a system. In fulfilling future regulatory demands, choosing Blockchain technology would be a wise selection by technology companies (Legal Issues and Regulatory Developments, 2018). Still some more research is required to design of Blockchain supportive and IoT enabled devices, good news is that European Parliament has approved new regulations and adopted them in some governmental services (Alvarez, 2018). General Data Protection Regulation (GDPR) and the Directive on Security of Network and Information Systems are approved legal acts for guiding the development and maintenance of information systems. There are minor differences in GDPR between these members, but it lays the foundation for a unified digital single market within the European Union by implementing its major theme. The NIS will likely be adopted by all states with minor modifications as per state laws of different European union member states but overall it defines a minimum level to implement security responsibilities for information systems which is the backbone of Blockchain enabled systems. There is another regulation related to general data 
protection regulation which splits the role of the controller and processor as totally separate legal entities. The GDPR also help to defines data in two categories which are known as personal and sensitive data under special category. An identifiable natural person is one who can be identified by reference such as a name, location of data, an identification number, or special category factors. IOT enables systems are not new in practical world but still security challenges are there which are still seeking attention to solve them with minimal security and privacy breach. In case of IOT enabled networks there are some findings which shows that they have potential to securely work without human supervision. There are also some limitations to use Blockchain in security solutions for IoT enabled systems (i.e. limited processing \& storage capabilities, absence of up to date firmware due to non-availability of rapid firmware updates. As a result, when Blockchain nodes increase in its blocks its ledger automatically grows. To alleviate these limitations, some alternate mining procedures should be opted and only a device-dependent transaction ledger should be maintained in case if device is too resource constrained.

\section{CONCLUSION AND FUTURE WORK}

In this article, we emphasized the prominent and vital impact of Blockchain technology and its effective use in the entire healthcare sector (i.e. from manufacturer till patients) by highlighting the hurdles in facilitating a clear exchange of information from origin till its destination and also discussed the role of Blockchain technology in solving problems related to grey market of organ donation and other related issues to help every stakeholder for making better-informed decisions. Based on our findings during this research we can conclude that use of Blockchain is going to be a must for any critical medical services and their tracking. As Blockchain can provide a temper-proof feature of recording every transmission in the digital communication, it will allow the saved data to be viewed publicly with no alteration risk by accomplishing decentralized agreements. Since health information of any person is very personal stuff which cannot be shared publicly so there is great need to address secrecy of individual health records. As medical records of a person have more fields of information so there is a need to address these issues because 
Blockchain was primarily designed for small data (bitcoins) to store and process so there was no issue related to data storage due to size and nature of this data while on the other hand storing health information systems consisted of huge information where the stored data are enormous, sensitive and it also needs further study to keep track of patient condition. It should be dealt by storing data in traditional database due to huge quantity and privacy of data and to track this hash references should be stored in the Blockchain which allow an authenticate access to the database keeping its authenticity intact. Further research can be done in this area to ensure security of data stored in the conventional databases and their linking with the Blockchain.

\section{REFERENCES}

Alarming Facts. (2019, Feb 12). Retrieved from: https://list25.com/25-alarmingfacts-about-organ-trafficking

Alvarez, M. (2018). A Comparative Analysis of Cryptocurrency Regulation in the United States, Nigeria, and China: The Potential Influence of Illicit Activities on Regulatory Evolution. ILSA Fournal of International \& Comparative Law, 33-56.

Ghen, Y. (2018). Blockchain-based medical records secure storage and medical service framework. Fournal of medical systems, 5 .

Decoded Science. (2019, February 07). Retrieved from: https://www. decodedscience.org/organ-harvesting-human-trafficking-black-market/56966

Decoded Science. (2019, March 7). Retrieved from: https://www.decodedscience. org/organ-harvesting-human-trafficking-black-market/56966

Diawar, N. R. (2019). Blockchain: Securing Internet of Medical Things (IoMT).

Diawar, N., Rizwan, M., Ahmad, F., \& Akram, S. (2019). Blockchain: Securing Internet of Medical Things (IoMT). International fournal of Advanced Computer Science and Applications, 82-89.

Global Distribution. (2018, december 17). Retrieved from: Global distribution of Living donor transplantation Activity -2017 
Ivan, D. (2016). Moving toward a blockchain-based method for the secure storage of patient records In ONC/NIST Use of Blockchain for Healthcare and Research Workshop. In ONC/NIST Use of Blockchain for Healthcare and Research Workshop (2837). Maryland: Gaithersburg.

Kuo, T.-T., Kim, H.-E., \& Ohno-Machado, L. (2017). Blockchain distributed ledger technologies for biomedical and health care applications. Journal of The American Medical Informatics Association, 1211-1220.

Legal Issues and Regulatory Developments. (2018). Review of Maritime Transport: UNCTAD. Retrieved from: https://unctad.org/en/PublicationChapters/ rmt2017ch5_en.pdf

List25. (2019, March 10). Retrieved from: https://list25.com/25-alarming-factsabout-organ-trafficking

Millet, J. (2019, 04 22). NewsBTC. Retrieved from: http:/ /www.newsbtc.com

Nakamoto, S. (2019, May 15). Bitcoin: A Peer-to-Peer Cash System. Retrieved from: https://nakamotoinstitute.org/bitcoin

Ojo, A. E. (n.d.). Blockchain as a next generation government information infrastructure: a review of initiatives in D5 countries. In Government 3.0-Next Generation Government Technology Infrastructure and Services. Springer, Cham, 283-298.

Shahbaz Pervez, M. M. (2018). Protective Measures For Security \& Privacy In Cyber Era Of Cloud Computing. International Conference on Electrical, Electronics, Computers, Communication, Mechanical and Computing. Villore: IEEE.

Shen, B. U. (2019). MedChain: Efficient Healthcare Data Sharing via Blockchain. Applied Sciences, 9.

Shimazono, Y. (2019). The state of the international organ trade: a provisional picture based on integration of available information. Bulletin of the World Health Organization, 85(12). Retrieved from: https://www.who.int/bulletin/ volumes/85/12/06-039370/en/

Snow, P. E., Deery, B., Kirby, P. \& Johnston, D. (2015). Factom ledger by consensus. 
The National Heath Gare Anti-Fraud Association. (2018, 11 13). Retrieved from: https://www.bcbsm.com/health-care-fraud/fraud-statistics.html

Waqas. (2019). Towards a Gateway-based Context-Aware and Self-Adaptive Security Management Model for IoT-based eHealth Systems. International fournal of Advanced Computer Science and Applications (IFACSA), 10.

Williams-Grut Technology Behind Bitcoin. (2019, january 04). 


$$
\text { /3/ }
$$




\section{CLOUD QUERY PROCESSING ANALYSIS: ENCRYPTION AND DECRYPTION}

Zainalabideen Ali

Faculty of Information Science and Technology, National University of Malaysia, Malaysia.

E-mail: gp06356@siswa.ukm.edu.my

Azana Hafizah Binti Mohd Aman

Faculty of Information Science and Technology, National University of Malaysia, Malaysia.

E-mail: azana@ukm.edu.my

Rosilah Hassan

Associate Professor, Faculty of Information Science and Technology, National University of

Malaysia. Selangor, Malaysia.

E-mail: rosilah@ukm.edu.my

Recepción: 26/07/2019 Aceptación: 18/09/2019 Publicación: 06/11/2019

\section{Gitación sugerida:}

Ali, Z., Aman, A.H.B.M. y Hassan, R. (2019). Cloud query processing analysis: encryption and decryption. 3 C Tecnología. Glosas de innovación aplicadas a la pyme. Edición Especial, Noviembre 2019, 65-75. doi: http://dx.doi.org/10.17993/3ctecno.2019.specialissue3.65-75

Suggested citation:

Ali, Z., Aman, A.H.B.M. \& Hassan, R. (2019). Cloud query processing analysis: encryption and decryption. $3 C$ Tecnología. Glosas de innovación aplicadas a la pyme. Special Issue, November 2019, 65-75. doi: http://dx.doi.org/10.17993/3ctecno.2019.specialissue3.65-75 


\section{ABSTRACT}

The usage of clouds to provide data query services is becoming an attractive solution to services that demand scalability and cost minimization. Despite the huge advantages, cloud consumers require their confidential or delicate data to be safe and secured, because violating their private data would be a great concern that is not tolerable. Therefore, corporations who use the cloud services especially the databaseas-a-service have tended to encrypt sensitive data for security and confidentiality purpose. Encrypting data would facilitate protecting private information from any violation by the service provider. Several studies have proposed AES and RSA encryption methods. Yet, each encryption method provides a specific level of security which comes with an opposite level of efficiency. Therefore, this work will examine the performance for both encryption methods. The environment setup consists of Microsoft SQL Server as cloud database simulation, and a Visual Studio platform to simulate the local processing of queries. The performance evaluation parameters are time consumption for encryption and decryption. Overall, the results appeared are not significant as each method has its own benefits.

\section{KEYWORDS}

RSA, AES, Processing Time, Cloud Query Processing. 


\section{INTRODUCTION}

Cloud computing is a term that was introduced in 2006 after the introduction of Amazon's Elastic Compute Cloud (EC2) (Singh, 2015) defined a cloud computing model as a model that facilitates easy and on-demand network access to a shared pool of configurable computing services and resources. These resources include networks (Aman, 2019), servers, storage, apps, and services. Modak, Chaudhary, Paygude, and Ldate (2018) noted that there are three components of cloud computing, which are data centers, the client computer, and distributed servers. A company that intends to create a database would prefer to rent an existing one provided by the cloud rather than initiating it from scratch, where there is a third party that can manage and controls these services (i.e. a virtual world) (Singh, Rishiwal, \& Kumar, 2018).

Despite cloud computing has huge advantages. Cloud consumers do not wish to place their confidential or delicate data, such as health records (Ibrahim, 2019), emails, and govern-mental important files; because violating their private data would be a great concern that is not tolerable. Encrypting data would facilitate protecting private information from any violation by the service provider (Vurukonda \& Rao, 2016). The daily usage of query processing over an encrypted data would require a long time where the query needs to be encrypted, and the retrieved data will be decrypted to be shown for the employees. Apparently, the efficiency would be significantly impacted. Recent efforts in the cloud query processing have shown some attempts to improve the efficiency of processing encrypted queries (Amini, 2018). However, there are still some concerns regarding the privacy in which the encryption type would be examined (Albadri \& Sulaiman, 2016; Ghaleb, Shukur, Sulaiman, \& Mobidin, 2018).

This paper consists of four (4) sections. Section I introduces an overview of cloud computing, Section II methods of evaluation. Section III presents the results and discussion. Lastly, section $\mathrm{V}$ concludes the paper with a summary of the findings and recommended future work. 


\section{RESEARCH METHODOLOGY}

The aim objective of this paper is to analyze the performance of two encryption methods namely: RSA and AES. SQL Server is used as a cloud database simulation and have been simulated the local processing of queries by using a Visual Studio platform. As shown in Graphic 1, the architecture of the proposed method contains three key components namely the local side, Encryption and Decryption methods (AES and RSA), and the cloud side. The queries include three types which are Insert data, retrieve data, and drop data.

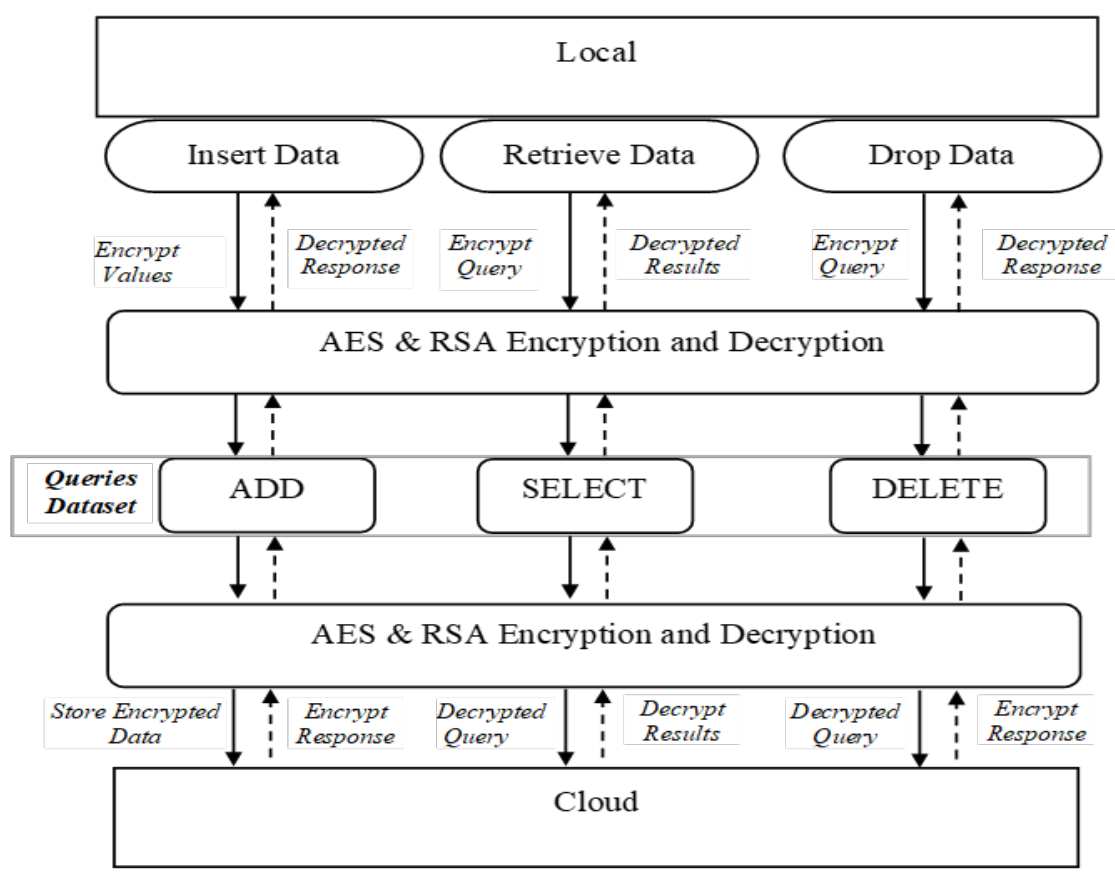

Graphic 1. Model of The Proposed Method.

The dataset is stored in Microsoft SQL Server Management Studio, for the experiments, a set of queries is prepared. This set contains three types of queries including 'Add', 'Delete' and 'Select'. Each type of query gives different results from where security and time consumption for each method. Each type of query is run 50 times with different data. The database name is Student with two tables represents 
RSA and AES table. The data type is using the non-variable character (nvarchar), since using nvarchar rather than varchar, avoid encoding conversions which consume time every time it reads from or writes to the database. Conversions take time and are prone to errors. The nvarchar size is depending on the key length for each method, 200 for AES and 2000 for RSA.

The computer which has been utilized having intel core i7-7500U CPU @2.70GHz $2.90 \mathrm{GHz}$ processor with 8GB RAM, system type 64-bit, Windows 10 Pro and computer type is LENOVO Ideapad 310. The AES has been implemented using a C\# library called AesManaged, while the RSA has been implemented a C\# library called RSACryptoServiceProvider. The interface of the proposed method enables the user to type a query from the predefined ones. Then, either by using AES or RSA encryption methods the interface will encrypt the query and attempt to execute it, meanwhile, decrypt the retrieved results to present it to the user. With regards the encryption and decryption, for RSA, the asymmetric key was 2048-bit key, while for AES, symmetric key generation using the 128-bit key.

\section{RESULTS AND DISCUSSION}

The results of applying the encryption time including AES encryption method, and RSA encryption method. Graphic 2, Graphic 3 and Graphic 4 shows the encryption is being performed for 'Add', 'Select', and 'Delete' queries respectively.

While the results of applying the dencryption time for AES and RSA method is shown in Graphic 5, Graphic 6 and Graphic 7 being performed for 'Add', 'Select', and 'Delete' queries respectively. 


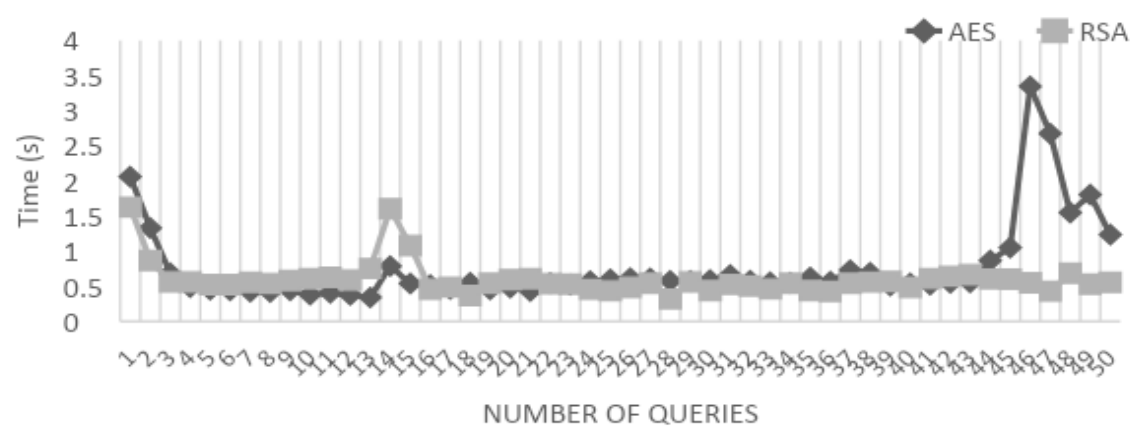

Graphic 2. Encryption Time for Add.

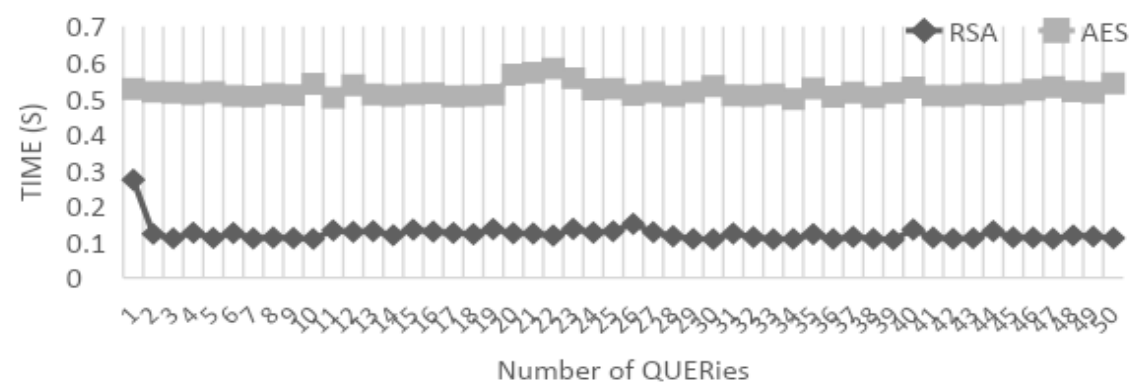

Graphic 3. Encryption Time for Select.

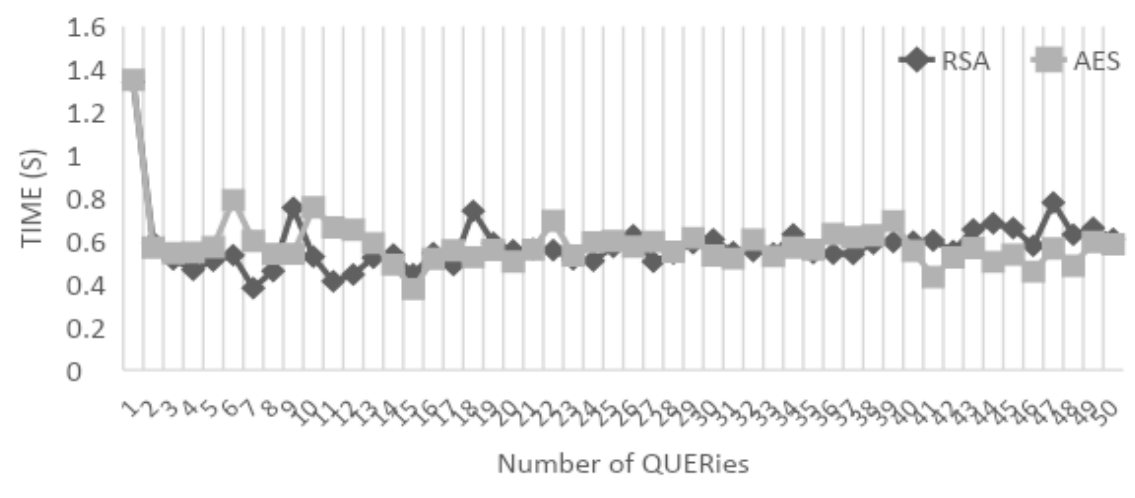

Graphic 4. Encryption Time for Delete. 


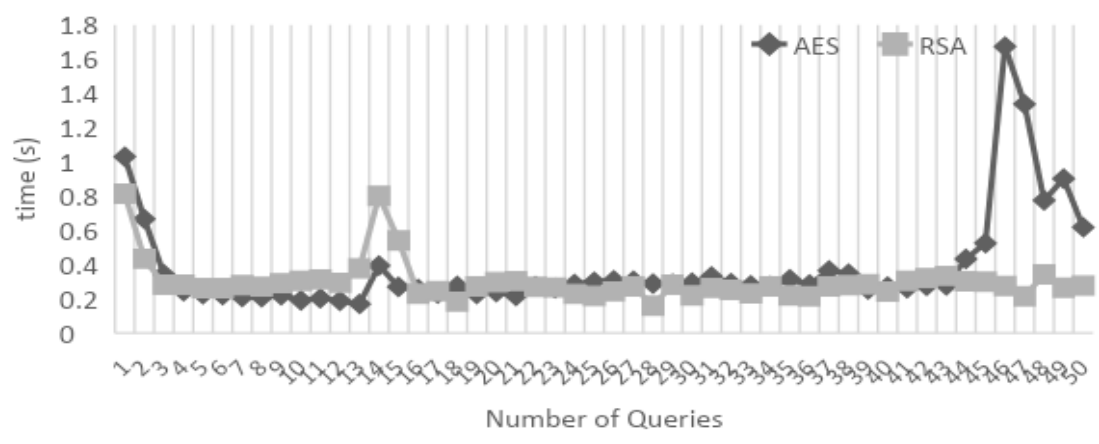

Graphic 5. Decryption Time for Add.

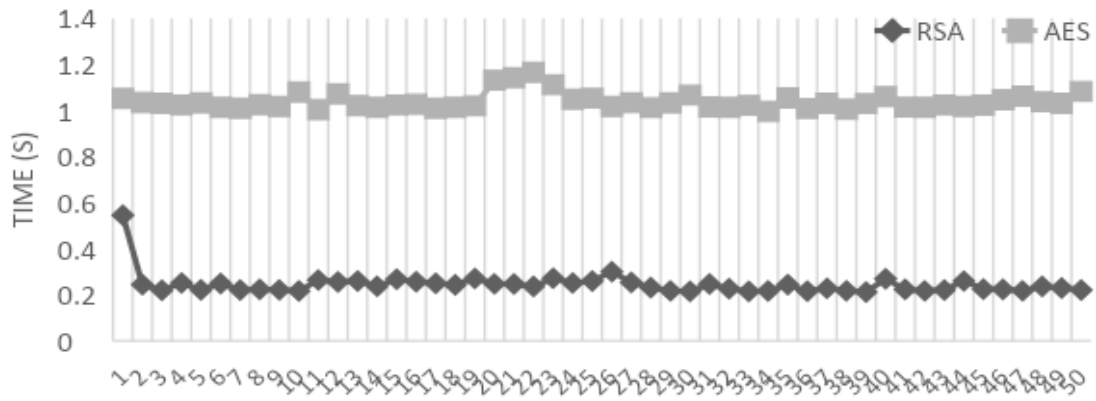

Number of QUERies

Graphic 6. Decryption Time for Select.

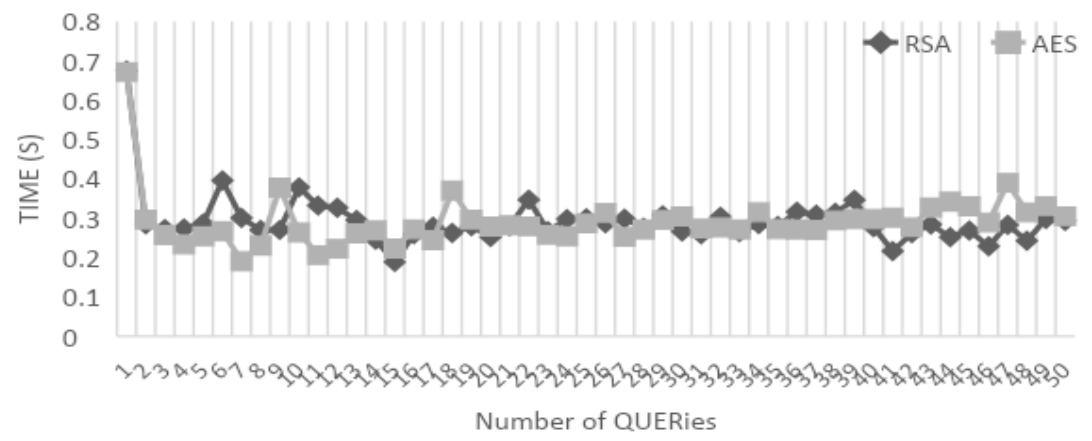

Graphic 7. Decryption Time for Delete. 
Obviously, the "Add" queries have taken the longest time to complete, given that Add process requires inserting new records which consume more time, compared to displaying existing record as in the "Select" query, or deleting existing record as in the "Delete" query. In general, the performance of the proposed study tends to be competitive between AES and RSA in terms of efficiency.

The results are not significant, as the percentage of improvement for each query types are calculated. It has appeared $23 \%$ for Add command, $2 \%$ for Select command, and $2 \%$ for Delete command between the two encryption methods. The RSA with 2048 key length has given slightly better results in terms of the processing time: "Add", "Select", and "Delete" when the data is set to nvarchar 2000. This might be because of the selection of key size; data type and data size play an important metric criterion in choosing the encryption methods. However, it is recommended, methods should be chosen based on types of cloud applications and services, as well as possible attacks and threats.

\section{ACKNOWLEDGEMENT}

The authors are grateful to Faculty of Information Science and Technology, National University of Malaysia. This research is also funded by research grant DIP-2018040 .

\section{CONCLUSIONS}

The potential enhancement that could be used in future studies are using another encryption method may improve encryption time and encryption security, suggest a combination of multiple encryption methods in order to enhance a part of the encryption time and enhance the security of some part, and using real-time dataset could provide some advantage regarding the tactical issue. 


\section{REFERENCES}

Albadri, H., \& Sulaiman, R. (2016). A Classification Method for Identifying Confidential Data to Enhance Efficiency of Query Processing over Cloud. Fournal of Theoretical and Applied Information Technology, 93 (2), 412-20.

Aman, A.H.M., Hassan, R., Hashim, A.H.A., and Ramli, H.A.M. (2019). Investigation of Internet of Things Handover Process for Information Centric Networking and Proxy Mobile Internet Protocol. In 3rd International Multi-Topic Conference on Engineering and Science 2019.

Amini, R., Sulaiman, R. \& Abd Rahman Kurais, A. H. (2018). CryptoROS: A secure communication architecture for ROS-based applications. International Fournal of Advanced Computer Science and Applications, 9(10), 189-194.

Ibrahim, R., Aman, A. H. M., Nur, A. M., \& Aljunid, S. M. (2019). Cost Centric Data Mining for Radiology Procedures at Teaching Hospital in Malaysia. In 3rd International Multi-Topic Conference on Engineering and Science 2019.

Ghaleb, H. S. M., Shukur, Z., Sulaiman, R. \& Mobidin, H. S. (2018). Implementation of AES algorithm in QGIS software. Proceedings of the 2017 6th International Conference on Electrical Engineering and Informatics: Sustainable Society Through Digital Innovation, ICEEI 2017. Institute of Electrical and Electronics Engineers Inc., Vol. 2017-November, 1-6.

Gupta, P., Verma, D. K. \& Singh, A. K. (2018). Improving RSA Algorithm Using Multi-Threading Model for Outsourced Data Security in Cloud Storage. Proceedings of the 8th International Conference Confluence 2018 on Cloud Computing, Data Science and Engineering, Confluence 2018, 163-69.

Modak, A., Chaudhary, S.D., Paygude, P.S., \& Ldate, S.R. (2018). Techniques to Secure Data on Cloud: Docker Swarm or Kubernetes? 2018 Second International Conference on Inventive Communication and Computational Technologies (ICICCT), 7-12. 
Singh, K. P., Rishiwal, V., \& Kumar, P. (2018). Classification of Data to Enhance Data Security in Cloud Computing. Proceedings-2018 3rd International Conference On Internet of Things: Smart Innovation and Usages, Io T-SIU 2018, 1-5. doi: https://doi. org/10.1109/IoT-SIU.2018.8519934

Singh, M. (2015). Study on Cloud Computing and Cloud Database. International Conference on Computing, Communication and Automation, ICCCA 2015, 708-13.

Vurukonda, N., \& Rao, B. T. (2016). A Study on Data Storage Security Issues in Cloud Computing. Procedia Computer Science, 92, 128-35. doi: https://doi. org/10.1016/j.procs.2016.07.335 
Edición Especial Special Issue Noviembre 2019 DOI: http://dx.doi.org/10.17993/3ctecno.2019.specialissue3.65-75 



\section{SIMULATION ANALYSIS FOR QOS IN INTERNET OF THINGS WIRELESS NETWORK}

Ghaith Mojib

Faculty of Information Science and Technology, National University of Malaysia.

Selangor (Malaysia).

E-mail: ghaith.alkhazraje@gmail.com

Azana Hafizah Mohd Aman

Senior Lecturer, Faculty of Information Science and Technology, National University of

Malaysia. Selangor (Malaysia).

E-mail: azana@ukm.edu.my

Mahdi Khalaf

Faculty of Information Science and Technology, National University of Malaysia.

Selangor (Malaysia).

E-mail:m1a2h3d4i5.mh@gmail.com

Rosilah Hassan

Associate Professor, Faculty of Information Science and Technology, National University of Malaysia. Selangor (Malaysia).

E-mail: rosilah@ukm.edu.my

Recepción: 29/07/2019 Aceptación: 18/09/2019 Publicación: 06/11/2019

\section{Gitación sugerida:}

Mojib, G., Aman, A.H.M., Khalaf, M. y Hassan, H. (2019). Simulation analysis for QoS in Internet of Things wireless network. 3C Tecnología. Glosas de innovación aplicadas a la pyme. Edición Especial, Noviembre 2019, 77-83. doi: http://dx.doi.org/10.17993/3ctecno.2019. specialissue $3.77-83$

\section{Suggested citation:}

Mojib, G., Aman, A.H.M., Khalaf, M. \& Hassan, H. (2019). Simulation analysis for QoS in Internet of Things wireless network. 3C Tecnología. Glosas de innovación aplicadas a la pyme. Special Issue, November 2019, 77-83. doi: http://dx.doi.org/10.17993/3ctecno.2019. specialissue 3.77-83 


\section{ABSTRACT}

The Internet of things (IoT) composed of numerous smart devices and communication technologies. The IoT devices interchange the information through wireless or wired network connections. Compared to the wired connection, the wireless connection in IoT is the current primary concern. In general, there are few wireless network protocols that can be used to connect smart devices such as 6LoWPAN, RPL, CoAP, MQTT, and AMQP. These protocols are used to transfer messages in the IoT network. This paper, compared IPv6 protocol wireless network, Low Power Wide Area Network (6LoWPAN) and Low Power and Lossy Network Routing (RPL) for IoT communications using Contiki:cooja simulator. The considered QoS parameters are throughput, end-to-end delay, and jitter. Based on the results, 6 LoWPAN achieved better QoS compared to RPL.

\section{KEYWORDS}

6LoWPAN, RPL, Simulation, Throughput, End-to-End Delay, Jitter. 


\section{INTRODUCTION}

Internet of Thing (IoT) system uses low power sensors and microcontrollers. The LoWPAN which known as Low Power Wide Area Network is the first IoT network that deploys many sensors and controllers linked into internet network. Since the network is using IPv6 protocol, thus the name of the IoT network under Internet Protocol Version 6 (IPv6). Ahmed (2017) and Aman (2016) is called 6LoWPAN (IPv6 over Low-Power Wireless Personal Area Networks) (Li, 2018). Another network that supports IoT system is called RPL (IPv6 Low-Power and Lossy Network Routing Protocol). RPL divides packet processing and adapt routing optimization objects, including energy consumption, communication delays and limits minimization (Parasuram, 2016). Multiple times of RPL can run simultaneously within the network (Kim et al. 2017).

\section{RESEARCH METHODOLOGY}

This research focused on the study of the Quality of Service (QoS) scenarios for IoT in 6LowPAN and RPL. This work assumes that the infrastructure developed supports 6LoWPAN and RPL architecture. The evaluation is done using Contiki: cooja network simulator. The Contiki: cooja is programmed so that the limited node speed is 200 as in (Xie et al., 2014). Also, the number of nodes varied from 10 to 50 nodes. The research metrics are shown in Table 1.

Table 1. Simulation Parameters General.

\begin{tabular}{|c|c|}
\hline Parameter & Value \\
\hline Node transmission range & $50 \mathrm{~m}$ \\
\hline Node carrier sensing range & $100 \mathrm{~m}$ \\
\hline Distribution of nodes & Random \\
\hline Routing protocol & 6LowPAN, RPL \\
\hline Mote type/startup delay & T-mote sky/1000ms \\
\hline MAC layer & CSMA/CA \\
\hline Bitrate & 250 kbps \\
\hline
\end{tabular}




\section{Parameter}

Mote type/startup delay

\section{Value}

T-mote sky/200ms

\section{RESULTS AND DISCUSSION}

The parameters considered for this paper are throughput (Aman, 2016), end-to-end delay (Hassan \& Jabbar, 2017) and jitter. Graphic 1 shows the results for throughput, Graphic 2 shows the results for end-to-end delay, finally Graphic 3 shows the results for jitter.

\section{Throughput}

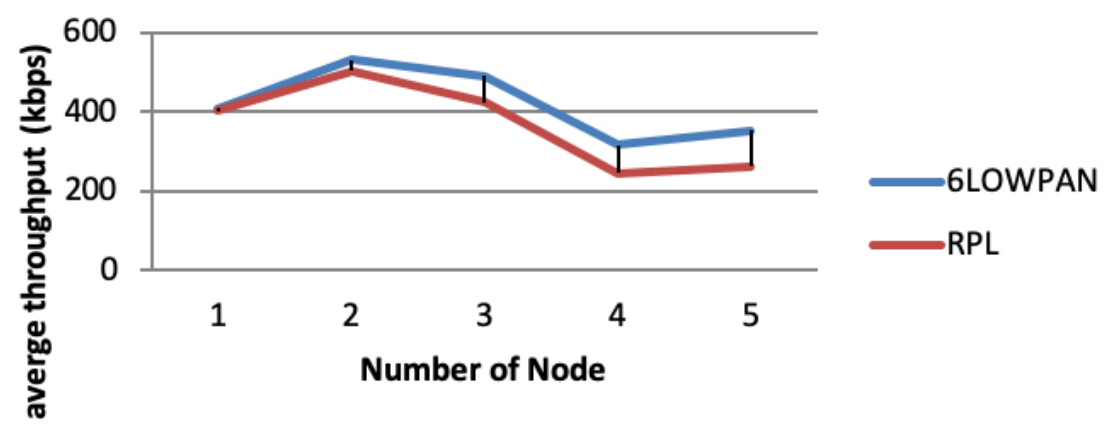

Graphic 1. Average Throughput Number of Nodes.

\section{e2e Delay}

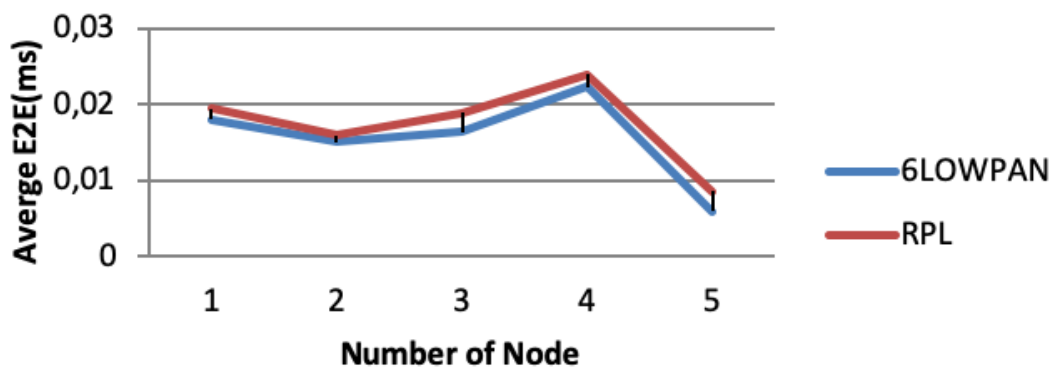

Graphic 2. End-to-end Delay Number of Nodes. 


\section{Jitter}

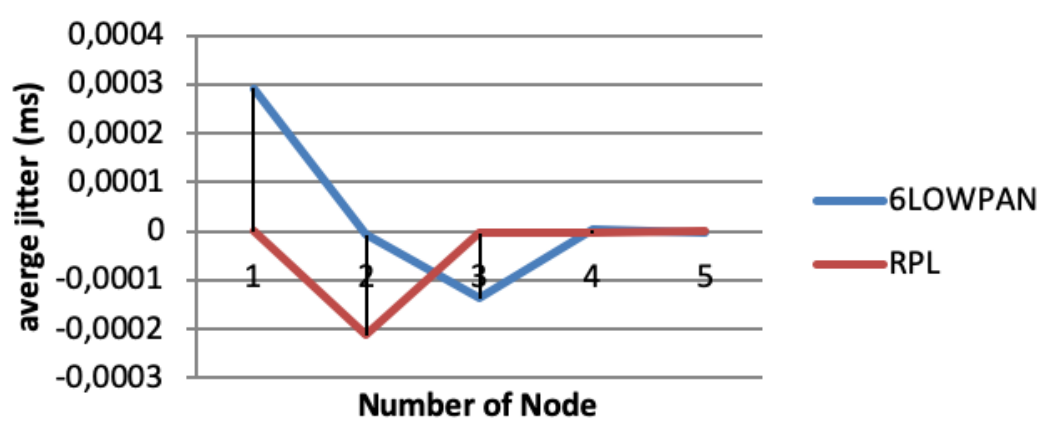

Graphic 3. Jitter Number of Nodes.

The average throughput from Graphic 1 shown at a data rate of $250 \mathrm{kbps}$, 6LoWPAN, RPL, and is slightly different from the selected number of nodes because the topology has changed during simulation. The average overall capacity of the two is mainly $3907 \mathrm{Kbps}$ or $3907 \mathrm{Mbps}$. Note that for both routing protocols, the number of nodes affected. Different routing tables over several nodes result from the random movement of nodes, which results in the fluctuation of the received average throughput. For RPL $2.57 \%$ and 6LoWPAN, 2.14\% is the difference between the highest throughput and the average throughput of the other Nodes, which indicates a different number of nodes impact significantly the average throughput, the 6LoWPAN has better throughput compared with RPL.

Graphic 2 shows the end-to-end delay of 6LoWPAN and RPL routing protocols. A distinct amount of nodes have no significant effects since each RPL node can keep a routing table that saved all data regarding current paths but 6LoWPAN sets the road on demand. That means the average end-to-end RPL is not much more effective compared to 6LoWPAN for some nodes chosen than for some.

Graphic 3 represents the variation in jitter. Jitter signifies a difference in delay with which packets reach the destination. Although the variety is almost same but on average 6LoWPAN performs well in terms of jitter compared to RPL. It shows that, if the nodes are higher, the RPL is less than 6LoWPAN. 


\section{ACKNOWLEDGEMENT}

The authors are grateful to Faculty of Information Science and Technology, National University of Malaysia. This research is also funded by research grant DIP-2018040 .

\section{CONCLUSIONS}

The Internet of Things considered as one of the most significant changes to the current innovation these days. By analyzing the QoS of IoT in 6LoWPAN and RPL, many features revealed to prove its suitability for IoT. Link layer of 6LoWPAN and RPL could support tiny things to participate. Protocol stack for both is appropriate for IoT. Nevertheless, 6LoWPAN yield marginally better results than RPL.

\section{REFERENCES}

Ahmed, A. S, Hassan, R., \& Nor, E. O. (2017). Securing IPv6 Link Local Communication Using IPSec. Obstacles and Challenges. Advanced Science Letters, 23(11), 11124-11128. doi: https://doi.org/10.1166/asl.2017.10234

Aman, A. H. M., Hashim, A. H. A, Abdullah, A., Ramli, H. A. M, \& Islam, S. (2016). Multicast Support in Network Based Mobility Management: Current Challenges and Solutions. Advanced Science Letters, 22(10), 2794-2798. doi: https:/ / doi.org/10.1166/asl.2016.7123

Aman, A. H. M., Hashim, A. H. A, Abdullah, A., Ramli, H. A. M, \& Islam, S. (2016). Evaluation of an Enhanced Multicast Data Flow Technique in Network Mobility. International Journal of Future Generation Communication and Networking, 9(7), 153-164. doi: http://dx.doi.org/10.14257/ijfgcn.2016.9.7.15

Aman, A. H. M., Hashim, A. H. A, Abdullah, A., Ramli, H. A. M., \& Islam, S. (2016). Parametric Comparison of Multicast Support for Network Mobility Management: A Qualitative Analysis. International Journal of Multimedia and Ubiquitous Engineering, 11(9), 203-210. doi: https://doi.org/10.14257/ ijmue.2016.11.9.21 
Hassan, R., \& Jabbar, R. (2017). End-to-end (e2e) Quality of Service (QoS) for IPv6 Video Streaming. 19th International Conference on Advanced Communication Technology (ICACT), 1-4, South Korea. doi: https://doi.org/10.23919/ ICACT.2017.7890045

Kim,H.S., Kim, H., Paek,J. \& Bahk,S. (2017).Load Balancing under Heavy Traffic in RPL Routing Protocol for Low Power and Lossy Networks. IEEE Transactions on Mobile Computing. doi: https://doi.org/10.1109/TMC.2016.2585107

Li, S., Xu, L. Da \& Zhao, S. (2018). 5G Internet of Things: A survey. Fournal of Industrial Information Integration, 10, 1-9. doi: https://doi.org/10.1016/j. jii.2018.01.005

Österlind, F., Dunkels, A., Eriksson, J., Finne, N. \& Voigt, T. (2006). Crosslevel sensor network simulation with COOJA. Proceedings-Conference on Local Computer Networks, LCN 641-648. doi: https://doi.org/10.1109/LCN.2006.322172

Parasuram, A., Culler, D. \& Katz, R. (2016). An Analysis of the RPL Routing Standard for Low Power and Lossy Networks. Retrieved from: http://digitalassets.lib.berkeley. edu/techreports/ucb/text/EECS-2016-106.pdf

Xie, H., Zhang, G., Su, D., Wang, P. \& Zeng, F. (2014). Performance evaluation of RPL routing protocol in 6lowpan. Proceedings of the IEEE International Conference on Software Engineering and Service Sciences, ICSESS, 625-628. doi: https://doi. org/10.1109/ICSESS.2014.6933646 
/5/ 


\section{APPLICATIONS OF UNMANNED AERIAL VEHICLES: AREVIEW}

Haque Nawaz

Shaheed Zulfikar Ali Bhutto Institute of Science and Technology (SZABIST) Karachi, Sindh, and Sindh Madressatul Islam University, Karachi, Sindh, Pakistan. E-mail: hnlashari@smiu.edu.pk

Husnain Mansoor Ali

Shaheed Zulfikar Ali Bhutto Institute of Science and Technology, Karachi, Sindh, Pakistan. E-mail: husnain.mansoor@szabist.edu.pk

Shafiq-ur-Rehman Massan Mohammad Ali Jinnah University, Karachi, Sindh, Pakistan.

E-mail:srmassan@hotmail.com

Recepción: 29/07/2019 Aceptación: 19/09/2019 Publicación: 06/11/2019

\section{Gitación sugerida:}

Nawaz, H., Ali, H.M. y Massan, S.U.R. (2019). Applications of unmanned aerial vehicles: a review. 3C Tecnología. Glosas de innovación aplicadas a la pyme. Edición Especial, Noviembre 2019, 85-105. doi: http://dx.doi.org/10.17993/3ctecno.2019.specialissue3.85-105

Suggested citation:

Nawaz, H., Ali, H.M. \& Massan, S.U.R. (2019). Applications of unmanned aerial vehicles: a review. 3C Tecnología. Glosas de innovación aplicadas a la pyme. Speciaal Issue, November 2019, 85-105. doi: http://dx.doi.org/10.17993/3ctecno.2019.specialissue3.85-105 


\section{ABSTRACT}

In recent development period of modern technology, the flying automatons UAVs (unmanned aerial vehicles) need are increasing day by day for different applications. However, this is an important area to explore and review the vicinity where UAVs can be deployed for a specific application. In this study, researchers have explored the usage of UAVs according to the areas of application in this domain. These vehicles can fly in various circumstances and zones and are capable to perform various missions. The paper presents the numerous applications of UAVs according to the current need of the autonomous technology in various areas of agriculture, military and civilian usage of the modern age. In this article, the applications of UAVs are studied and summarized in tabular form.

\section{KEYWORDS}

UAV, Unmanned aerial vehicles, Applications areas of UAVs, Agriculture, Military, Civilian applications. 


\section{INTRODUCTION}

The UAVs are known as the flying robots, airborne devices that do not convey signals to human administrator but they fly remotely, self-sufficiently to convey lethal or non-lethal shipments. A disaster is a characteristic of hazards bringing about the occasion of large degree causing critical physical harm or damage including loss of life or intense nature (Militaru, Popescu, \& Ichim, 2018). The characterization as any shocking occasion originating from natural incidents. For example, earthquakes, accidents, floods, fire or blast. It can make harm to lives, property and destroy the financial, social or cultural life of individuals. There are numerous approaches to scale typical disasters. Misadventures can be mounted for limited influenced region or population from the expulsion to steadily spreading when it occurs or in numerous different routes depending upon the condition. This paper makes use of specifically a few calamities, for example, earthquakes, floods, atomic mishaps, and jungle fires, anyway conclusively communicate that point is so gigantic, all displayed work is simply touching the surface.

\section{LITERATURE REVIEW}

Before going through the detail first we should see how UAVs takeoff and function. We have to know the fundamentals of development and structure of a typical UAVs. Different UAVs are made of numerous kind of light fused materials in order to lighter the weight and expand the rate of mobility while flying, can be additionally installed with other needful equipment's, including camera, GPS (global positioning system), GPS guided rockets, navigation, sensors (Chen \& Gao, 2019). The UAVs The different type of UAVs are available in the market, it depends upon cost, an expansive assortment of shapes, sizes, capacities, and functions. The present models can be launched manually and can be controlled by remotes or from special ground cockpits. The simplified UAVs are developed for commercial applications. The vehicle is reasonable and suitable for kids since they are easy to move but difficult to control and are found in multiple varieties. The waterproof engine frame is one of the fundamental parts of each UAV other than this flight engine controllers, motors, 
transmitter and collector, propellers, and batteries are some other energy cradle (Sładkowski \& Kamiński, 2019).

In addition, escape UAVs is very effective or it is the sole tool for supporting disaster management. Just in case of the nuclear accidents a number of the foremost information square measures are there to sturdy the emission. What's the affected location currently is and the way quick spreading the emission. In most cases, we know that emission is limitedly allowed for human. Therefore, for any man-on-board operation, it's simply dangerous, however even useless for human, if there are many and similar effective resolutions. Observant and observance the emission sometimes created by aerials that mean these days, not simply man-on-board resolution however conjointly for UAVs application (Sugisaka, 2011).

It may be a speedy escalating disaster. Where no alternative method for speedy injury assessment is available then an aerial reconnaissance is the solution. For special rescue groups, the UAVs application will facilitate a very speedy location choice in abundance. The earthquake may be a disaster that is broke with none pre-sign and inflicting not simply seriously building damages however conjointly several deaths. The possibility for surviving of individuals at bay in folded buildings depends in the main on the injury forms of the affected buildings. A speedy mapping of affected space is incredibly necessary not only assessing damages however additional to optimize sources. The restricted resource, the tiny UAVs is often the best solution for speedy mapping (Yamazaki, Matsuda, Denda, \& Liu, 2015).

Flood is a type of disaster. The authority or disaster management head office has a large amount of data for the prediction of size and intensity of heaviness of disaster. The slow flood development in repeatedly giant affecting the space, voters, and trees. Though UAVs it is easy to facilitate the situation, around a restricted space and it helps the management. As a pre-disaster activity, UAVs follow the stream of rivers and collect the dam's status. In the case of un-usual recognition, the authority will react in time to look after the situation. This activity is incredibly elastic while the flight patrol will be optimized counting on time or alternative work load. While exaggerated areas are usually outsized. However, supervising floods by aerial is normally suffered from 
controlled sources. Hence, UAVs will support disaster management at a native level. The task needs military science or operational UAVs (Liu et al., 2014).

Flood is normally for a slow inception disaster. In the peculiarity, managing flood may be an extremely complicated and troublesome task and it needs continuous observation of the flood and threatened areas. The UAVs will facilitate to authorities mostly keep a neighborhood underneath observation.

The UAVs can be used for fireplace recognition, observation and conjointly for the post-fire execution. The UAVs applications of fire management are definitely the foremost incontestable activity among all disasters. The police investigation is hot spots aerial prior to reportage by civilians those clearly helps hearth authorities limiting the cause of the fire damages. It has studied that, the reason why this methodology is not perpetually used for its vast price through aerial devices. If this procedure fashioned by UAV is an inexpensive resolution than the standard one that possibility of UAV use that higher resolution (United States Patent No US20130134254A1, 2013).

At huge fires, exploitation manned craft for bombing water or simply for supporting data the reconnaissance mission could be a traditional procedure. On the other hand, the little fires don't need aerial support, these area units managed by ancient instrumentality. The hearth size is larger than management might be suppressing it with success simply with ancient instrumentality. However not enough giant asking manned craft for facilitating. During this manned craft is economically clearly not effective. However, the answer is similar to the UAVs which is cheaper than the utilization of manned aircraft.

In this century in the field of medical sciences, the UAVs will provide first aid to the team need medical services like dispensing to faraway and arduous locations. These help in identifying the injured in critical areas and distribute necessary supply until the medical squad team arrives. These types of UAVs are being placed in the market. It can be helpful and have an important impact on the drugs field because it will provide its helpful amenities that as a result augment the remedial services (Bitar, Jamal, Sultan, Alkandari, \& El-Abd, 2017). 
Unfavorable climate means low visibility of weather condition that causes a severe impact on the safety and operations of drivers on an interstate highway. It disturbs the driver and vehicle performance. In this situation, no one can rescue through conventional vehicles. The observing of climate sometimes causes similar issues of visibility impairments, precipitation, high winds, and temperature. This extreme issue has an effect on the competences of the driver and the performance of the vehicle. However, the UAVs plays an important role in monitoring the weather condition through the highway. Same as of fog issue the visibility distance is reduced which ends up and multiplied speed. That increment will enhance the risks of a crash (Dandois, Olano, \& Ellis, 2015).

The Improving farmer's yields in the conventional system are very difficult nowadays. However, in the current era, digital and technological advancement modify the farmer's yields and performance increased through the use of technology. The matter of feeding an international population this can be more sophisticated with the problems of environmental impact, the necessity to scale back water waste, eliminate chemical break out, and greenhouse gas emissions. The current technology will pay to these issues and establish farming processes. Maximum members should be part of this enhancement. The giant farms will take pleasure in a variety of applicable knowledge to extend the amount of yields the source of food from an equivalent space. The latest technology involvement can improve the finance, agriculture and improve the performance of farmers and increase the yield that leads towards better profits. The small farm may become smart due to technology usage and it will boost the crops. However, the UAVs are the smart vehicle which can be deployed for smart farming. In these days the UAVs are mostly used in the developed countries for smart farming, these devices play an important role in exactitude farming, crop health analysis, observance stock, and different agricultural uses has been deemed a game changer by one exactitude agriculture professional mechanism (Burwood-Taylor, 2017; Garcia-Ruiz et al., 2013; Gonzalez-Dugo et al., 2013; Lu, Nagata, \& Watanabe, 2017; Zhang \& Kovacs, 2012). 


\section{APPLICATION AREAS OF UAVS}

The following are the areas of UAVs applications which have been explored in this research study, are agriculture, military, and civilian usage. Each has been discussed as:

\section{AGRICULTURE USAGE}

Agriculture is an important area of research which can be improved by modern technology. The feeding of human beings is totally depending upon agricultural crops. The traditional method is not fulfilling the demands of the market. And, the population is increasing with linearity with respect to time. However, the matter of feeding of the massive population at international level is going to raise the problem due to low cultivation and production of agricultural goods. This can be more sophisticated with the problems of environmental impact, the necessity to scale back water waste, eliminate chemical break out, and greenhouse gas emissions. The new digital technology will contribute to solve these issues and establish proper farming processes by introducing smart farming (Garcia-Ruiz et al., 2013).

Agricultural farming can be improved by using UAVs technology. By introducing a new methodology of cultivation. For example, the soil analysis mechanism, crop spray technique, monitoring of crops, irrigation system reconnaissance should be carried out by these UAVs and timely prevent the crops and can improve the yields production (Zhang \& Kovacs, 2012). Different purposes of using UAVs are discussed below:

\subsection{UAV IN ANALYSIS OF FIELD SOIL}

The UAVs can be the initial stage of the cycle applies for the crop to create 3-D mappings for early soil analysis that is useful. Installing the UAVs-driven soil analysis it provides data that can be used for irrigation and nitrogen level management, and the steps can be taken for proper fertilizer dosages that can be given to crops to protect the soil fertilization. Through this mechanism, the soil will get the proper nutrients and increase with healthy growth (Lu et al., 2017). 


\subsection{UAV IN HEALTH ASSESSMENT OF CROPS}

The different health issues in crops take place, however, it is necessary here to discuss the plant's, crops health. It spots bacterial or fungal infections. The crop scanning, assessment is essential for providing an immediate remedy as cultivation of field is not affected. Hence the conventional method of assessment is not more useful in the future by using visible and near-infrared light individually. The UAVs are the best assessment approaches through which the scanning of crops are very easy to identify the diseases and agronomy measures can be taken for proper production (Wu et al., 2018).

\subsection{UAV IN PLANT PREVENTION SPRAY}

The equipment which can measure from far a distance with the help of ultrasonic or echoing and lasers technology used for detection of light, and set the range of LiDR that enables the UAVs to set altitude with respect to topography and landscape. However, this type of mechanism available in UAVs, that why it is possible for UAVs to do the scanning of land to perform spray activities using the exact quantity of liquid and to modulate the actual distance from the ground. In the result with a reduction of penetrated chemicals amount into groundwater will increase the efficiency. According to the expert's estimation, the spray which can be completed with the help of UAVs is five times faster as compared to manual or traditional machinery (Garcia-Ruiz et al., 2013).

\subsection{UAV IN MONITORING CROP}

With the passage of time, different areas are being monitored in a different way such that crops are not left behind. However, the monitoring system of crops is not appropriate usually, so the unpredictable weather conditions also affect this process. However, satellite photography is the major and superior form of observation with some disadvantages due to the low quality of images the decision could not be taken properly sometimes (Lu et al., 2017). Hence UAVs are very important for monitoring the crops and for collecting correct high-quality images for taking the right decision through this monitoring approach. 


\subsection{UAV IN IRRIGATION SYSTEMS}

UAVs multi spectral, hyper spectral or thermal sensors can discover the needs of the field that which part of the field is dry and have need of improvements. In addition, as the crop is growing once, the UAVs can start the computation of the foliage index. This index elaborate the practical concentration and physical condition of the field crops and exhibit the total of energy and the temperature emitted from the crops (Jiménez-Bello, Royuela, Manzano, Zarco-Tejada, \& Intrigliolo, 2013)

\section{MILITARY USAGE}

The UAVs have a variety of applications within the military and defense area (Bucaille et al., 2013; Tesfa-Alem Tekle, 2013). UAVs can be used in military operations that develop interest nowadays. Actually, the technology started within the military that may blow your mind away. UAVs are used for varied military operations because of high convenience to reduce the losses and facilitate the execution of the status of the mission. It has been studied that France had the thought of developing a craft that had no human pilot on board to be utilized in warfare. Initially, these crafts were used throughout Vietnam. Military UAVs square measure a part of an outsized system that is associated with remote-controlled craft System, a term that encompasses the entire system with the bottom management and sensors being factored. The square measures have many categories and therefore the difference relies on weights. Military UAVs can be classified according to their operations, these UAVs performs the operation for specific targets and decoy to provide intelligence, which can be used in combat. However, in this modern era, the traditional craft is not appropriate for these missions. In the recent, period the UAVs are used which can trigger the information remotely and play an important role within the resolution of future military usage. The swarm of UAVs concept is used to collect the information and for taking some square measures. The variety of applications and usage of UAVs for military operations are discussed as follows. 


\subsection{UAV IN BOMB RECOGNITION}

The slight size of the UAVs sometimes penetrates constricted areas. The elevation of effective cameras that makes capable of UAVs for performing an appropriate functionality of bomb recognition. These UAVs are created by the United States for triggering the alerts about the undercharged bombs and save the human lives (Sathyamoorthy, 2015).

\subsection{UAV IN SURVEILLANCE}

To substantiate security in the region, mostly the surveys take place in the selected locations. The conventional mechanism is not appropriate which ensure the security in the period of digital technology. However, UAVs are very important to perform the surveillance that is might noteworthy solution, it will not only reduce strive and you get a wider field of the geographical area but also get more information with limitation of smaller time. This conjointly doesn't hamper the lives of the individuals but an easy and economical solution (Yang et al., 2019).

\subsection{UAV IN AIR STRIKE}

The UAVs are used to intending of Air strikes. It was declared by a political entity that they used these UAVs for often to attack militants of the Asian countries. It hovers around the highlighted suspected areas and controlled by defense authorities. It can be deployed for a particular area to satisfy the military operations or to get information about subject data. However, the authors recommending the findings of the article concerning the enforcement of UAVs (Clary \& Narang, 2019).

\subsection{UAV IN SECURITY}

The prompt implementation of UAVs is necessary for the purpose of security. In addition, the confidentiality point of view, UAVs engaged by voyeurs and paparazzi to get images of inhabitant groups in their residences or dissimilar places formerly implicit to be individual. The UAVs swarm can be installed in deemed areas which are almost certainly unsafe, like metropolitan areas and near to the landing field 
means airports. However, UAVs plays a vital role in the provisioning of security. It is an important area, the researcher can further explore in depth (Hein, Kraft, Brauchle, \& Berger, 2019).

\section{UAV IN CIVILIAN USAGE}

The civilian applications of UAVs are photography, shipping and delivery, rescue in disaster management, rescue operations, archaeological survey, safety inspection, life observance, weather forecasting and livestock surveillance which is discussed below.

\subsection{UAV IN PHOTOGRAPHY}

The aerial photography is one of the glorious applications of UAVs. This technology equipped and holds significant camera gear that would extremely facilitate enthusiasts in delivering the aerial views of the precise regions. UAVs aerial photography may provide you with crisp and clear pictures. And have the options of live Wi-Fi streaming, you're conjointly entitled to urge person views of the UAVs movements. Live broadcasting of aerial footage is changing the most effective UAVs for motionpicture photography (Bravo, Leiras, \& Oliveira, 2019). The UAVs perform a significant role which would extremely facilitate the regions (Li \& Yang, 2012).

\subsection{UAV IN SHIPPING AND DELIVERY}

The shipping and delivery application of UAVs is also an important area; this concept is a revolutionary idea of modern times. It reduces the delivery times and improves the performance of the system and decrease the individual manual labor, such as, distribute the pizzas, correspondence, small parcel packages, the automatic UAVs provide services to society but still limitedly. DHL has dispatched parcel and deliver with a UAV. As a matter of reality, Amazon is functioning on its resources to facilitate the services by using UAVs in 30 minutes delivery. If this is often delivered at execution, over 1/2 you are looking for food orders may be placed inside a span of a number of minutes, UAVs delivering your packages at your doorstep in minutes. 
These types of civil services carried out by UAVs in the future (Perna \& Rodrigues, 2018).

\subsection{UAV IN DISASTER MANAGEMENT}

The foremost necessary application of pilotless UAVs can be used for disaster management. It is usually observed that the complete anarchy takes place in the direction of resources in a moment once a disaster occurs. In this situation, the UAVs plays an important responsibility to rescue the operation team in the affected area. These UAVs have powerful and special cameras through which the affected peoples, properties highlighted through footages and then save the human beings (Erdelj, Natalizio, Chowdhury, \& Akyildiz, 2017).

\subsection{UAV IN RESCUE OPERATIONS}

In the rescue operations and care, UAVs can be launched through the flood areas. These are more helpful for provisioning of food and medicines to those human resources which are out of reach of these facilities before the reaching of rescue team assistance. The UAVs are the primary solution to be used to provide necessary products which can save human lives during this difficult time. The flood affected region data can be easily collected through aerial view during the rescue operations (Scherer et al., 2015).

\subsection{UAV IN ARCHAEOLOGICAL SURVEY}

Many individuals have spent lots of time and energy over archaeological surveys. Nowadays, UAVs are used for this work. It is easier, as they will bring necessary information concerning archaeological sites through the aerial view. UAVs archaeological surveys will consider the mission of discovery as well (Saleri et al., 2013). 


\subsection{UAV IN GEOGRAPHIC MAPPING}

The UAVs have a massive impact in the field of 3-D geographic mapping. In the globe, there are numerous areas, regions which could not accessible to humans. This may embody hazardous coastline, unrealizable peaks of mountains. Except for the aim of learning about a parcel in addition to making ready 3-D maps UAVs place to use. Geographic mapping through UAVs is very significant to make ensure capturing the required locations, sites for mapping processes. It is easier for a geologist to gather essential information nowadays all the way through UAVs (Sun, Wang, \& Zhong, 2018).

\subsection{UAV IN HUMAN HEALTH}

The UAVs are advanced technology devices which can be used in many risk-based human health remedies. The risk means such as, plethora disease that is caused due to stagnant contaminated water having mosquitoes and houseflies. Hence due to these tiny mosquitoes, the diseases spread in Pakistan, India, Thailand, Cambodia, Srilanka, and Brazil. The dengue is a famous disease which affects these countries population and spreads very fast and very critical to handle. However, the UAVs can be used to locate the dengue spots or the ponds of dirty water in the environment and the rapid measures can be taken for remedies which cause the health problems (Sreeram \& Shanmugam, 2018).

\subsection{UAV IN LIVESTOCK SURVEILLANCE}

The livestock surveillance is a more reliable solution through UAVs to scan the large area very easily for counting the animals throughout making the videos. The animal can be tracked or analyzed through the recorded video or images (Chamoso, Raveane, Parra, \& González, 2014). The UAVs have been considered for livestock monitoring, several peoples do not know that UAVs are used for monitoring the cattle in real, they know that this is science fiction. Tracking the livestock in huge farms is very difficult, however, the UAVs is a novel solution for surveillance of dairy cattle's (Barbedo \& Koenigkan, 2018). These UAVs are important for inspecting of availability of water and food for the livestock. Hence, by using these tiny devices that 
can save the time of farmers from tedious work. To keep the cattle's out of the reach of thieves within the ranch can be possible through UAVs tracking and remain up-todate about the animal counts. The UAVs are equipped with thermal sensors through these the animal health can be monitored (AG. TECH., 2016).

\subsection{UAV IN SAFETY INSPECTION}

The safety is an important factor for individual, society, organization, and nation. Hence, safety measures, inspections are essential in this modern age. However, to perform regular inspections to make sure about safety and security is considered on high priority. So at the national level, the aerial inspection is mandatory for safety. Therefore the UAVs can be used for safety by the brink of capturing the representational process which will provide an additional careful plan for safety and development (Choi \& Kim, 2015).

\subsection{UAV IN LIFE OBSERVANCE}

The life observance of the lakes and rivers. For example, why millions of useful birds are vulnerable due to lack of feed and diseases. Hence aerial observations and footages facilitate to know the behavior of birds and analyze the data and collect the required statistics. However, UAVs perform this operation without disturbing the bird's life. Besides this, UAVs can be used in the dark with thermal cameras, sensors to observe these birds at any times. Millions of life sanctuaries and conservation parks area can be observed (Ward, Hensler, Alsalam, \& Gonzalez, 2016).

\subsection{UAV IN WEATHER FORECASTING}

The application of UAVs is weather forecasting that means the prediction of climate conditions. Hence, these UAVs can be used in hurricanes, tornado, and provides the essential footages, in addition, test the patterns and occurrence. However, UAVs are an economical solution to perform the operation of weather prediction (Cecil, 2018). While the UAVs sniff out an impending storm or on another hand, some threatening interruption, the additional UAVs can be launched. For this, the swarm of UAVs that can communicate with each other on how finest to cross-examine that 
area of the environment, by collecting more data, by using different mobility models as per need. Slighter, dispensable winged UAVs are dropped into the storm, which can gather more samples.

Table 1 shows a summary of unmanned aerial vehicles applications.

Table 1. Summary of UAVs Applications.

\begin{tabular}{|c|c|c|}
\hline \multicolumn{3}{|c|}{ Summary of UAVs Applications } \\
\hline S. N. ${ }^{\circ}$ & $\begin{array}{l}\text { Category of } \\
\text { Application }\end{array}$ & UAVs Applications \\
\hline \multirow{5}{*}{1} & \multirow{5}{*}{$\begin{array}{l}\text { Agriculture } \\
\text { Usage }\end{array}$} & Analysis of field soil \\
\hline & & Health assessment of crops \\
\hline & & Plant prevention spray \\
\hline & & Monitoring crop \\
\hline & & Irrigation system \\
\hline \multirow{4}{*}{2} & \multirow{4}{*}{$\begin{array}{l}\text { Military } \\
\text { Usage }\end{array}$} & Bomb recognition \\
\hline & & Military surveillance \\
\hline & & Air strikes \\
\hline & & Military security \\
\hline \multirow{11}{*}{3} & \multirow{11}{*}{$\begin{array}{c}\text { Civilian } \\
\text { Usage }\end{array}$} & Photography \\
\hline & & Shipping and delivery \\
\hline & & Disaster management \\
\hline & & Rescue operation \\
\hline & & Archeological survey \\
\hline & & Geographic mapping \\
\hline & & Human Health \\
\hline & & Livestock surveillance \\
\hline & & safety Inspection \\
\hline & & Life observance \\
\hline & & Weather forecasting \\
\hline
\end{tabular}

\section{CONCLUSION}

In this study, the applications of UAVs explored with respect to the modern needs of society. The variety of applications meets the current demand. Three categories 
of UAVs applications are focused which are agricultural usage, military usage, and civilian usage. Each category has a variety of applications. Furthermore, it is a significant area for the advancement of technology usage. However, researchers can explore this domain of technology according to society needs and can develop testbed scenarios for different purposes and evaluate each application domain. These vehicles can fly in various circumstances and zones and can perform various missions.

\section{ACKNOWLEDGMENT}

I would like to articulate the heartfelt thanks to my mentor and guide; and also we are grateful to the management of SZABIST for their continuous support, guidance, and provision of resources. In addition, we would like to indebt the mysterious critics for their helpful and valuable observation remarks and suggestions which definitely helped us in the improvement of the manuscript.

\section{REFERENCES}

AG. TECH. (2016, August 8). Farmers are Using Cattle Surveillance Drones to Keep an Eye on their Livestock. Retrieved from: https:/ / dairynow.ca/using-drones-for-monitoringdairy-cattle/

Barbedo, J., \& Koenigkan, L. (2018). Perspectives on the use of unmanned aerial systems to monitor cattle. Outlook on Agriculture, 47, 214-222. doi: https://doi. org/10.1177/0030727018781876

Bitar, A., Jamal, A., Sultan, H., Alkandari, N., \& El-Abd, M. (2017). Medical Drones System for Amusement Parks. 2017 IEEE/ACS 14th International Conference on Computer Systems and Applications (AICCSA), 19-20. doi: https:// doi.org/10.1109/ AICGSA.2017.62

Bravo, R. Z. B., Leiras, A., \& Oliveira, F. L. C. (2019). The Use of UAVs in Humanitarian Relief: An Application of POMDP-Based Methodology for Finding Victims. Production and Operations Management, 28(2), 421-440. doi: https:// doi.org/10.1111/poms.12930 
Bucaille, I., Héthuin, S., Munari, A., Hermenier, R., Rasheed, T., \& Allsopp, S. (2013). Rapidly Deployable Network for Tactical Applications: Aerial Base Station with Opportunistic Links for Unattended and Temporary Events ABSOLUTE Example. MILCOM 2013-2013 IEEE Military Communications Conference, 1116-1120. doi: https://doi.org/10.1109/MILCOM.2013.192

Burwood-Taylor, L. (2017, March 16). The Next Generation of Drone Technologies For Agriculture. Retrieved June 27, 2019, from https://agfundernews.com/thenext-generation-of-drone-technologies-for-agriculture.html

Gecil, J. (2018). A conceptual framework for supporting UAV based cyber-physical weather monitoring activities. 2018 Annual IEEE International Systems Conference (SysCon), 1-8. doi: https://doi.org/10.1109/SYSCON.2018.8369588

Chamoso, P., Raveane, W., Parra, V., \& González, A. (2014, June 20). UAV s Applied to the Counting and Monitoring of Animals. 291. doi: https://doi.org/10.1007/978-3319-07596-9_8

Ghen, D., \& Gao, G. X. (2019). Probabilistic graphical fusion of LiDAR, GPS, and 3D building maps for urban UAV navigation. Navigation, 66(1), 151-168. doi: https://doi.org/10.1002/navi.298

Choi, S., \& Kim, E. (2015). Design and implementation of vision-based structural safety inspection system using small unmanned aircraft. 2015 17th International Conference on Advanced Communication Technology (ICACT), 562-567. doi: https://doi. org/10.1109/ICACT.2015.7224924

Glary, G., \& Narang, V. (2019). India's Counterforce Temptations: Strategic Dilemmas, Doctrine, and Capabilities. International Security, 43(3), 7-52. doi: https://doi.org/10.1162/isec_a_00340

Dandois, J. P., Olano, M., \& Ellis, E. G. (2015). Optimal Altitude, Overlap, and Weather Conditions for Computer Vision UAV Estimates of Forest Structure. Remote Sensing, 7(10), 13895-13920. doi: https://doi.org/10.3390/rs71013895 
Erdelj, M., Natalizio, E., Chowdhury, K. R., \& Akyildiz, I. F. (2017). Help from the Sky: Leveraging UAVs for Disaster Management. IEEE Pervasive Computing, 16(1), 24-32. doi: https://doi.org/10.1109/MPRV.2017.11

Garcia-Ruiz, F., Sankaran, S., Maja, J. M., Lee, W. S., Rasmussen, J., \& Ehsani, R. (2013). Comparison of two aerial imaging platforms for identification of Huanglongbing-infected citrus trees. Computers and Electronics in Agriculture, 91, 106-115. doi: https://doi.org/10.1016/j.compag.2012.12.002

Gonzalez-Dugo, V., Zarco-Tejada, P., Nicolás, E., Nortes, P. A., Alarcón, J. J., Intrigliolo, D. S., \& Fereres, E. (2013). Using high resolution UAV thermal imagery to assess the variability in the water status of five fruit tree species within a commercial orchard. Precision Agriculture, 14(6), 660-678. doi: https://doi. org/10.1007/s11119-013-9322-9

Hein, D., Kraft, T., Brauchle, J., \& Berger, R. (2019). Integrated UAV-Based Real-Time Mapping for Security Applications. ISPRS International fournal of GeoInformation, 8(5), 1-16. doi: https://doi.org/10.3390/ijgi8050219

Jiménez-Bello, M. A., Royuela, A., Manzano, J., Zarco-Tejada, P. J., \& Intrigliolo, D. (2013). Assessment of drip irrigation sub-units using airborne thermal imagery acquired with an Unmanned Aerial Vehicle (UAV). In J. V. Stafford (Ed.), Precision agriculture '13, 705-711. Wageningen Academic Publishers.

Li, X., \& Yang, L. (2012). Design and Implementation of UAV Intelligent Aerial Photography System. 2012 4th International Conference on Intelligent Human-Machine Systems and Cybernetics, 2, 200-203. doi: https: / / doi.org/10.1109/IHMSC.2012.144

Liu, P., Chen, A. Y., Huang, Y.-N., Han, J.-Y., Lai, J.-S., Kang, S.-G., ... Tsai, M.-H. (2014). A review of rotorcraft Unmanned Aerial Vehicle (UAV) developments and applications in civil engineering. Smart Structures and Systems, 13(6), 1065-1094. doi: https://doi.org/10.12989/SSS.2014.13.6.1065 
Lu, Z., Nagata, F., \& Watanabe, K. (2017). Development of iOS application handlers for quadrotor UAV remote control and monitoring. 2017 IEEE International Conference on Mechatronics and Automation (ICMA), 513-518. doi: https:/ / doi.org/10.1109/ICMA.2017.8015870

Militaru, G., Popescu, D., \& Ichim, L. (2018). UAV-to-UAV Communication

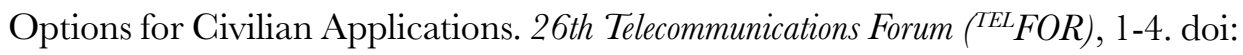
https://doi.org/10.1109/TELFOR.2018.8612108

Moore,J. (2013). United States Patent No. US20130134254A1. Retrieved from: https:/ / patents.google.com/patent/US20130134254A1/en

Perna, M. D., \& Rodrigues, L. (2018). A UAV software flight management system using arinc communication protocols. IEEE Aerospace and Electronic Systems Magazine, 33(9), 18-28. doi: https://doi.org/10.1109/MAES.2018.170085

Saleri, R., Gappellini, V., Nony, N., Luca, L. D., Pierrot-Deseilligny, M., Bardiere, E., \& Campi, M. (2013). UAV photogrammetry for archaeological survey: The Theaters area of Pompeii. 2013 Digital Heritage International Congress (DigitalHeritage), 2, 497-502. doi: https://doi.org/10.1109/ DigitalHeritage.2013.6744818

Sathyamoorthy, D. (2015). A review of security threats of Unmanned Aerial Vehicles and mitigation steps. The Fournal of Defence and Security, 6(2), 1-14.

Scherer, J., Yahyanejad, S., Hayat, S., Yanmaz, E., Andre, T., Khan, A., ... Rinner, B. (2015). An Autonomous Multi-UAV System for Search and Rescue. Proceedings of the First Workshop on Micro Aerial Vehicle Networks, Systems, and Applications for Civilian Use, 33-38. doi: https:/ / doi.org/10.1145/2750675.2750683

Sładkowski, A., \& Kamiński, W. (2019). Using Unmanned Aerial Vehicles to Solve Some Civil Problems. Cases on Modern Computer Systems in Aviation, 52-127. doi: https://doi.org/10.4018/978-1-5225-7588-7.ch003 
Sreeram, S., \& Shanmugam, L. (2018). Autonomous Robotic System Based Environmental Assessment and Dengue Hot-Spot Identification. 2018 IEEE International Conference on Environment and Electrical Engineering and 2018 IEEE Industrial and Commercial Power Systems Europe (EEEIC / I CPS Europe), 1-6. doi: https://doi. org/10.1109/EEEIC.2018.8493849

Sugisaka, M. (2011). Working robots for nuclear power plant desasters. 5th IEEE International Conference on Digital Ecosystems and Technologies (IEEE DEST 2011), 358361. doi: https://doi.org/10.1109/DEST.2011.5936593

Sun, Z., Wang, D., \& Zhong, G. (2018). Extraction of Farmland Geographic Information Using OpenStreetMap Data. 2018 7th International Conference on Agro-Geoinformatics (Agro-Geoinformatics), 1-4. doi: https://doi.org/10.1109/AgroGeoinformatics.2018.8476088

Tesfa-Alem Tekle. (2013, February 14). Ethiopia produces first military drone aircraft-Sudan Tribune: Plural news and views on Sudan.

Ward, S., Hensler, J., Alsalam, B., \& Gonzalez, L. F. (2016). Autonomous UAVs wildlife detection using thermal imaging, predictive navigation and computer vision. 2016 IEEE Aerospace Conference, 1-8. doi: https://doi.org/10.1109/ AERO.2016.7500671

Wu, W., Qurishee, M. A., Owino,J., Fomunung, I., Onyango, M., \& Atolagbe, B. (2018). Coupling Deep Learning and UAV for Infrastructure Condition Assessment Automation. 2018 IEEE International Smart Cities Conference (ISC2), 1-7. doi: https://doi.org/10.1109/ISC2.2018.8656971

Yamazaki, F., Matsuda, T., Denda, S., \& Liu, W. (2015). Construction of 3D models of buildings damaged by earthquakes using UAV aerial images. Proceedings of the Tenth Pacific Conference on Earthquake Engineering Building an Earthquake-Resilient Pacific, 1-8.

Yang, T., Li, Z., Zhang, F., Xie, B., Li, J., \& Liu, L. (2019). Panoramic UAV Surveillance and Recycling System Based on Structure-Free Camera Array. IEEE Access, 7, 25763-25778. doi: https://doi.org/10.1109/ACGESS.2019.2900167 
Zhang, G., \& Kovacs, J. M. (2012). The application of small unmanned aerial systems for precision agriculture: A review. Precision Agriculture, 13(6), 693-712. doi: https://doi.org/10.1007/s1 $1119-012-9274-5$ 



\section{TOWARDS A NEW SDN NFV APPROACH FOR THE MANAGEMENT OF MPLS INFRASTRUCTURES}

Faycal Bensalah

Ph.D Student, Network and Telecommunications team.

Faculty of Sciences, Chouaib Doukkali University.

El Jadida (Morocco).

E-mail: f.bensalah@ucd.ac.ma

Najib E1 Kamoun

Ph.D, professor in the dept. of physics.

Researcher member on STIC laboratory, header of Network and Telecommunications team. Faculty of Sciences, Chouaib Doukkali University.

El Jadida (Morocco). E-mail: elkamoun@ucd.ac.ma

Recepción: 29/07/2019 Aceptación: 19/09/2019 Publicación: 06/11/2019

\section{Gitación sugerida:}

Bensalah, F. y El Kamoun, N. (2019). Towards a new SDN NFV approach for the management of MPLS infrastructures. 3C Tecnología. Glosas de innovación aplicadas a la pyme. Edición Especial, Noviembre 2019, 107-1 19. doi: http://dx.doi.org/10.17993/3ctecno.2019. specialissue3.107-119

\section{Suggested citation:}

Bensalah, F. \& El Kamoun, N. (2019). Towards a new SDN NFV approach for the management of MPLS infrastructures. 3 C Tecnología. Glosas de innovación aplicadas a la pyme. Speciaal Issue, November 2019, 107-119. doi: http://dx.doi.org/10.17993/3ctecno.2019. specialissue3.107-119 


\section{ABSTRACT}

Network infrastructure virtualization has become an active research area. Indeed, network feature virtualization (NFV) brings unparalleled flexibility to nextgeneration networks and goes far beyond cost reduction. This technology reduces vendor dependency and allows new features to be deployed faster than ever before. In this article we propose a new solution for the virtualization of network services, particularly in relation to concepts related to MPLS technology. Our solution ensures fast access to the access network while guaranteeing quality of service.

\section{KEYWORDS}

NFV, SDN, MPLS, Automation. 


\section{INTRODUCTION}

NFV (virtualization of network functions) is a way to reduce costs and accelerate service deployment for network operators by dissociating functions such as firewalls or encryption from any dedicated hardware and moving them to virtual servers (Hawilo, Shami, Mirahmadi, \& Asal, 2014). The NFV concept for virtualization of network functions is like a new step towards creating a more agile and cost-effective network infrastructure. Network function virtualization (NFV) extracts network functions, allowing software components running on standardized compute nodes to install, control and manipulate them. NFV integrates cloud and virtualization technologies to quickly develop new network services while optimizing flexibility in terms of scalability and automation. These technologies are often combined in NFV and SDN solutions. This virtualization of network functions reduces network operators' dependence on dedicated hardware and improves scalability and customization across the entire network. Unlike a virtual network, the NFV only seeks to offload certain network functions rather than the entire network.

The NFV reduces the need for dedicated hardware to deploy and manage networks by transferring network functions to software that runs on standard hardware and can be managed from anywhere on the operator's network.

The separation of network functions from hardware provides many advantages for the network operator, including:

- Reduction of the space required for the network's physical equipment.

- Reduction of grid power consumption.

- Reduction of network maintenance costs.

- Simplification of network upgrades.

- Extension of the life cycle of network physical equipment.

- Reduced maintenance and material costs. 
The desire to automate the orchestration and management of the network, storage and computing resources is a key factor in NFV and SDN development. Imagine a scenario involving a physical server with 10 virtual machines or hundreds of containers. This concept cannot be evolutionary if it involves manual operations. Automation enables virtualized network functions (VNFs) such as virtual machines (VMs), containers, routers, firewalls and intrusion prevention systems (IPSs) to be quickly created or removed to automatically adapt them to dynamic demand.

SDN and NFV are not an integral part of each other (Bahnasse, Louhab, Oulahyane, Talea, \& Bakali, 2018). While the two concepts are quite different, they are nevertheless related. The NFV can thus be implemented without the need for an SDN, although these two approaches can be combined to provide greater added value.

The objectives of the NFV can be achieved by using non-SDN mechanisms, using techniques currently used in many datacenters. But approaches based on the separation of control and data transfer plans, as proposed by the SDN, can improve performance, simplify compatibility with existing deployments and facilitate operation and maintenance procedures.

The NFV can support the SDN by providing the infrastructure on which the SDN software can be run. In addition, the NFV is closely aligned with the SDN's objectives for the use of servers and switches.

\section{STATE OF THE ART}

The SDN and NFV technologies propose to revolutionize the way networks operate, and the success of these two technologies may well depend on their ability to interact harmoniously, if not support each other. To this end, and according to Ding, Qi, Wang, and Chen (2015), the SDN can provide connectivity between NFV files in a flexible and automated manner, thus simplifying network management. In addition, NFV can use the SDN as part of a service function chain (SFG). In this case, SDN controllers and business applications can run as NFV files in a scalable environment and benefit from essential features such as availability, reliability and elasticity. 
Several studies focus on the integration of NFV and SDN in different environments such as cloud computing, intelligent wide area networks, customer premises equipment, 5G, telemedicine, etc. These studies address several challenges, such as reliability, performance and scalability. These studies use a distinct architectural design logic as well as functional and non-functional requirements (Basta, Kellerer, Hoffmann, Morper, \& Hoffmann, 2014; Ordonez-Lucena, Ameigeiras, Lopez, Ramos-Munoz, Lorca, \& Folgueira, 2017; Vilalta et al., 2016).

Ensuring a good QoS level for multi-path networks is one of the major challenges, both for wireline networks $\mathrm{Wu}$, Cheng, Yuen, Cheung, \& Chen, 2015; Wu, Yuen, Cheng, Shang, \& Chen, 2014) and wireless networks more precisely those with energy consumption constraints (Wu, Cheng, Wang, \& Chen, 2018; Wu, Yuen, Cheng, Wang, \& Chen, 2016). The undesirable effects of multi-path and service degradation can only be truly felt when multimedia or real-time applications are routed through the network, more precisely and especially in wireless networks where bandwidth is one of the major concerns. Despite the many CMT (Concurrent Multipath Transfer) solutions, they remain limited due to the asymmetry of link performance and especially the sensitivity of some applications to SLA constraints. Wu, Yuen, Wang and Chen (2015) in their work considered as an improvement of CMT solutions considering video distortion in the path selection process, the proposed solution is published as Distortion Aware CMT (CMT-DA). The latter consists of first estimating the available bandwidth per path using Round Trip Time (RTT), congestion window and Timeout retransmission (RTO). Then, perform a flow rate allocation, i. e. send the acknowledgement packets via the most efficient uplinks in order to be able to adapt the congestion window. CMT-DA has been tested in a variety of heterogeneous wireless networks: WiFi, WiMax and cellular, the results obtained in terms of PSNR (Peak Signal to Noise Ratio), Goodput and InterPacket delay have shown the radical improvement in the QoS of multimedia traffic compared to existing wireless heterogeneous network solutions. 


\section{PROPOSED APPROACH}

Our approach is based on three logical layers; the service layer, the orchestration layer, and the physical layer. Figure 1 illustrates the architecture of the proposed approach.

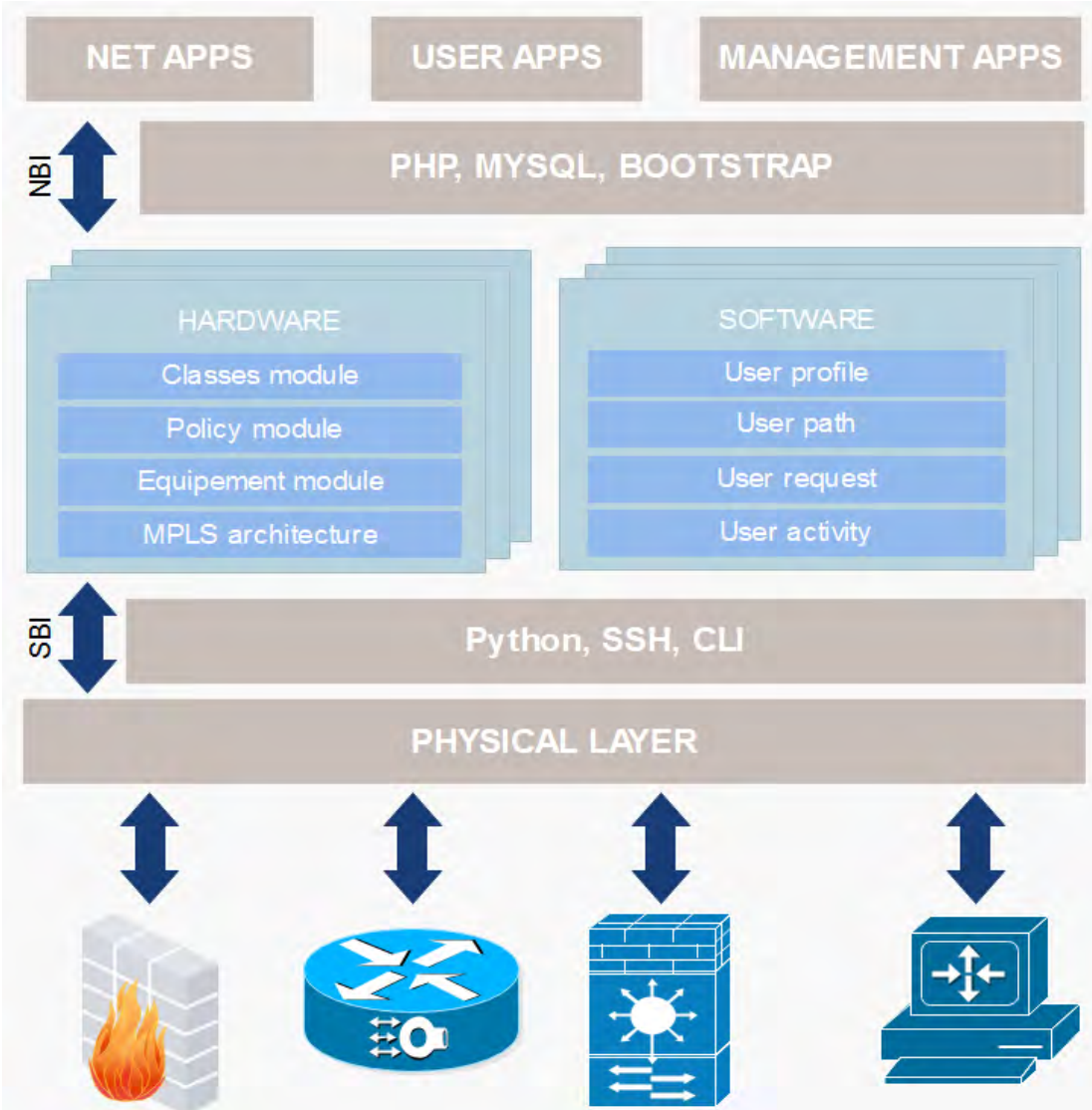

Figure 1. The proposed NFV architecture for virtualizing quality of service in an MPLS infrastructure.

The service layer provides all applications and services that affect the process of routing and routing MPLS frames (Bahnasse, Louhab, Oulahyane, Talea, \& Bakali, 2018). This layer provides all the graphical interfaces through which the infrastructure administrator can specify the applications to be used, their characteristics, and their QoS constraints. Figure 2 illustrates an example of the service layer interface. 


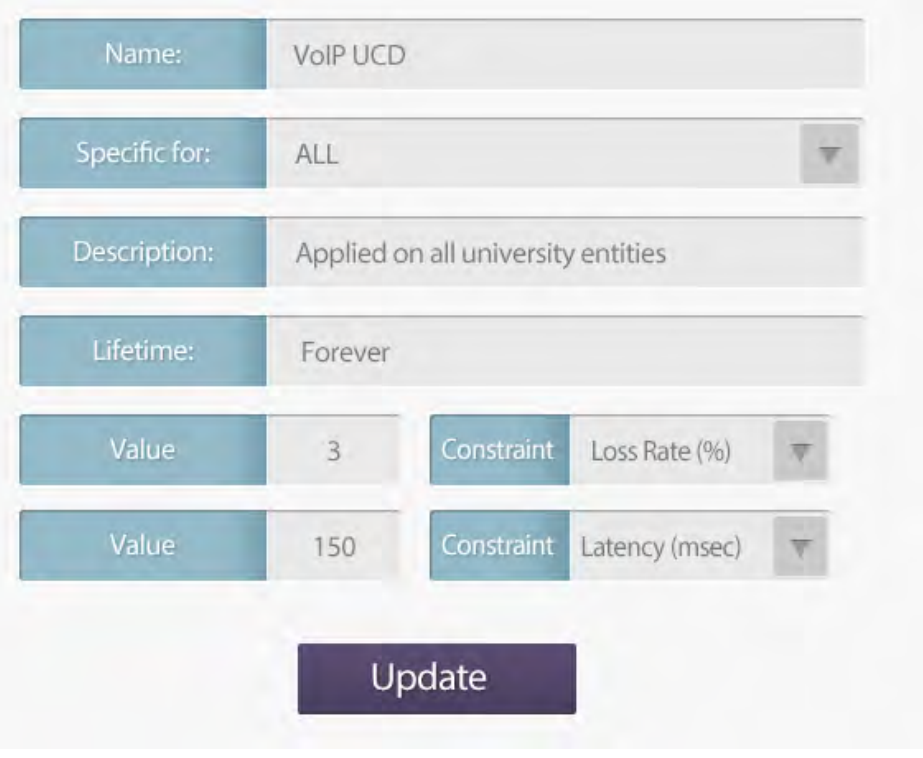

Figure 2. Service layer interface.

The software layer provides the necessary mechanisms for detecting user activity, including:

- The destination IP address;

- The state of the best way to this destination;

- The other possible paths for this destination;

- The user's subscription type;

- The bandwidth requested by the user;

- The user's permanent activity;

This layer is based on active metrology protocols (SNMP, CMIP) to ensure these objectives mentioned above.

The software layer also allows intelligent management of the paths that a user must take for a better quality of service. This path determination process is based on the RSVP protocol for the a priori establishment of the path. A list of paths is then 
defined in a stack sorted in terms of available bandwidth, the operating steps are as follows:

1. Calculate all paths between a source and a destination and store them in a stack.

2. Sort these paths according to the available bandwidth of each link.

3. Stack the results according to the number of links.

4. If the available bandwidth is enough to transmit user traffic, traffic is routed by the first path.

5. Otherwise, the priority of active traffic is checked. If it exceeds that of the generated traffic, then the traffic is routed by the following path.

To address the path with QoS constraints and the shortest path, we assume that the graph $\mathrm{G}=[\mathrm{X}, \mathrm{U}]$ represents a network of an $\mathrm{N}$ router and $\mathrm{M}$ links. Au, represents the available bandwidth of a link for each u $\mathrm{U}$.

for each request to establish an $\operatorname{LSP}(K)$, defined by a source $S(k)$, a destination $R(k)$, the requested bandwidth $\mathrm{dk}$ and the nth path between $\mathrm{s}(\mathrm{k})$ and $\mathrm{R}(\mathrm{k})$ for all $\mathrm{n}[1, \mathrm{P}(\mathrm{k})]$.

The links responding to bandwidth constraints are defined by:

$$
\operatorname{Min}\{\}, u[1, M]
$$

It is essential to detect a user's activity, and it is according to this activity that the routing process and QoS will be executed, to achieve this objective our model is based on the NBAR and Netflow protocols. Our model is based on flow sampling methods:

- Full: generates for each network flow an information that will be exported. This method is the oldest and the one supported on almost all routers but is no longer very common among operators because the router load and the amount of accounting information generated, especially during a shared denial of service, are too high. On the other hand, in the context of an internal network, 
it is almost mandatory if we want to be able to detect slow recognitions or violations of policies that try to be discreet.

- Sampled: Allows you to define the percentage of flows to be exported over the total number of flows generated. In general, operators are limited to 1 per 100 or even 1 per 1000. Even at 1 per 1000, a shared denial of service remains relatively easy to detect. The advantage of this method is the reduction of the router's CPU load and the amount of Netflow exported. The disadvantage is that it is not statistically good (deterministic function).

- Random Sampled: has been introduced relatively recently and on platforms of the 72xx/75xx type (whereas sampled was only available on GSR and 76xx, i.e. routers that support distributed CEF). The difference between sampled and random sampled is that the latter selects a random datagram from the configured $<x>$ which is statistically better.

Indeed, thanks to the monitoring of the user's activity, our model can detect the user's need in terms of bandwidth according to the type of application.

The Hardware layer allows several VRFs to be instantiated within the same gateway in accordance with user-specific routing policies. It allows to define within the gateways the different QoS classes and policies adapted for a user within a well determined architecture (MPLS, MPLS VPN, or traditional IP).

As soon as policies are configured, our platform establishes sockets with the different gateways of the network using the Python language. These sockets are used to connect to the gateways and execute information gathering and configuration commands, Figure 3 illustrates an example of the sockets used. 


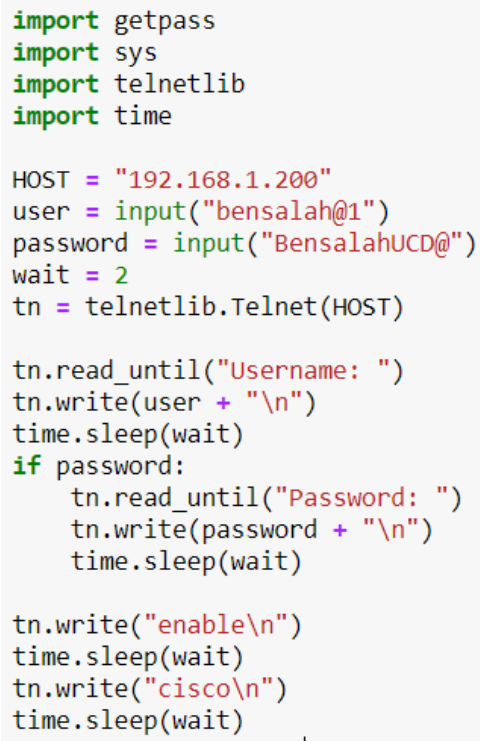

Figure 3. Python socket for connection with Cisco routers.

\section{CONCLUSIONS}

In this paper we have proposed a new architecture for virtualization of MPLS infrastructures by combining SDN and NFV approaches. The proposed architecture manages network services and equipment to meet subscriber QoS requirements. The adoption of such an architecture can provide unparalleled flexibility and cost reduction, as a single gateway can instantiate multiple virtual routing tables, each of which is subject to a routing policy that meets users' QoS requirements.

\section{REFERENCES}

Bahnasse, A., Louhab, F. E., Oulahyane, H. A., Talea, M., \& Bakali, A. (2018). Novel SDN architecture for smart MPLS traffic engineering-DiffServ aware management. Future Generation Computer Systems, 87, 115-126. doi: https:// doi.org/10.1016/j.future.2018.04.066 
Bahnasse, A., Louhab, F. E., Oulahyane, H. A., Talea, M., \& Bakali, A. (2018). Smart bandwidth allocation for next generation networks adopting software-defined network approach. Data in brief, 20, 840-845. doi: https://doi. org/10.1016/j.dib.2018.08.091

Basta, A., Kellerer, W., Hoffmann, M., Morper, H. J., \& Hoffmann, K. (2014, August). Applying NFV and SDN to LTE mobile core gateways, the functions placement problem. In Proceedings of the 4th workshop on All things cellular: operations, applications, \& challenges, 33-38. ACM. doi: https://doi. org/10.1145/2627585.2627592

Ding, W., Qi, W., Wang, J., \& Chen, B. (2015). OpenSCaaS: an open service chain as a service platform toward the integration of SDN and NFV. IEEE Network, 29(3), 30-35. doi: https://doi.org/10.1109/MNET.2015.7113222

Hawilo, H., Shami, A., Mirahmadi, M., \& Asal, R. (2014). NFV: State of the art, challenges and implementation in next generation mobile networks (vEPC). arXiv preprint arXiv:1409.4149

Ordonez-Lucena, J., Ameigeiras, P., Lopez, D., Ramos-Munoz, J. J., Lorca, J., \& Folgueira, J. (2017). Network slicing for 5G with SDN/NFV: Concepts, architectures, and challenges. IEEE Communications Magazine, 55(5), 80-87. doi: https://doi.org/10.1109/MCOM.2017.1600935

Vilalta, R., Mayoral, A., Pubill, D., Gasellas, R., Martínez, R., Serra, J., ... Muñoz, R. (2016, March). End-to-end SDN orchestration of IoT services using an SDN/NFV-enabled edge node. In 2016 Optical Fiber Communications Conference and Exhibition (OFC), 1-3. IEEE. doi: https://doi.org/10.1364/OFG.2016. W2A.42

Wu, J., Cheng, B., Wang, M., \& Chen, J. (2018). Energy-aware concurrent multipath transfer for real-time video streaming over heterogeneous wireless networks. IEEE Transactions on Circuits and Systems for Video Technology, 28(8), 20072023. doi: https://doi.org/10.1109/tcsvt.2017.2695368 
Wu, J., Gheng, B., Yuen, C., Cheung, N. M., \& Chen, J. (2015). Trading delay for distortion in one-way video communication over the internet. IEEE Transactions on Circuits and Systems for Video Technology, 26(4), 711-723. doi: https:// doi.org/10.1109/tcsvt.2015.2412774

Wu, J., Yuen, G., Gheng, B., Shang, Y., \& Chen, J. (2014). Goodput-aware load distribution for real-time traffic over multipath networks. IEEE Transactions on Parallel and Distributed Systems, 26(8), 2286-2299. doi: https://doi.org/10.1109/ TPDS.2014.2347031

Wu, J., Yuen, C., Cheng, B., Wang, M., \& Chen, J. (2016). Energy-minimized multipath video transport to mobile devices in heterogeneous wireless networks. IEEE Journal on Selected Areas in Communications, 34(5), 1160-1178. doi: https: / doi. org/10.1109/JSAC.2016.2551483

Wu, J., Yuen, C., Wang, M., \& Ghen, J. (2015). Content-aware concurrent multipath transfer for high-definition video streaming over heterogeneous wireless networks. IEEE Transactions on Parallel and Distributed Systems, 27(3), 710-723. doi: https://doi.org/10.1109/TPDS.2015.2416736 
Edición Especial Special Issue Noviembre 2019

DOI: http://dx.doi.org/10.17993/3ctecno.2019.specialissue3.107-119 


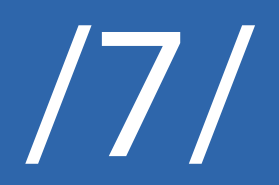




\section{ECOSYSTEM FOR HEALTHCARE SERVICES AND MANAGEMENT SYSTEM}

\author{
Azana Hafizah Mohd Aman \\ Senior Lecturer, Faculty of \\ Information Science and Technology, \\ National University of Malaysia. \\ Selangor (Malaysia). \\ E-mail: azana@ukm.edu.my
}

Syed Abdul Mutalib Al Junid Senior Lecturer, Faculty of Electrical Engineering, Universiti Teknologi MARA, Shah Alam, Selangor (Malaysia).

E-mail:samaljunid@uitm.edu.my

\section{Hasimi Salehudin}

Senior Lecturer, Faculty of Information Science and Technology, National University of Malaysia. Selangor (Malaysia). E-mail: hasimi@ukm.edu.my
Adil Hidayat

Director, My6 Initiative Berhad. Cyberjaya

(Malaysia).

E-mail: adil@my6.my

Rosilah Hassan

Associate Professor, Faculty of Information Science and Technology, National University of Malaysia. Selangor (Malaysia). E-mail:rosilah@ukm.edu.my

\section{Syed Mohamed Aljunid}

Professor, Faculty of Medicine, National University of Malaysia. Kuala Lumpur

(Malaysia).

Faculty of Public Health, Dept of Health Policy and Management, Kuwait University (Kuwait). E-mail: smohamed@ppukm.ukm.edu.my

Recepción: 29/07/2019 Aceptación: 19/09/2019 Publicación: 06/11/2019

\section{Gitación sugerida:}

Aman, A.H.M., Al Junid, S.A.M., Salehudin, H., Hidayat, A., Hassan, R. y Aljunid, S.M. (2019). Ecosystem for healthcare services and management system. 3C Tecnología. Glosas de innovación aplicadas a la pyme. Edición Especial, Noviembre 2019, 121-131. doi: http:/ / dx.doi.org/10.17993/3ctecno.2019.specialissue3.121-131

\section{Suggested citation:}

Aman, A.H.M., Al Junid, S.A.M., Salehudin, H., Hidayat, A., Hassan, R. \& Aljunid, S.M. (2019). Ecosystem for healthcare services and management system. $3 C$ Tecnología. Glosas de innovación aplicadas a la pyme. Speciaal Issue, November 2019, 121-131. doi: http:/ / dx.doi.org/10.17993/3ctecno.2019.specialissue3.121-131 


\section{ABSTRACT}

Dengue fever is one of the neglected tropical diseases (NTDs) in the Southeast Asian Countries (ASEAN), almost 70 million cases of dengue fever occur annually. This infection is now one of the most economically important NTDs in the region. Hence, there are urgent needs to spread public awareness on NTDs, the prevention, the treatment and the clinical cost involved. An innovation in health services and management system is needed to cater this issue. Intelligent Ecosystem for Healthcare Service and Management (IEHSM) is an integration of healthcare management, health knowledge base and data reference, control and elimination tools, and clinical costing. The main objective of this research is to provide a model for the improvement of fundamental understanding of public health especially NTDs and at the same time improve the existing healthcare services and management system. IEHSM adapts the optimization of prevention emphasizing on therapeutic approaches through Big Data Analytics, Artificial Intelligent, Cloud Computing, Machine Learning and Information Centric Networking. The IEHSM framework is based on Casemix system, a system that aggregates information about patients and associated procedures based on the type and mix of patients' treatment.

\section{KEYWORDS}

Intelligent Healthcare Ecosystem, Artificial Intelligence, Cloud Computing, Big Data. 


\section{INTRODUCTION}

The Southeast Asian Countries (ASEAN) are still facing issues of neglected tropical diseases (NTDs). Nearly 650 million people live in ASEAN countries, about 200 million come from the low or lower middle-income countries and many of them are affected by at least one NTD (World Health Organization, 2019). However, NTDs also affect upper middle-income ASEAN countries such as Malaysia. In Malaysia as reported by World Health Organization (WHO), during week 26, 2019 , a total of 2,806 dengue cases including one death was reported, bringing the cumulative number as of 29 June 2019 to 62,421 cases including 93 deaths. This is higher compared to 32,425 cases with 53 deaths reported during the same period last year (World Health Organization, 2019). Weakness in public awareness and understanding, shows that the health systems need to be improved. An urgency to effectively spread public awareness on NTDs prevention (Asat, 2018), treatment and clinical cost (Ibrahim, 2019) involved. Obviously current health services are unable to attract the public interest and awareness, despite having heterogenous technology and excellent infrastructure, these services are not interesting, not approachable or not user friendly to the public.

Intelligent Ecosystem for Healthcare Service and Management (IEHSM) is an integration of healthcare management (doctors, medical experts and patients), health knowledge base and data reference, control and elimination tools, and clinical costing. One of the goals of this research is to help the public by educating them about their medical status and keeping them health-aware as the saying goes 'prevention is better than cure'. The main objective of this research is to provide a model for the improvement of fundamental understanding of public health especially NTDs and at the same time improve the existing healthcare services and management system. IEHSM also empowers public to self-manage information, an emphasis on improving the quality of interesting and deliverable health awareness information. IEHSM helps in utilizing available current health system resources to their maximum potential. It also aids remote monitoring of patients and helps in reducing the cost of treatment via medical practitioners' support that extend their services without any geographical barriers. 
IEHSM adapts the optimization of prevention emphasizing on therapeutic approaches through Big Data Analytics (Wikipedia, 2019), Artificial Intelligent (AI) (Wikipedia, 2019), Machine Learning (Wikipedia, 2019), Cloud Computing (Wikipedia, 2019) and Information Centric Networking (ICN) (Aman, 2019). Machine learning is the scientific study of algorithms and statistical models that computer systems use in order to perform a specific task effectively without using explicit instructions, relying on patterns and inference instead. It is seen as a subset of artificial intelligence. In computer science, artificial intelligence, sometimes called machine intelligence, is intelligence demonstrated by machines, in contrast to the natural intelligence displayed by humans. While Big data is a field that treats ways to analyze, systematically extract information from, or otherwise deal with data sets that are too large or complex to be dealt with by traditional data-processing application. Cloud computing (Al Junid et al., 2012) is the on-demand availability of computer system resources, especially data storage and computing power that is available to many users over the Internet. Information Centric Networking is an approach to evolve the current Internet infrastructure to content based distribution. It is hoped that, with the integration of these technologies the new proposed IEHSM will help to produce better healthcare ecosystem.

\section{RESEARCH METHODOLOGY}

The IEHSM framework is based on Casemix system (Casemix, 2019), a health system that aggregates information about patients and associated procedures based on the type and mix of patients' treatment. The current Casemix grouper uses International Classification of Disease, Tenth Revision (ICD-10), as for this research ICD-10 will be upgraded, modified and improved based on the new IEHSM model. The first stage of the research methodology will involve investigation of research problem followed by framework design stage and finally validation of the proposed model. The details of the stages are explained in Table 1. 
Table 1. Methodology Stages.

\begin{tabular}{|c|c|c|}
\hline Stages & $\begin{array}{c}\text { Description } \\
\text { Sroblems, solutions and methodology identification phase. The target } \\
\text { scopes are NTDs, Casemix, IEHSM, Therapeutic approaches, Big Data } \\
\text { Analytics, Artificial Intelligent, Machine Learning, Cloud Computing and } \\
\text { Information Centric Networking. Hence this phase focuses on identifying } \\
\text { research problems and research gap for NTDs and Casemix system } \\
\text { Stage 1 } \\
\text { environment. Also, to find the possible solutions and methodology offered by } \\
\text { Big Data Analytics, Artificial Intelligent, Machine Learning, Cloud Computing } \\
\text { and Information Centric Networking that satisfies the improvement of public } \\
\text { health especially NDTs. Additionally, other critical system information and } \\
\text { system parameters that affect the functionality of the IEHSM system will also } \\
\text { be identified. }\end{array}$ \\
\hline Stage 2 & $\begin{array}{c}\text { Framework design and implementation phase. This phase focuses on how to } \\
\text { initialize solution and satisfy the information requirement to develop IEHSM } \\
\text { environment. In order to accomplish this goal, by using stage 1 results the } \\
\text { baseline model for the proposed IEHSM will be logically drawn. Based on } \\
\text { the baseline design, the pseudo code/flowchart, communication process, } \\
\text { mathematical models and algorithm will then be developed. }\end{array}$ \\
\hline Stage 3 & $\begin{array}{r}\text { Evaluation and results analysis phase. The proposed IEHSM will be } \\
\text { analyzed through user acceptance test. The performance will be evaluated } \\
\text { and benchmark with existing system. }\end{array}$ \\
\hline
\end{tabular}

This research will produce preliminary analysis for IEHSM in order to adapt new ICD-11 and therapeutic prevention approaches. As per above research background, the following research questions and objectives mapping are formulated and presented in Table 2.

Table 2. Research Questions and Objectives.

\section{Research Questions}

How to intelligently adapt prevention approaches in IEHSM?

How to employ Big Data Analytics, Artificial Intelligent, Machine Learning, Cloud Computing and Information Centric

Networking for an effective IEHSM environment?

How to efficiently provide approachable, interesting, deliverable and public friendly IEHSM system?

\section{Research Objectives}

To intelligently adapt prevention approaches in IEHSM

To employ Big Data Analytics, Artificial Intelligent, Machine Learning and Cloud

Computing for an effective IEHSM environment.

To efficiently provide approachable, interesting, deliverable and public friendly IEHSM system. 


\section{PRELIMINARY ANALYSIS}

Casemix is one of the available health systems in ASEAN. Currently Casemix system solutions consist of Grouper, DataTool, Code Assist, Clinical Cost, Casemix Cloud and Casemix Hospital Information System (HIS). Grouper (Aljunid et al., 2011) is a universal and unified patient grouping to convert diagnosis and procedures done by clinician into a single Casemix code called UNU-CBG. While the DataTool assigns diagnosis and procedure codes, it simplifies the coding process and help to improve coding quality. Clinical Cost Modeling consists of CGM module, Casemix Module, and Hospital Tariff module. CGM module is used to calculate cost per patient per stay by ward and cost per patient per visit by clinic. Meanwhile, Casemix module is used to impute cost per UNU-CBG group. Lastly, Hospital Tariff module is used to calculate the UNU-CBG group tariff per patient. Casemix is also accessible via web based in cloud computing. Casemix has a centralized Hospital Information System (HIS). Casemix systems are shown in Graphic 1, Graphic 2, Graphic 3 and Graphic 4.

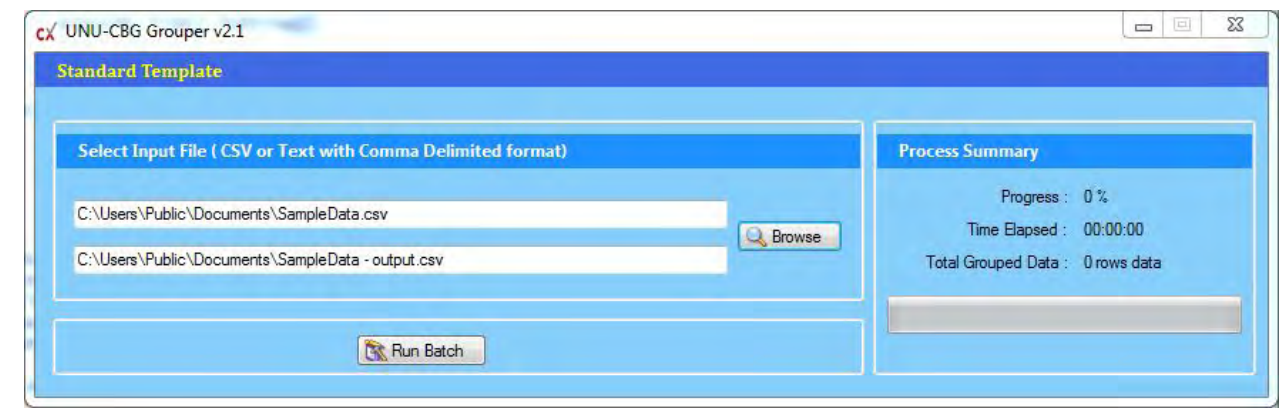

Graphic 1. Grouper. Source: (Casemix Solutions, 2019). 
Edición Especial Special Issue Noviembre 2019 DOI: http://dx.doi.org/10.17993/3ctecno.2019.specialissue3.121-131

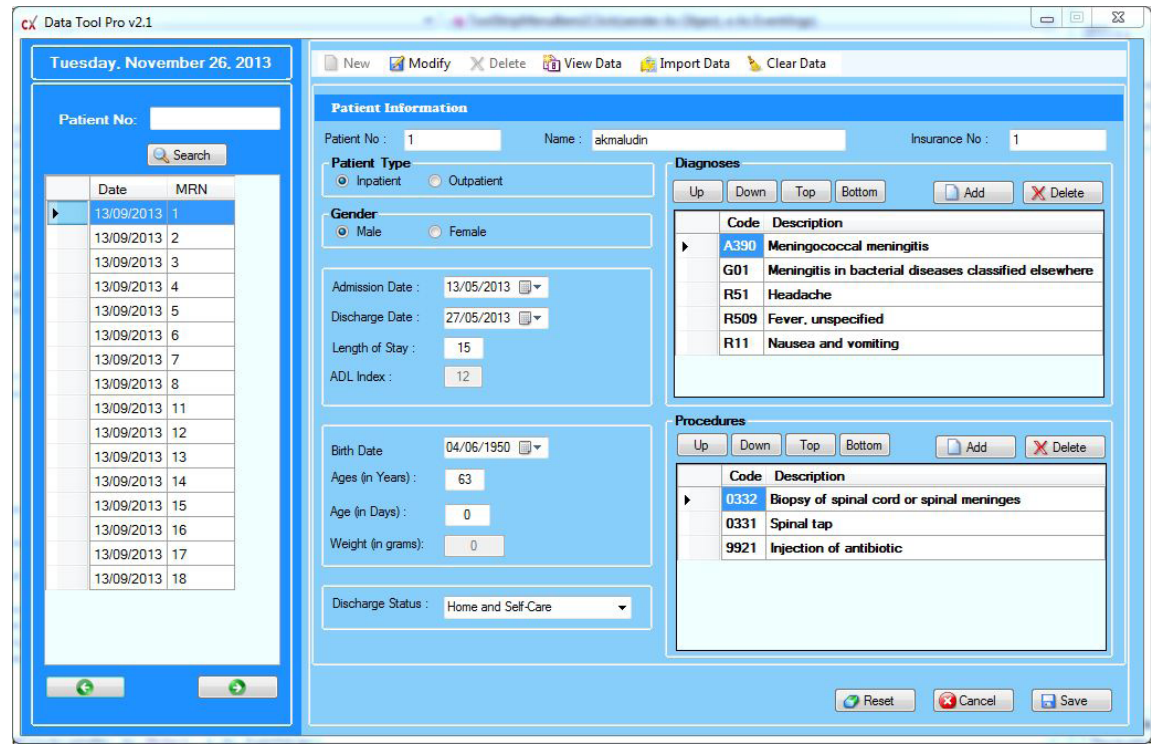

Graphic 2. Data Tool. Source: (Casemix Solutions, 2019).

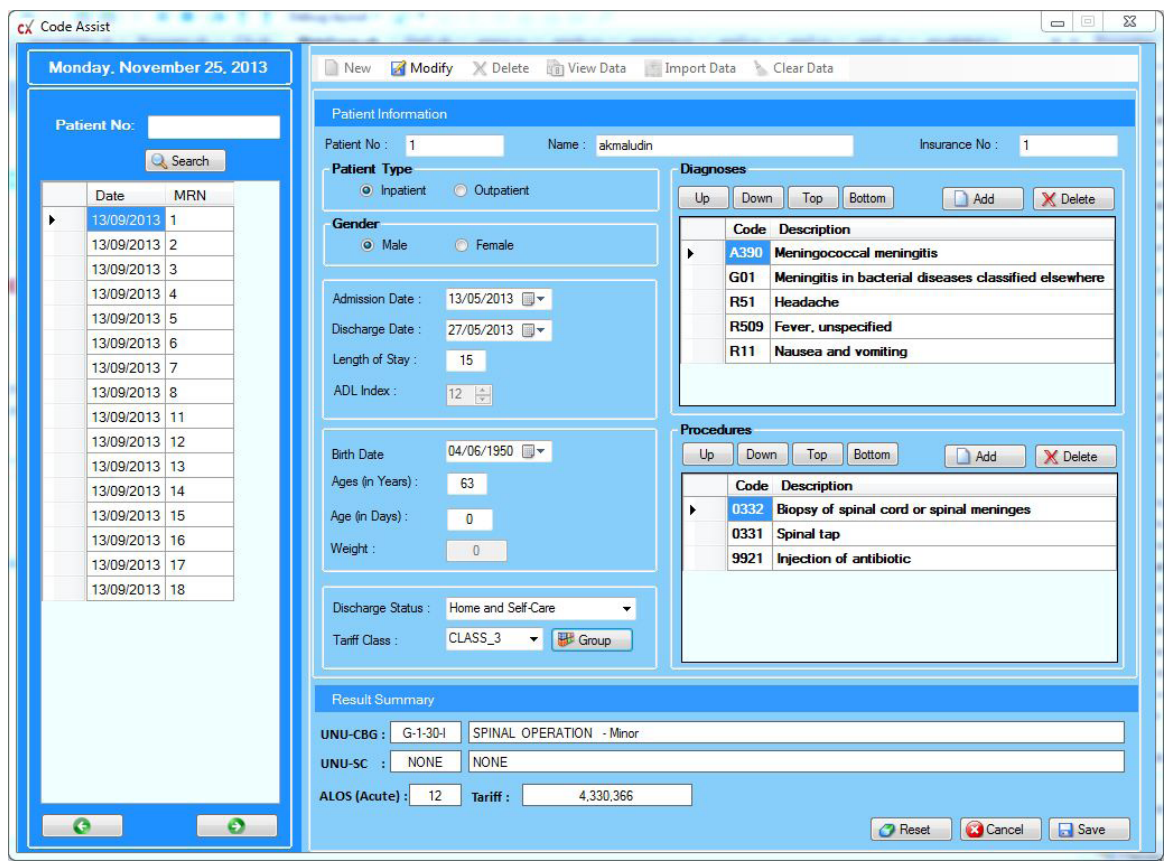

Graphic 3. Code Assist. Source: (Casemix Solutions, 2019). 


\section{Clinical Cost Modelling}
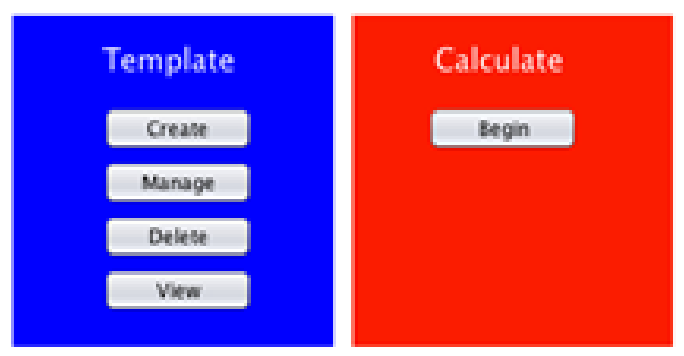

Graphic 4. Clinical Cost. Source: (Casemix Solutions, 2019).

Despite all these solutions Casemix still needs to be improved and upgraded for future changes in diagnosis and procedure classifications as well as features such as prevention of NTDs using therapeutic approaches. An innovation in health services and management to improve health system deliverable and efficient public health awareness system is highly needed. Table 3 shows the preliminary analysis between casemix and IEHSM.

Table 3. Preliminary Analysis.

\begin{tabular}{|c|c|c|}
\hline Parameter & Casemix & IEHSM \\
\hline Healthcare management & Yes & Yes \\
\hline Clinical costing & Yes & Yes \\
\hline Prevention approaches & No & Yes \\
\hline Health knowledge base & Yes & Yes \\
\hline Interactive communication & No & Yes \\
\hline Public friendly & No & Yes \\
\hline Smart technologies & Cloud Computing & $\begin{array}{r}\text { Big Data, Al, Machine } \\
\text { Learning, Cloud Computing } \\
\text { and ICN. }\end{array}$ \\
\hline
\end{tabular}




\section{ACKNOWLEDGEMENT}

The authors are grateful to Faculty of Information Science and Technology, National University of Malaysia. This research is also funded by research grant DIP-2018040 .

\section{CONCLUSIONS}

IEHSM preliminary analysis based on Casemix framework is necessary in order to knows the enhancement needed. It is the initial stage of the IEHSM development phase. As for future work, investigation will be done for other scope areas which are NTDs, Therapeutic approaches, Big Data Analytics, Artificial Intelligent, Machine Learning, Cloud Computing and Information Centric Networking. It is hoped that the completed research will empower smart and intelligent health services and management system to be sustainable globally and greater public health engagement.

\section{REFERENCES}

Al Junid, S. A. M., Aljunid, S., Sulong, S., Hamzah, S. M., Nur, A. M., \& Mustafa, H. R. (2012). Cloud Computing: Feasibility of Developing Webbasd UNU Casemix Grouper. IEEE Business, Engineering \& Industrial Applications Colloquium (BELAC). doi: https://doi.org/10.1109/BEIAC.2012.6226092

Aljunid, S. M., Hamzah, S. M., Mutalib, S. A., Nur, A. M., Shafie, N., \& Sulong, S. (2011). The UNU-CBGs: development and deployment of a real international open source Casemix grouper for resource challenged countries. BMC Health Services Research, 11(Suppl. 1). doi: https://doi.org/10.1186/14726963-11-S1-A4

Aman, A. H. M., Hassan, R., Hashim, A. H. A., \& Ramli, H. A. M. (2019). Investigation of Internet of Things Handover Process for Information Centric Networking and Proxy Mobile Internet Protocol. 3rd International Multi-Topic Conference on Engineering and Science, 2019. 
Artificial Intelligence. (2019). Wikipedia. Retrieved from: https://en.wikipedia. org/wiki/Artificial_intelligence

Asat, A. N., Mahat, A. F., Hassan, R. \& Ahmed, A. S. (2018). Development of dengue detection and prevention system (Deng-E) based upon open data in Malaysia. Proceedings of the 2017 6th International Conference on Electrical Engineering and Informatics: Sustainable Society Through Digital Innovation, ICEEI 2017. Institute of Electrical and Electronics Engineers Inc. Retrieved from: https://ukm. pure.elsevier.com/en/publications/development-of-dengue-detection-andprevention-system-deng-e-base

Big Data. (2019). Wikipedia. Retrieved from: https://en.wikipedia.org/wiki/Big data

Casemix Solutions. (2019). Retrieved from: http://www.casemix.com.my/web/

Gloud Computing. (2019). Wikipedia. Retrieved from: https://en.wikipedia.org/ wiki/Cloud_computing

Ibrahim, R., Aman, A.H.M., Nur, A.M., \& Aljunid, S.M. (2019). Cost Centric Data Mining for Radiology Procedures at Teaching Hospital in Malaysia. 3rd International Multi-Topic Conference on Engineering and Science, 2019.

Information Gentric Networking. (2019). Wikipedia. Retrieved from: https:// en.wikipedia.org/wiki/Information-centric_networking

Machine Learning. (2019). Wikipedia. Retrieved from: https://en.wikipedia.org/ wiki/Machine_learning

World Health Organization. (2019). Retrieved from: https://www.who.int/ 
Edición Especial Special Issue Noviembre 2019

DOI: http://dx.doi.org/10.17993/3ctecno.2019.specialissue3.121-131 


\section{/8/}




\section{D MODELING FOR WILDLIFE ENCYCLOPEDIA USING BLENDER}

Sallar Khan

Sir Syed University of Engineering and Technology. Karachi, Pakistan. E-mail: sallarkhan_92@yahoo.com

Sallar Ghanna Sir Syed University of Engineering and Technology. Karachi, Pakistan.

E-mail: salarchana55@gmail.com

Syed Abbas Ali

N.E.D University of Engineering and Technology. Karachi, Pakistan.

E-mail: saaj.research@yahoo.com

Muhammad Haaris Khan

Sir Syed University of Engineering and Technology. Karachi, Pakistan.

E-mail: haariskhan255@gmail.com

Arhum Hayat Qazi

Sir Syed University of Engineering and Technology. Karachi, Pakistan.

E-mail: arhum.hayat@gmail.com

Kamran Mengal

Sir Syed University of Engineering and Technology. Karachi, Pakistan. E-mail: kami_mengal@hotmail.com

Recepción: 30/07/2019 Aceptación: 20/09/2019 Publicación: 06/11/2019

\section{Gitación sugerida:}

Khan, S., Channa, S., Ali, S.A., Khan, M.H., Qazi, A.H. y Mengal, K. (2019). 3D modeling for Wildlife Encyclopedia using Blender. 3C Tecnología. Glosas de innovación aplicadas a la pyme. Edición Especial, Noviembre 2019, 133-147. doi: http://dx.doi. org/10.17993/3ctecno.2019.specialissue3.133-147

\section{Suggested citation:}

Khan, S., Channa, S., Ali, S.A., Khan, M.H., Qazi, A.H. \& Mengal, K. (2019). 3D modeling for Wildlife Encyclopedia using Blender. 3C Tecnología. Glosas de innovación aplicadas a la pyme. Speciaal Issue, November 2019, 133-147. doi: http://dx.doi. org/10.17993/3ctecno.2019.specialissue3.133-147 


\section{ABSTRACT}

In this modern era of technology, the ways of learning are changing drastically, and $3 \mathrm{D}$ is becoming one of the popular learning methods around the globe for experts and researchers. While it has been observed from past studies that the wildlife researchers, students, and experts need different sources like books and websites to gather and learn information about wildlife, which may be a time taking task and old approach seems to be. In this paper, we have used a 3D creation software blender for developing live 3D models of different species and providing a complete user friendly control to the user which will assist them to retrieve any information about different species from region to region around the world. These models are less complex and more attractive way of learning for the user.

\section{KEYWORDS}

3D Modeling, Blender, Wildlife, Animation. 


\section{INTRODUCTION}

The universe of 3D illustrations is an intricate field, powering ventures from gaming and film to design and building. 3D specialists and fashioners utilize explicit procedures and procedures like 3D visual computerization, rendering, perception, and activity to breathe life into a dream onscreen. Be that as it may, we are in the beginning of another kind of vivid registering, where 3D models will turn into a run of the mill resource we will almost certainly find on sites. The utilization of 3D introductions, as fundamental method for showing items or administrations in another period of web innovation wherein the online world, as observed from our perspective, there is a wide scope of choices for the acknowledgment of 3D plan where it very well may be utilized in a one of a kind, and unique way, showing the article from various perspectives, from the presentation of the subject's detail to connection or mobility of parts. 3D models can speak to any item, any administration, and can be utilized as an outline of the item, generation innovation, and so forth in any part of the industry, including those branches that don't have direct contact with 3D structure or exercises whose items or administrations are of "elusive" nature.

There has been a few learning on realistic, verbalized, 3D models of the animal body. Taking in of model from a little arrangement of 3D outputs of toy dolls in subjective postures has been done through utilizing a novel part-based shape model for figuring an underlying enrollment to the sweeps, subsequent to normalizing their posture, getting a measurable shape model, and by refining the enlistments and the model together, they precisely adjusted creature checks from various quadruped families with altogether different shapes and presents, and with the enlistment to a typical format, a shape space speaking to creatures of various species were found out (Zuffi, Kanazawa, Jacobs, \& Black, 2017).

The other research demonstrated the guideline of a programmed change from a 2D site page into a 3D site and explained about 3D portrayal strategies and change systems connected to change over a conventional two-dimensional website page into a completely utilitarian three-dimensional stage through the strategies and ideas dependent on advances like HTML, CSS, JavaScript (Hristov, \& Petkov, 2016). 
A strategy for displaying a practical inside of a structure dependent on polygonal information from stereoscopic picture sets is introduced. Subsequent to accepting the information from a past stage in a pipeline, for rendering and sending out a model into the game motor Irrlicht, 3D demonstrating project Blender is utilized. To transport the information from crude data into .obj document, shipper and vertex consolidating tools are made. .obj records are utilized for the presentation of a work in Blender and after that are traded into COLLADA group for rendering in Irrlicht (Ribe, Killian, \& Anderson, 2012).

Presentation of 3D information procurement gear and displaying strategies were given and the characters and improvements of the laser filtering framework and ImageBased Modeling and Rendering (IBMR) were likewise examined, also introduces applications of 3D modeling including tissue Engineering and heritage protection (Luan, Xie, Ying, \& Wu, 2008). An article introduced a product module intended for proficient and advantageous representation of 3D models inside the internet browser condition written in JavaScript by exploiting the HTML 5 standard, concentrating on the cell phones, unique consideration was given on effectiveness and low system utilization, likewise a proposed arrangement dependent on dynamic work spilling was contrasted and the server-side rendering approach (Sawicki \& Chaber, 2013).

The presentation of the compelling perception of 3D lattices dependent on the inherent highlights of an internet browser supporting HTML5 (Canvas, WebGL) norms was introduced and the calculations identified with dynamic work spilling over Internet system were examined and was exhibited that utilizing depicted programming, 3D models could be effectively imagined on any advanced, cell phone (web tablets, PDAs or netbooks) (Sawicki \& Chaber, 2012). A theory was exhibited to make a water reenactment utilizing WebGL and Three.js, which they talked about, will rely upon an illustrations part called a shader that produces moving water and actualizes a water surface. They expected the last recreation should look practical and be execution situated so it tends to be utilized in enormous scenes (Pereira, 2013). The examination was exhibited on the utilization of $3 \mathrm{D}$ demonstrating thought about when developing and breaking down point of view projections and shadows for the formation of a photograph sensible picture. 
The point of view of the development venture and the portrayal of its picture were given for instance. They considered the advancement of a dynamic square as a strategy for graphical information amassing and robotization of geometric improvements. The case of the dynamic square development at making a support hub was illustrated. The developments were considered as connected to Auto-CAD programming (Kheyfets, \& Vasilieva, 2017). A paper was displayed for general strategies and rules to successfully assemble a basic model made of shortcomings and skylines from normal inadequate information. A run of the mill 3D auxiliary displaying work process dependent on triangulated surfaces were portrayed. Their aspiration was not to supplant programming client directs but rather to give key ideas, standards, and methods to be connected during geomodeling undertakings, with a spotlight on quality control (Caumon, Collon-Drouaillet, Le Carlier de Veslud, Viseur, \& Sausse, 2009). A paper was composed on the primary 3D stereo motion picture made with Blender as per high philological guidelines and identified with the historical backdrop of a whole city with four distinctive geo-referenced authentic advanced territory models and a few situations, from the Etruscan up to the present day. The way of thinking made for this affirmation concentrated on open source and interdisciplinary structure (Ponti, 2013).

Drawing on their work with the Digital Life Project, they depicted their procedure for utilizing open-source programming to reproduce living creatures in $3 \mathrm{D}$, from photograph catch to movement. They analyzed the training and specialty of creating 3D models of live creatures utilizing photogrammetry (deriving estimations in 3D space utilizing photos), Focusing especially on the specialized work process utilizing open-source programming. A paper went for loosening up the demonstrating cost of the genuine space and the getting to cost on WWW proposed a straightforward methodology by utilizing beautiful pictures taken by a computerized camera or a camcorder without mutilating them and by amplifying or contracting a symbol picture and gluing it on a foundation grand picture as per the client's contribution, there had the option to imagine the profundity of the scene as pseudo-3D space. The technique was known as the picture based non-rendering (IBNR), they accentuated 
on two Focuses, the scene independency, and the stage independency (Tsukamoto, 1999).

A research paper gave knowledge into HTML 5 components, (for example, canvas and foundation specialists), JavaScript and Web Graphics Library (WebGL) advancements, and portrayed the experience picked up in utilizing the most recent developments for customer side programming by utilizing the program as an application preparing unit to empower module free running of a high caliber and processing serious game application with 3D illustrations rendering and material science impacts (Nazarov \& Galletly, 2013).

An examination inspected the impact of site dimensionality on psychological ingestion, saw usability, and, in a roundabout way, saw site value and expectations to purchase web-based utilizing the site. Their discoveries demonstrated that shopping sites utilizing 3D conditions are related without lifting a finger of utilization and lower intellectual retention, contrasted with conventional 2D sites. They believed the impact of site dimensionality on subjective assimilation is directed by client experience (Visinescu, Sidorova, Jones, \& Prybutok, 2015). A 3D reference book site of the protein nucleic corrosive and other biomolecule structures was made as a method for imparting biomolecule structures to an assorted logical group of spectators it presents basic explanation in a natural intelligent arrangement which enables individuals from mainstream researchers to contribute their very own comments. they gave a status report on their webpage by depicting propels in the web asset concentrating on highlights of potential direct use to established researchers and furthermore talked about its encouraging as a community-oriented 3d-reference book of structures just as its utilization as a supplement to logical distributions and PowerPoint introductions and portrayed the site's utilization for 3D representation in structure-related teaching method (Prilusky, 2011).

Further paper is divided into these sections, in second our overall research approach is defined, while in $3^{\text {rd }}$ section results are discussed according with modeling phase, in $4^{\text {th }}$ section we gave our hypothesis in the shape of future work and in the last section we have concluded our research in conclusion section. 


\section{RESEARCH METHODOLOGY}

The accomplishment of our undertaking and our possible strategy of making the 3D models of creatures through an open-source program and sending it into a site relies on the immense measure of point by point examine on creatures and 3D demonstrating. We have analyzed a few types of creatures and noticed the subtleties of their body parts from head to toe. Our examination centers on giving data about creatures by utilizing the 3D demonstrating system we have profited by a $3 \mathrm{D}$ displaying programming framework considered Blender and utilized it to alter a $2 \mathrm{D}$ picture into a 3D model to give it a reasonable look and feel.

\subsection{D MODEL CREATION}

The background image has been chosen for the desired 3D model and image axis was set to left, right, top, bottom, front and back through the software blender 3D. The whole body of the desired shape is created with the help of tool cube, as this tool helps in resizing, scaling and extending the shape, minor details are given through vertices as shown in Figure 1. The cube is mutilated according to the need of the shape through 'CONTROL+R'. The key ' $\mathrm{B}$ ' is used to select a specific area on the model. 'CONTROL' key was used for the selection of different points/vertices at the same time and the key ' $\mathrm{E}$ ' is used for extending the selected area for scaling of the cube the key ' $\mathrm{S}$ ' and rotation the key ' $\mathrm{R}$ ' is used. The desired shape is created with the help of tool cube.

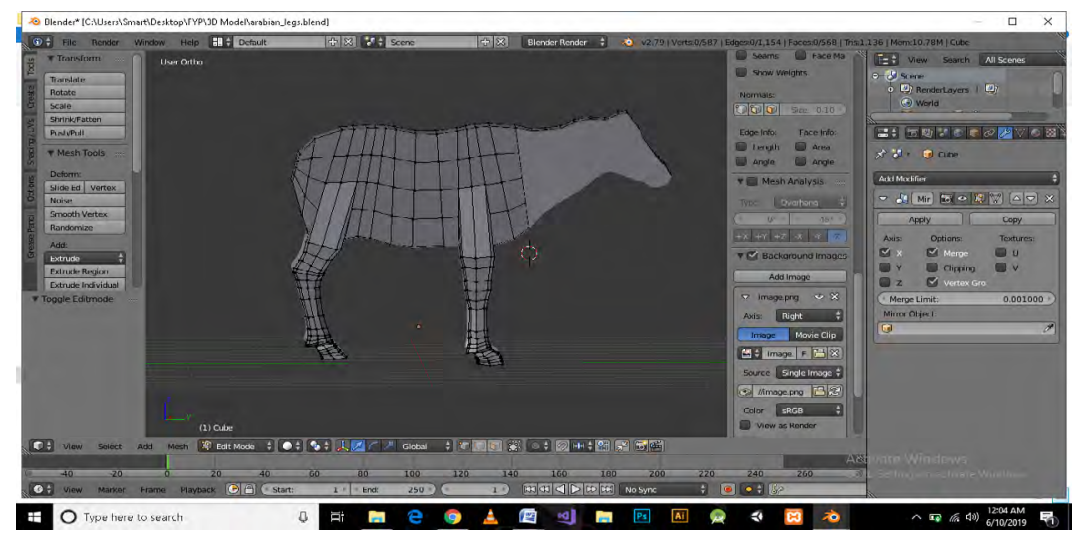

Figure 1. Mutilating the cube according to the shape of background image. 
The tools used in this process are. Cube, UV sphere and Plane and for transformation rotate, scale and translate are used for smoothing the vertices, the mesh tools are used along with shading. The 'TAB' key is used to select the working done on the object as shown in Figure 2.1 while the 'A' key selects and deselect the whole object. There is another key known as 'ESG' key it always cancels blender functions without changes and fortunately we did not use it. And for the wireframe ' $\mathrm{Z}$ ' key is used in Figure 2.2. As shown in Figure 3, to check the result of our working on the model we took the help of SHIFT $+Z$ key it showed us the rendered model.

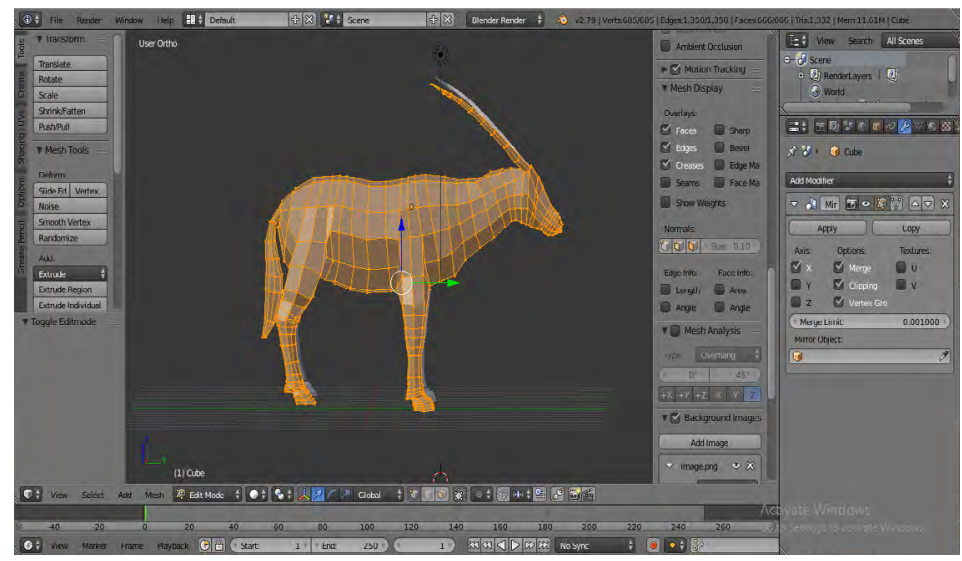

Figure 2.1. All the working done on object is selected.

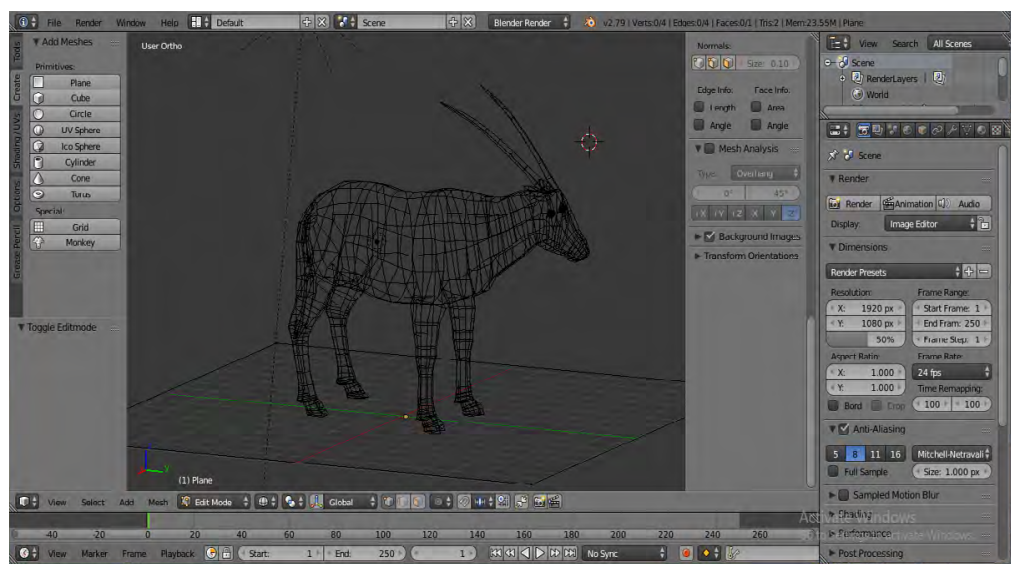

Figure 2.2. Visualizing the model in wireframe mode. 


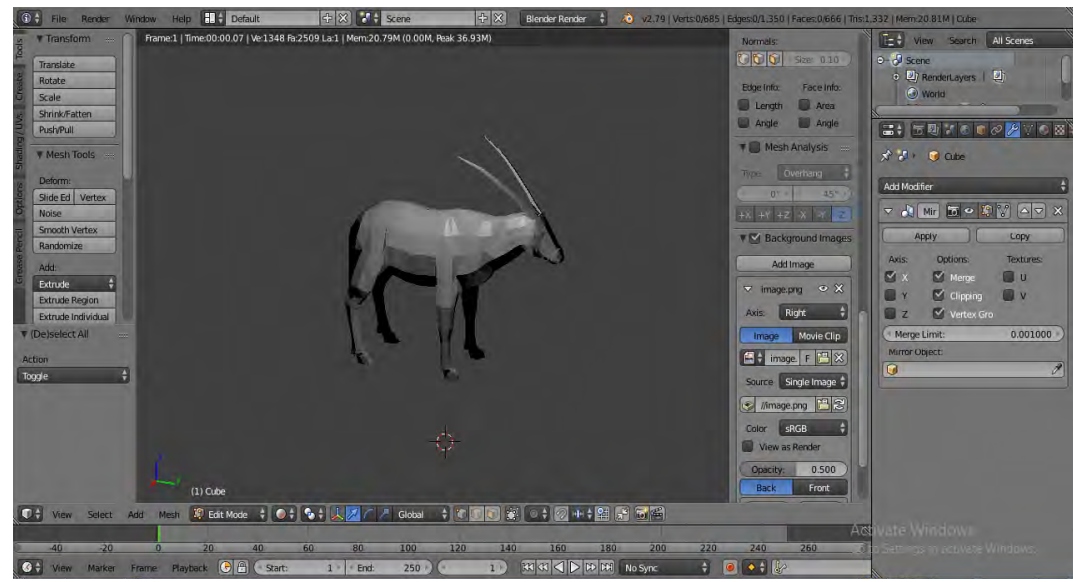

Figure 3. 3D demonstration of the object after being rendered.

\subsection{APPLYING 2D IMAGE TEXTURE USING UV WRAP}

We also used the mirror modifier to cut the mesh/cube in half. Eyes of the 3D model are made with UV sphere tool by using the key 'I' to do the inset. We used it on the face behind the eye and behind the nails. In the end after completing the shape of the 3D model we applied the texture in Figure 4, by clicking on the material tab and adding a new material on the texture tab. After selecting the image type we click on open button and selected the texture which we wanted to apply. After changing the coordinates to UV, we have changed the default window to UV editing window. Two screens appeared on our laptop.

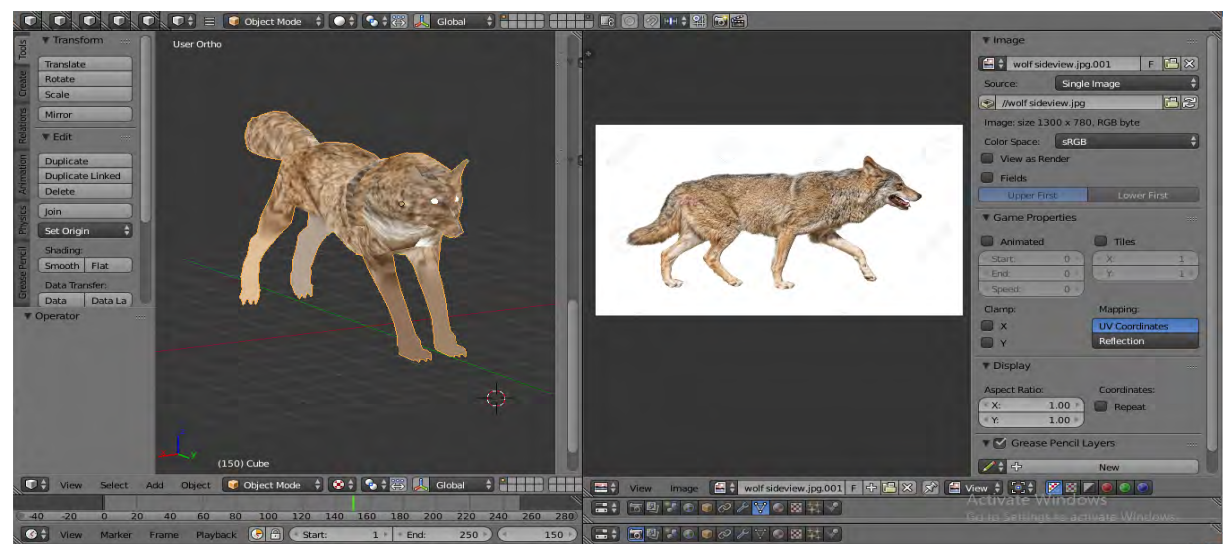

Figure 4. 2D image texture applied on object using UV wrap. 


\subsection{UNWRAPPING THE MODEL}

In UV editing window we select the texture which we had already added in default window. We then selected the model and went to the edit mode, pressed the ' $U$ ' key to unwrap the model. In the default window we selected the texture in viewport shading and the final model can be seen in viewport shading. Now we rendered our model to see the result of our working Figure 5.
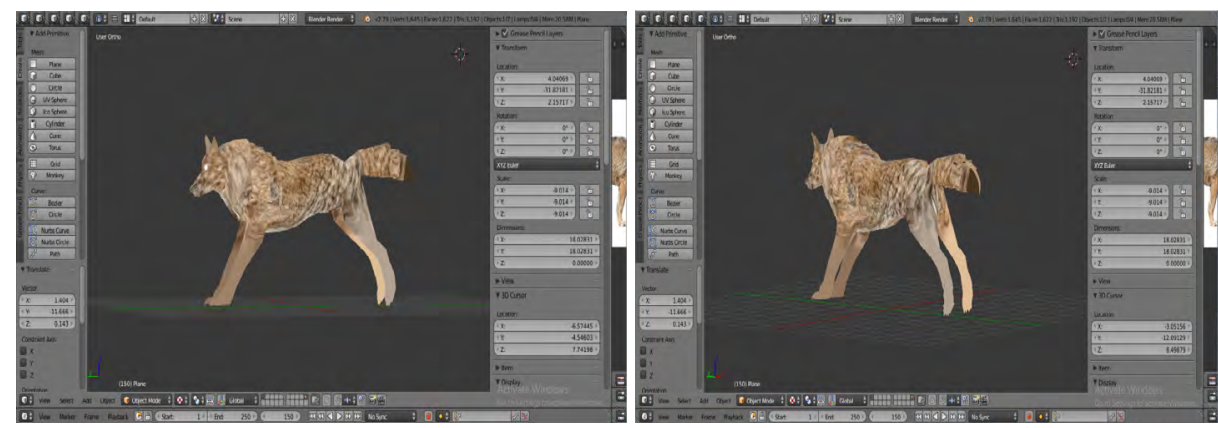

Figure 5. Rendered 3D visualization of the model after un wrapping the texture.

\section{3D MODELING AND RESULTS}

3D demonstrating is the way toward building up a numerical portrayal of any surface of an item in 3 measurements through specific programming. Blender is one of the free and open-source 3D creation software. It bolsters the sum of the 3D pipeline that is displaying, fixing, liveliness, rendering, composting, finishing, and movement following even video altering and game creation. In our project we have benefitted it from the blender 3D modeling software by using it in modifying the image into a 3D model to give it a realistic look. 3D displaying has changed the way venture plans are exhibited. It resembles consolidating various 2D illustrations and gluing them together. It has without a doubt changed the way we take a gander at undertakings and how we present data. The maxim "words usually can't do a picture justice" is really duplicated when a picture can be moved, turned, controlled, and hued. 3D demonstrating can give you a lovely one-shot image of your structure. It is progressively reasonable, speedier and simpler than 2D. You can likewise put your undertaking in other 3D models to check clearances, address access and departure, 
and even envision sightlines. Simple on the spot changes can be made to decide their reasonability.

After following all the steps above, we get a perfectly shaped textured 3D model of animal, which can benefit any individual throughout the world who is eager to learn more about animals and wildlife. The figures [6-8] are representing the rendered 3D models of animals as an example.
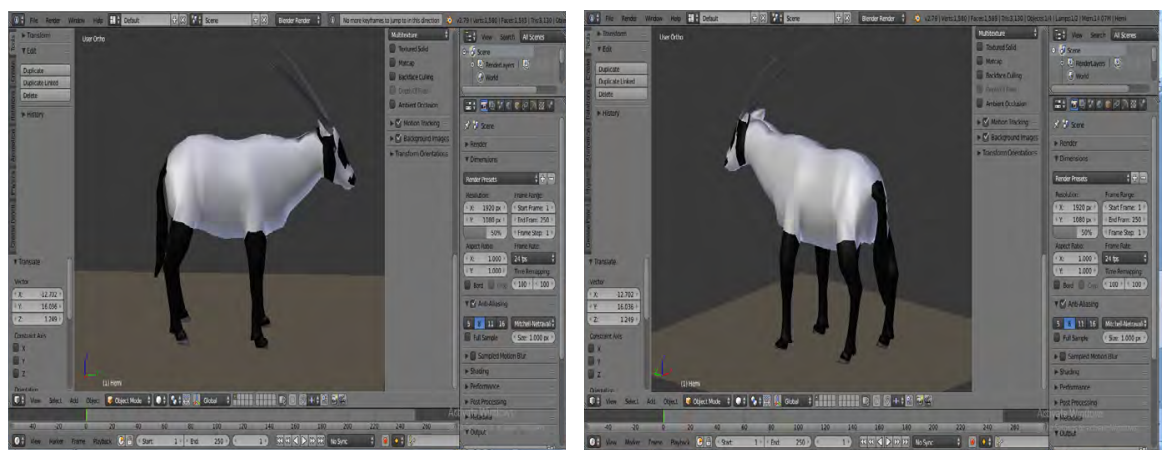

Figure 6. Rendered 3D model after applying diffuse colors in the areas.
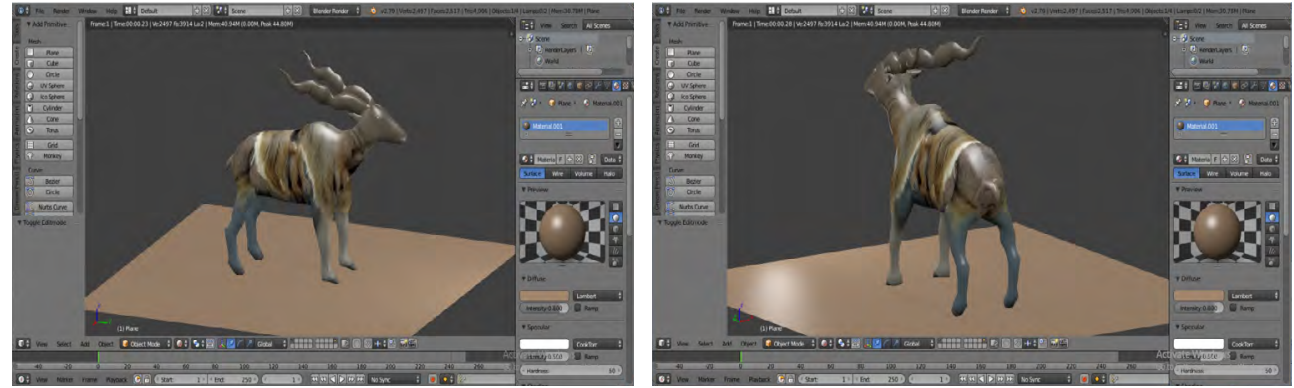

Figure 7. Rendered 3D model of the animal after unwrapping a 2D image texture.

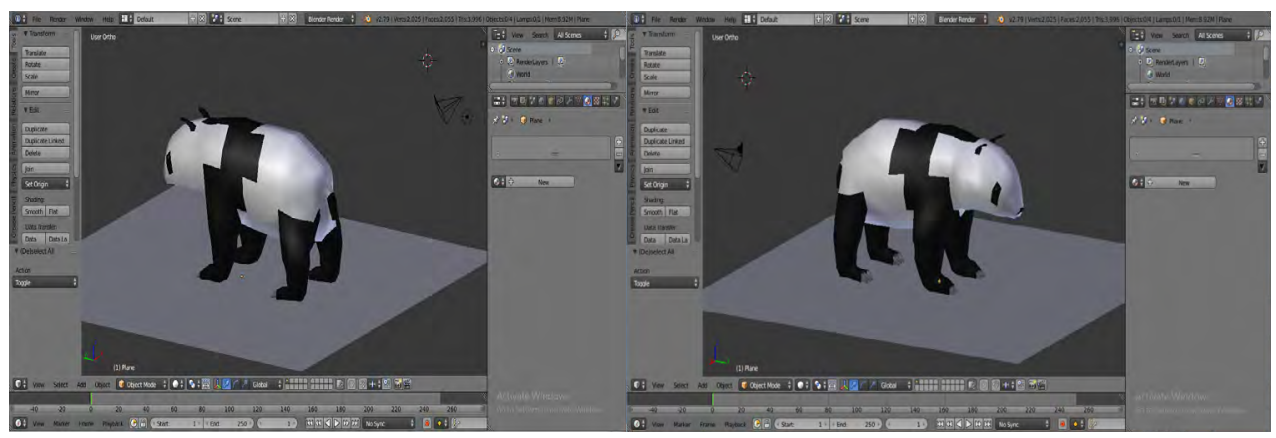

Figure 8. Rendered 3D model of a Panda after applying diffuse colors in the areas of the object. 


\section{FUTURE WORK}

In future we will deploy our 3D models to our website where users will be able rotate the model in $360^{\circ}$ and will get enough information by hovering the mouse into that body part. We will be labeling the information on models through different programming frameworks like three.js. We will accomplish our goal of making things easy by giving much information with details about wildlife. This project will serve students, families, scholars and educators around the world. This project evolves 3D multimedia educational brand to suit the constant needs of learners today.

\section{CONCLUSION}

$3 \mathrm{D}$ processing is an emerging and growing need in the multimedia domain. The successful method to create $3 \mathrm{D}$ recreation of pictures is altering three-dimensional meshes to fit the state of the item. If we want to see the object in its natural posture, it is very important to understand how the object can be eloquent and de-shaped. This research paper presents a method of deforming and articulating an object from 2D image to a 3D model. We have worked on cubes and UV sphere and by applying texture, our 3D models show that using the tools effectively works well. We hope this work of our will motivate further developments in the field of 3D blender software and it will enable completely mechanized 3D displaying of creatures from 2D pictures soon.

\section{REFERENCES}

Gaumon, G., Collon-Drouaillet, P., Le Carlier de Veslud, G., Viseur, S. \& Sausse, J. (2009). Surface-Based 3d Modeling of Geological Structures. Mathematical Geosciences, 41, 927-945. doi: https://doi.org/10.1007/s11004-0099244-2 
Hristov, P. \& Petkov, E. (2016). Development of web-based information system for visualization of three-dimensional models of museum exhibits. Conference on Digital Presentation and Preservation of Cultural and Scientific Heritage (DiPP2016). Regional Museum of History and P.R. Slaveykov Regional Public Library in Veliko Tarnovo, Bulgaria.

Kheyfets, A. L., \& Vasilieva, V. N. (2017, November). 3D Modeling as Method for Construction and Analysis of Graphic Objects. In Materials Science and Engineering Conference Series (Vol. 262, N. ${ }^{\circ}$ 1, 12104).

Luan, X., Xie, Y., Ying, L., \& Wu, L. (2008). Research and Development of 3D Modeling. International Journal of Computer Science and Network Security (IFCSNSS), 8(1), 49-53. Retrieved from: http://paper.ijcsns.org/07_book/200801/20080108.pdf

Nazarov, R., \& Galletly, J. (2013). Native browser support for 3D rendering and physics using WebGL, HTML5 and Javascript. BCI, 1036, 21-24. Retrieved from: https://www.semanticscholar.org/paper/Native-browser-support-for-3Drendering-and-physics-Nazarov-Galletly/ 1f8e52394a4d4d9de9da1 10c036ccace 5 bb97221

Pereira, K. J. (2013). Water Simulation on WebGL and Three. js. Retrieved from https://aquila.usm.edu/cgi/viewcontent. cgi? referer $=\&$ httpsredir $=1 \&$ article $=1151 \&$ context $=$ honors_theses

Ponti, F. D., Guidazzoli, A., Imboden, S., \& Liguori, M. G. (2013). A Blender open pipeline for a 3D animated historical short film. In $12^{\text {th }}$ International Symposium on Virtual Reality, Archaeology and Intelligent Cultural Heritage. doi: https:// doi.org/10.2312/PE/VAST/VAST11S/081-084

Prilusky, J., Hodis, E., Canner, D., Decatur, W. A., Oberholser, K., Martz, E., ... \& Sussman, J. L. (2011). Proteopedia: a status report on the collaborative, 3D web-encyclopedia of proteins and other biomolecules. Fournal of structural biology, 175(2), 244-252. doi: https://doi.org/10.1016/j.jsb.2011.04.011 
Ribe, J., Killian, A., \& Anderson, D. (2012). 3D Modelling in Blender Based on Polygonal Data. Midwest Instruction and Computing Symposium. Retrieved from: http://micsymposium.org/mics2012/submissions/mics2012_submission_9.pdf

Sawicki, B., \& Chaber, B. (2012). 3D mesh viewer using HTML5 technology. Przeglad Elektrotechniczny, 88(5a), 155-157.

Sawicki, B., \& Chaber, B. (2013). Efficient visualization of 3D models by web browser. Computing, 95(1), 661-673.

Tsukamoto, M. (1999, September). Image-based pseudo-3D visualization of real space on WWW. In Kyoto Workshop on Digital Cities, 288-302. Springer, Berlin, Heidelberg.

Visinescu, L. L., Sidorova, A., Jones, M. G., \& Prybutok, V. R. (2015). The influence of website dimensionality on customer experiences, perceptions and behavioral intentions: An exploration of $2 \mathrm{D}$ vs. $3 \mathrm{D}$ web design. Information $\mathcal{E}^{\circ}$ Management, 52(1), 1-17. doi: https://doi.org/10.1016/j.im.2014.10.005

Zuff, S., Kanazawa, A., Jacobs, D. W., \& Black, M. J. (2017). 3D menagerie: Modeling the 3D shape and pose of animals. In Proceedings of the IEEE Conference on Computer Vision and Pattern Recognition, 6365-6373. 
Edición Especial Special Issue Noviembre 2019

DOI: http://dx.doi.org/10.17993/3ctecno.2019.specialissue3.133-147 


\section{/9/}




\section{DETERMINING THE EFFECTIVENESS OF PROPOSED CUSTOMIZED FINANCIAL SOFTWARE IN A PUBLIC SECTOR UNIVERSITY}

Muneer A. Shaikh

Mehran University of Engineering and Technology, Pakistan.

E-mail: munir.shaikh@admin.muet.edu.pk

Rizwan Hassan

Mehran University of Engineering and Technology, Pakistan.

E-mail:rizwanmtc@gmail.com

Mujawar Malik

Mehran University of Engineering and Technology, Pakistan.

E-mail: mujawar2@gmail.com

Ali Akbar Shah

Mehran University of Engineering and Technology, Pakistan. E-mail: shah.aliakber32@gmail.com

Recepción: 30/07/2019 Aceptación: 20/09/2019 Publicación: 06/11/2019

\section{Citación sugerida:}

Shaikh, M.A., Hassan, R., Malik, M. y Shah, A.A. (2019). Determining the effectiveness of proposed customized financial software in a Public Sector University. 3C Tecnología. Glosas de innovación aplicadas a la pyme. Edición Especial, Noviembre 2019, 149-165. doi: http:// dx.doi.org/10.17993/3ctecno.2019.specialissue3.149-165

\section{Suggested citation:}

Shaikh, M.A., Hassan, R., Malik, M. \& Shah, A.A. (2019). Determining the effectiveness of proposed customized financial software in a Public Sector University. 3C Tecnologia. Glosas de innovación aplicadas a la pyme. Speciaal Issue, November 2019, 149-165. doi: http:// dx.doi.org/10.17993/3ctecno.2019.specialissue3.149-165 


\section{ABSTRACT}

Professionals all around the globe use various available software products for the data solutions of their firm. These software products are general and are available publically. But in order to develop customized software, huge amount of money and efforts are needed. Therefore in this proposed paper, a budget friendly software based on basic business infrastructure of accounting in finance is developed. The contribution of the software is in PV payments, inspection of personal ledger accounts, ledger reports and summary of various vouchers as well as it can fetch and print the details of the cheques as well. In the result section of this paper a survey is conducted for showcasing the effectiveness and importance of this software.

\section{KEYWORDS}

Software products, Customized software, Budget friendly software, Accounting, PV payments, Ledger accounts, Ledger reports, Voucher, Cheque, Survey. 


\section{INTRODUCTION}

Various software products are available in the open source and licensed that have applications in accounting and finance (Hoefler et al., 2012; Cook, 2017; Ryan, Scapens, \& Theobald, 2002; Atanasov \& Black, 2016; Bangemann, 2005). Software products like Oracle, SPSS, Peachtree, SAAS and Microsoft excel are at the pinnacle of the software products chart based on business applications (Beckett, Castagno, Lockwood, \& Mcdougald, 2017). Whereas, in terms of customization SAP is at very best of its game (Lorenc \& Szkoda, 2015). Modules like SAP Hana provide user friendly interface to its customers but the problem with these software products like SAP is its pricing (Cook, 2017; Rasmussen, Goldy, \& Solli, 2002). SAP modules are very expensive therefore it is not possible for the companies with less financial backing to afford them. So for overcoming this problem, a new software solution is required that has similar user friendly interface like the SAP (Driesen, Engelko, Jahr, Muscarella, \& Storz, 2015).

The main problem with the development of the software is its architecture, user interface and back coding (Yousouf \& Stanev, 2015). Moreover, it must also contain applications that are essential for the operation of the enterprises (Rogaway \& Coppersmith, 1998). Basic accounting software requires many functionalities and data tools for analyzing the company's data as well its interface must be properly encrypted so that a third party cannot access the classified data. Encryption plays a vital role in securing the data and in preventing the online attacks. Attacks like Ransomware had taken most of the multinational firms with the threat of hacking their most sensitive data (Kharraz, Robertson, Balzarotti, Bilge, \& Kirda, 2015; Kharaz, Arshad, Mulliner, Robertson, \& Kirda, 2016). So it is the task of the software developers to understand the risks of the software development and any loophole in the software development can be have fatal outcomes. 


\section{SYSTEM FLOW}

The system flow diagram of the proposed software is mentioned in the below Figure 1 :

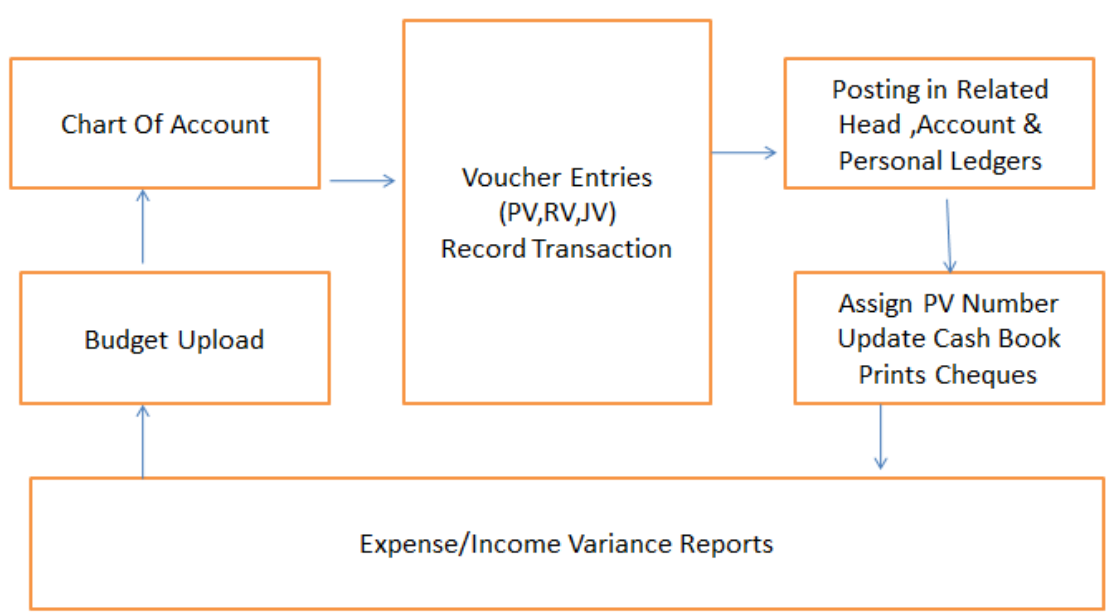

Figure 1. Signal Flow Chart.

In the above Figure 1, it is clearly illustrated that the details of the account are linked with the voucher entries that are basically the transactions that are made by the user. These transactions are being recorded. After this process, the software fetches the details of the transactions and to whom it is being sent. After the process of sender classification is finished then the transaction is moved to designated head of that specific department. After approval of those transactions by the head, each of the transactions is assigned with a unique PV number and later the cheque is printed. With the completion of this process, the cheque books are updated automatically by the software.

This software also provides data analysis tools like the income variance report that shows the variations in the withdrawal of the transactions whereas the remaining budget is updated accordingly to the account sheets. 


\section{NETWORK TOPOLOGY}

Star topology is implemented by connecting the end users with a common server that is shown in the figure below:

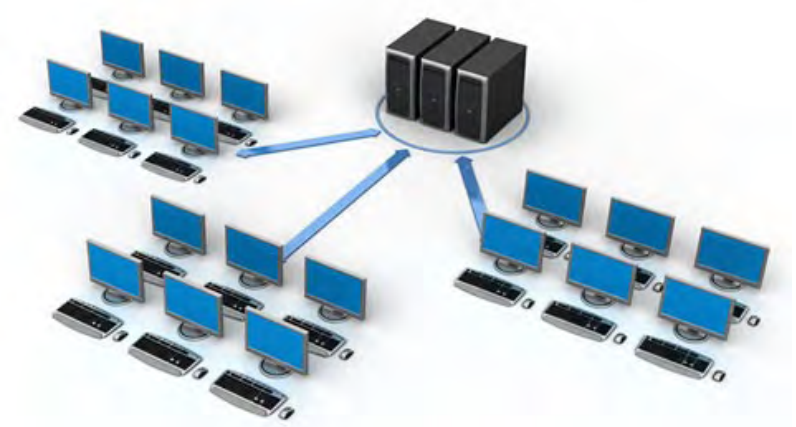

Figure 2. Star Network Topology.

The end user can access the server with the local domain IP which can be accessed by the end users that relate to the common network connection. WPA/WPA2 PSK protocol of the network is implemented for accessing the local server that requires the username and password which will be given by system administrator to the end users. Moreover keeping the security into consideration the variations in the software can only be controlled by the master administrator.

\section{WORKING OF THE SOFTWARE}

\subsection{CHART OF ACCOUNT}

A separate chart of the account is prepared based on each designation in which the employee is employed on. Various allowances and charges are incorporated based on the designations. These charts of the account are then allocated with specific number for their classification based on the grades of the employees. A sample account chart is shown in the mentioned below figure: 


\begin{tabular}{|c|c|c|}
\hline & \multicolumn{2}{|c|}{ Mehran University of Engineering and Technology, Jamsh } \\
\hline & \multicolumn{2}{|c|}{ CHART OF ACCOUNT } \\
\hline \multicolumn{2}{|c|}{ Account Type } & \multirow[t]{2}{*}{ HEC Code } \\
\hline $05-03-022-0026$ & Quality Coordinator Allowance & \\
\hline $05-03-022-0027$ & Leave Salary / Pension Contribution & A0127801 \\
\hline \multicolumn{3}{|c|}{ Teaching Department (Allied Staff) -Other Allowances } \\
\hline $05-03-022-0028$ & Leave Salary & A0127801 \\
\hline \multicolumn{3}{|c|}{ Teaching Department (Allied Staff) -Other Regular Allowances } \\
\hline $05-03-022-0029$ & Adhoc. R Allowance $2015-10 \%$ & A012091 \\
\hline $05-03-022-0030$ & Adhoc.R Allowance $2016-10 \%$ & A012091 \\
\hline \multicolumn{3}{|c|}{ Teaching Department (Allied Staff) -Other Allowances } \\
\hline 05-03-023-0001 & Overtime Allowance to Drivers & $\mathrm{A} 01271$ \\
\hline $05-03-023-0002$ & Night Duty Allowance & $\mathrm{A} 01272$ \\
\hline $05-03-023-0003$ & Honorarium & $\mathrm{A} 01273$ \\
\hline $05-03-023-0004$ & Medical Charges - Ho spitalization etc. & $\mathrm{A} 01274$ \\
\hline $05-03-023-0005$ & Contingent Paid Staff / Daily Wages & $\mathrm{A} 01277$ \\
\hline $05-03-023-0006$ & Teaching Allowance/Technical Allowance & A01289 \\
\hline $05-03-023-0008$ & Group Insurance & $\mathrm{A} 0127802$ \\
\hline $05-03-023-0009$ & Others (Leave Encashment) & $\mathrm{A} 01275$ \\
\hline $05-03-023-0010$ & Bills Payable & $\mathrm{A} 0127804$ \\
\hline $05-03-023-0011$ & Payment of Difference (Pay Allow \& Others) & $\mathrm{A} 01290$ \\
\hline \multicolumn{3}{|c|}{$\begin{array}{l}\text { Establishment Charges Others } \\
\text { Other Establishment Charges }\end{array}$} \\
\hline $05-04-024-0001$ & Honorarium (OEO) & $\mathrm{A} 01273$ \\
\hline $05-04-024-0002$ & Medical Charges - Hospitalization etc (OEQ) & $\mathrm{A} 01274$ \\
\hline $05-04-024-0003$ & Group Insurance (OEC) & $\mathrm{A} 0127802$ \\
\hline $05-04-024-0004$ & Other (Leave Encashm ent) (OEO & $\mathrm{A} 01275$ \\
\hline
\end{tabular}

Figure 3. Account Chart.

As this software is designed for an educational institution so for each allowances and charges, a unique HEC code is allocated.

\subsection{ALLOCATION OF THE BUDGET}

The budget that is allocated by the institution is then feed on the proposed software along with the HEC codes. The software is capable enough of the updating the amount of the budget once the money is withdrawn or is transferred to the account as shown in the figure below: 
Edición Especial Special Issue Noviembre 2019 DOI: http://dx.doi.org/10.17993/3ctecno.2019.specialissue3.149-165

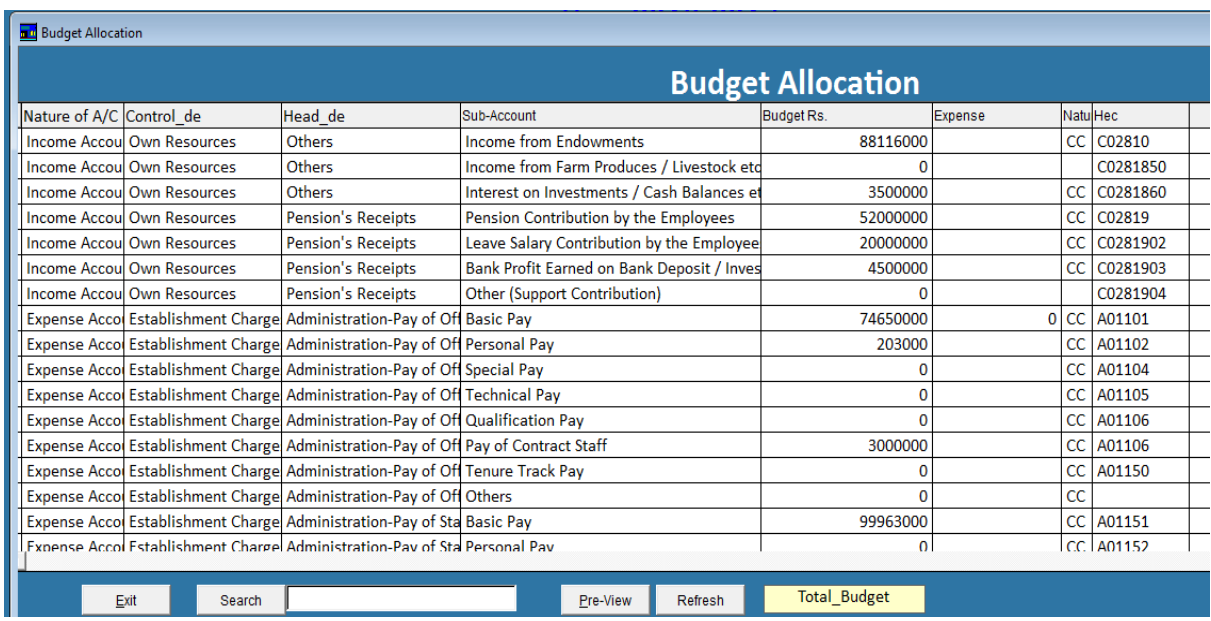

Figure 4. Budget Allocation Sheet.

\subsection{VOUCHERS AND TRANSACTION RECORDS}

After the prerequisites are fulfilled after feeding the numeric needed for the budget allocation and account charts, then vouchers are made for keeping the record of the account based on the budget of the project and the salaries that awarded to the project team members as shown in the figure below:

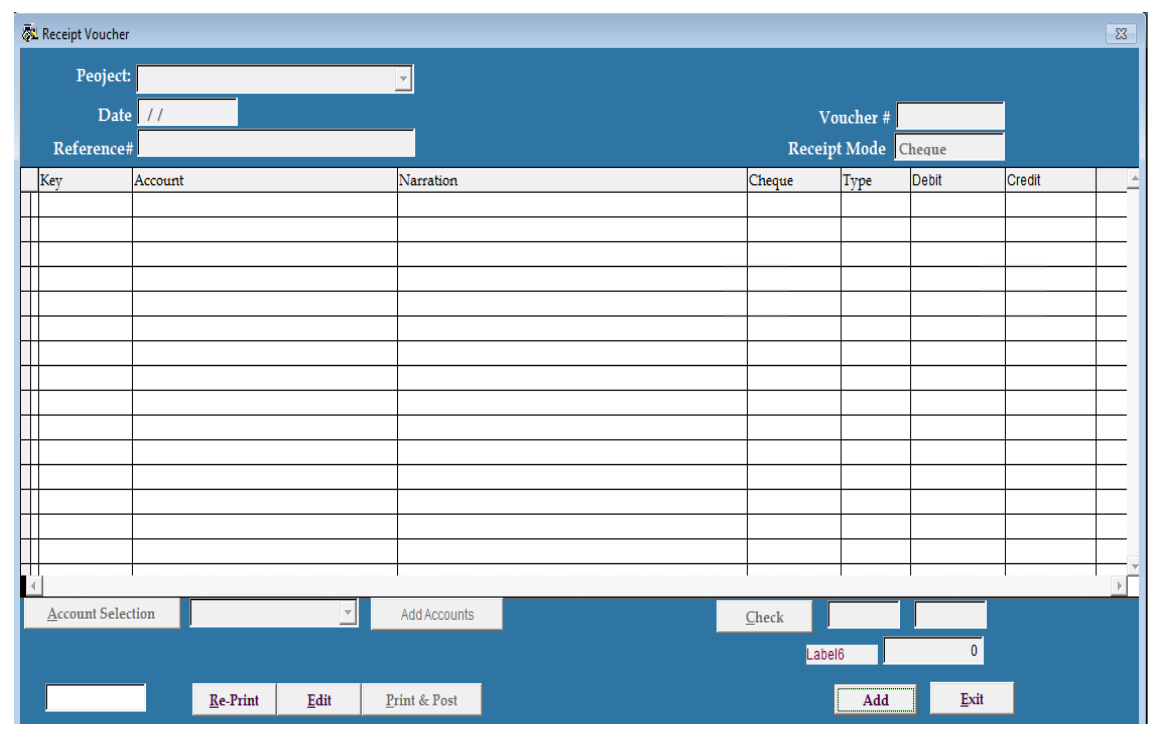

Figure 5. Voucher Sheet. 
After the saving the data of the vouchers in the proposed software, the software provides various customized options that include cost of the project, reference number for the transaction, account key, account title, details of the bank transactions, etc. as shown in the mentioned below figure:

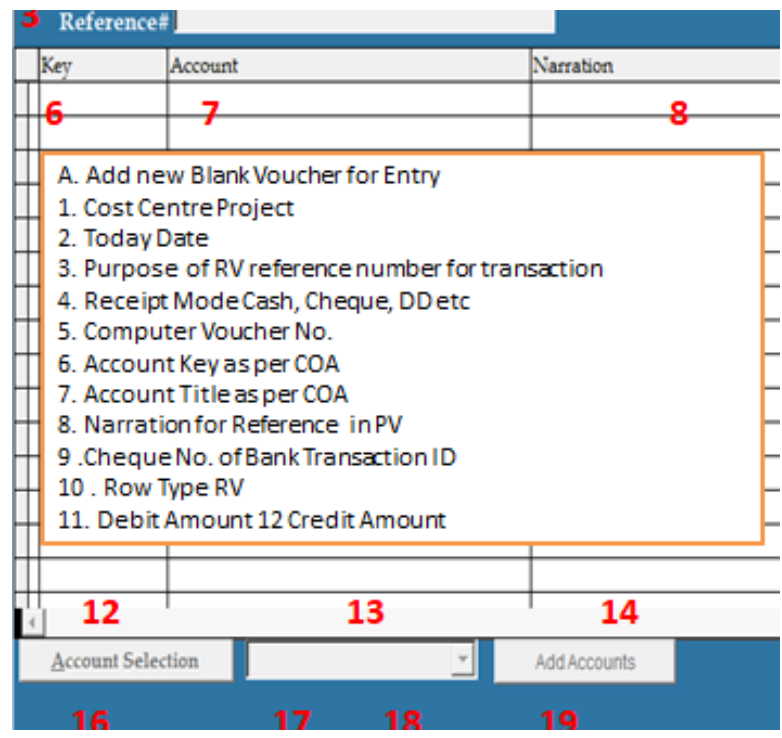

Figure 6. Software Options.

This business transaction records are present in the account ledger which can be accessed by the user and it contains all the necessary data of the transaction that are done previously as shown in the figure below:

\begin{tabular}{|c|c|c|c|c|c|}
\hline \multirow{4}{*}{ (1) } & & \multicolumn{4}{|c|}{ Mehran University of Engineering and Technology, Jamshoro. } \\
\hline & & \multicolumn{4}{|l|}{$\underline{\text { Account Ledger }}$} \\
\hline & \multirow[t]{3}{*}{$05-05-0$} & Registration & & \multirow{2}{*}{$\begin{array}{r}\text { Page \# : } \\
\text { Print Date : }\end{array}$} & 001 \\
\hline & & Complete Ledger & & & $17 / 05 / 17$ \\
\hline Ref\# & & Description & Debit & Credit & Balance \\
\hline $\begin{array}{|ll|}P V-28 & P V \\
\end{array}$ & 8 Jul 15 & $\begin{array}{l}\text { Peimbusement Paid to Mr. Fiaz Hassan Quershi For Notor Vehide } \\
\text { Annual Tax3 Nos Veh: Nos GL-7038, GL No.7051 \& GSB-986 for the } \\
\text { year }\end{array}$ & \begin{tabular}{l|l|}
$1,900.00$ &
\end{tabular} & & $1,900.00 \mathrm{DB}$ \\
\hline$=$ PV-3599 PV & 22 Ma 16 & \begin{tabular}{|l|} 
Reimbursement Paid to Mr. Fiaz Hassan Quershi for the Registration \\
02 Uni: Veh: No GS0659,FA-8922, \& GSC. 545 \& CU 9892
\end{tabular} & $60,500.00$ & & $62,400.00 \mathrm{DB}$ \\
\hline PV-4049 & 21 Apr 16 & Dif: Sal. of Mr. Ali Asghar & & & $62,400,00 \mathrm{DB}$ \\
\hline & & Total Amount : & $62,400.00$ & & $-62,400.00$ \\
\hline
\end{tabular}

Figure 7. Sample Account Ledger. 
Whereas, the voucher summary based on the financial budget of the project can also be viewed as shown below:

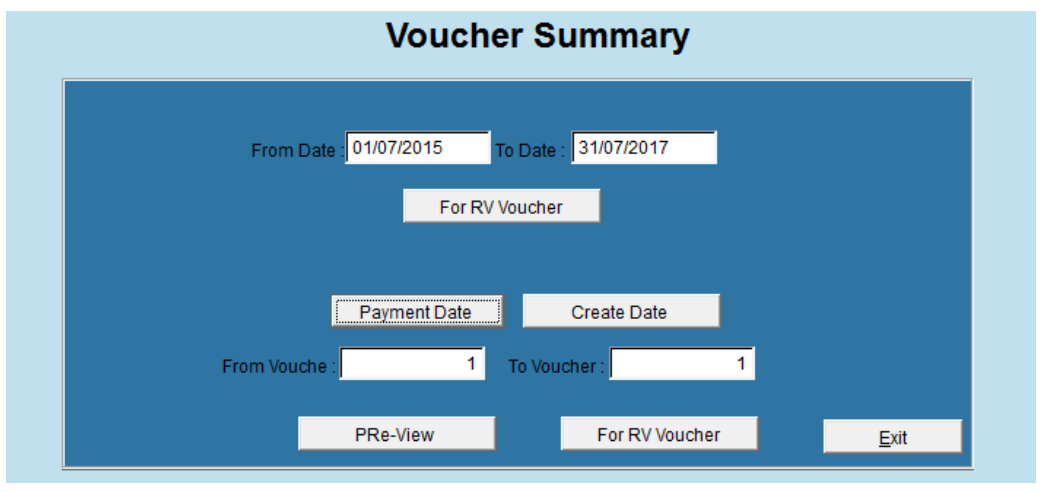

Figure 8. Voucher Summary.

Based on these records, the cheques can be later printed with the reference to the chart of the account and allocation of the budget as shown below:

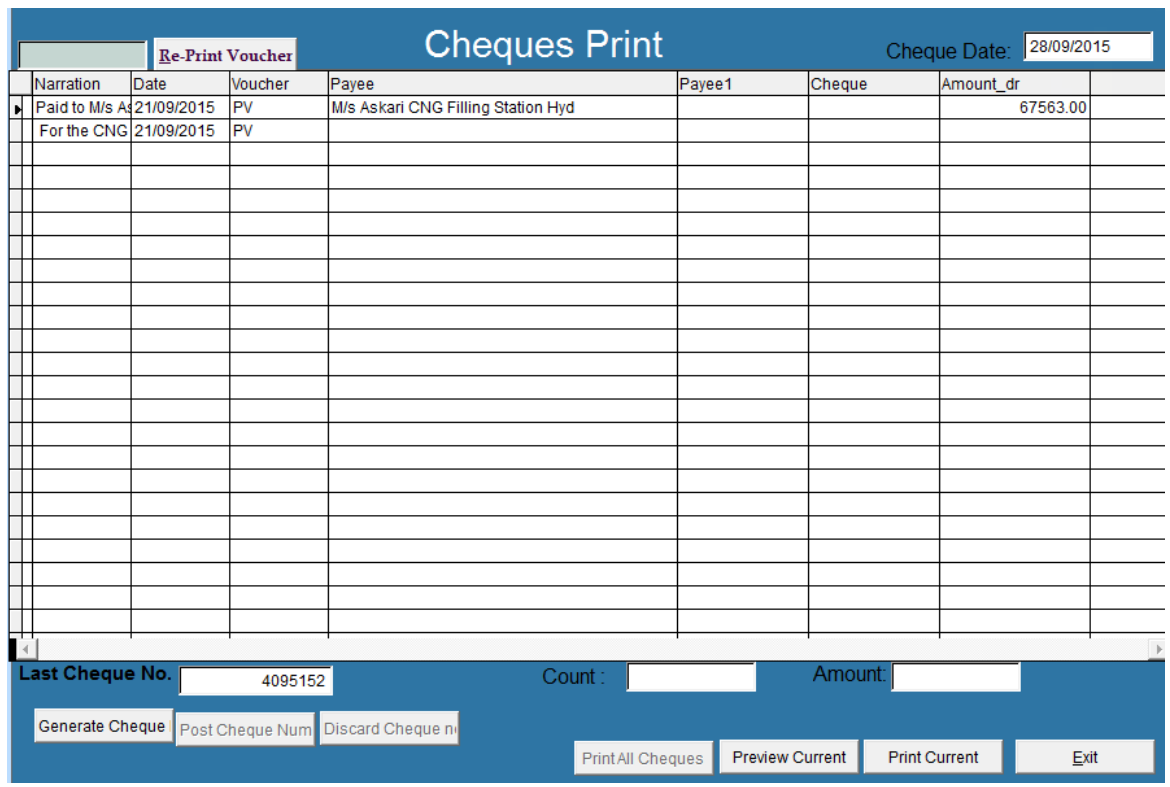

Figure 9. Cheque Print Sheet.

While the receipt can be also viewed along with the variance report of the profit and expense of the project as shown below: 


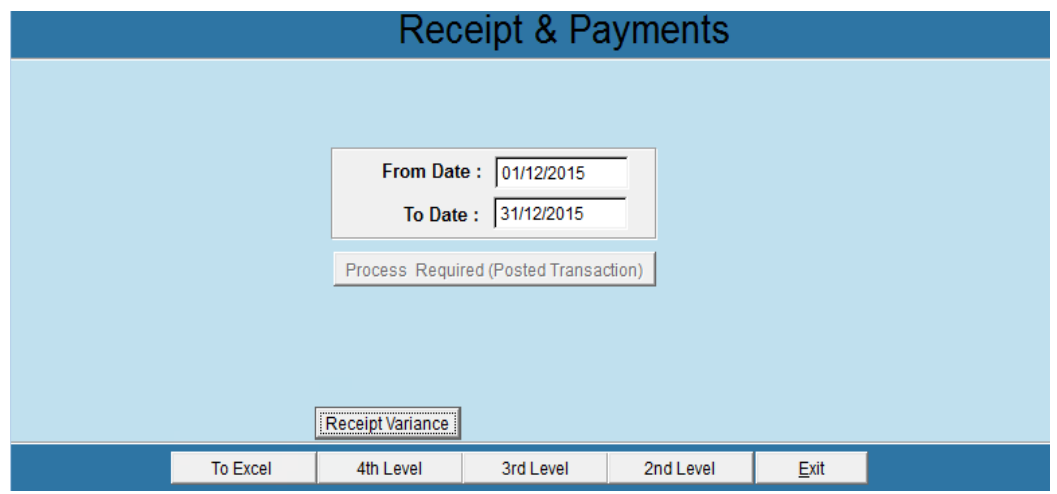

Figure 10. Receipt and Payment.

In order to demonstrate the effectiveness of the personal record of a voucher, the personal ledger of a sample is shown as below:

\section{$\underline{\text { Personal Ledger }}$}

\section{M/s TCS Private Ltd.}

Page \# : 001

Date : $17 / 05 / 17$

\begin{tabular}{|c|c|c|c|c|c|c|}
\hline Date & Vou \# & Narration & Account & Debit & Credit & Balance \\
\hline \multicolumn{2}{|c|}{13 Jul 15 PV -74} & $\begin{array}{l}\text { Payment Paid to Ms Tos Put Ltd Office of the } \\
\text { V.C Secett: for the month of June } 2015\end{array}$ & Courier And Flot Services & 237 & & 237) \\
\hline \multicolumn{2}{|c|}{13 Jul 15 'PV -76} & $\begin{array}{l}\text { Payment Paid to M/s Tes PvtLtd office of the } \\
\text { REgistrar for the month of June } 2015\end{array}$ & Courier And Plot Services & 5,702 & & ( 5,939$)$ \\
\hline \multicolumn{2}{|c|}{23 Jul 15 PV-155 } & $\begin{array}{l}\text { Payment Paid to M/s Tes PvtL to for the month of } \\
\text { June } 2015 \text { office of Director Works }\end{array}$ & Courier And Hlot Services & 2,286 & & ( 8,225$)$ \\
\hline \multicolumn{2}{|c|}{6 Avg 15 PV-284 } & $\begin{array}{l}\text { Payment Paid to M/s Tcs PutLtd For the month } \\
\text { of June } 2015 \text { Controller of Exam: }\end{array}$ & Courier And Flot Services & 7,771 & & ( 15,996$)$ \\
\hline \multicolumn{2}{|c|}{6 Aug 15 PV-285 } & $\begin{array}{l}\text { Payment Paid to M/s Tes Pvt Ltd For The month } \\
\text { of June } 2015 \text { Controller Exam: Bill No } \\
\text { HD211004 }\end{array}$ & Courier And Flot Services & 17,064 & & ( 33,060$)$ \\
\hline \multicolumn{2}{|c|}{7 Aug 15 PV-313 } & $\begin{array}{l}\text { Payment Paid to M/s Tcs PvtLtd For the month } \\
\text { of bill July } 2015 \text { from V.C Secretariat }\end{array}$ & Courier And Hlot Services & 418 & & ( 33,478$)$ \\
\hline \multicolumn{2}{|c|}{11 Aug 15 PV-344 } & $\begin{array}{l}\text { Payment Paid to M/s Tcs PvtL td For the office of } \\
\text { Registrar month of July } 2015\end{array}$ & Courier And Flot Services & 4,941 & & ( 38,419$)$ \\
\hline \multicolumn{2}{|c|}{17 Aug 15 PV- -420} & $\begin{array}{l}\text { Payment Paid to M/S TCS PvtL to for the month } \\
\text { of July } 2015 \text { Bi1N0-HDD212662 Dt:31/7/2015 }\end{array}$ & Courier And Plot Services & 2,474 & & ( 40,893$)$ \\
\hline \multicolumn{2}{|c|}{25 Aug 15 PV -505} & $\begin{array}{l}\text { Payment Paid to M/s TCS Put Ltd for the of } \\
\text { month July } 15 \text { office of controller Exam }\end{array}$ & Courier And Flot Services & 8,292 & & ( 49,185$)$ \\
\hline \multicolumn{2}{|c|}{26 Aug 15 PV- 531} & $\begin{array}{l}\text { Payment Paid to M/s TCS PvtLtd: For The } \\
\text { month of July } 2015 \text { from Controller Exam: }\end{array}$ & Courier And FlotServices & 6,890 & & ( 56,075$)$ \\
\hline \multicolumn{2}{|c|}{14 Sep 15 PV-766 } & $\begin{array}{l}\text { Payment Paid to M/s Tcs PvtL td For the month } \\
\text { of August } 2015 \text { Office of director works \& } \\
\text { services }\end{array}$ & Courier And Flot Services & 2,348 & & ( 58,423$)$ \\
\hline
\end{tabular}

Figure 11. Sample Personal Ledger Sheet. 


\section{RESULTS}

The performance of the software was tested based on the survey conducted from the end users that are currently using the proposed software. First and foremost the installation and the compatibility of the software with the hardware were concerned. The bar graphs of the survey are shown in the Figure 12 and Figure 13, respectively. The survey was taken of 20 employees that were also the end users of the proposed software. Majority of them expressed their satisfaction towards the installation of the software.

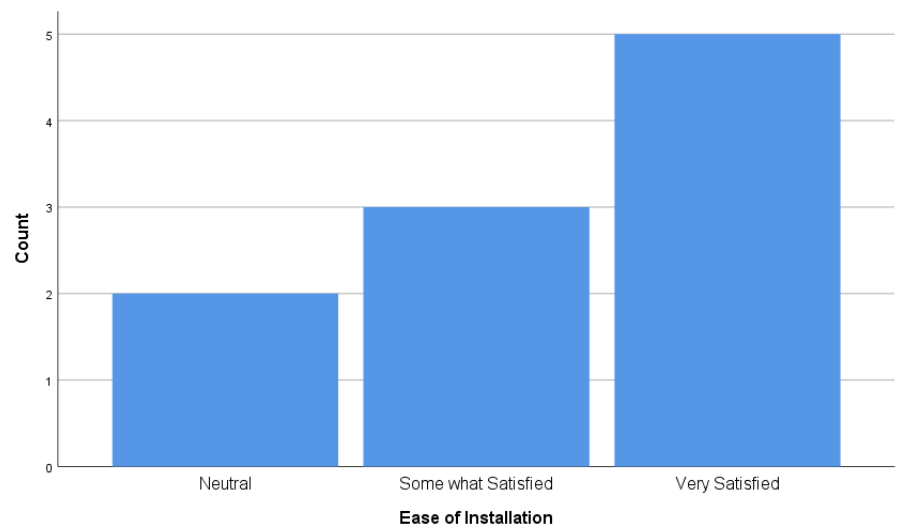

Figure 12. Survey of Ease of Installation.

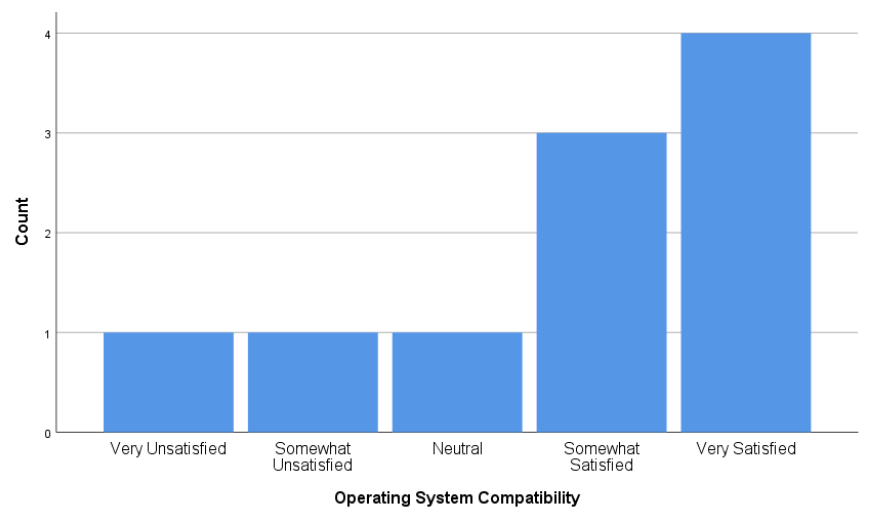

Figure 13. Survey of Operating System Compatibility.

The second most important issue of the financial software is the completeness of the needed tools and clarity in the documentation. In the survey of this, majority of the 
end users were satisfied with the completeness of the needed tools and clarity of the proposed documentations as shown in the mentioned below Figure 14 and Figure 15 , respectively.

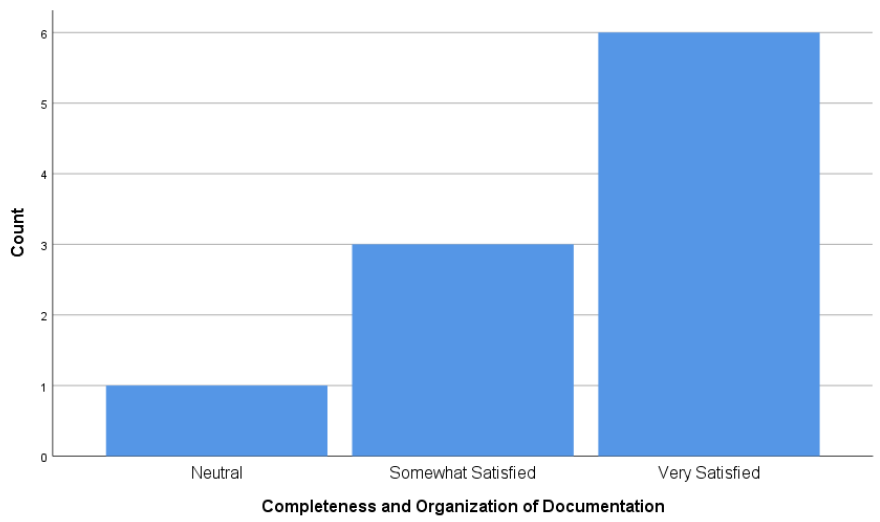

Figure 14. Survey of Completeness and Organization of the Data.

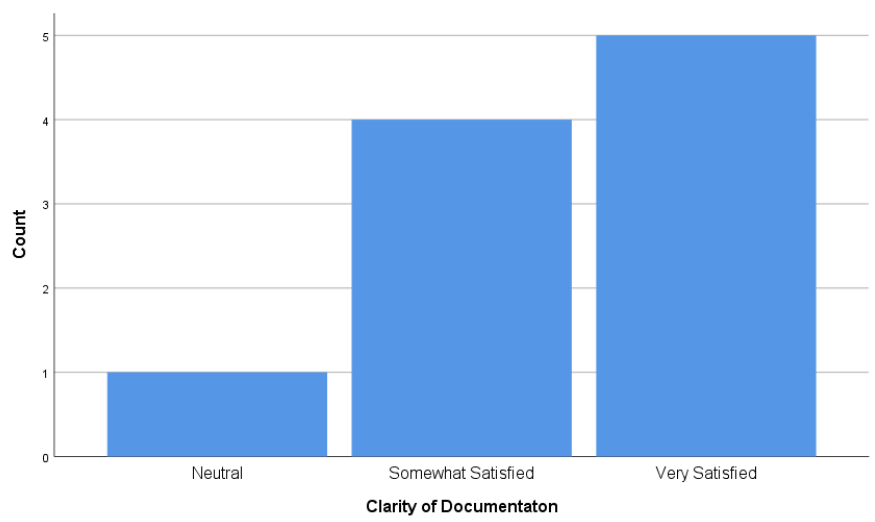

Figure 15. Survey of Clarity of Documentation.

While considering the quality of the software support most of the end users were somewhat satisfied as shown in the below Figure 16. But as the software is at its initial stage and it is new in comparison with the legacy software so therefore the end users had certain problems, dealing with the software interface support environment. 


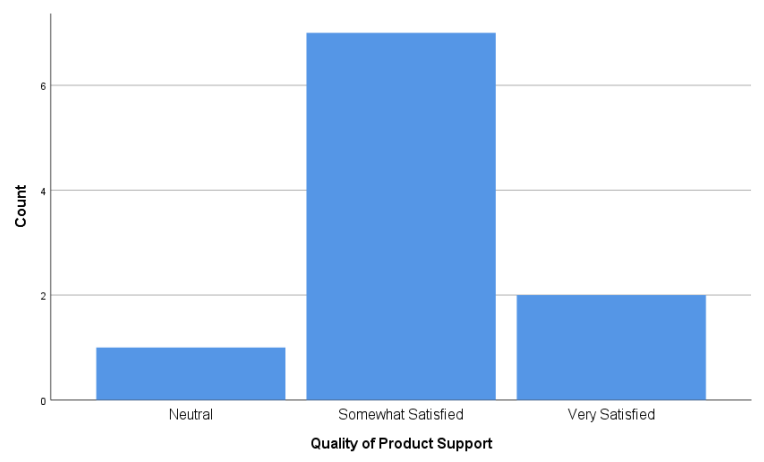

Figure 16. Survey of Quality of Product Support.

Moreover the software was stated to be very cost efficient and reliable. The end users as shown in the survey mentioned in the below Figure 17 were quite satisfied with the overall cost of the software in comparison with the software products that are already available in the market. Where as in the reliability as shown in the survey mentioned in the figure, almost all the end users claimed that their none of the data was lost nor any reports of the software crashed where been recorded by any of the end user.

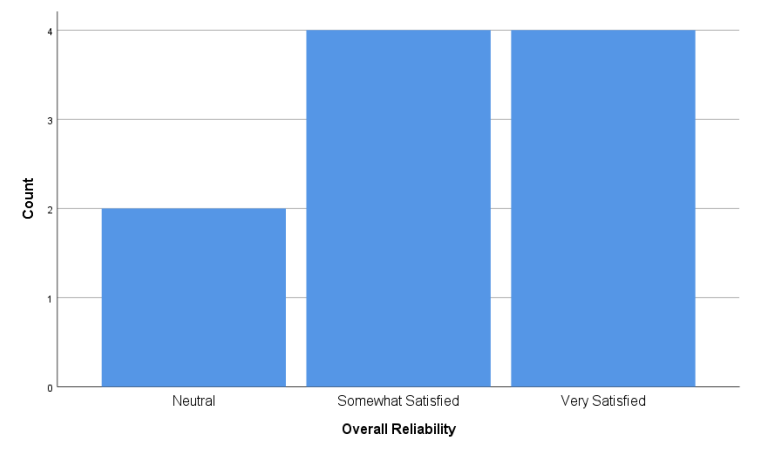

Figure 17. Survey of Software Reliability.

\section{CONCLUSION}

Considering the overall performance of the software which is mentioned in the mentioned below Figure 18 that is the survey of the end users, almost all the end users had expressed their satisfaction as shown in the survey mentioned in the Figure 19. 


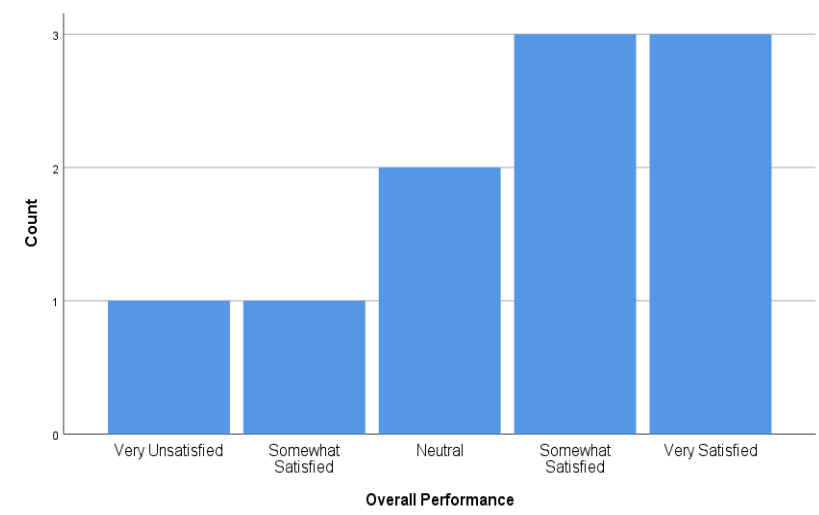

Figure 18. Survey of Overall Software Performance.

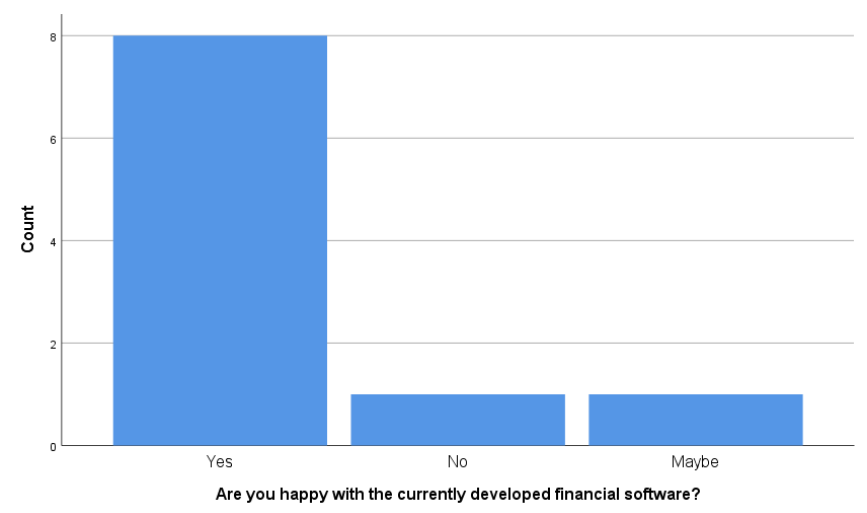

Figure 19. Customer Satisfaction Survey.

As well as most of the end users had agreed on proclaiming this proposed software to be better and more budget friendly than the other software products that are currently available in the market as shown in the Figure 20 and Figure 21 below: 


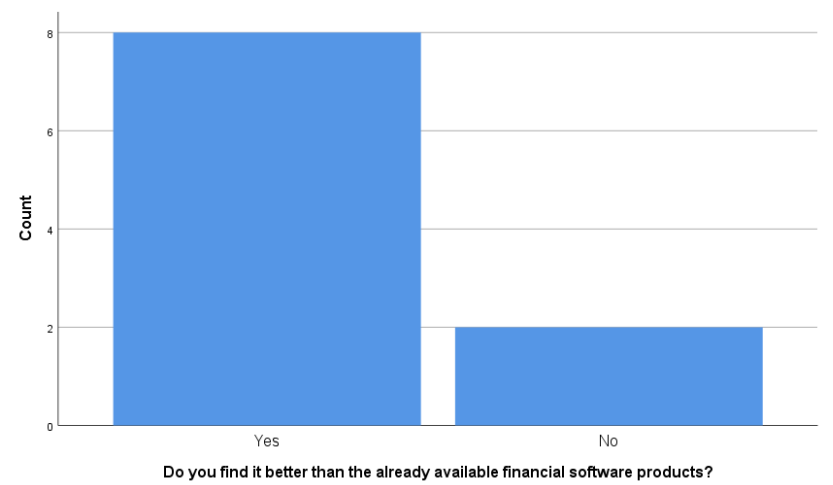

Figure 20. Survey of Optimization.

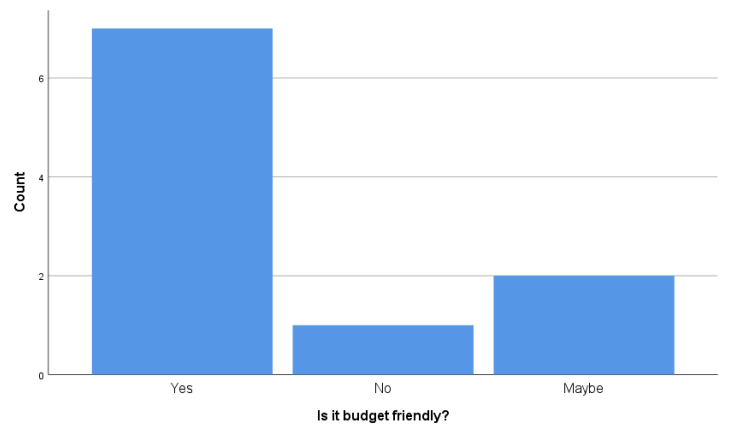

Figure 21. Survey of Cost Efficiency.

\section{ACKNOWLEGEMENT}

We are highly indebting of the Finance department of MUET and its employees for testing the software and Mr. Mujawar Malik without whom this software wouldn't have been possible.

\section{REFERENCES}

Atanasov, V. A., \& Black, B. S. (2016). Shock-based causal inference in corporate finance and accounting research. Critical Finance Review, 5, 207-304. doi: http:// dx.doi.org/10.1561/104.00000036 
Bangemann, T. O. (2005). Shared services in finance and accounting. Gower Publishing, Ltd.

Beckett, S. M., Castagno, A. J., Lockwood, D. G., \& Mcdougald, H. D. (2017, September 19). System and method for non-programmatically constructing software solutions. Google Patents.

Cook, N. (2017). Enterprise 2.0: How social software will change the future of work. Routledge.

Driesen, V., Engelko, A., Jahr, A., Muscarella, F., \& Storz, G. (2015, November 17). Software logistics protocols. Google Patents.

Hoefler, D., Jansen, J., Stegmueller, H., Karolin, L., Chen, X., Wang, C., \& Bai, X. (2012, May 8). Software maintenance management. Google Patents.

Kharaz, A., Arshad, S., Mulliner, C., Robertson, W., \& Kirda, E. (2016). UNVEIL: A Large-Scale, Automated Approach to Detecting Ransomware. 25th USENIX Security Symposium (USENIX Security 16), 757-772.

Kharraz, A., Robertson, W., Balzarotti, D., Bilge, L., \& Kirda, E. (2015). Cutting the gordian knot: A look under the hood of ransomware attacks. International Conference on Detection of Intrusions and Malware, and Vulnerability Assessment, 3-24. Springer. Retrieved from: https://seclab.ccs.neu.edu/static/publications/ dimva2015ransomware.pdf

Lorenc, A., \& Szkoda, M. (2015). Customer logistic service in the automotive industry with the use of the SAP ERP system. 2015 4th International Conference on Advanced Logistics and Transport (ICALT), 18-23. IEEE.

Rasmussen, N. H., Goldy, P. S., \& Solli, P. O. (2002). Financial business intelligence: trends, technology, software selection, and implementation. John Wiley \& Sons.

Rogaway, P., \& Coppersmith, D. (1998). A software-optimized encryption algorithm. Journal of Cryptology, 11(4), 273-287. doi: https://doi.org/10.1007/ s001459900048 
Ryan, B., Scapens, R. W., \& Theobald, M. (2002). Research method and methodology in finance and accounting. Retrieved from: https://pdfs.semanticscholar.org/ f5b8/78307fc6c8a2139a9c2265c28894b41d1847.pdf

Yousouf, S., \& Stanev, G. (2015, June 23). Deployment of software applications on a cloud computing platform. Google Patents. 


$$
\text { /10/ }
$$




\title{
DESIGN AND TUNING OF DIGITAL POWER LINE CARRIER TO IMPROVE NETWORK LINE PARAMETERS AT HIGH VOLTAGE TRANSMISSION LINES
}

\begin{abstract}
Mukhtiar Hussain Khowaja
Mater's Student, Communication System Engineering, Institute of Information and Communication Technologies, Mehran UET, Jamshoro, Pakistan.

E-mail: mukhtiar.ntdc@gmail.com

Irfan Ahmed Halepoto

Associate Professor, Department of Electronic Engineering, Mehran UET, Jamshoro,

Pakistan.

E-mail: irfan.halepota@faculty.muet.edu.pk
\end{abstract}

Shakeela Memon

Assistant Professor, Department of Electronic Engineering, Mehran UET, Jamshoro,

Pakistan.

E-mail: shakila.memon@faculty.muet.edu.pk

Recepción: 30/07/2019 Aceptación: 20/09/2019 Publicación: 06/11/2019

\section{Citación sugerida:}

Khowaja, M.H., Halepoto, I.A. y Memon, S. (2019). Design and tuning of digital power line carrier to improve network line parameters at high voltage transmission lines. $3 \mathrm{C}$ Tecnología. Glosas de innovación aplicadas a la pyme. Edición Especial, Noviembre 2019, 167-183. doi: http://dx.doi.org/10.17993/3ctecno.2019.specialissue3.167-183

\section{Suggested citation:}

Khowaja, M.H., Halepoto, I.A. \& Memon, S. (2019). Design and tuning of digital power line carrier to improve network line parameters at high voltage transmission lines. $3 C$ Tecnología. Glosas de innovación aplicadas a la pyme. Speciaal Issue, November 2019, 167-183. doi: http://dx.doi.org/10.17993/3ctecno.2019.specialissue3.167-183 


\section{ABSTRACT}

In this work, Digital Power Line Carrier (DPLC) over 3-phase 500kV/220kV high voltage transmission line is designed, configured, tuned and simulated using Micom software. The DPLC was configured for faster and efficient data transmission at longer distance in the range of $800 \mathrm{~km}$ by reducing the noise using different enhanced digital techniques and advanced indoor/outdoor equipment. In this work, only YELLOW phase of 3-phase is used on the existing network of National Transmission and Dispatching Center, Pakistan while other phases can be used for transmission of data by reducing noise. The line matching units, coupling capacitors, wave traps and high frequency cables for the connection of DPLC to the HV line in grid yard were considered.

The Actual line condition measurent for attenuation and noise were carried out between two remote stations between $500 \mathrm{kV}$ Jamshoro and NKI Karachi. The line spectrum shows that in $\mathrm{Rx}(116 \mathrm{KHz}$ to $124 \mathrm{KHz})$ band there is very high level of noise during the sweep time of $10 \mathrm{sec}$, the initial condition of $\mathrm{HV}$ transmission line indicates the high noise of $-3.951 \mathrm{~dB}$ and analog line gain of $10.45 \mathrm{~dB}$. To reduce this noise level, the DPLC was configured according to the line parameters.

After synchronizing the both DPLCs of $500 \mathrm{kV}$ Jamshoro and NKI Karachi, the initial line condition of $\mathrm{HV}$ line were measured again. The result confirms that line parameters (Noise, Attenuation and BER) are improved significantly. The results shows the in $\mathrm{Rx}$ band from $116 \mathrm{kHZ}$ to $124 \mathrm{kHZ}$ line spectrum, the noise level is decreased from $-3.951 \mathrm{~dB}$ to $-13.471 \mathrm{~dB}$ due to which the analog line gain was also improved from $10.45 \mathrm{~dB}$ to $19 \mathrm{~dB}$. When DPLC was used for data transmission it confirms an excellent performance in terms of BER that is $99.6 \%$ error free during the 30minutes running time.

\section{KEYWORDS}

High voltage transmission lines, Digital Power Line Carrier, 500kV Jamshoro, NKI Karachi, Actual line Condition. 


\section{INTRODUCTION}

High voltage transmission lines (HVTL) are a considered as good means of transmitting information over different distance ranges. In most part of the world, power line carrier is used to transfer information via High voltage $(\mathrm{HV})$ lines and has become an important instrument of the management and safety of electrical power systems (Arora, Thomas \& Jain, 2019). The extremely high mechanical rigidity and high reliability of the interconnecting lines and terminal equipment under the control of power utility exhibits attenuation and moderate to long duration noise under normal atmospheric conditions. The HV lines exhibit attenuation in the carrier frequency range of $20 \mathrm{~K} \mathrm{~Hz}$ to $500 \mathrm{KHz}$ (Acakpovi, Mohammed, Nwulu, Fifatin, Nounangnonhou, \& Abubakar, 2019). Additionally the HV lines produce high short duration level (bursts) due to the operation of circuit breakers and load break isolators. Traditionally over HV lines, power line carrier (PLC) is widely used because it provides multiple channels for speech, data and teleprotection (Cortes, \& Idiago, 2019). Previously analog power line carriers had been used to transfer information/data via $\mathrm{HV}$ lines but due to band width limitations, noise problems and low features in the analogue PLCs, the international recommendations for digital power line carrier (DPLC's) have come in to force. Additionally, the system may have the possibility of false signals or any kind of tripping in the presence of burst noise; the DPLC's can combat these problems. Through DPLC, 100 to $800 \mathrm{~km}$ distance long range information can be transmitted without any use of repeater stations (Ndjiongue, \& Ferreira, 2019).

Digital power line carrier is consisted of processing unit, amplifier unit and service unit configured in master/slave relationship offers comprehensive transmission capabilities over HV lines (Sagar, 2011). It supports voice/speech, data transmission and teleprotection with various commands to react to problems in the electrical network (Pavlidou, Vinck, Yazdani, \& Honary, 2003). The DPLC has adaptive behavior and can also be used with SCADA system. The grid information/data can be taken from the RTU serial/parallel ports and then put to the DPLC for efficient transmission. The additional features can be achieved by using service unit and it is observed practically that the system does not produce perturbations or spurious noise 
within the band. DPLC can transmit data using particular frequency band from 4 $\mathrm{kHz}$ to $16 \mathrm{kHz}$ wide within the range of 20 to $500 \mathrm{khz}$. DPLC can be configured for wide range of parameters such as voice, data and protection of $\mathrm{HV}$ lines. Some parameters are set during the manufacturing stage and some are set during the installation and service start-up time.

\section{MATERIALS AND METHODS}

In this work, a DPLC based model is proposed for faster and efficient data transmission over high voltage transmission lines by reducing the noise. The proposed model is shown in Figure 1.

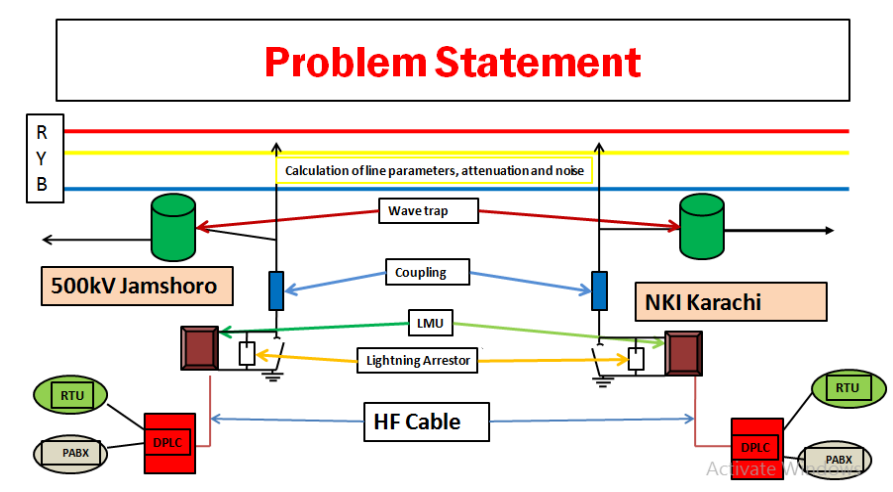

Figure 1. Proposed DPLC based model for data transmission.

In proposed model, a 3-phase $\mathrm{HV}$ transmission line from $500 \mathrm{kV}$ Jamshoro to NKI Karachi is considered with indoor and outdoor equipment arrangement. In this work, only single YELLOW phase is used on the existing network of National Transmission and Dispatching Center (NTDC), Pakistan while other one or two phases can be used for transmission of data by reducing noise. In the yard side, outdoor equipment contains the wave trap, coupling capacitor and line matching unit (LMU) with lightening arrestors which may protect the line equipment from heavy lightening strokes during the rainy season. The outdoor equipment is connected with the indoor equipment that is DPLC via HF (high frequency) cable of $75 \Omega$. The data from RTU and PABX relates to DPLC for transmission. 


\subsection{DPLC CONFIGURATIONS}

DPLC consists of mainly three parts; power amplifier, processing module and service module as shown in Figure 2.

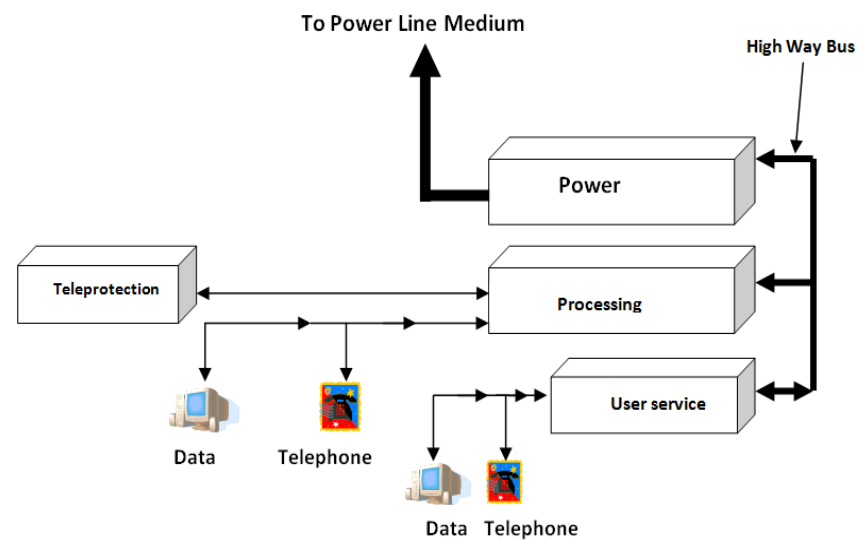

Figure 2. Digital power line carrier.

\subsubsection{POWER AMPLIFIER}

The DPLC offers programmable amplifier which is configurable with the HumanMachine Interface that can provide $40 \mathrm{~W}$ power and it can be increased up to $80 \mathrm{~W}$ for the long distance transmission HV line by adding a single AMPX unit Extension Amplifier (Waseer, Halepoto, \& Joyo, 2014). The main boards that are used for power amplifier settings are amplifier (AMP), transmission filter board (TXF) and reception filter board (RXF). The AMP board is 40W class AB amplifier board (Halepoto, Kumar, Memon, \& Ismaili, 2013). The TXF board is programmable $40 \mathrm{~W}$ transmit filter, impedance matching; summing stage for $80 \mathrm{~W}$ is always present. Filter setting is achieved with jumpers. Fine tuning is obtained by adjusting the inductance value of the 2 coils (screw adjusting) on the board. RXF is board programmable receive filter, it is only present on one of the two amplifier units. Fine-tuning is obtained by adjusting the inductance value of the three coils (screw adjusting). Jumpers on the TXF and on the RXF allow frequency settings: the pass-band can be $4 \mathrm{kHz}, 8 \mathrm{kHz}$, or $16 \mathrm{kHz}$ wide, and is in the range $20 \mathrm{kHz}$ to $500 \mathrm{kHz}$. After the setting of jumpers 
the fine tuning can be performed by using selective and feeding meters. After the completion of tuning process, the amplifier is configured, as shown in Figure 3.

Figure 3 shows the power amplifier configuration for $8 \mathrm{kHz}$ frequency band. During the configuration process it is very important to select the QAM center frequency for Tx and Rx. The analog band of $4 \mathrm{kHz}$ is selected for speech while other $4 \mathrm{kHz}$ is selected for DATA transmission.

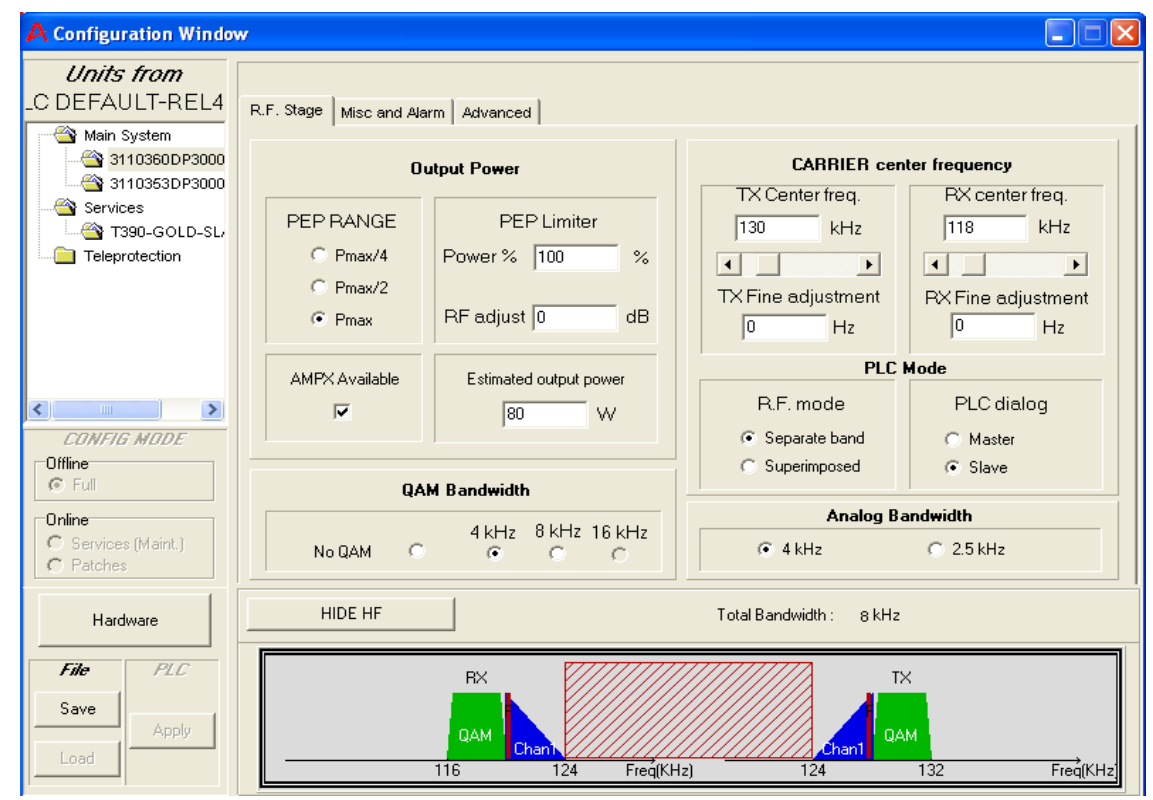

Figure 3. Amplifier Configuration.

\subsubsection{PROCESSING UNIT}

The processing unit (PRCS) is responsible to prepare the signals to be sent for the modulation, error detection and correction scheme. The PRCS digitally samples and modulates the signal using either QAM for normal data (to increase the data rates) or FSK for out-of-band data. The PRCS unit offers the high speed channel V11 can be configured by using a clock signal generated by processing unit on the master/ slave basis. The channel speed can also be set from the tool box of Micom software. The default value is 64kbps. The Signal to Noise Ratio (SNR) or Bit Error Ratio (BER), or both can be used as an exit and entry condition points at which the system 
switches into or out of fallback mode. The PRCS has different data ports, various combinations of DATA equipment (DTE or DCE) can be connected to DPLC. The data channel is configured as shown in Figure 4.

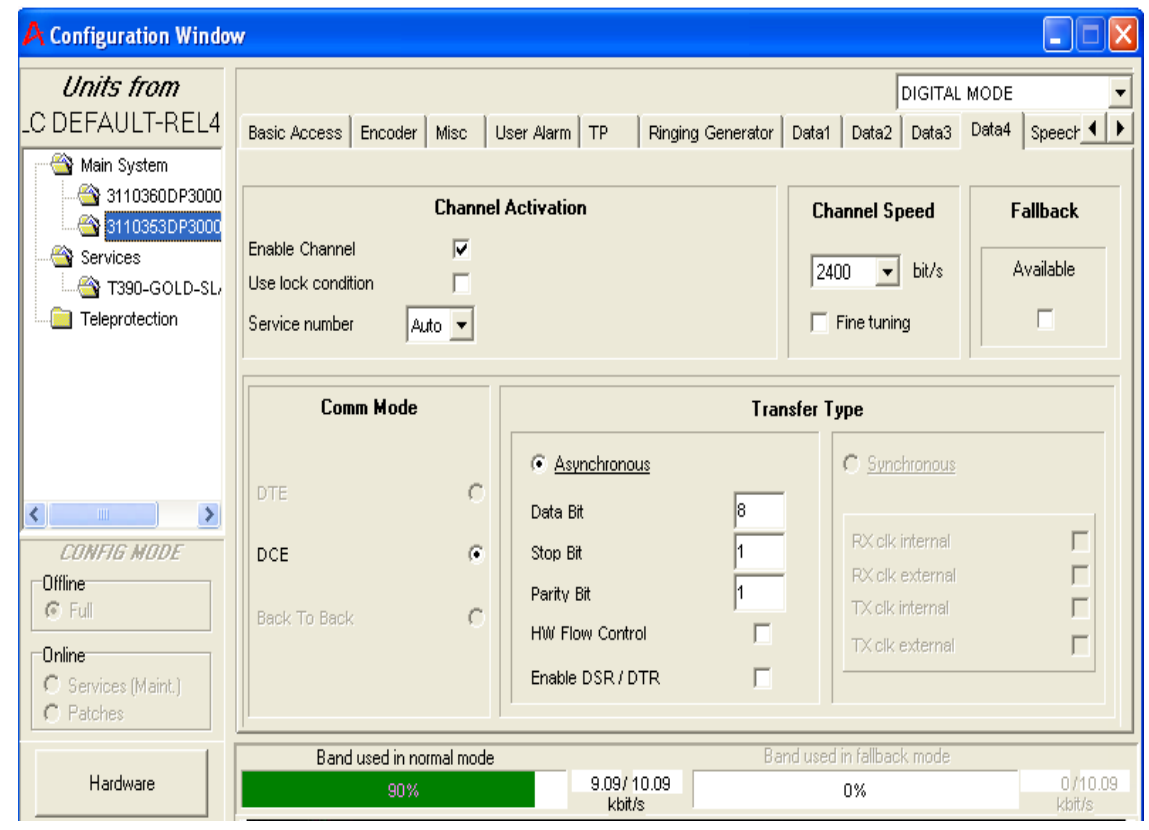

Figure 4. Processing Unit configuration for DATA.

In Figure 4, the PRCS is configured for data channel. Different data channels are available (DATA1, DATA2, DATA3 and DATA4) that can be used for transmission of data at various channel speeds. It is necessary to select the same speed at both stations. The data bits should be an integer from 1 to 9 , whereas stop bit and parity bit 1 is used.

\subsubsection{USER SERVICE UNIT}

The services can be expanded by adding different service modules (maximum up to nine modules). The User Service Unit (USR) supports combinations of speech/ telegraph channels and data channels with up to six channels in total. Speech channels can be configured for both analog and digital modes in the service module. The input and output levels for analog speech is adjustable between $-30 \mathrm{db}$ to $+7 \mathrm{db}$ range. The level setting should be identical at both end stations. This is set in accordance with 
the capabilities of the PABX line to which the channel is connected.2W/4W/ defines how many wires are to be used for the channel on the PABX. The options are two (the default), four, or automatic detection from the PABX using W-Wire. To reduce the noise for improving the quality of speech several combinations of equipment such as PABX, phone and fax can be connected to the DPLC. The configuration for speech is set as shown in Figure 5.

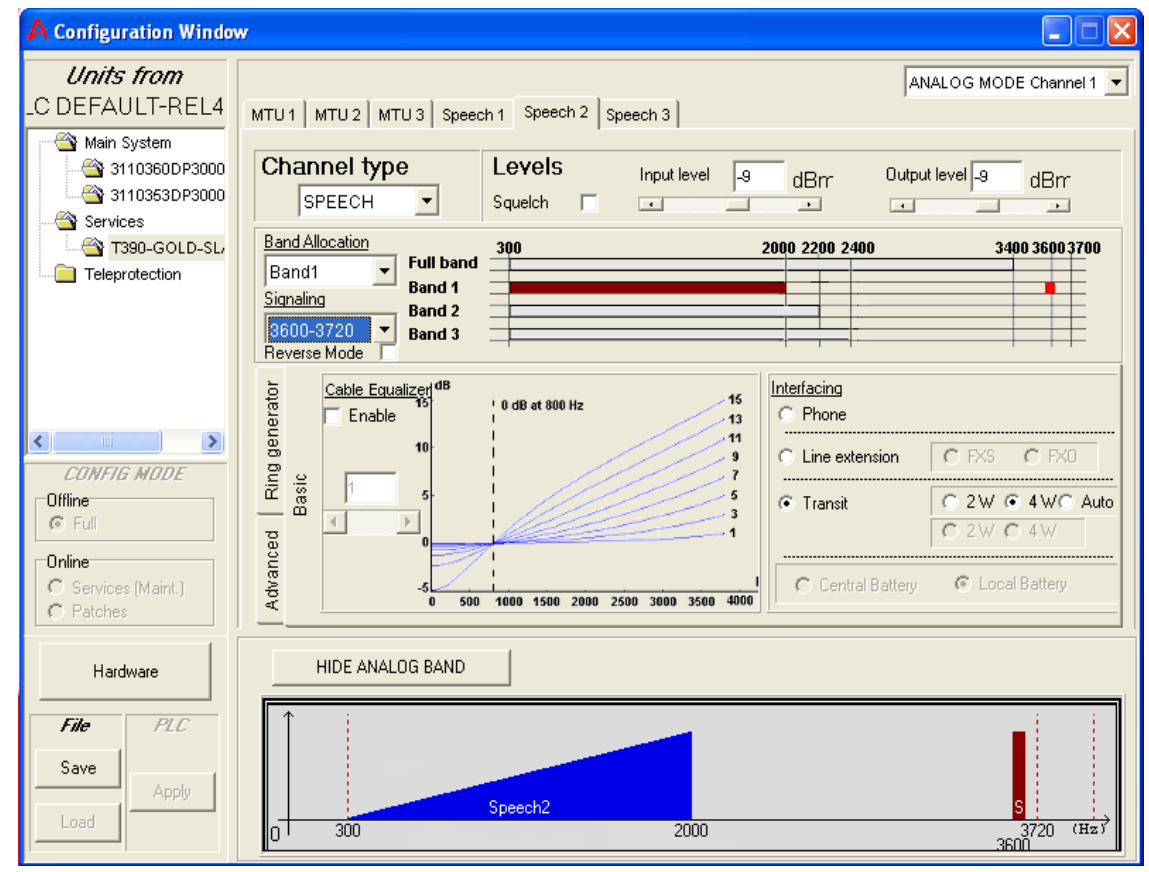

Figure 5. User Service Unit configuration for speech.

In Figure 5, the speech channel is configured by setting the input and output $\mathrm{dB}$ levels by keeping the measured noise levels of the HV line. The burst noise and atmospheric noise both are the main factors which affect the quality of speech. In this work the capacitive coupling and band rejection filters are used to reduce the noise level for the improvement of speech. 


\section{RESULTS}

\subsection{TRANSMISSION LINE AND NETWORK CHARACTERISTIC PARAMETERS}

In $\mathrm{HV}$ lines, 3-phase transmission is preferred due to minimum system losses by using different methods for the transmission of speech and data. In this work, the various characteristics of HV line are taken into consideration.

\subsubsection{NOISE IN HV LINE}

Noise is the random fluctuations in an electrical signal, which generates an error or undesired random disturbance in information signal. Noise is the major problem in HVTL due to which the interruptions occur in the data dissemination from one station to the next station. The HV lines can be affected by various types of noise including burst noise, atmospheric (Static) noise, solar noise and etc. According to the typical noise levels of 3-phase HVTL are given in Table 1.

Table 1. Noise levels of 3-phase HVTL.

\begin{tabular}{|c|c|c|c|c|c|c|c|c|c|}
\hline $\begin{array}{l}\text { Power line } \\
\text { voltage } \\
\text { (kV) }\end{array}$ & $\begin{array}{c}\text { frequency } \\
\mathrm{KHz}\end{array}$ & $48-100$ & 150 & 200 & 250 & 300 & 350 & 400 & 450 \\
\hline \multirow[t]{2}{*}{$34.5-161$} & $\begin{array}{c}\text { Fair } \\
\text { weather }\end{array}$ & -38 to -43 & -39 to -44 & -40 to- 45 & -41 to -46 & -42 to -47 & -43 to -48 & -44 to -49 & -45 to -50 \\
\hline & $\begin{array}{l}\text { Adverse } \\
\text { weather }\end{array}$ & -21 to -26 & -22 to -27 & -23 to -28 & -24 to -29 & -25 to -30 & -26 to -31 & -27 to -32 & -28 to -33 \\
\hline \multirow[t]{2}{*}{$230-345$} & $\begin{array}{c}\text { Fair } \\
\text { weather }\end{array}$ & -33 to -38 & -34 to -39 & -35 to -40 & -36 to -41 & -37 to -42 & -38 to -43 & -39 to -44 & -40 to -45 \\
\hline & $\begin{array}{l}\text { Adverse } \\
\text { weather }\end{array}$ & -16 to -21 & -17 to -22 & -18 to -23 & -19 to -24 & -20 to -25 & -21 to -25 & -22 to -26 & -23 to -26 \\
\hline \multirow[t]{2}{*}{500} & $\begin{array}{c}\text { Fair } \\
\text { weather }\end{array}$ & -31 to -36 & -32 to -37 & -33 to -38 & -34 to -39 & -35 to -40 & -36 to -41 & -37 to -42 & -38 to -43 \\
\hline & $\begin{array}{l}\text { Adverse } \\
\text { weather }\end{array}$ & -11 to -16 & -12 to -17 & -13 to -18 & -14 to -19 & -15 to -20 & -16 to -21 & -17 to -22 & -18 to -23 \\
\hline
\end{tabular}

\subsubsection{LINE NOISE OF 500KV HV LINE}

In this work, two stations have been selected for the measurement of noise levels by using selective meter ALT-2000 500kv Jamshoro and 500kv NKI, Karachi. The Table 2 shows the calculated values of noise. 
Table 2. Line Noise of 500kv HV line.

\begin{tabular}{|c|c|c|c|}
\hline \multirow{2}{*}{ S/No. } & \multirow{2}{*}{$\begin{array}{c}\text { Frequency }(\mathrm{KHz}) \\
\text { Impedance: } 75 \Omega \\
\text { Level: } 0 \mathrm{dBm} \\
\text { LMU: } 48-136 \mathrm{KHZ}\end{array}$} & $\begin{array}{l}\text { Line Noise at } 500 \mathrm{kV} \\
\text { Jamshoro }\end{array}$ & Line Noise at NKI Karachi \\
\hline & & $\begin{array}{l}\text { ALT } 2000 \text { Settings, RF } \\
\text { Response at } 75 \Omega\end{array}$ & $\begin{array}{l}\text { ALT } 2000 \text { Settings, } \\
\text { RF Response at } 75 \Omega\end{array}$ \\
\hline 1 & 50 & -10.6 & -12.6 \\
\hline 2 & 60 & -10.5 & -12.7 \\
\hline 3 & 70 & -11.2 & -11.4 \\
\hline 4 & 80 & -12.0 & -13.2 \\
\hline 5 & 90 & -12.1 & -13.7 \\
\hline 6 & 100 & -13.2 & -14.8 \\
\hline 7 & 110 & -13.9 & -14.9 \\
\hline 8 & 120 & -13.8 & -15.1 \\
\hline 9 & 130 & -13.1 & -15.2 \\
\hline 10 & 140 & -13.7 & -15.5 \\
\hline
\end{tabular}

\subsubsection{LINE ATTENUATION}

Attenuation is the loss in the transmitted signal due to line impedance and power cable impedance. In HV lines, attenuation weakens the signal strength. The maximum allowable attenuation is dependent on the DPLC receivers used at transmission line terminals. Mathematically it can be calculated as follows:

Where,

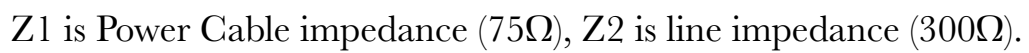

\subsubsection{LINE ATTENUATION OF 500KV HV LINE}

The line attenuation between $500 \mathrm{kV}$ Jamshoro and $500 \mathrm{kV}$ NKI, Karachi is carried out by using ALT-2000 meter. The Table 3 showing the results of line attenuation.

Table 3. Line Attenuation of 500kV HV line.

\begin{tabular}{|c|c|c|c|}
\hline \multirow{2}{*}{ S/No. } & \multirow{2}{*}{$\begin{array}{c}\text { Frequency }(\mathrm{KHz}) \\
\text { Impedance: } 75 \Omega \\
\text { Level: } 0 \mathrm{dBm} \\
\text { LMU: } 48-136 \mathrm{kHz}\end{array}$} & $\begin{array}{l}\text { Line Attenuation } 500 \mathrm{kV} \\
\text { Jamshoro }\end{array}$ & Line Attenuation NKI Karachi \\
\hline & & $\begin{array}{l}\text { ALT } 2000 \text { Settings } \\
\text { RF Response at } 75 \Omega\end{array}$ & $\begin{array}{l}\text { ALT } 2000 \text { Settings } \\
\text { RF Response at } 75 \Omega\end{array}$ \\
\hline 1 & 50 & 15.5 & 16.0 \\
\hline
\end{tabular}




\begin{tabular}{|c|c|c|c|}
\hline \multirow{2}{*}{ S/No. } & \multirow{2}{*}{$\begin{array}{c}\text { Frequency }(\mathrm{KHz}) \\
\text { Impedance: } 75 \Omega \\
\text { Level: } 0 \mathrm{dBm} \\
\text { LMU: } 48-136 \mathrm{kHz}\end{array}$} & $\begin{array}{l}\text { Line Attenuation 500kV } \\
\text { Jamshoro }\end{array}$ & Line Attenuation NKI Karachi \\
\hline & & $\begin{array}{l}\text { ALT } 2000 \text { Settings } \\
\text { RF Response at } 75 \Omega\end{array}$ & $\begin{array}{l}\text { ALT } 2000 \text { Settings } \\
\text { RF Response at } 75 \Omega\end{array}$ \\
\hline 2 & 60 & 17.3 & 18.2 \\
\hline 3 & 70 & 19.6 & 19.0 \\
\hline 4 & 80 & 21.4 & 22.4 \\
\hline 5 & 90 & 22.8 & 22.0 \\
\hline 6 & 100 & 23.5 & 23.0 \\
\hline 7 & 110 & 23.9 & 24.0 \\
\hline 8 & 120 & 24.1 & 23.0 \\
\hline 9 & 130 & 25.3 & 25.0 \\
\hline 10 & 140 & 26.2 & 25.5 \\
\hline
\end{tabular}

\subsection{MEASUREMENT OF INITIAL LINE CONDITION}

After synchronising the both DPLCs of $500 \mathrm{kV}$ Jamshoro and NKI respectively, different characteristics of the network were being viewed and studied for the transmission of data over the line, but it was found that the initial condition of $\mathrm{HV}$ line is very noisy as shown in the Figure 6.

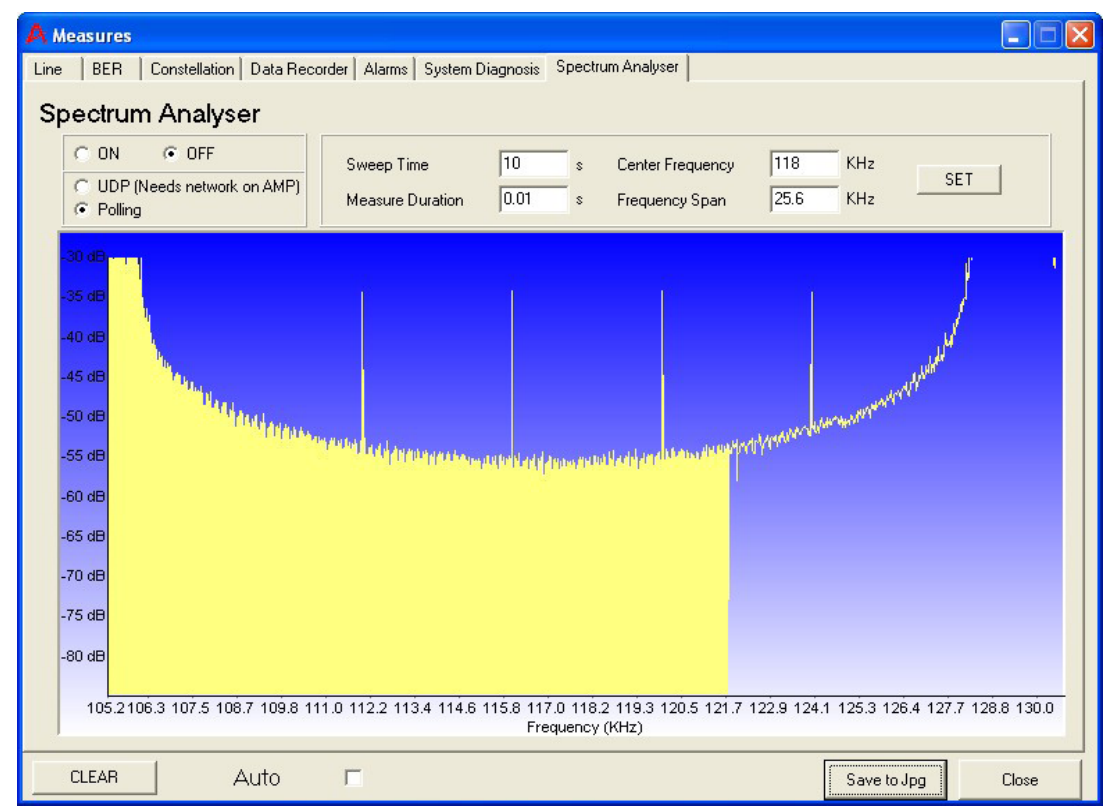

Figure 6. Initial condition of HV line. 
The Figure 6 illustrates the initial line condition with high level of noise; the line spectrum shows that in $\mathrm{Rx}(116 \mathrm{KHz}$ to $124 \mathrm{KHz})$ band there is very high level of noise during the sweep time of 10sec. When DPLC related to the active line at $500 \mathrm{kV}$ Jamshoro in direction to NKI Karachi, the Active HV line results are shown in Figure 7.

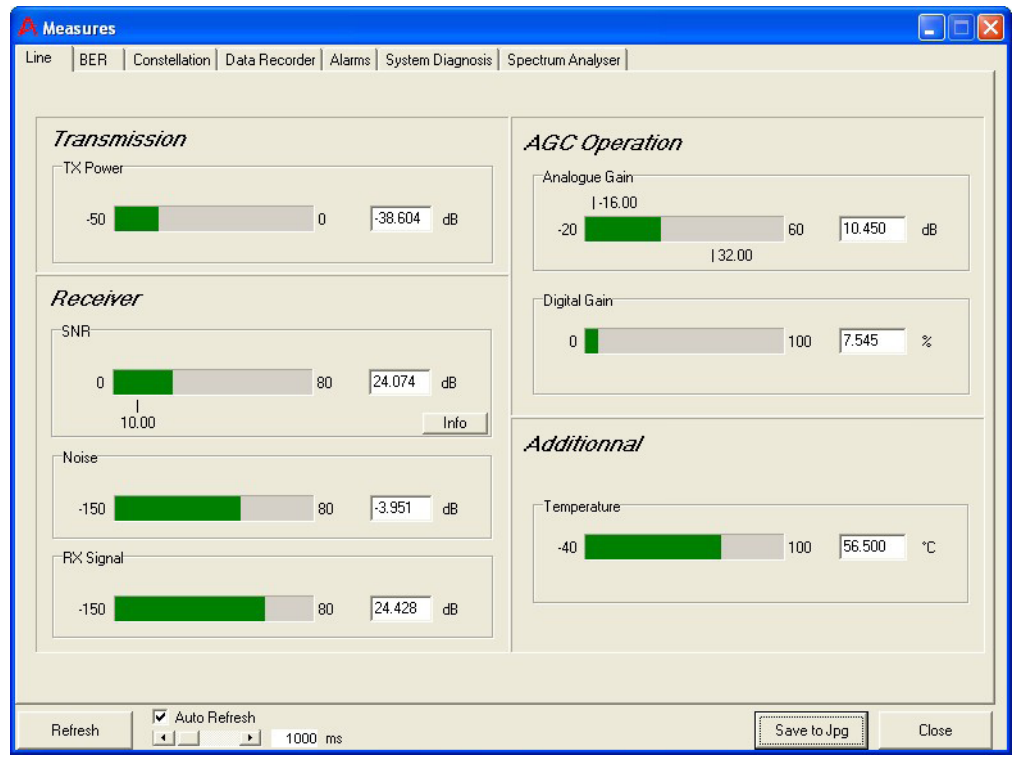

Figure 7. Active HV line results.

Figure 7 shows the initial condition of $\mathrm{HV}$ transmission line which indicates the high noise of $-3.951 \mathrm{~dB}$ and analog line gain is $10.45 \mathrm{~dB}$. There are certain effects of atmospheric conditions on the $\mathrm{HV}$ line, as in Figure 7 the temperature is approximately $56.5 \dot{\mathrm{C}}$ due to which the noise increases in the line. In order to get the desired results DPLC will be configured by setting its parameters.

\section{DISCUSSION AND/OR CONCLUSIONS}

During the experimental work and measurements, it was concluded that there are certain noise problems in the HV line between from Jamshoro to Karachi. Thus, DPLC was designed and configured to take the initial condition line spectrum. 


\subsection{TUNING AND CONFIGURATION OF DPLC FOR INITIAL LINE CONDITION}

To reduce the initial line condition noise, DPLG was tuned as shown in Figure 8.

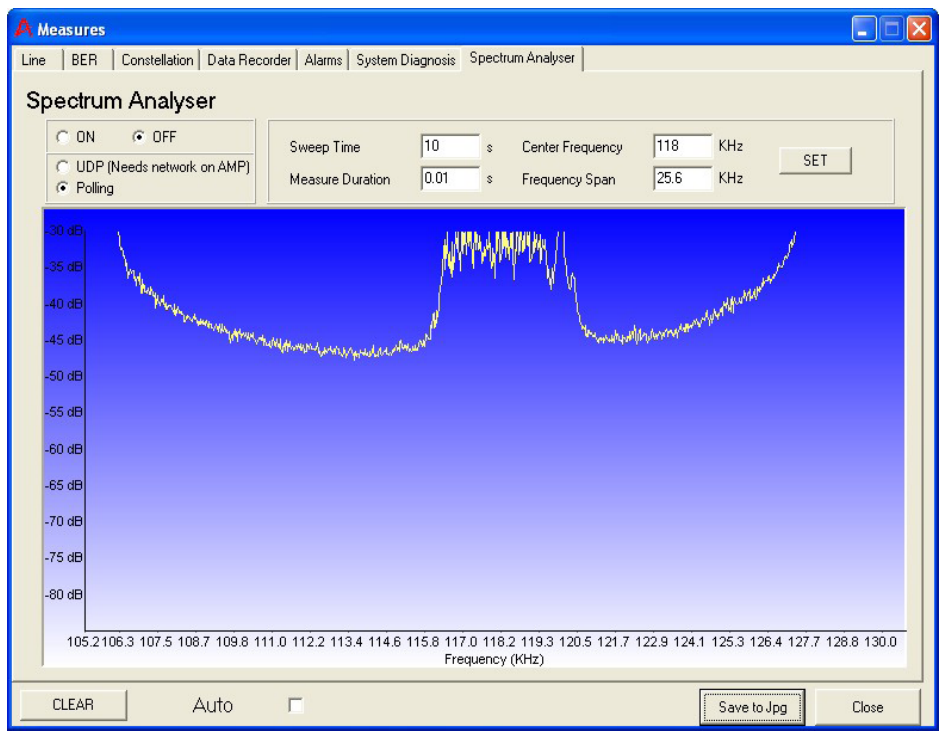

Figure 8. Low noise in Rx band after DPLC tuning.

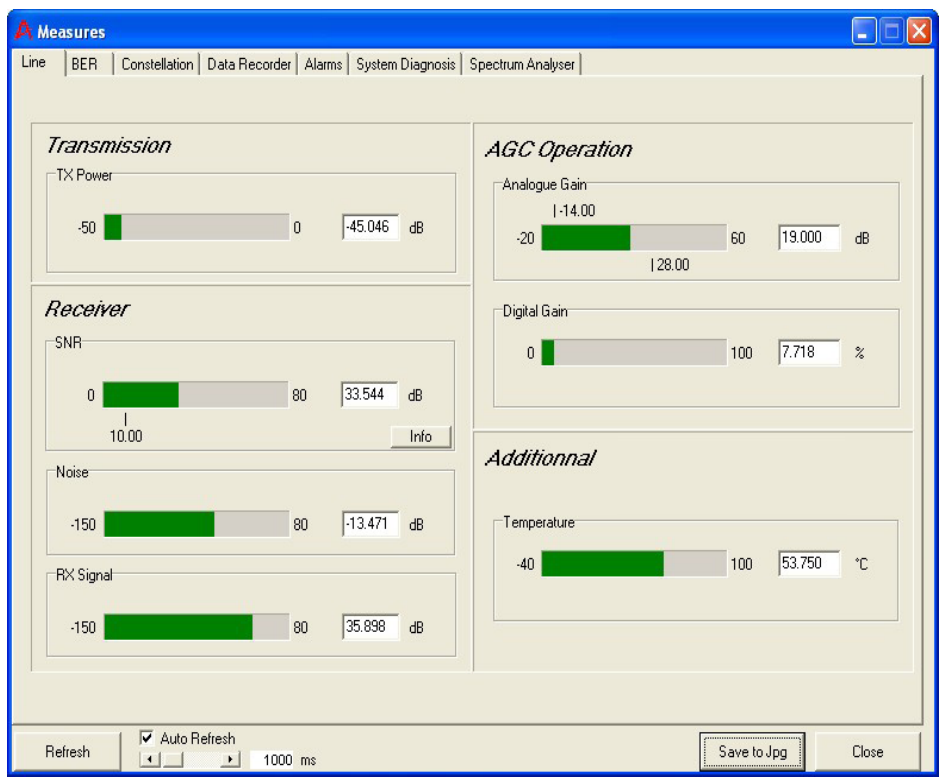

Figure 9. Reduced Noise Measurement Window. 
From Figure 8, it can be observed that in $\mathrm{Rx}$ band from $116 \mathrm{kHZ}$ to $124 \mathrm{kHZ}$ the spectrum is much better as compared to Figure 6. The noise measurement window is shown in Figure 9, where the noise level is decreased from $-3.951 \mathrm{~dB}$ to $-13.4 \mathrm{~dB}$ due to which the AGC is also improved. On this line, the data transmission can be observed in terms of BER as shown in Figure 10.

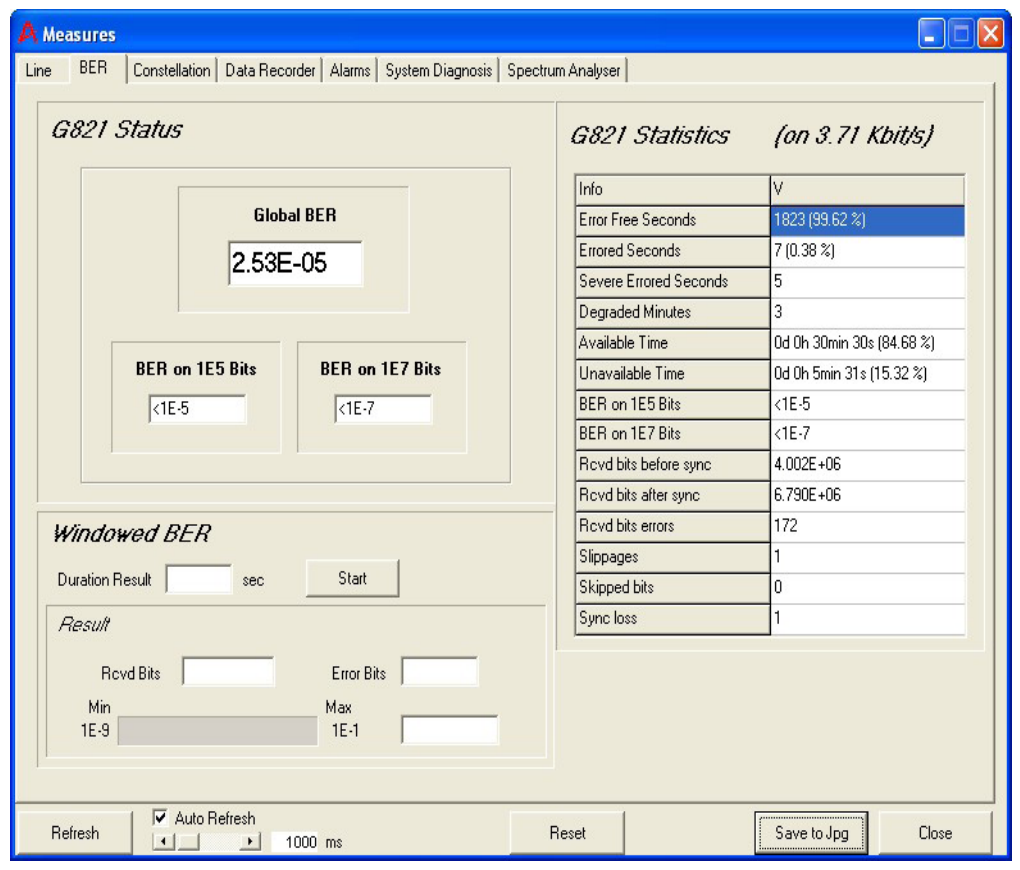

Figure 10. Improved BER.

When DPLC was used for data transmission as shown Figure 10, it confirms an excellent performance in terms of BER that is $99.6 \%$ error free during the $30 \mathrm{~min}$ running time.

\section{ACKNOWLEDGMENTS}

Authors are highly grateful to Mehran University of Engineering and Technology, Jamshoro, Pakistan, for the necessary support, technical laboratory facilities and comfortable research environment. 


\section{REFERENCES}

Acakpovi, A., Mohammed, H., Nwulu, N., Fifatin, F. X. N., Nounangnonhou, T. G., \& Abubakar, R. (2019). Evaluation of Noise Effects on Power Line Communication in a Narrow and Wide Band Frequency Spectrum: A Case Study of Electricity Distribution Network of Ghana. In IEEE International Conference on Computing, Computational Modelling and Applications (ICCMA), 27-276. doi: https:// doi.org/10.1109/ICAMA.2019.00012

Arora, S., Thomas, M. S., \& Jain, M. (2019). Designing Coupling Circuits for Communication of High-Frequency Signals over Power Lines. In Advances in System Optimization and Control, 47-63. Springer, Singapore. doi: https://doi. org/10.1007/978-981-13-0665-5_5

Cortés, J. A., \& Idiago, J. M. (2019). Smart Metering Systems Based on Power Line Communications. In Smart Grids and Their Communication Systems, 121-170. Springer, Singapore. doi: https://doi.org/10.1007/978-981-13-1768-2_4

Halepoto, I. A., Kumar, W., Memon, T. D., \& Ismaili, I. A. (2013). Quantifying the Effect of Lookup Table Size and Coefficients Complexity for Non-Linearity Compensation in Power Amplifiers. Sindh University Research Journal (Science Series), 45(2), 447-452. Retrieved from: https://www.academia.edu/9011941/ Quantifying_the_effect_of_Look_up_Table_Size_and_Coefficients_ Complexity_for_Non-Linearity_Compensation_in_Power_Amplifiers

Ndjiongue, A. R., \& Ferreira, H. G. (2019). Power line communications (PLC) technology: More than 20 years of intense research. Transactions on Emerging Telecommunications Technologies, 30(7), e3575. doi: https://doi.org/10.1002/ett.3575

Pavlidou, N., Vinck, A. H., Yazdani, J., \& Honary, B. (2003). Power line communications: state of the art and future trends. IEEE Communications magazine, 41(4), 34-40. doi: https://doi.org/10.1109/MCOM.2003.1193972

Sagar, N. (2011). Powerline Communications Systems: Overview and Analysis (Doctoral dissertation, Rutgers University-Graduate School-New Brunswick). 
Waseer, T. A., Halepoto, I. A., \& Joyo, M. A. (2014). Quantifying the Q-factor and minimizing BER in 32-channel DWDM system design using EDFA and RAMAN amplifiers. Mehran University Research fournal of Engineering and Technology, 33(1), 1-8. Retrieved from: https://www.ingentaconnect.com/content/doaj/02547821/20 14/00000033/00000001/art00001 
Edición Especial Special Issue Noviembre 2019

DOI: http://dx.doi.org/10.17993/3ctecno.2019.specialissue3.167-183 


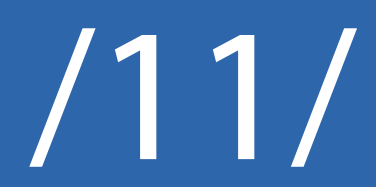




\title{
ACHIEVING HIGH INPUT POWER FACTOR FOR DCM BUCK PFC CONVERTER BY VARIABLE DUTY-CYCLE CONTROL
}

\author{
A. Hakeem Memon \\ IICT, Mehran UET, Jamshoro. \\ E-mail: hakeem.memon@faculty.muet.edu.pk \\ M. Osama Nizamani \\ IICT, Mehran UET, Jamshoro. \\ E-mail: osama12el118@gmail.com \\ Anwar A. Memon \\ IICT, Mehran UET, Jamshoro. \\ E-mail: anwar.memon@faculty.muet.edu.pk \\ Zubair A. Memon \\ IICT, Mehran UET, Jamshoro. \\ E-mail: zubair.memon@faculty.muet.edu.pk \\ Amir M. Soomro \\ IICT, Mehran UET, Jamshoro. \\ E-mail: amir.soomro@faculty.muet.edu.pk
}

Recepción: 31/07/2019 Aceptación: 20/09/2019 Publicación: 06/11/2019

\section{Citación sugerida:}

Memon, A.H., Nizamani, M.O., Memon, A.A., Memon, Z.A. y Soomro, A.M. (2019). Achieving high input power factor for DCM Buck PFG converter by variable Duty-Cycle Control. 3C Tecnología. Glosas de innovación aplicadas a la pyme. Edición Especial, Noviembre 2019, 185-199. doi: http://dx.doi.org/10.17993/3ctecno.2019.specialissue3.185-199

\section{Suggested citation:}

Memon, A.H., Nizamani, M.O., Memon, A.A., Memon, Z.A. \& Soomro, A.M. (2019). Achieving high input power factor for DCM Buck PFG converter by variable Duty-Cycle Control. 3C Tecnología. Glosas de innovación aplicadas a la pyme. Speciaal Issue, November 2019, 185-199. doi: http://dx.doi.org/10.17993/3ctecno.2019.specialissue3.185-199 


\section{ABSTRACT}

Buck power factor correction (PFG) converter is widely used for a broad range of AC/DC applications because of its many advantages However, the traditional discontinuous conduction mode (DCM) buck power factor correction converter (PFC) operates on constant duty-cycle control (CDCC) scheme, due to which its input power factor $(\mathrm{PF})$ is low. For improving PF near to unity, a variable-duty-cycle control (VDCC) method has been proposed. Fitting duty-cycle method is also introduced to make circuit implementation easier. For verifying the validity of proposed technique, the simulation results are carried out.

\section{KEYWORDS}

Variable duty-cycle control (VDCC), Constant duty-cycle control (CDCC), Discontinuous conduction mode (DCM), Power factor correction (PFG). 


\section{INTRODUCTION}

For achieving high power factor (PF) and low total harmonic distortion (THD), power factor correction (PFC) converters are normally used in most of ac-dc power conversion applications. PFC converters may be divided into active and passive types. Active PFC converters have more advantages as compared to passive ones in terms of high PF and small size (Memon, Yao, Chen, Guo, \& Hu, 2017). Various types of topologies and control schemes are available to implement the active PFC techniques. Amongst them, buck PFC converter is a good choice especially for a broad range of ac/dc applications due to its several advantages like high efficiency, cost reduction, low output voltage, and life time improvement. In literature, many researchers (Memon et al., 2017-2019) have introduced buck PFC converter as a preregulator. The buck ac-dc converter can overcome the disadvantages of the universal input condition. On the other hand, if this converter works in hard switching mode, switching losses will be higher especially at high input voltage that deteriorates the advantages of buck converter (Chiang \& Chen, 2009). The problem of hard switching mode can be overcome by operating it in critical conduction mode (CRM) or discontinuous conduction mode (DCM), which can provide zero voltage switching (ZVS) and reduce reverse recovery losses in diode (Yang, Wu, Zhang, \& Qian, 2010).

For modifying the performance of traditional buck converter, various researches have proposed various techniques and control schemes.

Endo, Yamashita, and Sugiura (1992) have introduced a high PF buck converter. Lee, Wang, and Hui (1997) have discussed modeling, analysis, and applications of buck converter in discontinuous input voltage mode operation. Huber, Gang, and Jovanovic (2010) have presented the performance evaluation on a clamped-current buck PFC converter. Jang and Jovanović (2011) have introduced a bridgeless buck PFC converter that substantially improves the efficiency at low line. Wu et al. (2011) have presented soft switched buck PFC converter operating with constant on-time control. Lamar, Fernandez, Arias, Hernando, and Sebastian (2012) have presented a tappedinductor high-brightness light-emitting diode (HB-LED) AC/DG driver operating in boundary conduction mode (BCM) for replacing incandescent bulb lamps. Wu et 
al. (2012) have put forward variable on-time control strategy to enhance the PF of buck converter. Xie, Zhao, Zheng, and Liu (2013) have proposed a new topology to enhance the PF. Yao et al., (2017) have proposed an injecting third harmonic method to realize high PF. Memon et al. (2017) have proposed a variable control scheme for integrated buck-flyback converter to enhance input PF.

In this paper, a variable duty-cycle control (VDCG) strategy is introduced for discontinuous conduction mode (DGM) buck converter to realize high input $\mathrm{PF}$.

The analysis of the operating principle of buck converter is discussed with traditional control (CDCG) scheme in Section 2. The VDGC is put forward in Section 3 to attain high PF. In Section 4, simulation results are discussed, and the conclusion is given in Section 5.

\section{OPERATION ANALYSIS OF DCM BUCK PFC CONVERTER}

The figure 1 illustrates the schematic diagram of a DCM buck PFC converter.

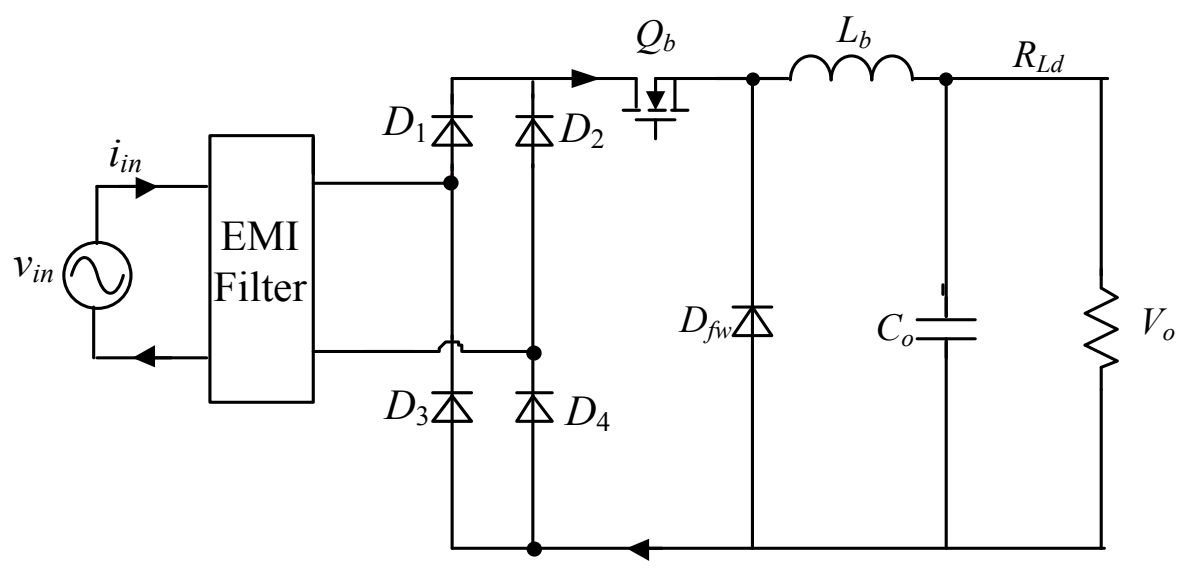

Figure 1. Schematic diagram of a DCM buck PFC converter.

The instantaneous and rectified input voltage during half line cycle can be given as:

$$
v_{i n}=v_{a}=V_{m} \sin \theta
$$


Whereas $V_{m}$ represent the input voltage amplitude, $\theta$ represent the input voltage angular frequency.

In switching cycle, peak current of inductor $i_{L b-p k}$ is:

$$
i_{L b_{-} p k}=\frac{V_{m} \sin \theta-V_{o}}{L_{b}} D_{y} T_{s}
$$

According to volt-second balance in the inductor:

$$
\left(V_{m} \sin \theta-V_{o}\right) D_{y} T_{s}=V_{o} D_{R} T_{s}
$$

Whereas $D_{y}$ represents duty-cycle, and $T_{s}$ represents switching cycle, $V_{o}$ represents voltage output and $D_{R}$ represents duty-cycle during turn off time of switch.

Re arranging Eq. no (3) we get:

$$
D_{R}=\frac{v_{g}-V_{o}}{V_{o}} D_{y}=\frac{V_{m} \sin \theta-V_{o}}{V_{o}} D_{y}
$$

The average value of inductor current is:

$$
i_{Q_{-} a v}=\frac{1}{2} i_{L b_{-} p k} D_{y}=\frac{\left(V_{m} \sin \theta-V_{o}\right) D_{y}^{2}}{2 L_{b} f_{s}}
$$

The input current of the buck converter can be expressed as:

$$
i_{\text {in }}= \begin{cases}\frac{\left(V_{m} \sin \theta-V_{o}\right) D_{y}{ }^{2}}{2 L_{b} f_{s}} & \theta_{0}<\theta<\pi-\theta_{0} \\ 0 & 0 \leq \theta<\theta_{0} \& \pi-\theta_{0}<\theta \leq \pi\end{cases}
$$

where $\theta 0=\arcsin \mathrm{Vo} / \mathrm{Vm}$ and Dy is constant.

The average input power with constant duty-cycle control (CDCG) is given as:

$$
P_{\text {in }}=\frac{1}{T_{\text {line }} / 2} \int_{0}^{T_{\text {tine }} / 2} v_{\text {in }} i_{\text {in }} d t=\frac{V_{m} D_{y}^{2}}{2 \pi L_{b} f_{s}} \int_{\theta_{0}}^{\pi-\theta_{o}} \sin \theta\left(\mathrm{V}_{m} \sin \theta-V_{o}\right) d \theta
$$


Whereas, $T_{\text {line }}$ represent the line cycle.

Suppose the converter's efficiency is $100 \%$, at that moment the duty-cycle is:

$$
D_{y}=\sqrt{\frac{2 \pi L_{b} f_{s} P_{o}}{V_{m} \int_{\theta_{0}}^{\pi-\theta_{o}} \sin \theta\left(\mathrm{V}_{m} \sin \theta-V_{o}\right) d \theta}}
$$

The input power factor $(\mathrm{PF})$ can be calculated from (6-8)

$$
P F=\frac{P_{i n}}{\frac{1}{\sqrt{2}} V_{m} I_{\text {in_rms }}}=\frac{\sqrt{\frac{2}{\pi}} \int_{\theta_{0}}^{\pi-\theta_{o}} \sin \theta(a \sin \theta-1) d \theta}{\sqrt{\int_{\theta_{0}}^{\pi-\theta_{o}}(a \sin \theta-1)^{2} d \theta}}
$$

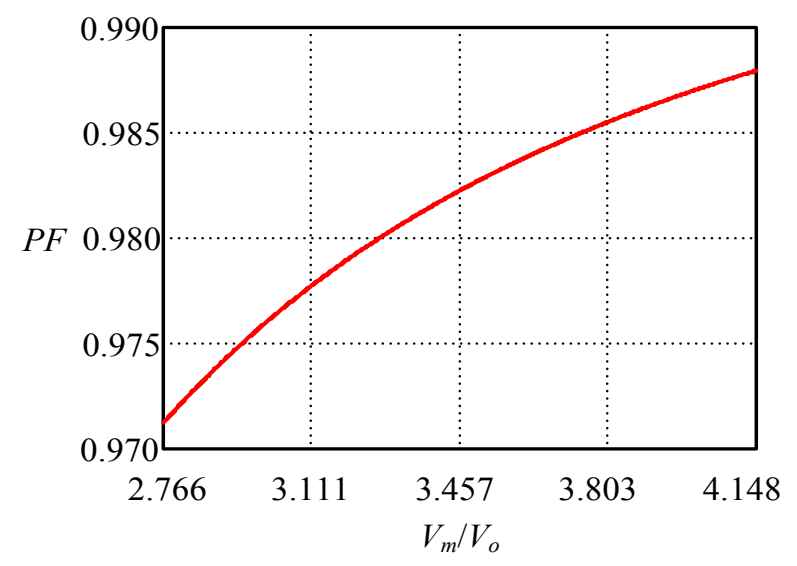

Figure 2. Relationship among the input PF and $a$.

Where $a=V_{m} / V_{o}$

The curve of input PF is drawn from (9) and is depicted in Figure 2. It can be observed that when the $V_{m} / V_{o}$ is greater, the $\mathrm{PF}$ is higher. When input voltage is 176VAC and output voltage is $90 \mathrm{~V}$, at that time PF is 0.971 . So, for achieving high $\mathrm{PF}$, a new control technique must be proposed. 


\section{PROPOSE CONTROL SCHEME TO ENHANCE INPUT PF}

\subsection{VARIABLE DUTY-CYCLE CONTROL TO REALIZE HIGH PF}

For realizing unity PF, the variation rule for duty-cycle must be:

$$
D_{y}=\sqrt{\frac{D_{0} V_{m} \sin \theta}{V_{m} \sin \theta-V_{o}}} \quad \theta_{0}<\theta<\pi-\theta_{0}
$$

where $D_{o}$ is a co-efficient,

By replacing the value of $D_{y}$ in (7), we get:

$$
i_{\text {in }}=\frac{D_{0} V_{m} \sin \theta}{2 L_{b} f_{s}} \quad \theta_{0}<\theta<\pi-\theta_{0}
$$

Eq. (11) shows that input current is pure sinusoidal and hence unity PF can be realized.

The average input power with proposed control scheme is given as:

$$
P_{i n}=\frac{1}{\pi} \int_{\theta_{0}}^{\pi-\theta_{0}} V_{m} \sin \theta \cdot \frac{D_{0} T_{s} V_{m} \sin \theta}{2 L_{b}} d \theta=P_{o}
$$

From (13), $D_{0}$ can be obtained as:

$$
D_{0}=\frac{4 \pi L_{b} f_{s} P_{o}}{\mathrm{~V}_{m}^{2}\left(\pi-2 \theta_{0}+\sin 2 \theta_{0}\right)}
$$

By putting (13) into (11) leads to:

$$
D_{y}= \begin{cases}\sqrt{\frac{4 \pi P_{o} L_{b} f_{s} \sin \theta}{\mathrm{V}_{m}\left(\pi-2 \theta_{0}+\sin 2 \theta_{0}\right)\left(V_{m} \sin \theta-V_{o}\right)}} & \theta_{0}<\theta<\pi-\theta_{0} \\ 0 & 0 \leq \theta<\theta_{0} \& \pi-\theta_{0}<\theta \leq \pi\end{cases}
$$




\subsection{THE FITTING DUTY CYCLE}

The subtraction, multiplication, division and root operation included, the dutycycle expressed in (14) is complicated to be realized by analog circuit. Therefore, it is necessary to simplify (14).

Defining $a=V_{m} / V_{v}, y=\sin \theta,(14)$ can be rewritten as:

$$
D_{y}= \begin{cases}\sqrt{\frac{D_{0} a y}{\mathrm{a} y-1}} & \theta_{0}<\theta<\pi-\theta_{0} \\ 0 & 0 \leq \theta<\theta_{0} \& \pi-\theta_{0}<\theta \leq \pi\end{cases}
$$

Based on Taylor's series:

$$
f(x)=f\left(x_{0}\right)+f^{\prime}\left(x_{0}\right)\left(x-x_{0}\right)+\frac{1}{2 !} f^{\prime \prime}\left(x_{0}\right)\left(x-x_{0}\right)^{2}+\cdots+\frac{1}{n !} f^{(n)}\left(x_{0}\right)\left(x-x_{0}\right)^{n}+\cdots
$$

Eq. (16) can be expressed as:

$$
D_{y}=\sqrt{a D_{0}} \cdot\left[\sqrt{\frac{y_{0}}{a y_{0}-1}}-\frac{1}{2} \cdot\left(\frac{y_{0}}{a y_{0}-1}\right)^{-\frac{1}{2}} \cdot \frac{1}{\left(a y_{0}-1\right)^{2}} \cdot\left(y-y_{0}\right)+\ldots\right] \quad \theta_{0}<\theta<\pi-\theta_{0}
$$

Keeping first derivative element, (17) is approximated as:

$$
D_{y_{-} f t}=\sqrt{\frac{D_{0} a y_{0}}{a y_{0}-1}} \cdot \frac{2 a y_{0}-1}{2\left(a y_{0}-1\right)} \cdot\left(1-\frac{y}{2 a y_{0}^{2}-y_{0}}\right)=D_{1} \cdot\left(1-\frac{y}{2 a y_{0}^{2}-y_{0}}\right) \quad \theta_{0}<\theta<\pi-\theta_{0}
$$

where $D_{1}=\sqrt{\frac{D_{0} a y_{0}}{a y_{0}-1}} \cdot \frac{2 a y_{0}-1}{2\left(a y_{0}-1\right)}$.

Substitution (18) into (6) and (7), respectively, leads to:

$$
i_{i n_{-} V D C C}=\frac{V_{o} D_{1}^{2}(a \sin \theta-1)\left(1-\frac{y}{2 a y_{0}^{2}-y_{0}}\right)^{2}}{2 L_{b} f_{s}} \quad \theta_{0}<\theta<\pi-\theta_{0}
$$




$$
P_{i n_{-} V D C C}=P_{o}=\frac{V_{m} V_{o} D_{1}^{2}}{2 \pi L_{b} f_{s}} \int_{\theta_{0}}^{\pi-\theta_{o}} \sin \theta(a \sin \theta-1)\left(1-\frac{\sin \theta}{2 a y_{0}{ }^{2}-y_{0}}\right)^{2} d \theta
$$

From (19) and (20), input PF is calculated as:

$$
P F=\frac{P_{\text {in }}}{V_{\text {in_rms }} I_{\text {in_rms }}}=\frac{\int_{\theta_{0}}^{\pi-\theta_{o}} \sqrt{\frac{2}{\pi}} \sin \theta\left(2 a y_{0}{ }^{2}-y_{0}-\sin \theta\right)^{2}(a \sin \theta-1) d \theta}{\sqrt{\int_{\theta_{0}}^{\pi-\theta_{0}}\left(2 a y_{0}{ }^{2}-y_{0}-\sin \theta\right)^{4}(a \sin \theta-1)^{2} d \theta}}
$$

If the input voltage range is 176-220 VAC, output voltage is $90 \mathrm{~V}$. Replacing $a=$ $176 \sqrt{2} / 90$ into (21), and differentiating (21) with $y_{0}$, also setting it to zero, $y_{0}=0.75$ is obtain.

Substituting $y_{0}=0.75$ into (19), the expression of duty cycle is:

$$
D_{y_{-} f t}=D_{1} \cdot \frac{1.125 V_{m}-0.75 V_{o}-V_{o} \sin \theta}{1.125 V_{m}-0.75 V_{o}} \quad \theta_{0}<\theta<\pi-\theta_{0}
$$

\subsection{IMPLEMENTATION OF THE CONTROL CIRCUIT}

The implementation of control circuit is presented in Figure 3. The dotted line represents the variable-duty cycle scheme. The rectified input voltage is detected by a voltage divider of $R_{1}$ and $R_{2}$, and $v_{g f}=k_{v g} V_{m} \sin \theta$, however $k_{v g}$ is the voltage sensor gain. $R_{3}, D_{1}, C_{1}$ and $R_{4}$ are the circuit to gain the peak value of the rectified input voltage, i.e., $v_{B}=k_{v g} \cdot \mathrm{V}_{m}$. The output voltage is detected by a voltage divider compared of $R_{5}$ and $R_{6}$, the voltage sensor gain is deliberately set to $0.353 k_{v g}$, so $v_{\text {of }}$ $=0.353 k_{v g} V_{o}$. Letting $R_{g}=1.125 R_{7}$, then, and letting $R_{g}=R_{10}=R_{13}=R_{14}$, and $R_{12}=2.833$ $R_{11}$, then, the error amplifier can be regulated by output voltage, the output voltage can sense through a voltage divider of $R_{15}$ and $R_{16}$ related to reference voltage $V_{o g}$. $R_{17}$ and $C_{2}$ form the compensation system. $v_{x}, v_{z}$ and $v_{E A}$ are sent to the multiplier, and $v_{P}=v_{E A} \frac{0.75 V_{o}-1.125 V_{m}+V_{o} \sin \theta}{0.75 V_{o}-1.125 V_{m}} . v_{P}$ is given to comparator and compared with the sawtooth carrier, and the comparators output calculate the required duty-cycle, 
which changes as in eq. no (22), whereas $v_{E A}$ and sawtooth amplitude calculate the coefficient $D_{l}$.

Through VDCG, the DCM buck PFC converter output voltage is operated at $90 \mathrm{~V}$. Now $V_{\text {og }}$ is set by $5 \mathrm{~V}$, then the output voltage sense gain can set at $1 / 18$, i.e., $R_{15}=$ $17 R_{16}$.

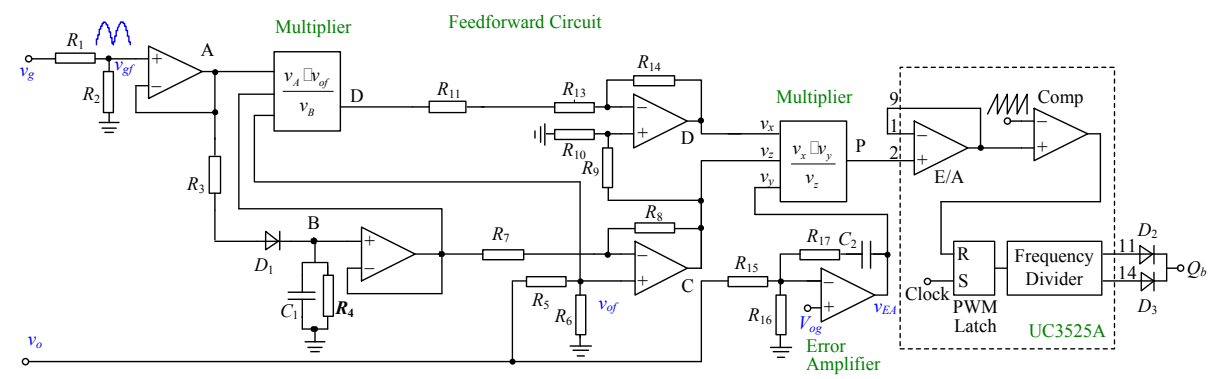

Figure 3. Control circuit of the variable duty-cycle control.

\section{ADVANTAGES OF PROPOSED CONTROL SCHEME}

\subsection{IMPROVEMENT OF THE INPUT PF}

From (9) and (21), the input PF curves with a CDCG and a VDCG are drawn and are depicted in Figure 4. It can be observed that VDCG improve the input PF. Once the input voltage is set at $176 \mathrm{VAC}$, the $\mathrm{PF}$ is improved from 0.971 to 0.983 .

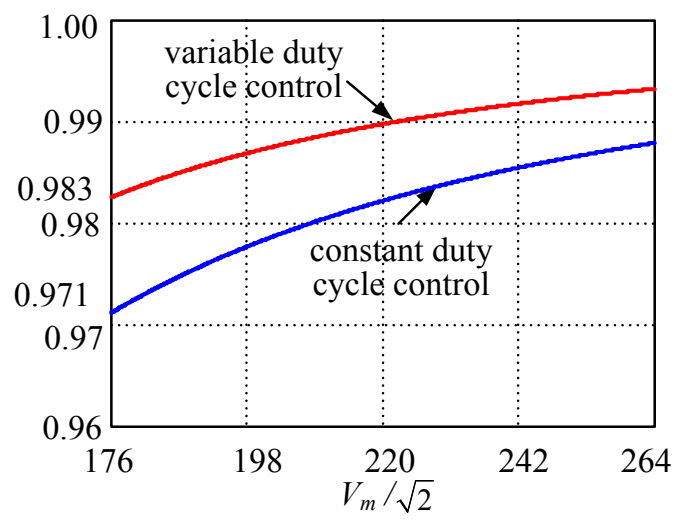

Figure 4. Comparison of the input between proposed and traditional control. 


\section{SIMULATION VERIFICATION}

For verifying the effectiveness of VDCG strategy, simulations are carried out. The input voltage range is $176-264 \mathrm{VAC}$, and the output is $90 \mathrm{~V}$. For ensuring the current to be in DCM, UC3525A IC is used. All the components in the circuit are selected as idea.

Figure 5 and Figure 6 show the simulation waveforms of $v_{i n}, i_{i n}$, and $v_{o}$ of buck converter with CDCG and VDCG at 176VAC inputs, respectively. It can be observed that the input current with VDCG is more sinusoidal as compared with CDCG.

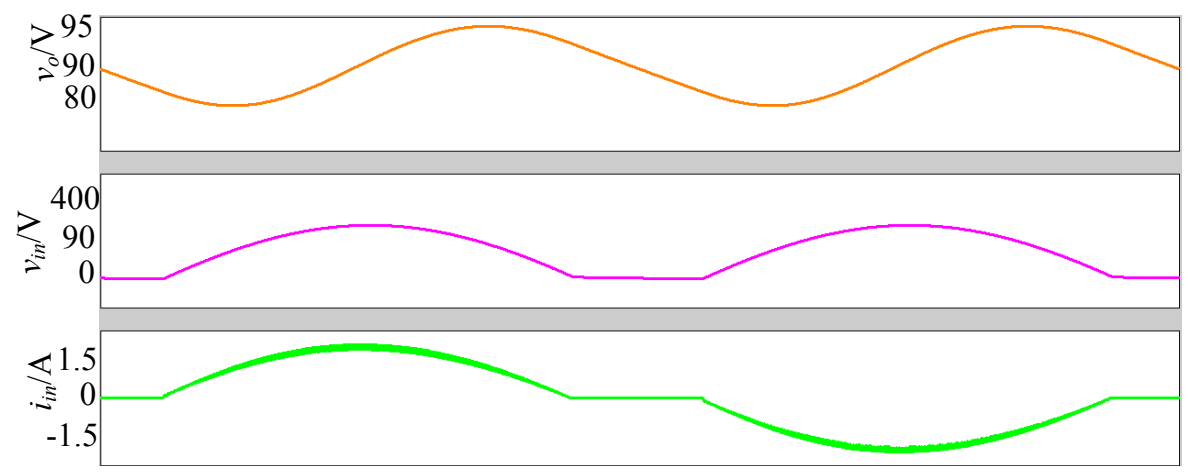

Figure 5. $v_{\text {in }}, \mathrm{i}_{\text {in }}$, and $v_{o}$ with CDCC.

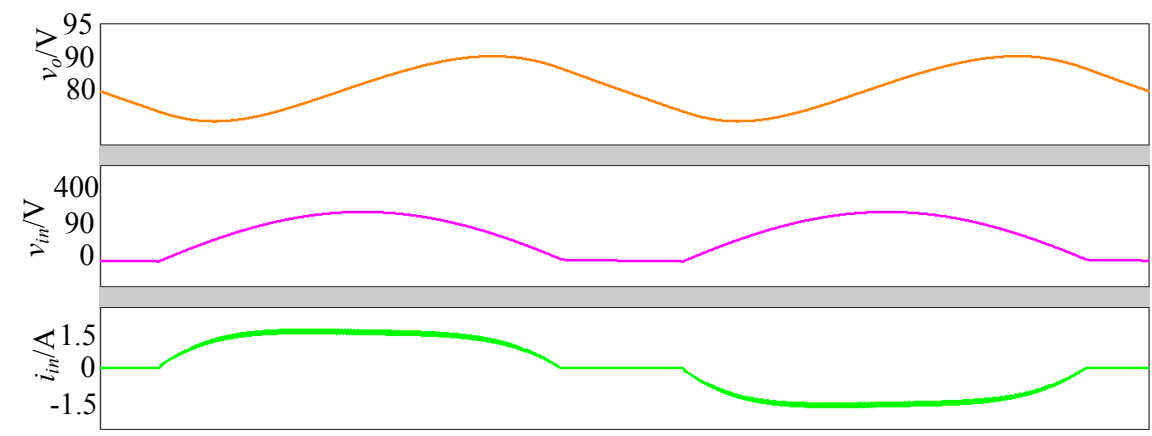

Figure 6. $v_{\text {in }}, \mathrm{i}_{\text {in }}$, and $v_{o}$ with VDCC. 


\section{CONCLUSION}

With constant duty-cycle control, the input power factor of discontinues conduction mode buck converter is low especially at low input voltages. A variable duty-cycle control scheme and the implementation circuit are proposed to realize high power factor. Simulation results are presented for the verification of the analysis.

\section{REFERENCES}

Ghiang, G. Y., \& Ghen, G. L. (2009). Zero-voltage-switching control for a PWM buck converter under DCM/CGM boundary. IEEE Transactions on Power Electronics, 24(9), 2120-2126. doi: https://doi.org/10.1109/TPEL.2009.2021186

Endo, H., Yamashita, T., \& Sugiura, T. (1992). A high-power-factor buck converter. PESC '92 Record. 23rd Annual IEEE Power Electronics Specialists Conference, 1071-1076 vol. 2. doi: https://doi.org/10.1109/PESG.1992.254766

Huber, L., Gang, L., \& Jovanovic, M. M. (2010). Design-oriented analysis and performance evaluation of buck PFG front end. IEEE Transactions on Power Electronics, 25(1), 85-94. doi: https://doi.org/10.1109/TPEL.2009.2024667

Jang, Y., \& Jovanović, M. M. (2011). Bridgeless high-power-factor buck converter. IEEE Transactions on Power Electronics, 26(2), 602-61 1. doi: https:/ / doi.org/10.1109/ TPEL.2010.2068060

Lamar, D. G., Fernandez, M., Arias, M., Hernando, M. M., \& Sebastian, J. (2012). Tapped-inductor buck HB-LED AC-DG driver operating in boundary conduction mode for replacing incandescent bulb lamps. IEEE Transactions on Power Electronics, 27(10), 4329-4337. doi: https:/ / doi.org/10.1109/TPEL.2012.2190756

Lee, Y. S., Wang, S.J., \& Hui, S. Y. R. (1997). Modeling, analysis, and application of buck converters in discontinuous-input-voltage mode operation. IEEE Transactions on Power Electronics, 12(2), 350-360. doi: https:/ / doi.org/10.1109/63.558762 
Memon, A. H., \& Yao, K. (2018). UPG strategy and implementation for buckbuck/boost PF correction converter. IET Power Electronics, 11(5), 884-894. doi: https://doi.org/10.1049/iet-pel.2016.0919

Memon, A. H., Baloach, M. H., Sahito, A. A., Soomro, A. M., \& Memon, Z. A. (2018). Achieving High Input PF for CRM Buck-Buck/Boost PFC Converter. IEEE Access, 6, 79082-79093. doi: https://doi.org/10.1109/ ACGESS.2018.2879804

Memon, A. H., Memon, Z. A., Shaikh, N. N., Sahito, A. A., \& Hashmani, A. A. (2019). Boundary conduction mode modified buck converter with low input current total harmonic distortion. Indian Fournal of Science and Technology, 12(17). doi: https://doi.org/10.17485/ijst/2019/v12i17/144613

Memon, A. H., Pathan, A. A., Kumar, M., Sahito, A. A J., \& Memon, Z. A. (2019). Integrated buck-flyback converter with simple structure and unity power factor. Indian Fournal of Science and Technology, 12(17). doi: https://doi.org/10.17485/ ijst/2019/v12i17/144612

Memon, A. H., Shaikh, N. N., Kumar, M., \& Memon, Z. A. (2019). Buck-buck/ boost converter with high input power factor and non-floating output voltage. International Fournal of Computer Science and Network Security, 19(4), 299-304. Retrieved from: http://paper.ijcsns.org/07_book/201904/20190442.pdf

Memon, A. H., Yao, K., Ghen, Q., Guo, J., \& Hu, W. (2017). Variable-on-time control to achieve high input power factor for a CRM-integrated buck-flyback PFG converter. IEEE Transactions on Power Electronics, 32(7), 5312-5322. doi: https://doi.org/10.1109/TPEL.2016.2608839

Wu, X., Yang, J., Zhang,J., \& Qian, Z. (2011). Variable on-time (VOT)-controlled critical conduction mode buck PFC converter for high-input AC/DG HB-LED lighting applications. IEEE Transactions on power Electronics, 27(1 1), 4530-4539. doi: https://doi.org/10.1109/TPEL.2011.2169812 
Wu, X., Yang, J., Zhang, J., \& Xu, M. (2011). Design considerations of softswitched buck PFG converter with constant on-time (COT) control. IEEE Transactions on Power Electronics, 26(11), 3144-3152. https://doi.org/10.1109/ TPEL.2011.2145391

Xie, X., Zhao, G., Zheng, L., \& Liu, S. (2012). An improved buck PFC converter with high power factor. IEEE Transactions on power electronics, 28(5), 2277-2284. doi: https://doi.org/10.1109/TPEL.2012.2214060

Yang, J., Wu, X., Zhang, J., \& Qian, Z. (2010). Design considerations of a high efficiency ZVS buck AC-DC converter with constant on-time control. Intelec 2010, 1-5. doi: https://doi.org/10.1109/intlec.2010.5525720

Yao, K., Zhou, X., Yang, F., Yang, S., Cao, G., \& Mao, G. (2017). Optimum third current harmonic during nondead zone and its control implementation to improve PF for DCM buck PFG converter. IEEE Transactions on Power Electronics, 32(12), 9238-9248. doi: https://doi.org/10.1109/TPEL.2017.2657883 
Edición Especial Special Issue Noviembre 2019

DOI: http://dx.doi.org/10.17993/3ctecno.2019.specialissue3.185-199 


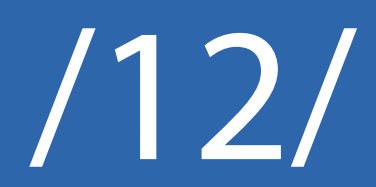




\title{
CRITICAL CONDUCTION MODE BUCK- BUCK/BOOST CONVERTER WITH HIGH EFFICIENCY
}

\author{
A. Hakeem Memon \\ IICT, Mehran UET, Jamshoro. \\ E-mail: hakeem.memon@faculty.muet.edu.pk \\ Mansoor A. Memon \\ IICT, Mehran UET, Jamshoro. \\ E-mail: mansoorjali74@gmail.com \\ Zubair A. Memon \\ IICT, Mehran UET, Jamshoro. \\ E-mail: zubair.memon@faculty.muet.edu.pk \\ Ashfaque A. Hashmani \\ IICT, Mehran UET, Jamshoro. \\ E-mail: ashfaque.hashmani@faculty.muet.edu.pk
}

Recepción: 31/07/2019 Aceptación: 23/09/2019 Publicación: 06/11/2019

\section{Citación sugerida:}

Memon, A.H., Memon, M.A., Memon, Z.A. y Hashmani, A.A. (2019). Critical Conduction Mode Buck-Buck/Boost Converter with High Efficiency. 3C Tecnología. Glosas de innovación aplicadas a la pyme. Edición Especial, Noviembre 2019, 201-219. doi: http:/ / dx.doi.org/10.17993/3ctecno.2019.specialissue3.201-219

\section{Suggested citation:}

Memon, A.H., Memon, M.A., Memon, Z.A. \& Hashmani, A.A. (2019). Critical Conduction Mode Buck-Buck/Boost Converter with High Efficiency. 3C Tecnologia. Glosas de innovación aplicadas a la pyme. Speciaal Issue, November 2019, 201-219. doi: http:// dx.doi.org/10.17993/3ctecno.2019.specialissue3.201-219 


\section{ABSTRACT}

The buck converter is commonly utilized in various low power applications because of maintaining high efficiency at universal input voltage and many other advantages. On the other hand, when the on-time is constant, the conduction and switching losses are more because the rms and peak value of the inductor current is more. So, the efficiency is low. For improving efficiency, a variable on-time control (VOTC) strategy has been proposed for buck-buck/boost topology with simple structure, minimum losses and less component cost. For verifying the validity of proposed technique, the simulation results are carried out by using saber simulator.

\section{KEYWORDS}

Variable on-time control (VOTC), Constant on-time control (COTG), Critical conduction mode (CRM), Buck/boost converter, Buck converter. 


\section{INTRODUCTION}

Power electronic technology is used in various types of modern equipment's which has made our life easier, simpler and luxurious. However, this technology is based on semiconductor devices, due to which the shape of average input current is distorted. The distorted current has various drawbacks such as voltage distortion, increased power loss and noise etc. So the industries have built various standards such as IEC61000-3-2 limit and IEEE 519 (International Electrotechnical Commission, 2014; Langella, Testa, \& Alii, 2014). Therefore, various types of power factor correction $(\mathrm{PFC})$ converters are put forward in the literature to improve the shape of distorted current (García, Cobos, Prieto, Alou, \& Uceda, 2003; Singh, Singh, Chandra, \& Al-Haddad, 2011) and the buck converter is one of them. Its advantages include protection against short circuit, high efficiency at universal input voltage, low output voltage, and less voltage stress on the switch. However, its input power factor $(\mathrm{PF})$ is low due to dead zone in the average input current. Integrating buck converter with buck/boost converters can solve the dead zone problem and enhance its PF. On the other hand, when the on-time is constant, the conduction and switching losses are more because the rms and peak value of the inductor current is more. So, the efficiency is low. Thus, it is necessary for the integrated buck-buck/boost converter to propose the technique which can attain high efficiency with simple structure and minimum losses.

For modifying the performance of traditional buck converter, various researches have proposed various control strategies and topologies.

Spiazzi and Buso (2000) have proposed a new solution for eliminating the dead zone in the buck converter. It has proposed flyback converter to work with buck converter during dead zone period. Alonso, Dalla Costa, and Ordiz (2008) have implemented integrated buck-flyback converter (IBFC) for low cost, high PF and fast output voltage regulations. Dalla Costa, Alonso, Miranda, García, and Lamar (2008) have presented IBFC for single-stage electronic ballast with high PF. Gacio, Alonso, Calleja, Garcia, and Rico-Secades (2011) have presented offline IBFC for high brightness light emitting diode (HB-LED) to cover the application of LED in street light. Xie, Zhao, 
$\mathrm{Lu}$, and Liu (2013) have put forward a new topology which combines buck and flyback converter to eliminate the dead zone. Zhang, Zhao, Zhao, and $\mathrm{Wu}$ (2017) have proposed a topology which combines buck converter with flyback converter. Yao et al. (2017) have proposed an injecting third harmonic method to realize high PF. Memon, Yao, Chen, Guo, and $\mathrm{Hu}$ (2017) have put forward a control scheme is put forward to improve input PF. Memon et al., (2019) have introduced flyback converter to work with buck converter for boundary conduction mode (BCM) buck converter to enhance PF. Memon et al., (2019) have introduced buck/boost converter to work with buck converter for BCM buck converter to enhance PF. Memon et al., (2019) have proposed control technique to improve input PF of integrated buckflyback converter.

In this paper, a variable on-time control (VOTC) strategy is introduced for critical conduction mode (CRM) buck-buck/boost converter to attain high efficiency with simple structure, minimum losses and minimum component cost. It requires one bridge rectifier (BR) and for passing the low frequency current to reduce losses, EMI filter is located after BR.

The analysis of the operating principle of buck converter is discussed with traditional control (COTC) scheme in Section 2. The VOTC is put forward in Section 3 to attain efficiency. In Section 4, power loss analysis is given. Section 5 deals with simulation results and the conclusion are given in Section 6.

\section{OPERATION ANALYSIS OF CRM BUCK-BUCK/BOOST PFC CONVERTER}

Figure 1 illustrates the schematic diagram of buck-buck/boost converter. The major components in the power circuit are: Bridge rectifier $(B R)$; an inductor $(L)$; a buck $\operatorname{switch}\left(Q_{b}\right)$; a buck/boost switch $\left(Q_{b / b}\right)$, a freewheeling diode $\left(D_{f \omega}\right)$, an output capacitor (Co), etc.

The operating time period between buck and buck/boost converter depends on the boundary voltage, whose value is little more as compared to output voltage $(V)$. The 
converter operates in buck/boost mode as the input voltage $\left(v_{i n}\right)$ is lower than $V_{o}$ and in buck mode for opposite condition (i-e $v_{i n}>V_{\text {boundary }}$ ). Thus, the operating principle of the converter can be divided into two cases.

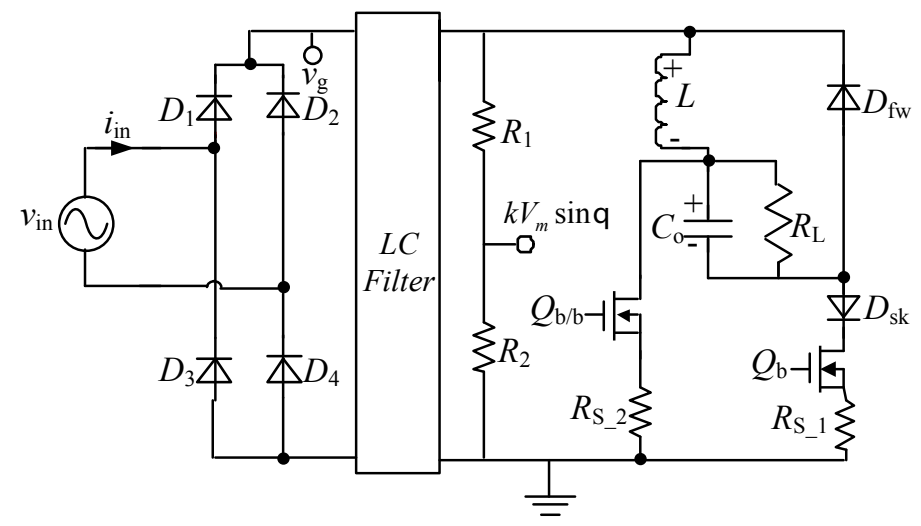

Figure 1. Schematic diagram of a CRM buck-buck/boost PFC converter.

The instantaneous and rectified input voltage during half line cycle can be given as:

$$
v_{i n}=v_{a}=V_{m} \sin \theta
$$

Whereas $V_{m}$ represent the input voltage amplitude, $\theta$ represent the input voltage angular frequency.

The converter is operating in buck mode when $v_{\text {in }}>V_{\text {boundary }}$. The buck/boost switch $\left(Q_{b / b}\right)$ remain closed while buck switch $\left(Q_{b}\right)$ keeps switching.

The maximum value of the inductor current and the average value of input current when the buck switch is conducting is respectively given as:

$$
\begin{gathered}
i_{L_{-} p k 1}=\frac{V_{m} \sin \theta-V_{o}}{L} t_{o n} \\
i_{i n_{-} b}=\frac{V_{o}\left(V_{m} \sin \theta-V_{o}\right) t_{o n}}{2 L V_{m} \sin \theta}
\end{gathered}
$$

The converter is operating in buck/boost mode when $v_{\text {in }}<V_{\text {boundary. }}$. The buck/boost switch $\left(Q_{b / b}\right)$ keeps switching, while buck switch $\left(Q_{b}\right)$ remains closed. 
Same as (2-3), the peak value of primary inductor and the average value of input current when $Q_{b / b}$ is switching is expressed respectively as:

$$
\begin{gathered}
i_{L_{-} p k_{2}}=\frac{t_{o n} V_{m} \sin \theta}{L} \\
i_{\text {in_blb }}=\frac{V_{o} V_{m} \sin \theta}{2 L\left(V_{m} \sin \theta+V_{o}\right)} t_{o n}
\end{gathered}
$$

By combining (3) and (5), the input current of the converter with traditional control is expressed as:

$$
i_{\text {in_trad }}= \begin{cases}\left(\frac{V_{m} \sin \theta}{V_{m} \sin \theta+V_{o}}\right) \frac{t_{o n} V_{o}}{2 L} & Q_{b} \text { Conducting } \\ \left(\frac{V_{m} \sin \theta-V_{o}}{V_{m} \sin \theta}\right) \frac{t_{o n} V_{o}}{2 L} & Q_{b / b} \text { Conducting }\end{cases}
$$

The conducting angle of $Q_{b}$ and $Q_{b / b}$ respectively given as:

$$
\begin{gathered}
\theta_{0} \leq \theta \leq \pi-\theta_{0} \\
0 \leq \theta<\theta_{0} \& \pi-\theta_{0}<\theta \leq \pi
\end{gathered}
$$

Where $\theta_{0}$ is the boundary angle between buck and buck/boost converter and is equal to arcsin $V_{\text {boundary }} / V_{m}$.

The average input power can be calculated from (1) and (6) as:

$$
P_{\text {in }- \text { trad }}=\frac{t_{o n}}{2 \pi L}\left[2 \int_{0}^{\theta_{0}} \frac{V_{o}\left(V_{m} \sin \theta\right)^{2}}{\left(V_{m} \sin \theta+V_{o}\right)} d \theta+\int_{\theta_{0}}^{\pi-\theta_{0}} V_{o}\left(V_{m} \sin \theta-V_{o}\right) d \theta\right]
$$

From (9), $t_{\text {on }}$ can be determined by assuming the efficiency to be $100 \%$ as: 


$$
t_{\text {on }}=\frac{2 \pi P_{o} L}{2 \int_{0}^{\theta_{0}} \frac{V_{o}\left(V_{m} \sin \theta\right)^{2}}{\left(V_{m} \sin \theta+V_{o}\right)} d \theta+\int_{\theta_{0}}^{\pi-\theta_{0}} V_{o}\left(V_{m} \sin \theta-V_{o}\right) d \theta}
$$

\section{PROPOSED CONTROL SCHEME TO ATTAIN HIGH EFFICIENCY}

For high efficiency and power balance, the input current must be:

$$
i_{\text {in_VOTC }}=\frac{2 P_{o} \sin \theta}{V_{m}}
$$

By combining (6) and (11), we can get required on-time of both switches as:

$$
\begin{gathered}
t_{o n_{-} b}=u_{o n} \frac{\left(V_{m} \sin \theta\right)^{2}}{V_{o}\left(V_{m} \sin \theta-V_{o}\right)} \\
t_{o n_{-} b / b}=u_{o n}\left(\frac{V_{m} \sin \theta+V_{o}}{V_{o}}\right)
\end{gathered}
$$

The input power with put forward control scheme is given as:

$$
P_{\text {in_prop }}=\frac{1}{\pi} \int_{0}^{\pi} v_{i n} i_{i n} d \theta=\frac{u_{o n} V_{m}^{2}}{4 L}
$$

The value of $u_{o n}$ is got as by assuming efficiency to be $100 \%$

$$
u_{\text {on }}=\frac{4 P_{o} L}{V_{m}^{2}}
$$

\section{POWER LOSS ANALYSIS}

The rms current of the on time period, i.e., the rms current of switch $Q_{b}$ and $Q_{b / b}$ can be got as: 


$$
\begin{aligned}
& I_{r m s\left(Q_{b / b} o n\right)}=\frac{\sqrt{2 \int_{0}^{\theta_{0}} i_{L(p k 2)}^{2}(\theta) D d \theta}}{3 \pi} \\
& I_{r m s\left(Q_{\left.b_{-} o n\right)}\right.}=\sqrt{\frac{\int_{\theta_{0}}^{\pi-\theta_{0}} i_{L(p k 1)}^{2}(\theta) D d \theta}{3 \pi}}
\end{aligned}
$$

The rms current of the off time period can be determined as:

$$
\begin{aligned}
& I_{r m s\left(Q_{b l b} \text { off }\right)}=\frac{\sqrt{2 \int_{0}^{\theta_{0}} i_{L(p k 2)}^{2}(\theta)[1-D] d \theta}}{3 \pi} \\
& I_{r m s\left(Q_{\left.b_{-} o f f\right)}\right.}=\sqrt{\frac{\int_{\theta_{0}}^{\pi-\theta_{0}} i_{L(p k 1)}^{2}(\theta)[1-D] d \theta}{3 \pi}}
\end{aligned}
$$

Where:

$$
D= \begin{cases}\frac{V_{o}}{V_{m} \sin \theta} & Q_{b} \text { Conducting } \\ \frac{V_{o}}{V_{o}+V_{m} \sin \theta} & Q_{b / b} \text { Conducting }\end{cases}
$$

While $Q_{b}$ and $Q_{b / b}$ is on and off, the current flows through the winding of the inductor, whose rms current is:

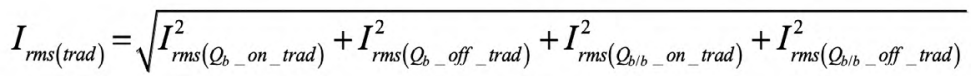

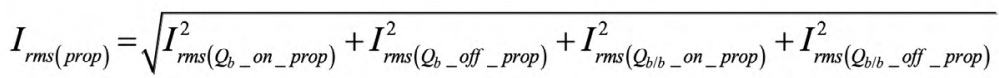

\subsection{BRIDGE RECTIFIER LOSS}

Bridge rectifier loss can be calculated by using below formula:

$$
P_{\text {con_bridge(trad) }}=2 V_{F D} I_{\text {in_avg(trad })}
$$




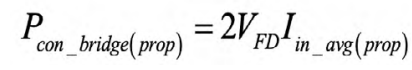

KBL10 is adopted as the rectifier bridge, whose forward voltage drop $V_{F D}$ is $0.9 \mathrm{~V}$. The input current with traditional and proposed control scheme is given as:

$$
I_{\text {in_avg(trad })}=\frac{1}{\pi}\left[\begin{array}{c}
\int_{0}^{\theta_{0}} \frac{\frac{\pi P_{o} V_{o} V_{m} \sin \theta}{\left(V_{o}+V_{m} \sin \theta\right)}}{\int_{0}^{\theta_{0}} \frac{V_{o}\left(V_{m} \sin \theta\right)^{2}}{\left(V_{o}+V_{m} \sin \theta\right)} d \theta+\int_{\theta_{0}}^{\pi / 2} V_{o}\left(V_{m} \sin \theta-V_{o}\right) d \theta} d \theta \\
+\int_{\theta_{0}}^{\pi-\theta_{0}} \frac{V_{o}\left(\frac{V_{m} \sin \theta-V_{o}}{V_{m} \sin \theta}\right)}{\int_{0}^{\theta_{0}} \frac{V_{o}\left(V_{m} \sin \theta\right)^{2}}{\left(V_{o}+V_{m} \sin \theta\right)} d \theta+\int_{\theta_{0}}^{\pi / 2} V_{o}\left(V_{m} \sin \theta-V_{o}\right) d \theta} d \theta \\
I_{\text {in_avg(prop) }}=\frac{4 P_{o}}{\pi V_{m}}
\end{array}\right]
$$

\subsection{CONDUCTION LOSSES OF THE SWITCHES}

The losses due to conduction of switches can be got as:

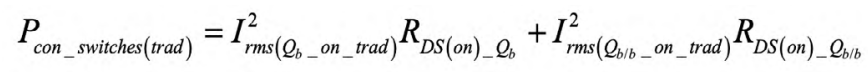

$$
\begin{aligned}
& P_{\text {con_s switches(prop })}=I_{r m s\left(Q_{b_{-}} \text {on_prop }\right)}^{2} R_{D S(\text { on })_{-} Q_{b}}+I_{r m s\left(Q_{b l b} \text { on_prop }\right)}^{2} R_{D S(o n) \_Q_{b l b}}
\end{aligned}
$$

$R_{D S(O n)}$ for the switch $20 \mathrm{~N} 60 \mathrm{C} 3$ is $0.19 \Omega$ and the value is found from datasheet.

\subsection{TURN OFF LOSSES OF THE SWITCHES}

The turn off losses of buck and buck/boost switch with traditional and proposed control scheme can be determined as:

$$
P_{\text {off_switches(trad })}=\frac{1}{\pi}\left[\begin{array}{l}
2 \int_{0}^{\theta_{0}} \frac{i_{L(p k 2, \text { trad })}\left(V_{m} \sin \theta+V_{o}\right)}{2} t_{f 1} f_{s(\text { trad })} d \theta \\
+\int_{\theta_{0}}^{\pi-\theta_{0}} \frac{i_{L(p k 1, \text { trad })}(\theta) V_{m} \sin \theta}{2} t_{f 2} f_{s(\text { trad })} d \theta
\end{array}\right]
$$




$$
P_{\text {off_switches (prop) })}=\frac{1}{\pi}\left[\begin{array}{l}
2 \int_{0}^{\theta_{0}} \frac{i_{L(p k 2, p r o p)}\left(V_{m} \sin \theta+V_{o}\right)}{2} t_{f 1} f_{s(p r o p)} d \theta \\
+\int_{\theta_{0}}^{\pi-\theta_{0}} \frac{i_{L(p k 1, p r o p)}(\theta) V_{m} \sin \theta}{2} t_{f 2} f_{s(p r o p)} d \theta
\end{array}\right]
$$

The value of turn off fall time can be got from the datasheet which is $12 \mathrm{~ns}$ for CMOS 20N60C.

The peak value of inductor current with both control scheme is given as:

$$
\begin{aligned}
& i_{p k(\text { trad })}=\left\{\begin{array}{l}
i_{L(p k 2, \text { trad })}=\frac{\pi P_{o} V_{m} \sin \theta}{\int_{0}^{\theta_{0}} \frac{V_{o}\left(V_{m} \sin \theta\right)^{2}}{\left(V_{o}+V_{m} \sin \theta\right)} d \theta+\int_{\theta_{0}}^{\pi / 2} V_{o}\left(V_{m} \sin \theta-V_{o}\right) d \theta} \\
i_{L(p k 1, \text { rrad })}=\frac{\pi P_{o}\left(V_{m} \sin \theta-V_{o}\right)}{\int_{0}^{\theta_{0}} \frac{V_{o}\left(V_{m} \sin \theta\right)^{2}}{\left(V_{o}+V_{m} \sin \theta\right)} d \theta+\int_{\theta_{0}}^{\pi / 2} V_{o}\left(V_{m} \sin \theta-V_{o}\right) d \theta}
\end{array}\right. \\
& i_{p k(p r o p)}=\left\{\begin{array}{l}
i_{L(p k 2, p r o p)}=\frac{4 P_{o} \sin \theta\left(V_{o}+V_{m} \sin \theta\right)}{V_{o} V_{m}} \\
i_{L(p k 1, p r o p)}=\frac{4 P_{o} \sin ^{2} \theta}{V_{o}}
\end{array}\right.
\end{aligned}
$$

The switching frequency in case of both control schemes can be found as:

$$
i_{p k(\text { trad })}=\left\{\begin{array}{l}
i_{L(p k 2, \text { trad })}=\frac{\pi P_{o} V_{m} \sin \theta}{\int_{0}^{\theta_{0}} \frac{V_{o}\left(V_{m} \sin \theta\right)^{2}}{\left(V_{o}+V_{m} \sin \theta\right)} d \theta+\int_{\theta_{0}}^{\pi / 2} V_{o}\left(V_{m} \sin \theta-V_{o}\right) d \theta} \\
i_{L(p k 1, \text { rrad })}=\frac{\pi P_{o}\left(V_{m} \sin \theta-V_{o}\right)}{\int_{0}^{\theta_{0}} \frac{V_{o}\left(V_{m} \sin \theta\right)^{2}}{\left(V_{o}+V_{m} \sin \theta\right)} d \theta+\int_{\theta_{0}}^{\pi / 2} V_{o}\left(V_{m} \sin \theta-V_{o}\right) d \theta} \\
i_{p k(\text { prop })}=\left\{\begin{array}{l}
i_{L(p k 2, p r o p)}=\frac{4 P_{o} \sin \theta\left(V_{o}+V_{m} \sin \theta\right)}{V_{o} V_{m}} \\
i_{L(p k 1, p r o p)}=\frac{4 P_{o} \sin ^{2} \theta}{V_{o}}
\end{array}\right.
\end{array}\right.
$$


The value of switching frequency is got as:

$$
f_{s(\text { trad })}=\left\{\begin{array}{l}
\frac{V_{o}\left(\int_{0}^{\theta_{0}} \frac{V_{o}\left(V_{m} \sin \theta\right)^{2}}{V_{o}+V_{m} \sin \theta} d \theta+\int_{\theta_{0}}^{\pi / 2} V_{o}\left(V_{m} \sin \theta-V_{o}\right) d \theta\right)}{\pi P_{o} L\left(V_{o}+V_{m} \sin \theta\right)} \\
\frac{V_{o}\left(\int_{0}^{\theta_{0}} \frac{V_{o}\left(V_{m} \sin \theta\right)^{2}}{V_{o}+V_{m} \sin \theta} d \theta+\int_{\theta_{0}}^{\pi / 2} V_{o}\left(V_{m} \sin \theta-V_{o}\right) d \theta\right)}{\pi P_{o} L V_{m} \sin \theta} \\
f_{s(\text { prop })}=\left\{\begin{array}{l}
\frac{V_{m}^{2} V_{o}}{2 P_{o} L\left(V_{o}+V_{m} \sin \theta\right)^{2}} \\
\frac{V_{o}^{2}\left(V_{m} \sin \theta-V_{o}\right)}{4 P_{o} L V_{m} \sin ^{3} \theta}
\end{array}\right.
\end{array}\right.
$$

\subsection{COPPER LOSS OF THE INDUCTOR}

The inductor's copper loss with traditional and proposed control scheme is given as:

$$
\begin{aligned}
& P_{\text {copper }(\text { prop })}=I_{r m s(\text { prop })}^{2} R_{\text {copper }} \\
& P_{\text {copper }(\text { trad })}=I_{r m s(\text { trad })}^{2} R_{\text {copper }}
\end{aligned}
$$

The equivalent resistance of the copper wire is $0.156 \Omega$.

\subsection{CORE LOSS OF THE INDUCTOR}

The inductor's core loss with traditional and proposed control scheme is calculated as:

$$
P_{\text {core }(\text { trad })}=\left[\int_{0}^{\pi} C_{m} f_{s(\text { trad })}^{x} B_{a c(t r a d)}^{y}\left(c t_{0}-c t_{1} T_{a}-c t_{2} T_{a}^{2}\right) d \theta\right] \frac{10^{3} V_{e}}{\pi}
$$




$$
\begin{gathered}
B_{a c(\text { trad })}=\left\{\begin{array}{l}
\frac{L i_{L(p k 2, \text { trad })}}{2 N A_{e}} \\
\frac{L i_{L(p k 1, \text { rrad })}}{2 N A_{e}}
\end{array}\right. \\
P_{\text {core (prop })}=\left[\int_{0}^{\pi} C_{m} f_{s(\text { prop })}{ }^{x} B_{a c(\text { prop })}{ }^{y}\left(c t_{0}-c t_{1} T_{a}-c t_{2} T_{a}^{2}\right) d \theta\right] \frac{10^{3} V_{e}}{\pi} \\
B_{a c(\text { prop })}=\left\{\begin{array}{l}
\frac{L i_{L(p k 2, p r o p)}}{2 N A_{e}} \\
\frac{L i_{L(p k 1, p r o p)}}{2 N A_{e}}
\end{array}\right.
\end{gathered}
$$

\subsection{CONDUCTION LOSS OF THE FREEWHEELING DIODE}

The conduction loss caused by freewheeling diode is given as:

$$
\begin{aligned}
& P_{\text {con_freewhelingdiode(trad) })}=\frac{V_{F D_{f w}}}{\pi} \int_{0}^{\pi} \frac{i_{p k(\text { trad })}}{2}[1-D] d \theta \\
& P_{\text {con_freewheelingdiode(prop) }}=\frac{V_{F D_{f w}}}{\pi} \int_{0}^{\pi} \frac{i_{p k(\text { prop })}}{2}[1-D] d \theta
\end{aligned}
$$

The forward voltage drop for freewheeling diode MUR 1560 is 0.67.

\subsection{THE THEORETICAL EFFICIENCY}

The theoretical efficiency in case traditional and proposed control scheme can be calculated by using below formula:

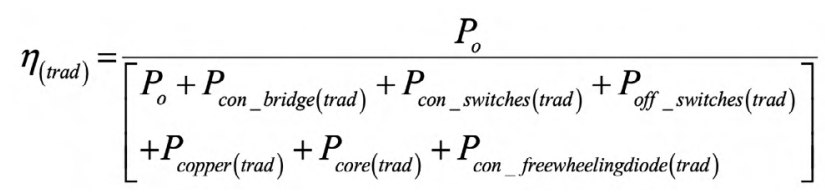




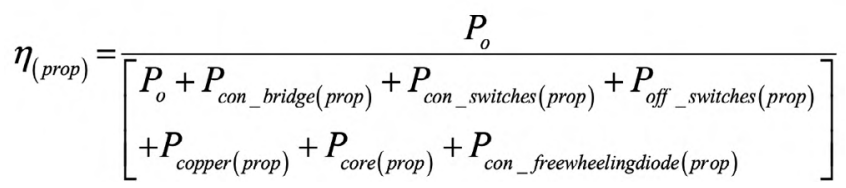

Based on above analysis and parameter of the converter, loss distribution at 90VAC, 220VAC and theoretical efficiency is illustrated in Figure 2-4 respectively. It can be observed that by using proposed control scheme, the overall losses of the converter are reduced, and the efficiency is increased

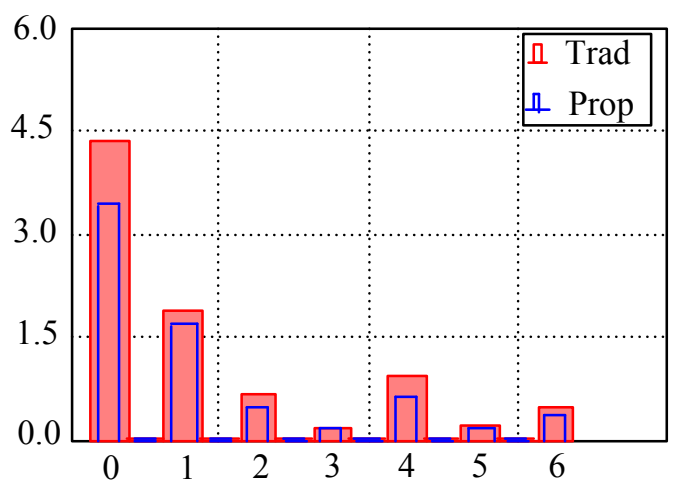

Figure 2. Loss distributions at 90VAC.

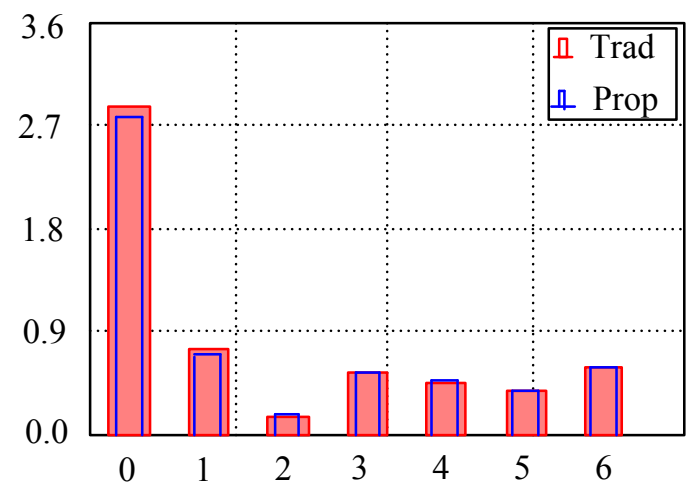

Figure 3. Loss distributions at 220VAC. 


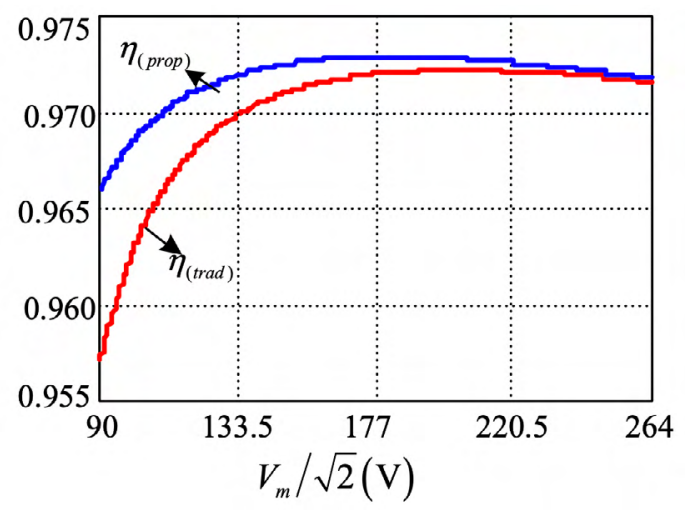

Figure 4. Efficiency at universal input voltage.

\section{SIMULATION VERIFICATION}

For verifying the effectiveness of proposed strategy, simulations are carried out. The input voltage range is $90-264 \mathrm{VAC}$, and the output is $80 \mathrm{~V}$. For ensuring the current to be in CRM, L6561 IC is used. All the components in the circuit are selected as idea.

Figure 5 and Figure 6 show the simulation waveforms of $v_{i n}$ and $i_{i n}$ of the converter with traditional and proposed control scheme at 220VAC inputs, respectively. It can be observed that the input current with proposed control scheme is less in magnitude as compared to current with traditional control strategy. So the overall conduction losses will be less in case of VOTG as compared to COTG.

Figure 7 shows the switches' gate drive signals of the converter, from which in both types of control schemes, the converter operates either in buck mode or in buck/ boost mode depending on the boundary voltage between them

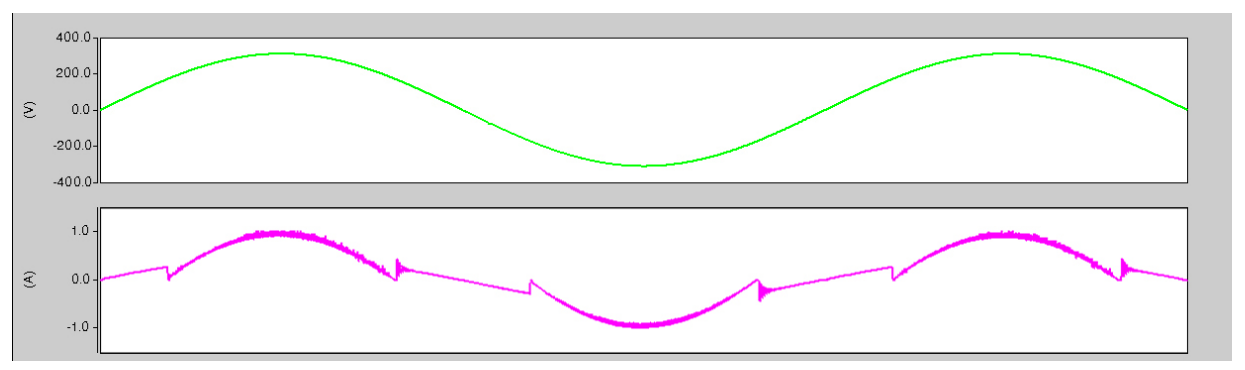

Figure 5. $v_{\text {in }} \& i_{\text {in }}$ with traditional control. 


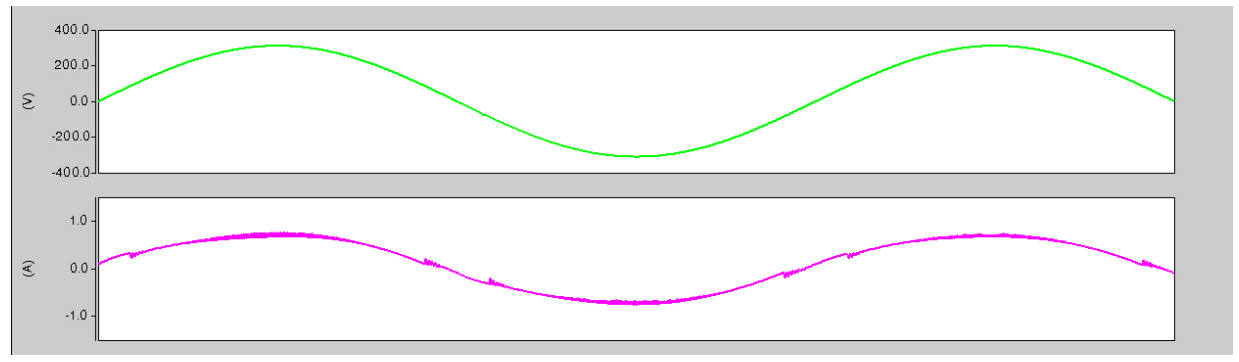

Figure 6. $v_{\text {in }} \& i_{\text {in }}$ with proposed control.

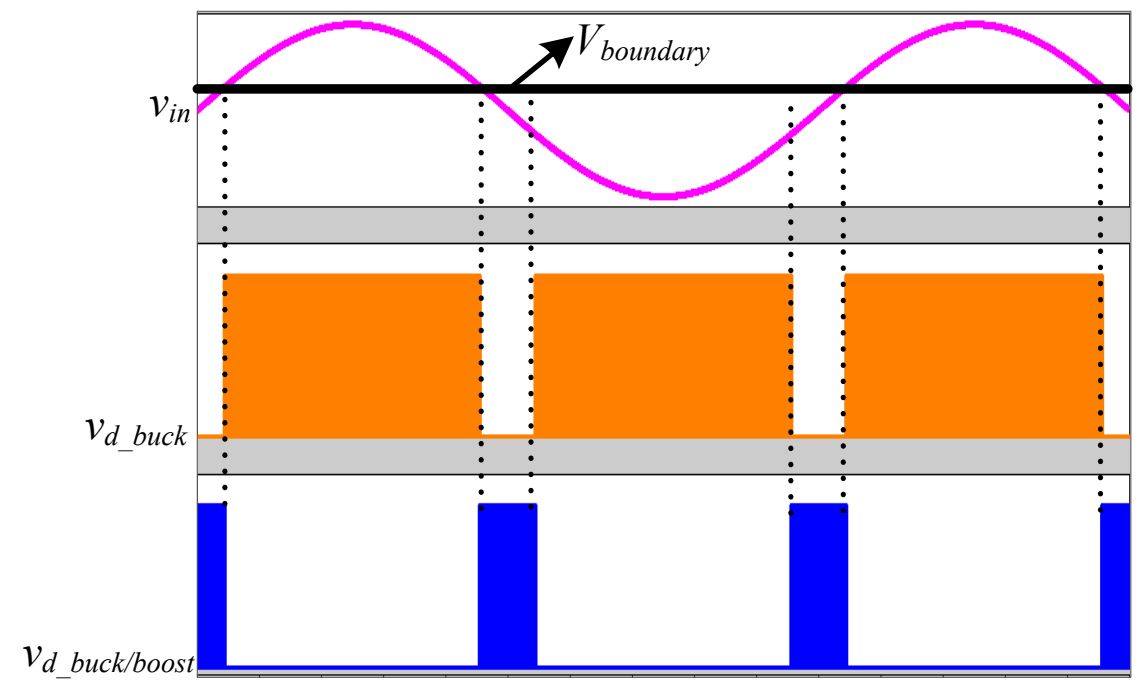

Figure 7. Switches' gate drive signals.

\section{CONCLUSION}

When the on-time is constant for buck-buck/boost converter, the conduction and switching losses are more because the rms and peak value of the inductor current is more. So, the efficiency is low. Thus, in this paper a control scheme is proposed to attain high efficiency with simple structure, minimum losses and minimum component cost. Simulation results are presented for the verification of the analysis. 


\section{REFERENCES}

Alonso, J. M., Dalla Costa, M. A., \& Ordiz, G. (2008). Integrated buck-flyback converter as a high-power-factor off-line power supply. IEEE Transactions on Industrial Electronics, 55(3), 1090-1100. doi: https://doi.org/10.1109/TIE.2007.908530

Dalla Gosta, M. A., Alonso, J. M., Miranda, J. G., García, J., \& Lamar, D. G. (2008). A single-stage high-power-factor electronic ballast based on integrated buck flyback converter to supply metal halide lamps. IEEE Transactions on Industrial Electronics, 55(3), 1112-1122. doi: https://doi.org/10.1109/TIE.2007.909729

Gacio, D., Alonso,J. M., Galleja, A.J., Garcia,J., \& Rico-Secades, M. (2011). A universal-input single-stage high-power-factor power supply for HB-LEDs based on integrated buck-flyback converter. IEEE Transactions on Industrial Electronics, 58(2), 589-599. doi: https://doi.org/10.1109/TIE.2010.2046578

Gacio, D., Alonso, J. M., Garcia, J., Campa, L., Crespo, M. J., \& RicoSecades, M. (2012). PWM series dimming for slow-dynamics HPF LED drivers: The high-frequency approach. IEEE Transactions on Industrial Electronics, 59(4), 1717-1727. doi: https://doi.org/10.1109/TIE.2011.2130503

García, O., Gobos, J. A., Prieto, R., Alou, P., \& Uceda, J. (2003). Single phase power factor correction: A survey. IEEE Transactions on Power Electronics, 18(3), 749755. doi: https://doi.org/10.1109/TPEL.2003.810856

Langella, R., Testa, A., \& Alii, E. (2014). IEEE recommended practice and requirements for harmonic control in electric power systems. In IEEE Std 5192014 (Revision of IEEE Std 519-1992), 1-29. doi: https://doi.org/10.1109/ IEEESTD.2014.6826459

Memon, A. H., Yao, K., Ghen, Q., Guo, J., \& Hu, W. (2017). Variable-on-time control to achieve high input power factor for a CRM-integrated buck-flyback PFG converter. IEEE Transactions on Power Electronics, 32(7), 5312-5322. doi: https://doi.org/10.1109/TPEL.2016.2608839 
Memon, A. H., \& Yao, K. (2018). UPG strategy and implementation for buckbuck/boost PF correction converter. IET Power Electronics, 11(5), 884-894. doi: https://doi.org/10.1049/iet-pel.2016.0919

Memon, A. H., Baloach, M. H., Sahito, A. A., Soomro, A. M., \& Memon, Z. A. (2018). Achieving High Input PF for CRM Buck-Buck/Boost PFC Converter. IEEE Access, 6, 79082-79093. doi: https://doi.org/10.1109/ ACGESS.2018.2879804

Memon, A. H., Pathan, A. A., Kumar, M., Sahito, A. A J., \& Memon, Z. A. (2019). Integrated buck-flyback converter with simple structure and unity power factor. Indian Fournal of Science and Technology, 12(17). doi: https://doi.org/10.17485/ ijst/2019/v12i17/144612

Memon, A. H., Memon, Z. A., Shaikh, N. N., Sahito, A. A., \& Hashmani, A. A. (2019). Boundary conduction mode modified buck converter with low input current total harmonic distortion. Indian Fournal of Science and Technology, 12(17). doi: https://doi.org/10.17485/ijst/2019/v12i17/144613

Memon, A. H., Shaikh, N. N., Kumar, M., \& Memon, Z. A. (2019). Buck-buck/ boost converter with high input power factor and non-floating output voltage. International Fournal of Computer Science and Network Security, 19(4), 299-304. Retrieved from: http://paper.ijcsns.org/07_book/201904/20190442.pdf

Singh, B., Singh, S., Chandra, A., \& Al-Haddad, K. (2011). Comprehensive study of single-phase AC-DC power factor corrected converters with highfrequency isolation. IEEE transactions on Industrial Informatics, 7(4), 540-556. doi: https://doi.org/10.1109/TII.2011.2166798

Spiazzi, G., \& Buso, S. (2000). Power factor pre regulators based on combined buck-flyback topologies. IEEE transactions on Power Electronics, 15(2), 197-204. doi: https://doi.org/10.1109/63.838091

Xie, X., Zhao, G., Lu, Q., \& Liu, S. (2013). A novel integrated buck-flyback nonisolated PFG converter with high power factor. IEEE Transactions on Industrial Electronics, 60(12), 5603-5612. doi: https://doi.org/10.1109/TIE.2012.2232256 
Yao, K., Zhou, X., Yang, F., Yang, S., Cao, C., \& Mao, G. (2017). Optimum third current harmonic during nondead zone and its control implementation to improve PF for DCM buck PFG converter. IEEE Transactions on Power Electronics, 32(12), 9238-9248. doi: https://doi.org/10.1109/TPEL.2017.2657883

Zhang, J., Zhao, G., Zhao, S., \& Wu, X. (2017). A family of single-phase hybrid step-down PFG converters. IEEE Transactions on Power Electronics, 32(7), 52715281. doi: https://doi.org/10.1109/TPEL.2016.2604845

International Electrotechnical Commission. (2014). Part 3-2: Limits-Limits for harmonic current emissions (equipment input current $\leq 16$ A per phase). International Standard IEC, 61000-3-2. 
Edición Especial Special Issue Noviembre 2019

DOI: http://dx.doi.org/10.17993/3ctecno.2019.specialissue3.201-219 


$$
\text { /13/ }
$$




\section{CONDUCTING TRAFFIC SURVEILLANCE FOR MOTOR VEHICLE TAXATION}

Anwar A.Memon

Mehran University of Engineering and Technology.

Jamshoro, Pakistan.

E-mail: anwar.memon@faculty.muet.edu.pk

Arslan R. Memon

Institute of Information \& Communication Technologies, Mehran University of Engineering \& Technology, Jamshoro. Pakistan.

E-mail: arslan.memon27@gmail.com

A. Hakeem Memon

Mehran University of Engineering and Technology.

Jamshoro, Pakistan.

E-mail: hakeem.memon@faculty.muet.edu.pk

Recepción: 01/08/2019 Aceptación: 23/09/2019 Publicación: 06/11/2019

\section{Gitación sugerida:}

Memon, A.A., Memon, A.R. y Memon, A.H. (2019). Conducting traffic surveillance for motor vehicle taxation. $3 C$ Tecnología. Glosas de innovación aplicadas a la pyme. Edición Especial, Noviembre 2019, 221-231. doi: http://dx.doi.org/10.17993/3ctecno.2019. specialissue 3.221-231

\section{Suggested citation:}

Memon, A.A., Memon, A.R. \& Memon, A.H. (2019). Conducting traffic surveillance for motor vehicle taxation. 3C Tecnología. Glosas de innovación aplicadas a la pyme. Speciaal Issue, November 2019, 221-231. doi: http://dx.doi.org/10.17993/3ctecno.2019. specialissue $3.221-231$ 


\section{ABSTRACT}

Excise taxation is the Sind government department that registers the vehicles running across Sind. This department is responsible for collecting the revenue in lieu of Token tax and annual running tax from the vehicles running under the registration number of Sind. The tax payment checking is manual, means every vehicle is stopped for snap checking. Manual verification is very tiring and cumbersome, so that every vehicle could not be checked. In developed countries this all is done through online automatic system. An online portal is introduced by the excise department on which the verification of the vehicle can be done in terms of its bogusness. But this portal and online recovery of annual tax is not concerned for the detecting of the defaulters. This research focuses on the detection of the defaulters. As the date expires the vehicle would be monitored at any toll tax stop after the recognition of the number plate data. An automatic checking method is used for detection. This method uses the technology that is called Automatic vehicle number plate recognition (AVNPR). This tool uses the image processing procedure to read the number plate numbers and characters.

\section{KEYWORDS}

AVNPR, Face recognition, Image processing. 


\section{INTRODUCTION}

As a developing country, Pakistan is in the revolution phase. The data of every resident is not available in any central database so that if any crime occurs the person could not be detected according to his/her background history. In developed countries every person is under observation and their record is available in a centralized database. The payment of taxes and recovery of default tax payers is very difficult task. The vehicle tax is collected by the excise and taxation department. In normal routine, motorists pay their tax by visiting any excise and taxation office or in any authorized bank. The tax payment is very difficult in rural area, where the office or authorized bank is not available. It is very difficult to observe the nonpayment of this tax. The only way of paid or unpaid vehicle is to look onto the wind screen that must have a sticker. Sometimes these stickers are not available in the tax office so only the receipt is issued to the customers. The checking of every vehicle by the police sergeants is a hard job.

This research is the design of an automatic recovery and checking system that will make the process easy and reliable. The motor vehicle tax is collected from the vehicle owners on annual or bi-annual basis. But the collection is not good percentage of the intended collection, because the checking system is very old manual in nature (Yan, 2001; Hontani, \& Koga, 2001). The procedure and design suggested in this document will make it easy and time saving. In this procedure, image of the number plate is captured when the vehicle stands at the toll tax plaza. The number plate numbers and characters are sent to the database of excise and taxation department for online checking. The message is sent to the mobile for the defaulter or clearance. The portal on the site of excise and taxation department Sind government is shown in Figure 1. 


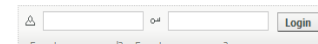

$\begin{array}{cccccc}\text { Home About Taxes Directory Contact us Downloads } & \text { Dearch... }\end{array}$

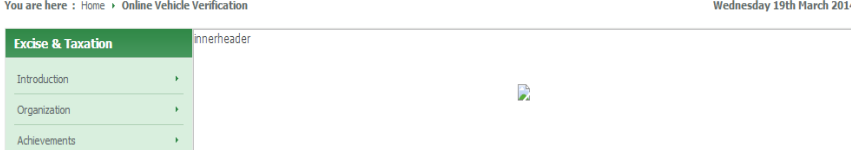

Online Vehicle Verification

\section{Nens \& Events}

Online Vehicle Verification

Advertsement

Eid Evaluation Report

Tender Notice

\section{Mews \& Events}

SINDH SEEKS RISE II PROFESTIONAL TAX LII KARACHI: The Sindh government has decided to invoke pariementary
process to raise professional tax lint process to raise professional tax limt
from Rs 100,000 to R.5500,000 for banks, nudarabas and linits

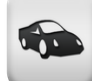

- Four Wheelers Verfication Please Enter Registration No.*

Two Wheelers Verification

gaAA-123)

\section{OWRHF}

Figure 1. The screen shot of the online portal.

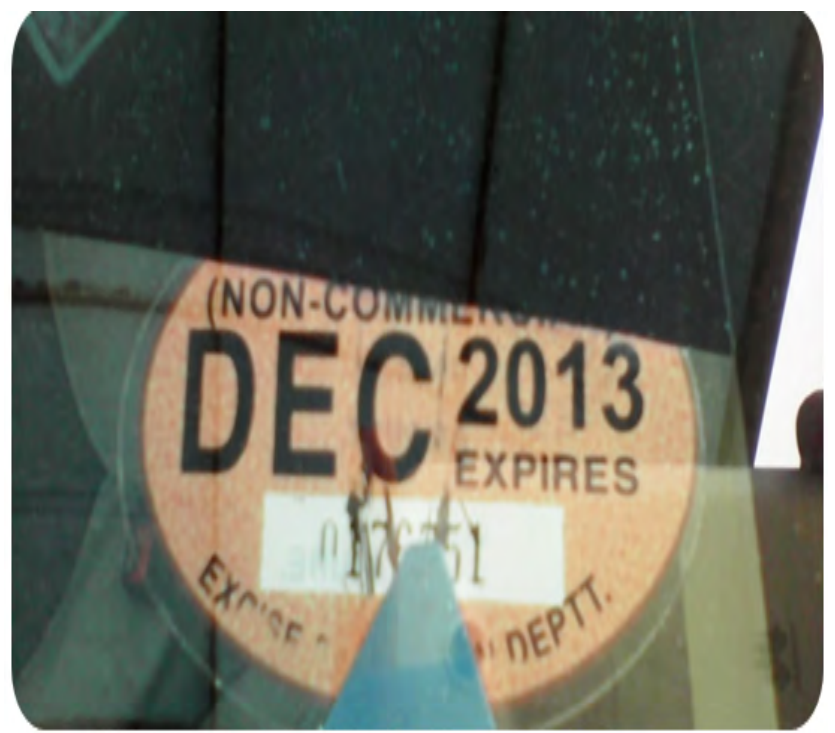

Figure 2. Sticker provided by the excise department fixed at wind screen.

It is very hard job to check every vehicle in hectic traffic at the toll plaza or at any other point. It may take hours to complete the job and traffic may be blocked (Mohamed Hussain, Allwyn Rajendran Zepherin, Shantha Kumar, \& Abirami, 2015). 


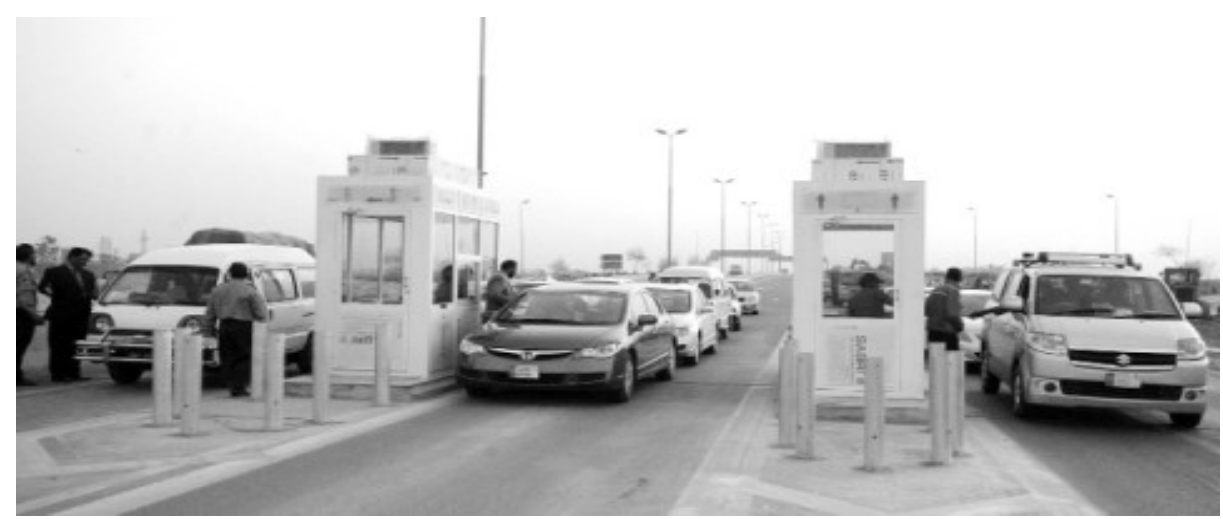

Figure 3. Manual road checking excise inspector causes traffic jam.

This research is documented to provide an automatic and technical solution of this problem. A prototype of this intelligent system is designed that uses a technology named automatic vehicle number plate recognition (AVNPR). This technology uses the image processing tool for capturing and processing the number plate fixed in front of every vehicle (Mohamed Hussain et al., 2015). The characters and numbers are identified and accessed from the database of the taxation department which is available online. The capturing is done through web cameras fixed at tool plazas or at any entrance of the city. The alert signal and message are sent to the cell phone of the vehicle owner about nonpayment of the tax.

\section{APPLICATIONS OF AVNPR SYSTEM}

The system of detection of the number plate uses the technology of image processing (Posada-Gómez, Sandoval-González, Martínez Sibaja, Portillo- Rodríguez, \& AlorHernández, 2011). It has unlimited application, in face recognition, monitoring of the employees in any industry, robotics systems and traffic signals etc. The problem is that how the owner of vehicle makes bound to pay the tax within the given time. The solution of this problem is documented in the literature (Figueiredo, Ribeiro, Arthur, \& Conforti, 2011; Hansen, 2002) which discusses the application and integration of the state of art computers with electronic hardware and global system of mobile communication, internet and AVNPR. 


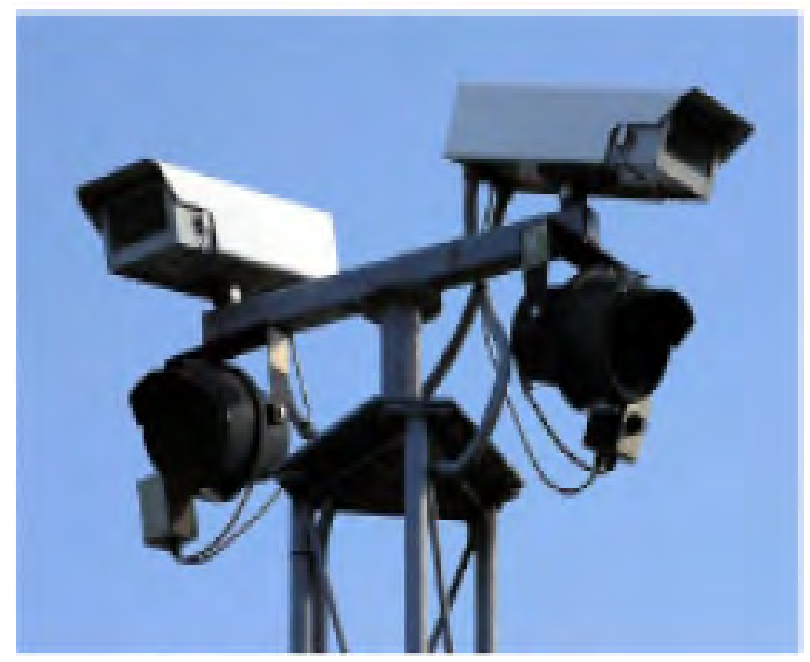

Figure 4. Web Cam fixed at any center point.

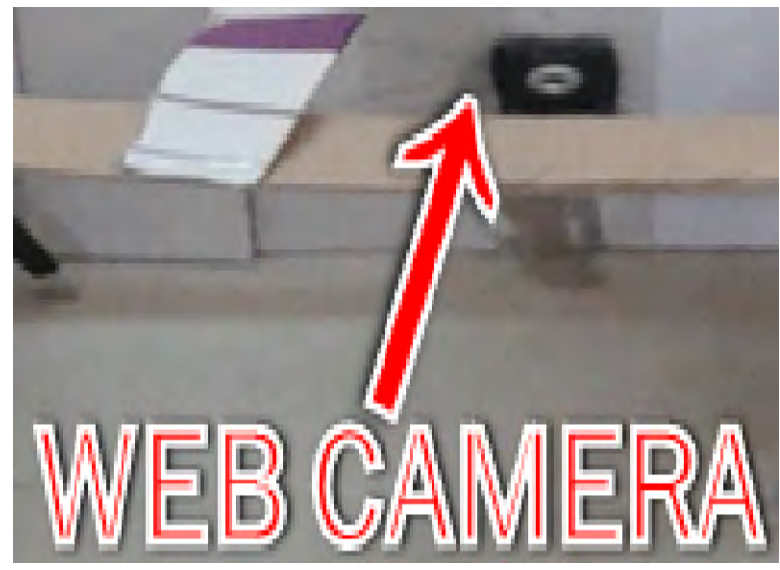

Figure 5. Camera.

The vehicle tax verification software is interfaced with LABVIEW that uses the computer application software along with recognition packages.

\section{HARDWARE}

Radio frequency system, global system of mobile GSM m900D kit and USB port is used as shown in Figure 7 and Figure 8. 
Edición Especial Special Issue Noviembre 2019

DOI: http://dx.doi.org/10.17993/3ctecno.2019.specialissue3.221-231

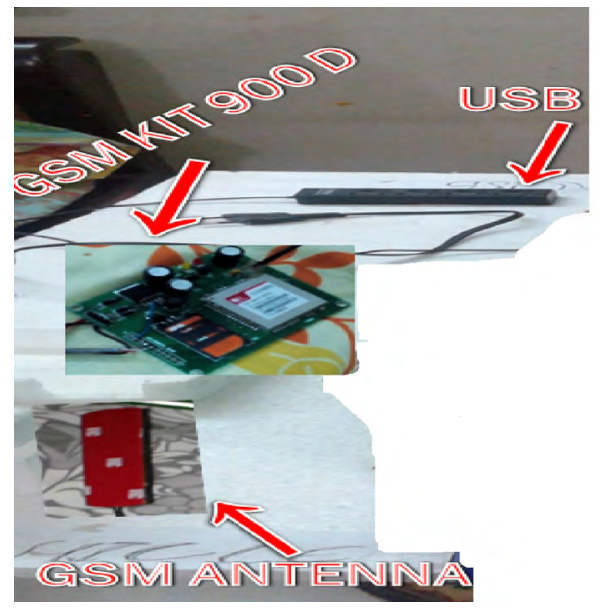

Figure 7. Hardware.

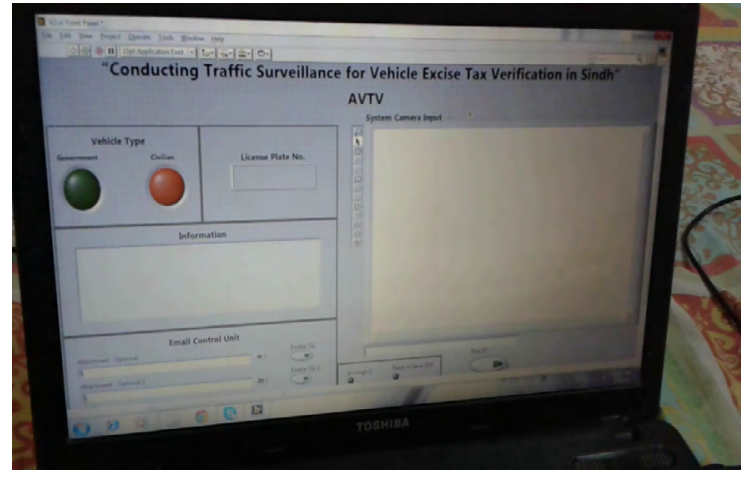

Figure 8. automatic vehicle tax verification (AVTV) software.

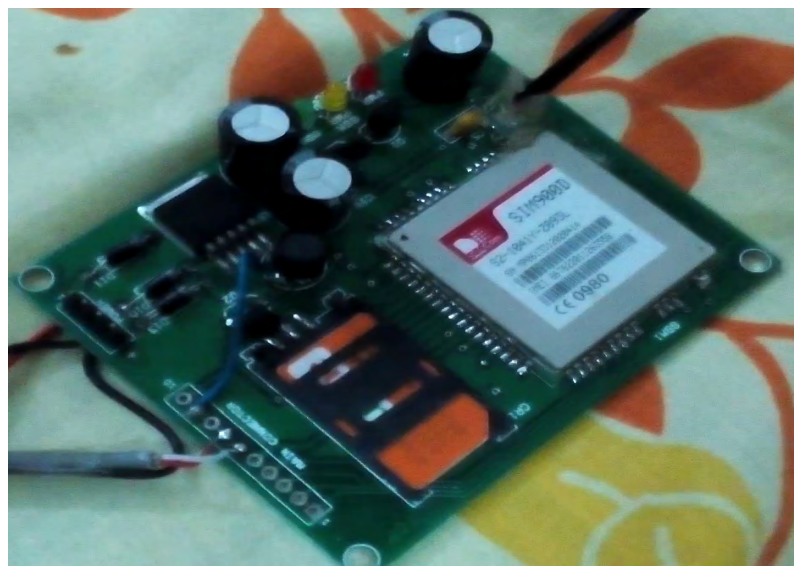

Figure 9. GSM Kit 900D. 


\section{DATABASE}

The data collected through the prototype is checked in the database created for prototype application. The database which is used for placing the information of car owner that is his name, make and model year, tax paid and unpaid information, last paid tax and mobile number. The block diagram of whole the process or algorithm is given in Figure 9.

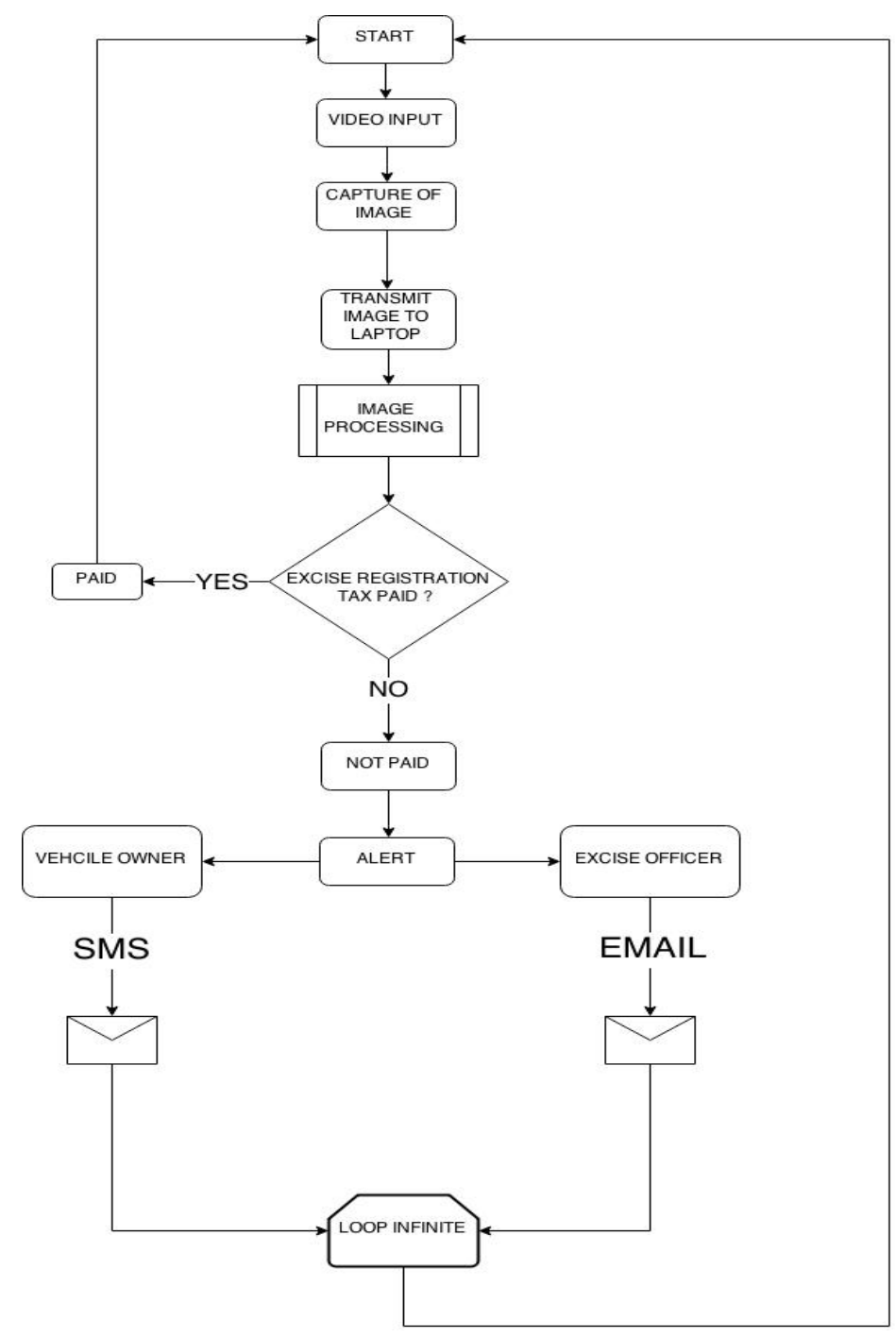

Figure 9. Block Diagram. 
A hardware is designed as prototype to show whole the process. A web cam is used for capturing the image of number plate and one module of GSM kit is also fitted into the prototype. This is shown in Figure 10.

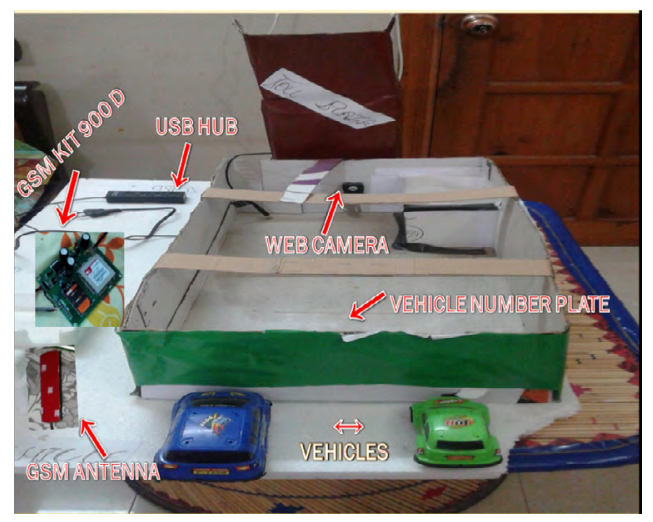

Figure 10. Hardware.

\section{CONCLUSION}

The Software VNPR needs the accuracy of the data and this may be difficult at a hectic road to go through whole the process starting from capturing the image of number plate, access the data base and send SMS to the cell phone. Efforts have been made by many researchers to solve this ambiguous problem. An automatic vehicle number plate recognition method is used to get the better results. Various studies conclude that the image processing is the best way to substitute the manual systems. Application of the technology to address the tax collection in Sindh excise and taxation department may generate the revenue and ultimately improve the economy of the province.

\section{AKNOWLEDGEMENT}

Authors are thankful to the higher authorities and Department of Electronic Engineering, Mehran University of Engineering \& Technology, Jamshoro, Pakistan, for providing workspace and necessary facilities to complete this research work. 


\section{REFERENCES}

Ahmed, M.M. (2011). The Viability of using automatic vehicle identification data for real time crash. Abdel-Aty Intelligent, 13, 459-468.

Ghirag, N. Paunwala \& Suprana, P. (2012). A Novel Multiple License Plate Extraction Technique for Complex Background in Indian Traffic Conditions. International fournal of Image Processing (If̈IP), 4(2).

Devi, R. K., \& Mathubala, G. (2015). Kinetic study of the effect of perchkoric acid, sodium perchlorate sodium chloride, p-toluenesulphanamide and temperature on the os(VIII) catalyzed oxidation of Schiff base by chloramine-tin aqueous acetic acid medium. International Fournal of Innovative Research in Science, Engineering and Technology (An ISO 3297: 2007 Certified Organization), 4(3), 1432-1436.

Dolui, K. Mukherjee, S., \& Datta, S.K. (2013). Traffic status monitoring using smart devices. International Conference on Intelligent Interactive Systems and Assistive Technologies (IISAT), 8-14.

Figueiredo, R. G., Ribeiro, A. M. O., Arthur, R., \& Conforti, E. (2011). Remote SMS Instrumentation Supervision and Control Using LabVIEW. Practical Applications and Solutions Using LabVIEW ${ }^{\mathrm{TM}}$ Software, Folea Silviu, IntechOpen. doi: https://doi.org/10.5772/22540

Hamami, L., \&, Berkani, D. (2002). Recognition System for Printed Multi-Font and Multi-Size Arabic Characters. The Arabian Fournal for Science and Engineering, 27, 57-72.

Hansen, H. (2002). Automatic recognition of license plates. Aalhorg University: Institute for Electronic System.

Hontani, H., \& Koga, T. (2001). Character extraction method without prior knowledge on size and information. Proceedings of the IEEE International Vehicle Electronics Conference (IVEC'01), 67-72. 
Khan, M. (2012). Online Vehicle Verification for Karachi / Sindh Launched. Retrieved from: https://propakistani.pk/2012/05/24/online-vehicleverification-for-karachi-sindh/

\section{Mohamed Hussain, K., AllwynRajendran Zepherin, R., Shantha Kumar,} M., \& Abirami, S. (2015). Conversion of Single Image into 3D Depth Image using NI-LabVIEW. International Fournal of Advanced Research in Electrical, Electronics and Instrumentation Engineering, 4(3), 1244-1248. Retrieved from: http://www. ijareeie.com/upload/2015/march/10_Conversion-1.pdf

Pandya, P., \& Singh, M. (2011). Morphology Based Approach to Recognize Number Plates in India. International Journal of Soft Computing and Engineering (IFSCE), 1(3).

Posada-Gómez, R., Sandoval-González, O. O., Martínez Sibaja, A., PortilloRodríguez, O., \& Alor-Hernández, G. (2011). Digital Image Processing Using LabView, Practical Applications and Solutions Using LabVIEW ${ }^{\text {тм }}$ Software. Retrieved from: http://cdn.intechopen.com/pdfs-wm/17632.pdf

Rich, J.H., Nielsen, O.A., \& Nielsen, U. (2006). Socio-economic assessment of road pricing - results from two projects in the Copenhagen area. In The European Transport Conference (ETC)I, Conference Proceeding, AET, Strasburg, September 2006.

Singh, R., Yadav, G. S., Verma, P., \& Yadav, V. (2010). Optical Character Recognition (OCR) for Printed Devnagari Script Using Artificial Neural Network. International Fournal of Computer Science \& Communication.

Uwe, K. \& Kuhfeld, H. (2007). The diverse structures of passenger car taxation in Europe and the EU Commissions proposal for reform.

Wikipedia. (2019). Vehicular communication systems. Retrieved from: http:// en.wikipedia.org/wiki/Vehicular_communication_systems

Yan, D. (2001). A high performance license plate recognition system based on the web technique. Proceedings IEEE Intelligent Transport Systems, 325-329. 


$$
\text { /14/ }
$$




\section{COMBINING THEETHICSANDSCIENCEOF DISASTER MANAGEMENT: KEY ISSUES, POLICY CONSIDERATIONS AND BEST PRACTICES}

Jason Levy
University of Hawaii, U.S.A.
E-mail: jlevy@hawaii.edu

Bishwajeet Pandey Director Gyancity Research Lab. E-mail: gyancity@gyancity.com

Recepción: 01/08/2019 Aceptación: 23/09/2019 Publicación: 06/11/2019

\section{Gitación sugerida:}

Levy, J. y Pandey, B. (2019). Combining the ethics and science of disaster management: key issues, policy considerations and best practices. 3C Tecnología. Glosas de innovación aplicadas a la pyme. Edición Especial, Noviembre 2019, 233-251. doi: http://dx.doi. org/10.17993/3ctecno.2019.specialissue3.233-251

\section{Suggested citation:}

Levy, J. \& Pandey, B. (2019). Combining the ethics and science of disaster management: key issues, policy considerations and best practices. 3C Tecnología. Glosas de innovación aplicadas a la pyme. Speciaal Issue, November 2019, 233-251. doi: http://dx.doi. org/10.17993/3ctecno.2019.specialissue3.233-251 


\section{ABSTRACT}

Around the world, the scientific discourse about disasters has historically focused predominantly upon the characteristics of the physical hazards themselves and the costs of mitigation actions to reduce the risks of these physical threats. While this physical science approach involves the expertise of talented experts from the fields of seismology, hydrology and geophysics the importance of addressing the root causes of disasters has become increasingly recognized in the social sciences. For example, in the broader public and policy literature, there are important ethical and social disaster issues which include understanding the root causes of community vulnerabilities and the ethical issues of not addressing climate change impacts (otherwise known as the costs of inaction). This research uses statistical tools including binary logistic regression to analyze ethical considerations in flood disaster management issues. Since many of Asia's worst floods have occurred in China they are used as a case study.

\section{KEYWORDS}

Disaster Management, Key Issues, Policy, Ethics and Science, Catastrophe. 


\section{INTRODUCTION}

Ethical decisions are key to shaping the disaster studies field and they must be included in the online classroom: It is important that values and ethical considerations are made explicit during the disaster planning process so that under conditions of pressure of urgency and criticality they can be made consistent with the ethical judgments that underlies the emergency management decision process. In the community disaster planning phase, there will be innumerable issues, each with its own ethical components. What humans and assets do we protect, and to what level of safety? How do we set disaster budgets and priorities? Answers explored during disaster preparedness activities should be based on key values and ethical analysis that can provide guidance during implementation Other issues include:

- How do we ensure that priority-setting judgments are not purely technical matters?

- How do we ensure the goals of transparency and accountability?

- Who should receive the most resources?

- Who do we rescue first?

- How do deal with families that refuse to follow mandatory evacuation orders?

- When do we stop expending resources to critically ill victims that are unlikely to survive?

- When do we phase out rescue efforts and shift to recovery mode?

The way these questions are answered reflects the ethical perspectives and moral analysis strategies of the planning group $(\mathrm{s})$. In this paper we consider the role of both ethical and scientific decisions in grave flood management challenges. Flood events often constitute a catastrophic disaster threat: they have an enormous impact on human wellbeing, jeopardizing important social development goals such as addressing poverty, ensuring adequate food, water, and sanitation, and protecting the environment. Direct losses from floods include drownings and injuries as well 
as damage to infrastructure and property, agricultural production, and sites of historical and cultural value. Indirect health problems often arise, such as waterborne infections, exposure to chemical pollutants released into flood waters, and vector-borne diseases.

\section{1998 YANGTZE RIVER FLOOD CASE STUDY}

At 6,300 km (3,900 miles) the Yangtze is Asia's longest river, the world's third longest and the most important waterway linking China's leading commercial hub, Shanghai, to the less industrialized regions of the Yangtze river basin: The fertile Yangtze River basin supports $40 \%$ of China's GDP (including $40 \%$ of the nation's agricultural and industrial output) and is home to one third of its people.. The Yangtze river basin is also a vital source of natural resources, accounting for $40 \%$ of China's freshwater resources, more than $70 \%$ of the country's rice and fishery production and half of its grain. The 1997-1998 El Nino and 1998 Asian summer monsoon was one of the strongest on record, and monsoon rains continued unabated for much of the summer. The central and southern parts of the country along the Yangtze river and its tributaries were severely impacted by more than 60 days of heavy flooding in the Yangtze River Valley. The Yangtze flooding constituted the world's single most devastating natural disaster in 1998 and China's worst flooding in over 40 years: approximately 200 million people were affected over 50 million acres as $670 \mathrm{~mm}$ of precipitation occurred in the Yangtze river valley from June to August, 1998 (Samel \& Liang, 2003). In July and August 1998, extensive flooding also occurred in northeast China, in the Songhuanjiang, Nenjiang and other rivers. The 1998 Yangtze floods affected more than 180 million people, killing approximately 4,000, damaging more than 10 million homes and forcing 14 million people to relocate. Direct economic losses were put at 31 billion US dollars.

Four factors which significantly worsened the impact of heavy rain during the 1998 flood were: 
- Deforestation and overgrazing, sharply reducing the capacity of forests and grasslands to retain water; Forest cover in Sichuan province fell from $20 \%$ of the land area in the 1950s to $9 \%$ by the late 1970s (Kirby, 2001).

- Loss of lakes and wetlands, cutting the capacity of the river's middle and lower reaches to store water. The surface area of the lakes along the Yangtze shrunk from 17,198 sq km in 1949 to only 6,605 sq km in 1980. In the early 1950s, the Yangtze basin had contained 4,033 large and small lakes, of which about 1,100 were lost over the past half century.

- Rising erosion rates, causing rivers and wetlands to fill with silt. For example, one of the largest reservoirs in Guangxi province, Changgang, has lost half a million cubic metres of capacity annually as it silts up.

- Snowmelt and melting glaciers in the Qinghai-Tibetan plateau.

Both the amount of precipitation over the Yangtze river catchment and the floodwater discharge from the upper basin of the Yangtze river did not exceed the historical extremes during the 1998 flooding, but water levels in the middle basin far exceeded the historical maximum. Historically, dikes have been built to control flooding along the Yangtze River, but the 1998 flood levels in the middle reaches of the Yangtze River forced Chinese officials to consider dramatic strategies to save large cities on the Yangtze River from inundation. During the summer of 1998, it was feared that Yangtze River flooding would cause the dikes along the Yangtze to fail to some degree, particularly those already weakened due to erosion, aging, or neglected repairs.

To minimize the probability of a catastrophic dike failure in the densely populated city of Wuhan (central China's largest industrial center, with more than 7 million residents in China's central Hubei province) and neighboring farmland, Chinese authorities deliberately destroyed dikes in Jianli County (Hubei province), about 90 miles upriver from Wuhan. This preventative action was successful in diverting floodwaters away from Wuhan, lowering the height of the Yangtze River at Wuhan. While this purposeful destruction of dikes at Jianli temporarily prevented Wuhan 
from being flooded, the social and economic impact on Jianli Country was immense: more than 500,000 people living adjacent to the Yangtze River were forced to evacuate (many on extremely short notice).

However, Chinese officials believed that saving Wuhan from inundation might also require opening floodgates and the deliberate destruction of dikes in the Jingiiang section of the Yangtze River which runs from Zhijiang (Hubei Province) to Chenglingji (Hunan Province). It is one of the most hazardous parts of the Yangtze River: the many bends in the river slow down the water and the riverbed is high due to the resulting sand and mud deposits. The higher water level in the Jingjiang leads to the ancient Chinese saying: "The danger of the Yangtze River lies in Jingjiang".

The $180 \mathrm{~km}$ Jingiiang river embankment provides defense for the central Chinese city of Wuhan and the major Beijing-Guanzhou Railway transportation artery. It also protects the productive 30,000 km2 Jianghan plain (an alluvial plain located in the middle and south of Hubei province which borders the Dongtinghu Plain and has an area of more than 30 thousand square kilometers).

The Jingjiang flood plain lies in central Hubei province which is home to over 300,000 people. The Jingiiang flood diversion area had not been used since 1954, when floods killed more than 30,000 people. However, purposefully destroying dikes at Jingiiang would reduce the risk of dikes suddenly bursting at Shashi City. Accordingly, extensive preparations were put in place to dynamite the Jingjiang dikes and divert waters into the Jingjiang floodplain. This was expected to submerge more than 1,000 square kilometers (386 square miles) of land and 27,000-33,000 ha (68,000-82,000 acres) of farmland in the Jingjiang floodplain. Deliberately flooding towns and villages in the Jingjiang area required the approval of the State Council of the People's Republic of China ((國務院), the chief administrative authority of the People's Republic of China. Since 1954 China's State Council has been constitutionally identical to the Central People's Government (Chinese: 中央人民政府), particularly in relation to local governments. China's state council is chaired by the Premier and includes the heads of each governmental department and agency. Currently, the council has 35 members: the premier, one executive vice premier, three vice premiers, five state 
councilors (of whom two are also ministers), and 25 additional ministers and chairs of major agencies.

In 1952 the Jingjiang Flood Diversion Project was undertaken in the northeastern part of the Gong'an County. Officials at the Jingjiang Flood Diversion Management Bureau were instructed to begin destroying dikes and opening floodgates when water levels on the Yangtze reached a record high of $45 \mathrm{~m}$ (149 feet) at the monitoring station in Shashi city, just north of the area that would be flooded. Fortunately, the water level at the Shashi monitoring station remained approximately $6 \mathrm{~cm}$ (2 in.) below the 45-m level. However, as a precautionary measure 330,000 people were evacuated from the Jingjiang region.

August 6, 1998: Hubai Provincial Flood Control Headquarters advised that there were critical flood levels. More than 300,000 people in the flood diversion area were evacuated to make room for diverted floodwaters

August 16, 1998: The water level in Shashi rose to 45.22 meters, which exceeded the 45.00 meter state stipulated flood diversion mark. However, in a bid to reduce losses, officials decided not to divert water.

August 20, 1998: The sixth Yangtze River crest threatened Wuhan and 2.3 million citizens and soldiers provided support for the Jingjiang River embankment.

However, in the summer of 1998 floods weakened the Jingjiang River embankment so 40,000 Chinese People's Liberation Army soldiers and half a million local citizens helped to withstand the floodwaters.

\section{YELLOW RIVER FLOOD WARFARE CASE STUDY}

The Imperial Japanese Army quickly obtained large swaths of Chinese territory at the onset of the Second Sino-Japanese War in 1937 and by June 1938, the Japanese had control of all of North China. On June 6, 1938 the Japanese imperial army captured Kaifeng, the capital of Henan, and threatened to take over Zhengzhou which would have directly endangered the major Chinese cities of Wuhan and Xi'an 
(as Zhengzhou stood at the junction of the critical Pinghan and Longhai Railways). To deter further Japanese advances into western and southern China, the Chinese Nationalist leader General Chiang Kai-shek opened the dikes on the Yellow River near Zhengzhou on the advice of Chen Guofu, a prominent political ally in party affairs. Specifically, the dike was destroyed on June 5, 1938 and June 7, 1938 at Huayuankou, on the south bank of the Yellow River causing flooding in the Eastern states of Henan, Anhui, and Jiangsu.

The deliberate floods constitute what many consider to be the largest war induced environmental disaster in history (Dutch, 2009; Lary, 2004). This act of environmental warfare destroyed thousands of square kilometers of farmland and shifted the mouth of the Yellow River hundreds of miles south. It is estimated that the disaster affected approximately five million people. In particular, the flood inundated thousands of villages, thereby driving villagers from their homes and creating three million refugees. It is estimated that at least 400,000-500,000 died from the flooding with another half a million becoming homeless. Besides this large death toll, the ecological toll on agricultural and other ecological resources was severe: crops in the abandoned, flooded countryside were destroyed and irrigation channels were ruined. Moreover, even once the water eventually receded the soil was often uncultivable as much of the land was covered in silt. Both private property and public infrastructure were destroyed, leaving survivors destitute. 


\section{ANALYSIS TOOLS FOR UNDERSTANDING ETHICAL AND SCIENTIFIC DIMENSIONS}
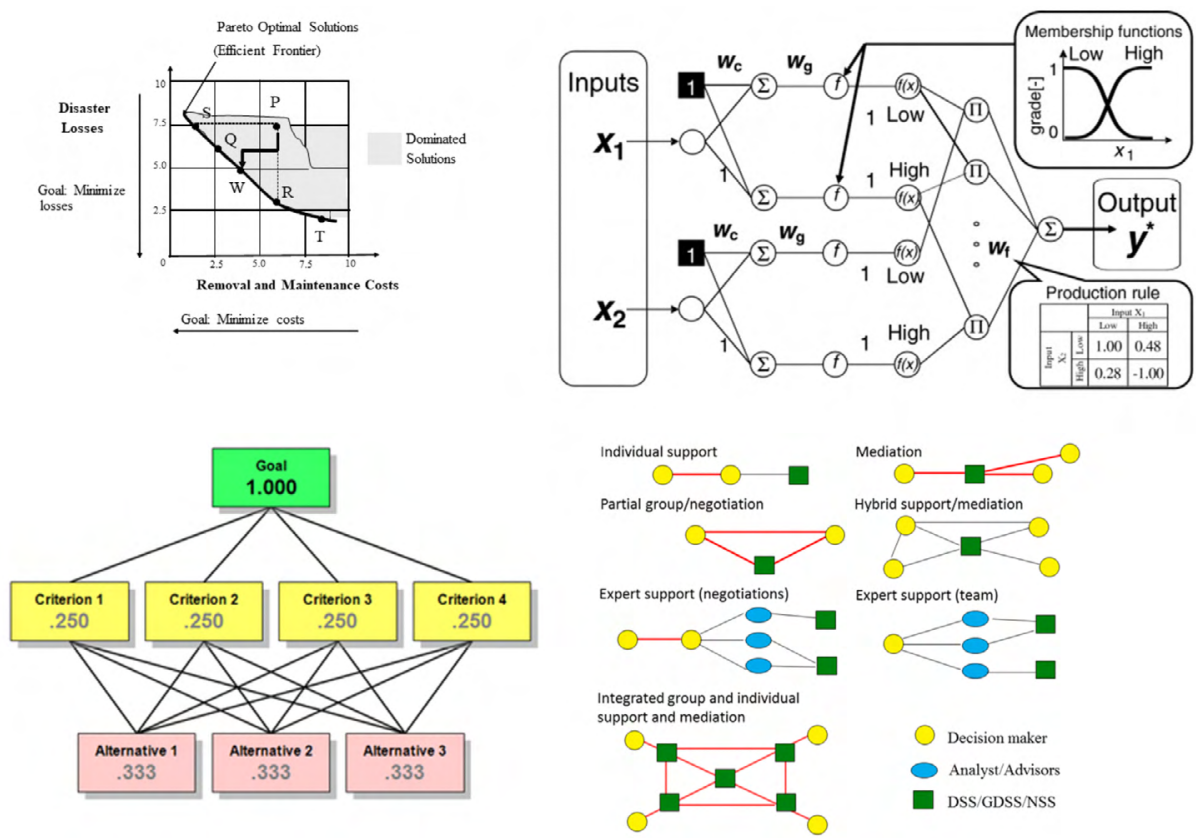

Figure 1. Analysis tools for combing the science and ethics of disaster management.

A wide number of tools have been proposed for integrating the science and ethics of disaster management, as shown in Figure 1 including group decision analysis and soft computing approaches including fuzzy-neural analysis. Discriminant function analysis (DFA) is typically employed in the presence of a categorical dependent variable if all of the predictors are continuous and nicely distributed about the mean. It is used primarily to predict group membership from a set of continuous predictors. Specifically, DFA assumes multivariate normality, i.e. the means of the various Dependent Variables (DVs) in each cell and all linear combinations of the DVs are normally distributed. On the other hand, Logit analysis is usually employed if all the predictors are categorical.

Logistic regression is used to predict a categorical (usually dichotomous) variable from a set of predictor variables where the predictor variables are a mix of continuous and categorical variables and/or if they are not nicely distributed. The medical 
community often uses logistic regression for problems in which the dependent variable is whether or not a patient has a disease.

For a logistic regression, the predicted dependent variable is a function of the probability that a particular individual will be in one of the categories (i.e. that an individual has a disease, given her set of scores on the predictor variables).

As an example of the use of logistic regression in disaster research consider the Yangtze River flood case study. Disaster management college students in India and USA $(\mathcal{N}=630)$ were asked to pretend that they were serving as a member of the State Council of the People's Republic of China hearing arguments for and against the destruction of dikes at Jianli and Jingjiang. The discussion included a description of the emergency management options in logical but emotional language. Various points of view were put forth and computer simulations were carried out to show the impact of the proposed evacuations and dam breaches on communities. Each participant read one of five different scenarios which described the goals and benefits of the proposed dam breaches. They were:

- ECONOMIC-protecting down-stream economic assets including the central Chinese city of Wuhan and the major Beijing-Guangzhou Railway transportation artery.

- ENVIRONMENTAL-the need to protect the productive Jianghan plain.

- SOCIAL-the challenges associated with evacuation and the threats to life safety associated with flooding.

- POLITICAL-understanding the decision making process in China's state council and the Jingjiang Flood Diversion Management Bureau.

- MILITARY-camouflaged soldiers reinforced the earthen dikes along the banks of the Yangtze river in order to help back the swollen river. With waters on the Yangtze at their highest levels in 44 years, nearly 5 million people in five provinces were mobilized to help fortify the embankments. 
After reading the background of the Yangtze River flooding and the other case materials, each student was asked whether or not to proceed with the study. Participating students were asked to fill out an Ethics Position Questionnaire (EPQ) (Forsyth, 1980) which assesses personal moral philosophy. The instrument contains two dimensions: relativism and idealism. Scoring high on the relativism subscale of the EQP is consistent with a personal and situational moral philosophy and a rejection of universal moral principles. Overall, high scorers on the idealism subscale of the EQP espouse a concern for the welfare of others and believe that ethical behavior leads only to positive outcomes, never to bad or mixed consequences (Forsyth, Nye, \& Kelley, 1985).

The EPQ asks questions about acceptance of issues that vary in terms of relativism and idealism. The instrument contains 20 Likert-type items (each with a 9-point response scale from "completely disagree" to "completely agree"). The relativism scale includes items such as "Different types of moralities cannot be compared as to "rightness" and "What is ethical varies from one situation to another." The idealism scale, in contrast, measures one's perspective on positive and negative consequences with such items as "A person should make certain that their actions never intentionally harm another even to a small degree" and "If an action could harm an innocent other than it should not be done" (Forsyth, 1980). It is important to note that idealists (persons who score high on the idealism dimension) do not make ethical decisions by balancing good consequences against negative outcomes; rather, for an idealist, the existence of any negative outcomes may make a behavior unethical, even though there may be many positive consequences.

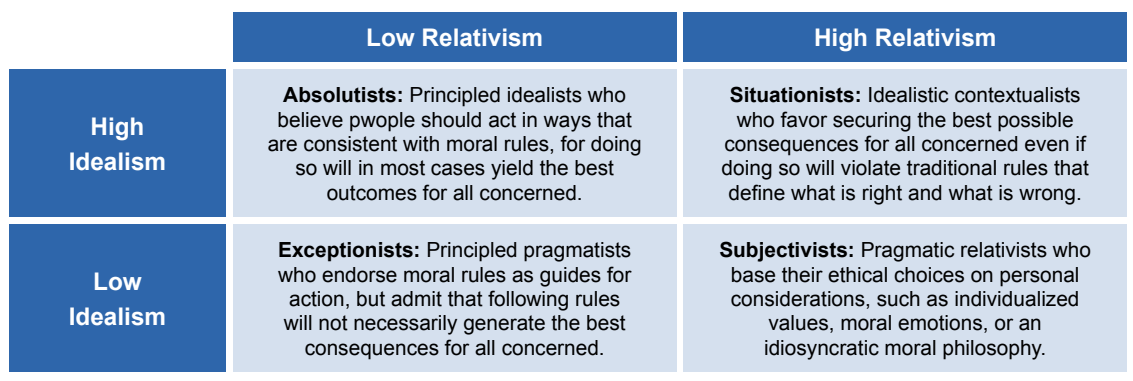

Figure 2. Four-fold classification of Personal Moralities based on Idealism and Relativism. Source: (Forsyth, 1980). 
A four-fold classification based on Idealism and Relativism is shown in Figure 2. There are four quadrants that categorize various individuals on the basis of their personal moral philosophy and ethical choices: Situationalists, Absolutists, Exceptionalists and Subjectivists. Situationalists are highly relativistic and idealistic contextualists: they believe that individuals should seek to achieve the best outcomes possible, but that moral rules cannot be universally applied across all situations: adherents prescribe close examination of individual situation in reaching a contextually appropriate moral evaluation. Absolutists, like Situationists, are also idealistic; they support decisions that yield positive, desirable consequences. However, Absolutists are not relativistic; they believe that ethical absolutes must be included in any code of ethics.

Subjectivists and Exceptionalists are both low in terms of idealism. Subjectivists are pragmatic relativists that reject universal moral rules (high relativism) and believe that following rules will not necessarily lead to the best outcomes for all concerned (less idealistic about the possibility of achieving humanitarian goals). Its adherents make subjective, individualistic moral judgments rather than basing their ethical choices on more "objective" information, such as universal moral absolutes or the extent to which a given action harms others. Finally, Exceptionists are principled pragmatists who endorse moral rules as guides for behavior but believe that following actions that lead to some negative consequences shouldn't necessarily be dismissed. Low in both relativism and idealism they are willing to make exceptions to their moral principles. Human and animal rights activists tend to be high in idealism and low in relativism. This study examines whether gender, idealism and relativism are related towards attitudes in complex emergency management decisions.

\section{LOGISTIC REGRESSION ANALYSIS}

We begin with a simple bivariate logistic regression, using student's decisions as the dichotomous criterion variable and gender as a dichotomous predictor variable where we have coded gender with $0=$ Female, $1=$ Male and decision with $0=$ stop the decision to breach the dam and $1=$ continue with the decision to breach the dam. 
Our regression model involves predicting the logit, i.e. the natural log of the odds of have made one or the other decision. That is:

$$
\ln (\text { odd } s)=\ln \left(\frac{\hat{y}}{1-\hat{y}}\right)=a+b X
$$

where $\hat{y}$ is the predicted probability of the event which is coded with 1 (continue with the plans to destroy the dykes and open the floodgates) rather than 0 (not to proceed with dynamiting the dykes and opening the floodgates). $1-\hat{y}$ is the predicted probability of the other decision and $\mathrm{X}$ is the predictor variable, gender. The intercept (constant term) is given by $a$ and $b$ is the slope from the logistic regression equation.

An iterative maximum likelihood procedure is used to construct a logistic regression model. Starting with an arbitrary value of the regression coefficients an initial model for predicting the observed data is constructed. Errors in the aforementioned prediction are then evaluated and the regression coefficients are changed in order to make the likelihood of the observed data greater under the new model. The procedure is iterative since the procedure repeats until the differences between the latest model and the previous model are trivial (i.e. the model converges).

Observing the statistical output we observe that 630 cases are used in the analysis (Figure 1).

Table 1. Case Processing Summary.

\begin{tabular}{|c|c|c|c|}
\hline \multicolumn{3}{|c|}{ Case Processing Summary $^{*}$} & \\
\hline Unweighted Cases & \\
\hline \multirow{2}{*}{ Selected Cases } & Included in Analysis & 630 & 100.0 \\
\hline & Missing Cases & 0 & .0 \\
\hline & Total & 630 & 100.0 \\
\hline Unselected Cases & 0 & .0 \\
\hline & Total & 630 & 100.0 \\
\hline
\end{tabular}

Block 0 output is for a model that includes only the intercept (constant term). Given the base rates of the two decision options $58.4 \%$ (i.e. 368/630) of students decided to stop the dam destruction implementation while $41.6 \%$ decided to allow it to continue (Table 2). Without any other information the best statistical inference is to predict, 
for every case, that the student will decide to stop the dam destruction. Using that strategy one would be correct $58.4 \%$ of the time.

Table 2. Classification Table.

\begin{tabular}{|c|c|c|c|c|c|}
\hline \multicolumn{6}{|c|}{ Classification Table ${ }^{a, b}$} \\
\hline & \multirow[t]{3}{*}{ Observed } & & \multicolumn{3}{|c|}{ Predicted } \\
\hline & & \multicolumn{2}{|c|}{ Decision } & \multirow{2}{*}{\multicolumn{2}{|c|}{ Percentage Correct }} \\
\hline & & Stop & Continue & & \\
\hline \multirow{3}{*}{ Step 0} & \multirow{2}{*}{ Decision } & Stop & 368 & 0 & 100.0 \\
\hline & & Continue & 262 & 0 & .0 \\
\hline & \multicolumn{2}{|c|}{ Overall Percentage } & & & 58.4 \\
\hline \multicolumn{6}{|c|}{ a. Constant is included in the model. } \\
\hline \multicolumn{6}{|c|}{ b. The cut value is .500} \\
\hline
\end{tabular}

Table 3 (variables in the equation) shows that the intercept only model is:

$\ln ($ odds $)=-0.340$ which yields the predicted odds is $[\operatorname{Exp}(\mathrm{B})]=0.711$. That is, the predicted odds of deciding to continue with the dyke destruction is 0.711 . Since 262 of the students decided to continue the dyke destruction and 368 decided to stop the destruction, our observed odds are 262/368 $=0.712$.

Table 3. Variables in the Equation.

\begin{tabular}{|c|c|c|c|c|c|c|c|}
\hline \multicolumn{8}{|c|}{ Variables in the Equation } \\
\hline & & B & S.E. & Wald & df & Sig. & $\operatorname{Exp}(B)$ \\
\hline Step 0 & Constant & -.340 & .081 & 17.664 & 1 & .000 & .712 \\
\hline
\end{tabular}

Now look at Block 1 output where the gender variable is added as a predictor. The Omnibus Test of Model Coefficients (Table 4) illustrates a Chi-square of 48.198 on 1 $d f$, significant beyond .001 . This is a test of the null hypothesis that adding the gender variable to the model has significantly increased our ability to predict decisions made by the students. The -2 Log likelihood statistic (807.247) models how well the model predicts the decisions (the smaller the better) as shown in the model summary (Table 5). The Cox and Snell $R^{2}(0.074)$ is like the interpretation of $R^{2}$ in multiple regression, but does not reach a maximum value of 1 , whereas the Nagelkerke $R^{2}$ can reach a maximum of 1 . 
Table 4. Omnibus Tests of Model Coefficients.

\begin{tabular}{|c|c|c|c|c|}
\hline \multicolumn{5}{|c|}{ Omnibus Tests of Model Coefficients } \\
\hline \multirow{2}{*}{ Step 1 } & Step & 48.198 & df & Sig. \\
\hline & Block & 48.198 & 1 & .000 \\
\hline & Model & 48.198 & 1 & .000 \\
\hline
\end{tabular}

Table 5. Model Summary.

\begin{tabular}{|c|c|c|c|}
\hline \multicolumn{4}{|c|}{ Model Summary } \\
\hline Step 1 & $\begin{array}{c}-\mathbf{2} \text { Log } \\
\text { likelihood }\end{array}$ & $\begin{array}{c}\text { Cox \& Snell R } \\
\text { Square }\end{array}$ & $\begin{array}{c}\text { Nagelkerke R } \\
\text { Square }\end{array}$ \\
\hline & $807.247^{\text {a }}$ & .074 & .099 \\
\hline \multicolumn{2}{|c|}{ a. Estimation terminated at iteration number 3 because parameter estimates } \\
changed by less than .001.
\end{tabular}

\section{ANALYSIS}

The Variables in the Equation output (Table 6) shows us that the regression equation is $\ln ($ odds $)=-.788+1.176$ Gender. We can now use this model to predict the odds that a subject of a given gender will decide to continue with the dyke destruction. When the student is a woman (gender $=0$ ), then odd $s=e^{-0.788+1.176(0)}=e^{-0.788}=0.455$. That is, a female student is only 0.455 as likely to approve the dyke destruction as she is to stop the destruction. For male students $\left(\right.$ gender $=1$ ) then odds $=e^{-0.788+1.176(1)}=e^{0.388}=1.474$. That is, a male student is 1.474 times more likely to decide to continue the dyke destruction as she is to stop the destruction.

The odds are now converted to probabilities. For women students in the study

$$
\hat{y}=\frac{o d d s}{1+o d d s}=\frac{0.455}{1+0.455}=0.31
$$

That is the model predicts that $31 \%$ of women will decide to continue to destroy the dykes. For men: 


$$
\hat{y}=\frac{o d d s}{1+o d d s}=\frac{1.474}{1+1.474}=0.60
$$

That is our model predicts that $60 \%$ of men will decide to continue to destroy the dykes.

The variables in Equation output (Table 6) provides the odds ratio predicted by the model: $\operatorname{Exp}(\mathbf{B})$ provided in the right most column. The odds ratio is obtained by raising the base of the natural $\log$ to the $b^{\text {th }}$ power, where $b$ is the slope from the logistic regression equation. In our model the result is $e^{1.176}=3.241$ which means that the model predicts the odds of deciding to continue the dam destruction are 3.241 times higher for men than they are for women. For men, the odds are 1.474, and for women they are 0.455 . The odds ratio is: $1.474 / 0.455=3.24$.

Table 6. Variables in the Equation.

\begin{tabular}{|c|c|c|c|c|c|c|c|}
\hline \multicolumn{8}{|c|}{ Variables in the Equation } \\
\hline \multirow{3}{*}{ Step 1 1} & B & S.E. & Wald & df & Sig. & Exp(B) \\
\cline { 2 - 9 } & Conder & 1.176 & .172 & 46.570 & 1 & .000 & 3.241 \\
\hline & Constant & -.788 & .108 & 53.424 & 1 & .000 & .455 \\
\hline & a. Variable(s) entered on step 1: gender. \\
\hline
\end{tabular}

In order to classify subjects according to their decision we establish the following decision rule: If the probability of the event is greater than or equal to 0.5 (the SPSS threshold set by default), then it is predicted that the event will take place (in some cases we may wish to set the threshold higher or lower than 0.5). Using the 0.5 threshold we classify a student into the "Continue with Dam Destruction" category if the estimated probability is more than 0.5 , which it is for every male student. A subject is classified into the "Stop the Dam Destruction" category if the estimated probability is less than 0.5 which it is for every female student.

The sensitivity of the prediction, i.e. the percentage of occurrences correctly predicted is now examined: $P$ (correct|event occurred). For the "Continue with Dam Destruction" event the Classification Table (Table 7) shows us that this rule allows us to correctly classify $137 /(125+137)=52.3 \%$ of the subjects where the 
predicted event was observed. For the specificity of the prediction, i.e. the percentage of nonoccurrence's correctly predicted we have: $P$ (correct|event did not occur) $=275 /(275+93)=74.7 \%$. Hence this rule correctly classifies $74.7 \%$ of the subjects where the predicted event did not occur (i.e. "Stop Dam Destruction"). Overall the predictions were correct 412 (i.e. $275+137$ ) out of 630 times for an overall success rate of $65.4 \%$. Recall that the overall success rate was $58.4 \%$ for the model with the intercept only.

Table 7. Classification Table.

\begin{tabular}{|c|c|c|c|c|c|}
\hline \multicolumn{6}{|c|}{ Classification Table } \\
\hline \multirow{5}{*}{ Step 1} & \multicolumn{2}{|c|}{ Observed } & \multicolumn{3}{|c|}{ Predicted } \\
\hline & \multirow{3}{*}{ Decision } & \multirow{2}{*}{$\begin{array}{l}\text { Stop } \\
\text { Stop }\end{array}$} & \multirow{2}{*}{$\begin{array}{c}\text { Continue } \\
275\end{array}$} & \multicolumn{2}{|c|}{ Percentage Correct } \\
\hline & & & & 93 & 74.7 \\
\hline & & Continue & 125 & 137 & 52.3 \\
\hline & \multicolumn{2}{|c|}{ Overall Percentage } & & & 65.4 \\
\hline \multicolumn{6}{|c|}{ a. The cut value is .500} \\
\hline
\end{tabular}

\section{CONCLUSIONS}

A wide number of tools are herein proposed for integrating the science and ethics of disaster management. These include group decision analysis and soft computing approaches including evolutionary algorithms and fuzzy-neural analyses. Discriminant function analysis (DFA) is typically employed in the presence of a categorical dependent variable if all of the predictors are continuous and uniformly distributed about the mean. On the other hand, Logit analysis is usually employed if all of the predictors are categorical It is shown that males are 1.474 times more likely to decide to continue dyke destruction and sacrifice human lives than females.

Ethical decisions are key to shaping the disaster studies field and they must be included in a formal disaster policy analysis: It is important that values and ethical considerations are made explicit during the disaster planning process so that under conditions of pressure of urgency and criticality they can be made consistent with the ethical judgments that underlies the emergency management decision process. It is 
concluded that in the community disaster planning phase, there will be innumerable issues, each with its own ethical components. What humans and assets do we protect, and to what level of safety? How do we set disaster budgets and priorities?

\section{REFERENCES}

Dutch, S. I. (2009). The Largest Act of Environmental Warfare in History. Environmental E Engineering Geoscience, 15(4), 287-297. doi: https://doi.org/10.2113/ gseegeosci.15.4.287

Forsyth, D. R. (1980). A taxonomy of ethical ideologies. Fournal of Personality and Social psychology, 39(1), 175.

Forsyth, D. R., Nye, J. L., \& Kelley, K. (1988). Idealism, relativism, and the ethic of caring. The fournal of Psychology, 122(3), 243-248.

Kirby, A. (2001). Plan to tame Yangtze floods. Retrieved from: http:/ / news.bbc.co.uk/2/ hi/science/nature/1595327.stm

Lary, D. (2004). The Waters Covered the Earth: China's War-Induced Natural Disaster. In Mark Selden and Alvin Y. So, ed. War and State Terrorism: The United States, Japan, and the Asia-Pacific in the Long Twentieth Century. Rowman \& Littlefield, 143-170.

Muscolino, M. S. (2014). The Ecology of War in China: Henan Province, the Yellow River, and Beyond, 1938-1950. Cambridge University Press.

Samel, A. N., \& Liang, X. Z. (2003). Understanding relationships between the 1998 Yangtze River flood and northeast Eurasian blocking. Climate Research, 23(2), 149-158. 
Edición Especial Special Issue Noviembre 2019

DOI: http://dx.doi.org/10.17993/3ctecno.2019.specialissue3.233-251 


$$
\text { /15/ }
$$




\section{OCCUPATIONAL HEALTH \& SAFETY IMPLEMENTATION FRAMEWORK FOR PAKISTANI CONSTRUCTION INDUSTRY IN SINDH PROVINCE}

Maryam Khokhar

School of Economics and Management

Yanshan, University, China.

E-mail: maryamkhokhar@stumail.ysu.edu.cn

Yumei Hou

School of Economics and Management

Yanshan, University, China.

E-mail: hym@ysu.edu
Inayatullah Sethar

School of Economics and Management

Yanshan, University, China.

E-mail: inayat90@stumail.ysu.edu.cn

Waqas Amin

School of Economics and Management

Yanshan, University, China.

E-mail: waqasamin@stumail.ysu.edu.cn

\section{Mohammad Shakib}

School of Economics and Management

Yanshan, University, China.

E-mail:shakibbd@gmail.com

Recepción: 02/08/2019 Aceptación: 24/09/2019 Publicación: 06/11/2019

\section{Gitación sugerida:}

Khokhar, M., Hou, Y., Inayatullah, Amin, W. y Shakib, M. (2019). Occupational Health \& Safety implementation framework for Pakistani construction industry in Sindh Province. 3C Tecnología. Glosas de innovación aplicadas a la pyme. Edición Especial, Noviembre 2019, 253285. doi: http://dx.doi.org/10.17993/3ctecno.2019.specialissue3.253-285

\section{Suggested citation:}

Maryam Khokhar, M., Hou, Y., Inayatullah, Amin, W. \& Shakib, M. (2019). Occupational Health \& Safety implementation framework for Pakistani construction industry in Sindh Province. 3C Tecnología. Glosas de innovación aplicadas a la pyme. Speciaal Issue, November 2019, 253-285. doi: http://dx.doi.org/10.17993/3ctecno.2019.specialissue3.253-285 


\section{ABSTRACT}

Construction companies' workers are facing higher injury rates as compared to other industries. The principal objective of this research is to investigate occupational health and safety $(\mathrm{OH} \& \mathrm{~S})$ training to be delivered effectively to the workers of the construction companies. The awareness level of employees' about OH\&S and how to facilitate the employees for OH\&S training to consequently have been studied. Both quantitative and qualitative method of study is implied collected by using construction self-administered questionnaire and face-to-face interviews. Statistical tools like frequency distribution and chi-square test has been used. Data obtained then examined by applying SPSS (Statistical Package for the Social Sciences) software. Three hundred respondents participated in the researcher's study to make the research valuable. It has been observed that levels of OH\&S knowledge vary from workers of various construction companies. It has also been investigated that varies how the construction workers been trained in $\mathrm{OH} \& \mathrm{~S}$.

\section{KEYWORDS}

Construction Company, Occupational health and safety (OH\&S), Construction workers, Survey, Pakistan. 


\section{INTRODUCTION}

Construction companies are treated as the backbone of any organization, playing a vigorous role in the economies of the country. This zone addresses immense people, and it deals with a varied range of audiences in terms of the workplace. The construction companies are like business access for the varietal change of people because governmental institutions, as well as private organizations, are stakeholders of these types of businesses and the boundaries of these companies are so broad that they ultimately get some difficulties along too. Construction industries are one of the most hazardous and risky among all industries (Imriyas, Pheng, \& Teo, 2007). Right at the beginning of these are concerns about OH\&S. Many analyses have confirmed that accidental occupational injuries and work-related diseases are under-compensated (Liao \& Chiang, 2015). According to them the workers must be educated in the OH\&S related concerns and on these issues several rules should be developed. Occupational coincidences not only scar employees' life and, loss the employers' human capital, but also increase the social cost of the country (Sámanoríos et al., 2019).

The majority of the workers in Pakistan are uneducated and not trained in the OH\&S. Moreover, $\mathrm{OH} \& \mathrm{~S}$ does not include in any curricula in Pakistan. The number of qualified workers in OH\&S is far less associated with the total labor force in Pakistan. It means that $\mathrm{OH} \& \mathrm{~S}$ training programs are not well-known in the country (Pasha, Liesivuori \& Finland, 2003). The arrival of the new Labor Policy 2002 (First after 1972), it was hoped that Pakistan would focus on the dignity of labor. The change in the existing labor legislation (as proposed in Labor Policy 2002) will help to solve the long-awaited questions. There is a great need for companies to surge the status of the OH\&S in Pakistan to compete in the international market and to encounter the developing tasks of globalization.

According to International Labour Organization (ILO) it was evaluated that at least 60,000 serious accidents happen annually on construction companies throughout the world (Cheng, Leu, Cheng, Wu, \& Lin, 2012) representing, one serious accident each and every 10 minutes and ILO also estimated that the total 
cost of work-related illness and injury are $4 \%$ of the gross national product of a given country (Shin, Oh, \& Yi, 2011)countries vary greatly with respect to how they organize workers' compensation systems. In this paper, we focus on three aspects of workers' compensation insurance in Organization for Economic Cooperation and Development (OECD . The construction companies are the most hazardous in the world because of fast industrialization and economic development. Inside the construction companies, the risk of a significant injury is 2.5 times higher, while the risk of fatality is five times higher than in manufacturing. There is a large number of unacceptable risks to all workers who are working in the variable nature of working conditions like dealing with construction projects, including workers, project managers, engineers, and so on (Zalk et al., 201 1; Bust, Gibb and Pink, 2008). Inside the construction companies, occupational injuries and fatalities have been related with important financial costs too. Estimated that such kind of hazardous injuries cost above 10 billion USD annually (Riaño-Casallas \& Tompa, 2018).

For approximating the cost of injuries and accidents, the worker's compensation is a vital origin (Friend \& Kohn, n.d.; Huang \& Hinze, 2006). It has been evaluated that the worker's compensation data from the United States were four times higher in direct the workers' compensation costs (medical treatment and indemnity) as compared to another company on average in construction companies (Marcum, Foley, Adams, \& Bonauto, 2018). In the construction companies, the fatal accident rate tends to be higher than that of other companies (Sørensen, Hasle, \& Bach, 2007). To reduce the ruins of occupational accidents, most of the countries have proposed laws for the prevention of occupational accidents and work-related injuries at the workplace. Predictably, these types of different means may have significant implications for system performance, including the employers and workers incentives to improve workplace safety and hence impact the actual occurrence rate of occupational injuries and diseases (Jain, Leka, \& Zwetsloot, 2018). Furthermore, Principles of $\mathrm{OH} \& \mathrm{~S}$ training of workers and ordinance provided that complete data about training has been issued. 
In the past few years, due to the focus on quality, time, cost, and the OH\&S issues are progressively being highlighted as a pointer for construction companies' success. For improving the construction sites providing the training to the workers as well as CCTV cameras would be helpful to recognize the approaching safety hazards in a sector (Seo, Han, Lee, \& Kim, 2015). Thibaut, Chi, Zhou, and Piramuthu, 2018 has recommended the wireless communication technology to overview the health and safety management related issues. In short, the mentioned experience intimates the desire or need to increase the training efficiency of workers who are working in construction companies. The specific training programs of workers improve the health and safety training of construction workers. These types of applications should be mainly concerned with accurate elucidations, unusually real time responsibilities. Training should be assembled on the model construction of the situation, approaches with reciprocal teaching methods, imaging techniques, containing databases and cataloged of frequently used solutions for the OH\&S.

The OH\&S has been measured as a main issue in the construction industry, especially in South Asian countries (Mohamed, Ali, \& Tam, 2009) where, OH\&S issues are significant anxiety because of the lack of Safety Acts (Zaid, Jaaron, \& Talib Bon, 2018). The lack of legislative regulations to keep construction workers, low standards in governance and corporate systems, high labor concentrated character and insufficient structure are other significant influences that combine to work in contradiction of safe conditions in south Asian countries, especially in Pakistan. Pakistan, a developing country, is presently facing a definite progress in construction activities. For this cause, the construction industry in Pakistan seriously funds to the gross domestic product and works about $8 \%$ of the total labor force (Zaid et al., 2018). Unfortunately, current general OH\&S rules do not directly apply to the industry. The lack of such a set of OH\&S rules poorly disturbs the implementation of a safe environment, thus resultant in more susceptible situations on the worker's performance. Current site examination facilities are not satisfactory enough to know or assess occupational injuries at the workplace. Accidents and injuries recording and reporting systems are dysfunctional. Both labors and administrators are not too 
worried about OH\&S since they are not educated about the statistics of injuries regarding different conditions.

\section{LITERATURE REVIEW}

During the last decades, there has been a growing awareness about OH\&S risk issues, and by administrative supervision in the construction industries. Moreover, despite the considerable developments succeeded, the rate of injuries is still significantly advanced than in other sectors (Sousa, Almeida, \& Dias, 2015). In the construction industry, the $\mathrm{OH} \& \mathrm{~S}$ has been measured as a significant issue, with construction actuality, one of the most hazardous industries. It is mainly so in south Asian countries (Coble \& Haupt, 1999; Ofori, 2000) where, the OH\&S is a central unease because of the lack of health and safety regarding Acts (Larcher \& Sohail, 1999). So many countries can play the leading role in the OH\&S training programs of the employees because OH\&S hazards are the universal content even though cultural differences. Therefore, the education-concentrated system, the working condition of the companies in various countries, the worker's profiles should be taken into notice. When talking about research studies related to OH\&S training in Pakistan, only few studies found in literature. Construction workers' approach to health and safety is subjective to awareness of safety at the workplace, guidelines and risk management issues regarding safety and health. South Asian counters are now facing a resilient development in its construction sides. Unluckily, the implementation of safety rules in Pakistan is not well-known. Definitely, some applicable principles are both outmoded and inappropriate to daily construction activities (Mohamed, Ali, \& Tam, 2009) Within a certain period of time, labor productivity is simply defined as the amount of work done by craft workers Kazaz and Acrkara (2015),Mahamid (2013) and Arditi and Mochtar (2000).

According to Jarullah, Abed, Ahmed, and Mujtaba (2019) both employers and employees lacked educational training of $\mathrm{OH} \& \mathrm{~S}$ rules/regulations, and no practices of this nature are passed at these construction operations. So, whenever work-related accidents happen, there are not given outstanding responsiveness and no official 
accident-report system. In the construction industries lack of OH\&S trainings occurs at an incredible human cost. Physical factors make joints and bonds less flexible and many lead young people to handle equipment more awkwardly, or their smaller size may place them at a higher risk of injury while handling operating instrument machines.

\subsection{CONSTRUCTION INDUSTRY IN PAKISTAN}

Health and Safety can be defined as the "ailment of being safe as of injury or damage, and consequently, live in a safe state. It is energetic that every participant/ worker/operative member of the civic is in a secure form, for both physical and mental well-being. Secure systems of labor tolerate compact opportunity of any worker, tools or organization being hurt or injured, and therefore decreasing the menaces of a worker losing incomes collected with improved construction budgets and intervals to a development. Hazardous work comprehends conditions such as individual abandon about messy work areas and non-reporting of possible health and safety issues. It is easy for contractors to change labors who are not performing well at a satisfactory level because of high unemployment rates. That's why employees commonly take risks which incline to raise the level of fatalities and accidents at the workplace. Employees will lean to hazardous accidents at the workplace because of their negligence and accept that working in construction sides is a hazardous occupation. Usually, regulations/ rules to defend employees are not severely imposed, and workers are not profoundly involved with economic advantage payments to incapacitated labors (Health, Safety \& Environment Aspects in Civil works, 2013).

These following general rules should be observed at the construction area like;

1) Only approved/authorized workers must check-in and checkout and they should report to site manager/security guard/supervisor

2) Under special conditions, visitors may visit and stay with authorized protectors during the project visit, and the escort must be familiar with the project site ultimately. 
3) All persons, including workers as well as visitors, must wear a hard cap, and the escort should make an availability of hard cape on construction sites.

4) All the workers should wear leader shoes while in the construction area.

5) Keep a safe distance from the construction site unless permitted by an authorized person.

6) Do not walk under the suspended material.

7) Obey all the signs and warnings marked as "no smoking" "warning" etc.

8) Waste dumping in the construction area is rigorously verboten.

9) Earplug must be worn while working on machinery.

10) Watch your every step and be aware of possible hazards.

11) All the time remain under the instruction of the emergency team supervisor at the time of an accident.

The construction sector has the highest injury accident rates in the workplace as compared to other industries result in extra avoidable labor-costs (Raheem \& Issa, 2016). All of these costs could be qualified to accepted complications of construction companies and the casual working environment at the workplace (Khan, Ali, De Felice, \& Petrillo, 2019)Occupational Health and Safety (OHS. This has through health and safety a significant subject for the construction operation, especially for south Asian countries because such countries are relatively meager at emerging and employing safety rules/regulations (Awwad, El Souki, \& Jabbour, 2016). Besides management, other issues such as low standards, inadequate infrastructure, and the labor force are the significant reasons of safety issues in these countries (Weissbrodt \& Giauque, 2017) and all of these issues mentioned above make the construction company one of the most dangerous companies (Mazlina Zaira \& Hadikusumo, 2017)the importance of safety intervention for changing unsafe to safe worker behaviour is known. For this reason, an integrated safety intervention model affecting workers' safety behaviour was developed and tested. This study was conducted by distributing a questionnaire 
survey to construction companies. The survey was randomly distributed, with a total of 198 responses received. Exploratory factor analysis (EFA.

Singh (1979) stated in their research that in the meanness of technical developments, construction side in south Asian countries, including Pakistan, sincerely trusts upon labor-intensive and conventional techniques of construction work. Such practices then give increase to $\mathrm{OH} \& \mathrm{~S}$ issues related to construction industry experts, end operators and the appropriate location is susceptible. South Asian countries' utmost need to investigate the situation, 'health and safety in Pakistan Construction Company' has acknowledged very less consideration from the academe and industrial researchers as well.

According to Hussain et al. (2013), working project executives at construction companies in Pakistan study the labor productivity of construction workers. Mohd Kamar, Lop, Mat Salleh, Mamter and Suhaimi (2014) have found out the awareness of the health and safety of construction workers. Injuries and accident rates in construction industries add to distract living values and manufacture financial and commercial difficulties for employees (By, Mushtaq, \& Khalid, 2015). Injuries are the leading cause of the global burden of disability and death for all working-age groups (WHO, 2012). As reported by the Australian industrial Commission (AIC), for every $\$ 1$ of the direct cost of injury estimates, $\$ 3$ to $\$ 5$ of indirect damages is also incurred (Bi et al., 2015). Globally Pakistan was ranked the 9th populated country in 2017, with the total labor force of 54.9 million (Government of Pakistan, 2018). Every year, an occupational injury/ incidences, 41 workers out of 1000 received an injury in the construction companies of Pakistan (Wu, Luo, Wang, Wang, \& Sapkota, 2018).

\subsection{OBJECT OF THE STUDY}

The main object of this research is to investigate the worker's awareness about in construction sites in Pakistan, to determine the way of training to be given, to analyze the reasons that caused occupational injury, possible injury rate by socio-economic, regional variables and find out OH\&S hazards. With similar companies' climate. These findings can potentially applicable with other developing countries or can be 
considered as prior research. The percent study aim is to understand the significance of $\mathrm{OH} \& \mathrm{~S}$ training to the construction workers in Pakistan construction industries. The present study will explore the effect of Socio-demographic characteristics of the workers who are working in Pakistan construction companies.

\section{METHODOLOGY}

Both quantitative and qualitative techniques were employed. The questionnaire tool as the quantitative method was used to determine the workers' profile and their knowledge OH\&S about containing 21 questions. The researcher studied previous literature and developed the questionnaire keenly. The survey was shown to experts and got their advice for the content of the review and its validity. Pilot testing was conducted to remove the possible faults in the survey so that organized and systematic results can be drawn efficiently. For this purpose, 28 workers were chosen to work on various construction sites. After testing the study, unnoticed spelling mistakes were removed, and some statements were made clear that were difficult to understand.

It is insured workers listed under the construction industry have been selected to determine the target population. A total of 284 respondents was selected with 5\% error margin and a $95 \%$ confidence level by utilizing the equilibrium provided in the following equation (Sanders, 1990).

$$
n=\frac{z 2 \mathcal{N} p q}{\mathcal{N} D 2+z 2 p q}
$$

In this survey, 300 participants have an essential role, and all of 300 reviews were analyzed by using statistical tools as the questionnaires were a little more than sampling numbers. This study is carried out 35 various big projects in Sindh especially, Karachi and Sukkar, as cities are considering the economic hub in Pakistan, especially in Sindh province. The respondents working on construction sites filled the questionnaire. The interviews were also organized at the workplace from November to December 2018. 
The obtained data of the worker's demographic knowledge, their level of education, and their concepts regarding OH\&S were analyzed by applying the SPSS. To find the frequency distribution of the data descriptive statistical tool was employed. For this purpose, pie charts and frequency tables have been used to unfolding the frequency distribution. To get comprehensive evidence of the data, the researcher analyzed the frequency and its distribution across the data. As well as chi-square test and cross-tabulations were also used to find out the relationship between the variables. The significant correlation between the variables is calculated by the chi-square test. The data were analyzed by the regulation/rule implemented in Pakistan. That's why, Dock Labourers Act 1934, Factories Act 1934, Mines Act 1923 is used to compare the action and obtained data.

\section{RESULTS AND DISCUSSIONS}

\subsection{FREQUENCY ANALYSIS}

The frequency analysis and distribution tools were used to obtain comprehensive evidence of the participating worker's data acquired from the survey. For that purpose, the answers related to sample study were obtained as frequency distributions and pie charts.

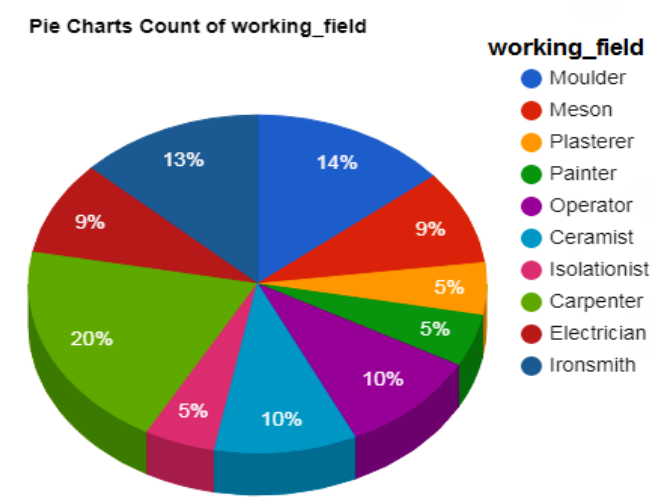

Figure 1. Division of workers' according to their work performed in the construction industry. 
Figure 1 described the worker's participation in the construction companies are distributed according to the base of their working field, respectively, the two fields acquired the highest percentage, the carpenter with $20.0 \%$, molder with $14.0 \%$ and ironsmith with $13.0 \%$. The field of study with a minimum percentage is a plasterer, painter and isolationist with $5.0 \%$ and the electrician with $9.0 \%$. It was observed that the high percentage of the workers were to be working in the comfortable zone.

Figure 3 illustrated the working period of workers in the workplace. Based on data, $12.0 \%$ of employees have less than a year working experience, $35.0 \% 1-10$ years, $29.7 \% 11-20$ years, $18.0 \%$ 21-30 years and $5.3 \%$ work for more than 30 years.

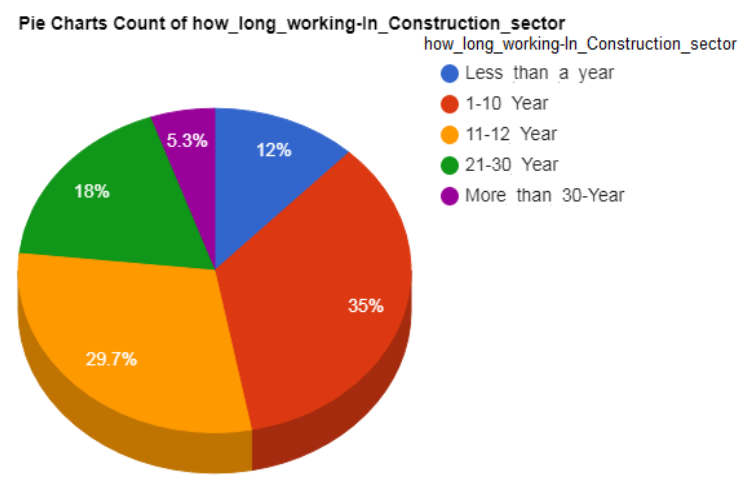

Figure 3. Illustrated working period of workers in the workplace.

Table 2 shown weekly and daily working hours in the form of a cross-tabulation. The Mines Act, 1923 (Section 22-B, C), Factories Act, 1934 (Section-34), 1969 (Section 8), Road Transport Ordinance, 1961(Section-4) and Shops Establishment Ordinance are used to define working hours and break time at different workplaces. Section 34 of the Factories Act described the weekly and daily working hours as follows; from the broad opinion, maximum 48 hours per week is enough. Regular working hours per week with the agreements of the parties is 56 hours, but if the work is seasonal 50 hours per week working time. According to the law no labor is allowed to work more than 9 hours per day (in case of the season; 10 hours). According to table 2, the majority of the labor involved more than 48 hour's limitations of the Factories Act. 
Table 2. Weekly and daily working schedule of employees.

\begin{tabular}{|c|c|c|c|c|c|c|c|c|}
\hline Days & \multicolumn{6}{|c|}{ The average number of hours/per day } \\
\hline per week & $\mathbf{6} \mathbf{h}$ & $\mathbf{7} \mathbf{h}$ & $\mathbf{8} \mathbf{h}$ & $\mathbf{9} \mathbf{h}$ & $\mathbf{1 0} \mathbf{h}$ & $\mathbf{1 1} \mathbf{h}$ & $\mathbf{1 2} \mathbf{~ h}$ \\
\hline $\mathbf{5}$ days & 0 & 0 & 16 & 0 & 0 & 0 & 0 \\
\hline $\mathbf{6}$ days & 11 & 48 & 65 & 32 & 16 & 15 & 0 \\
\hline $\mathbf{7 d a y s}$ & 0 & 0 & 17 & 49 & 15 & 0 & 16 \\
\hline
\end{tabular}

Figure 5 illustrates the job satisfaction level of the staff involved in the survey. As shown in, $10.7 \%$ are unsatisfied with their professions, $21.3 \%$ are neutral, and $68.0 \%$ of the employees are satisfied with their works.

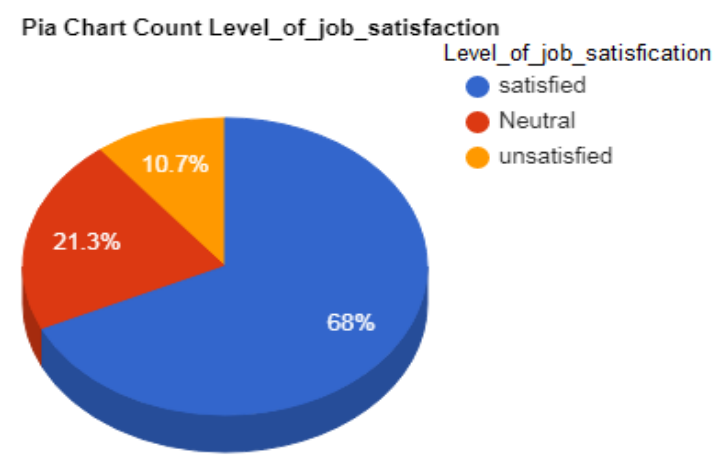

Figure 5 Distribution of workers according to their job satisfaction level.

Figure 6 calculation shows the data of construction workers that they have work experience to another company before joining the construction side. Accordingly, $37.0 \%$ of the workers have knowledge working in a different business sector while the $63.0 \%$ majority of the worker did not have working experience before working in the construction company. Few of the companies have programmed as fishing, beekeeping, the barbers, shoemaking, municipal workers, picking tea leaves, shepherding, café house/tea shop management, and warehouse workforces, etc. 


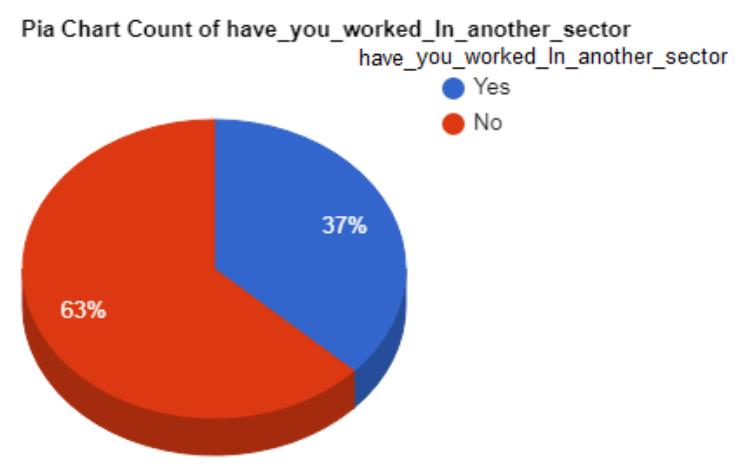

Figure 6. Dispersal of the workers have works experience of different sectors before joining the construction side.

Figure 7 illustrates whether construction workers read books that are involved in the survey. As shown in the results, it observed that $66.0 \%$ of the construction staff not habitual of reading books, although 34.0\% used to. It has been examining that 102 workers are readers, $43.3 \%$ read religious books, $17.7 \%$ read historic books, 33.0\% read stories, and $6.0 \%$ read all categories of books. Also; this frequency distribution shows that the majority of workers who are working in construction companies are uneducated; that way, they are not interested in reading books.

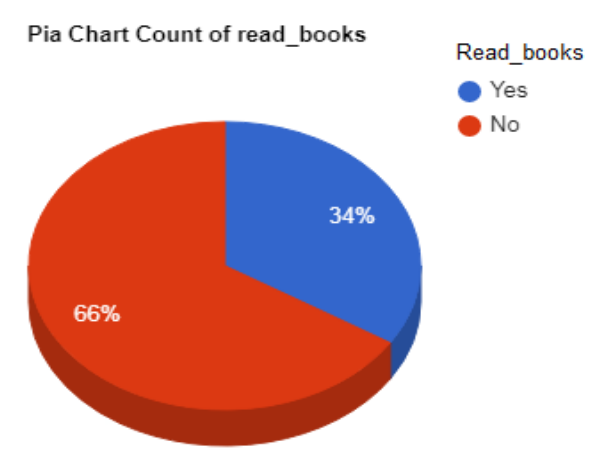

Figure 7. Distribution of workers according to whether they involve in reading books. 


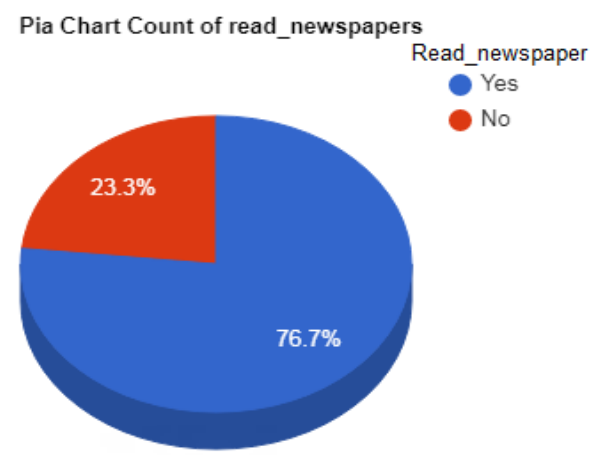

Figure 8. Disruption of construction workers about reading newspapers.

Figure 8 distribution shown that the construction workers read the newspaper or not. As obtained data described that $76.7 \%$ of the staff habitual of reading the newspaper, while $23.3 \%$ of some staff do not like to read the newspaper. It has been declared that the majority of the respondents regular reading the newspaper, $21.3 \%$ read headlines, $22.7 \%$ read all the parts of the newspaper, $6.0 \%$ read magazine portion, $12.0 \%$ read columns, and $38.0 \%$ read the sports news.

Figure 9 described that whether the construction workers watch television. Accordingly, it has been seen that $84.3 \%$ of construction workers like to watch TV, while $15.7 \%$ of construction workers do not like it. It has been declared that the majority of the workers watching TV, 11.7\% watch spiritual, $10.7 \%$ movies, $33.0 \%$ all kind of program, and $33.0 \%$ watch news and $11.6 \%$ watch comedy program.

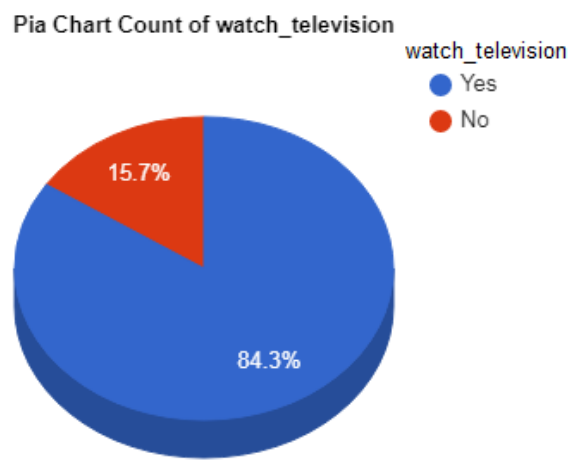

Figure 9. Description of construction workers about watching television. 
Figure 10 shown the data about construction workers who are part of the survey whether they use the internet or not. Accordingly, it has been analyses that $21.7 \%$ of the construction workers use the internet, whereas $78.3 \%$ do not use it. It is also observed that $6.0 \%$ of staff use the internet for shopping purposes, $11.7 \%$ for religious work, $16.0 \%$ use for the current fair, $11.3 \%$ for the sake of research, $20.7 \%$ for watching movies, playing games and $34.3 \%$ use the internet for Facebook, twitter, Instagram.

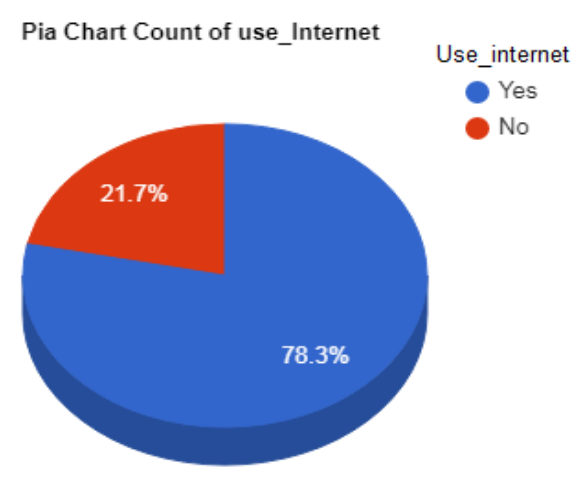

Figure 10. Construction workers according to their use of the internet.

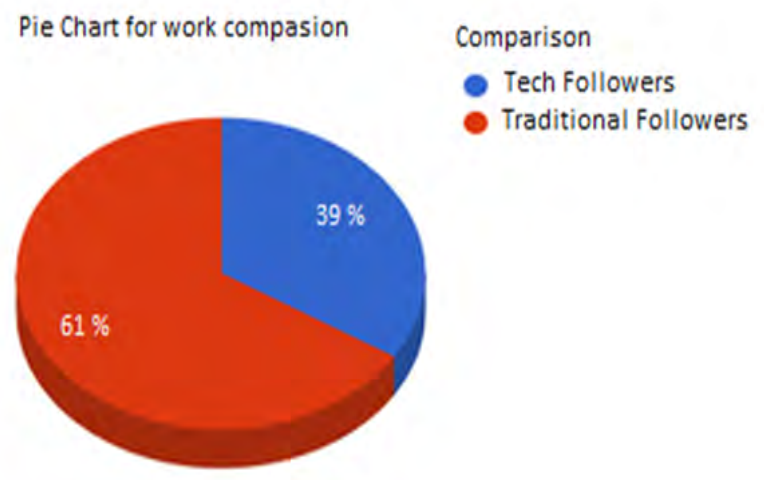

Figure 11. Distribution of workers according to their work method.

Figure 11 described construction workers whether they follow the industrial changes related to the innovations at the construction site (materials, construction tools, and so on). Accordingly, $39.0 \%$ seek the progresses related to the improvements at the 
construction site; perhaps $61.0 \%$ construction workers do not follow the innovations developments. Consequently, 117 workers that fallow the innovations developments, $11.7 \%$ follow the current events over magazines, $10.7 \%$ from goods export construction firms, $44.0 \%$ from the internet, 11.7 from the engineer coworkers and $22.0 \%$ from the construction firms.

Dissemination of the construction workers have knowledgeable any work-related coincidence has been shown in Figure 12. According to this, it has been observed that $16.7 \%$ of the workers suffering from occupational accidents while $83.3 \%$ other workers had never been experienced. 49.3\% experienced work-related accidents once, $22.7 \%$ experienced occupational accidents twice, $10.7 \%$ experienced the occupational accident three times, 5.7\% experienced occupational accidents four times, and $11.6 \%$ experienced occupational accidents five times.

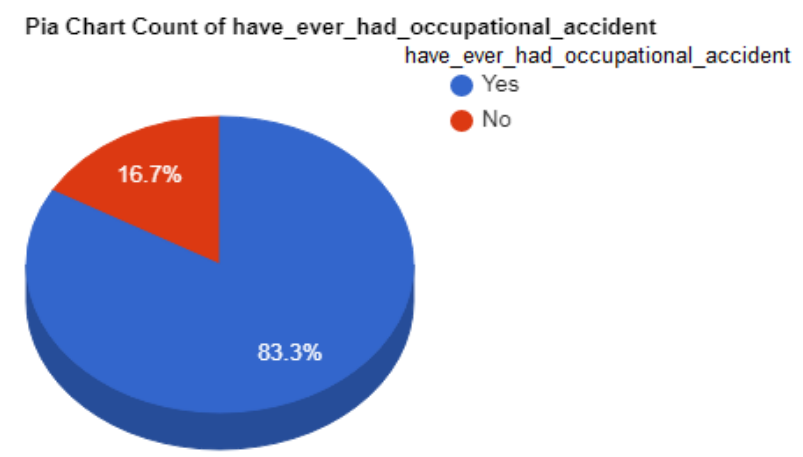

Figure 12. Distribution of whether workers have had occupational accidents.

Dissemination of the work related to OH\&S for the construction workers at the initial stages. As respects the Work-related OH\&S, following law exists in Pakistan: Factories Act 1934. The OH\&S laws in Pakistan generally cover the official zone construction companies. The Factories Act, 1934, the main law covering OH\&S supplies is appropriate to industrial initiatives paying 10 or more labors. Additionally, the Mines Act of 1932 covers the mining zones. Another region is either not enclosed under the $\mathrm{OH} \& \mathrm{~S}$ or the attention is very inadequate, while in Provincial Factories Rules (Sindh Factories Rule 1975) prepared the rules and regulation to the employment law which is practically related to each other. They provide detailed 
rules for the company's inspections, employer certification, and employer's training, working hours, notification and investigation of $\mathrm{OH} \& \mathrm{~S}$ exposures, coincidences, and salaried holidays and so on. In this for the OH\&S training of construction workers, there is the following expression; "the employer must provide the OH\&S training for the construction workers. Practically trained the workers, before starting work, when the job workplace changes, in case of new technology implementation or work equipment changes. Hence, it has been analyzed that $67.0 \%$ of the construction workers receive training on $\mathrm{OH} \& \mathrm{~S}$, whereas $33.0 \%$ did not. The percentage of untrained construction workers and those who have not yet been trained in OH\&S is notable. All 201 trained construction workers listed that they were trained by OH\&S experts.

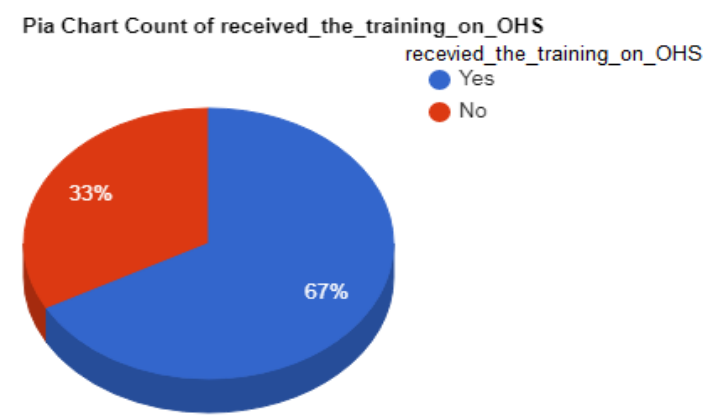

Figure 13. Construction workers training on $\mathrm{OH} \& \mathrm{~S}$.

Figure 14 has been shown the most recent training on the OH\&S. When the most recent training on $\mathrm{OH} \& \mathrm{~S}$ are examined, results described that 201 trainers, 32.7\% received training on the $\mathrm{OH} \& \mathrm{~S}$ in less than one month, $21.3 \%$ in $1-2$ months, $17.7 \%$ in $3-4$ months, $10.7 \%$ in $4-5$ months, $11.7 \%$ in $5-6$ months and $6.0 \%$ since one year. In Factories Act 1934 and Dock Labourers Act 1934 by-law of workers about the Principles and Processes of OH\&S Training, the following expression for this; "the training on OH\&S should be given to the employees working in very hazardous construction companies by the employer at least once a year." According to the survey research, it is observed that $6.0 \%$ of the construction workers were trained on OH\&S more than 14 months and it is analyzed that regulation is not practiced according to the specific schedule. 


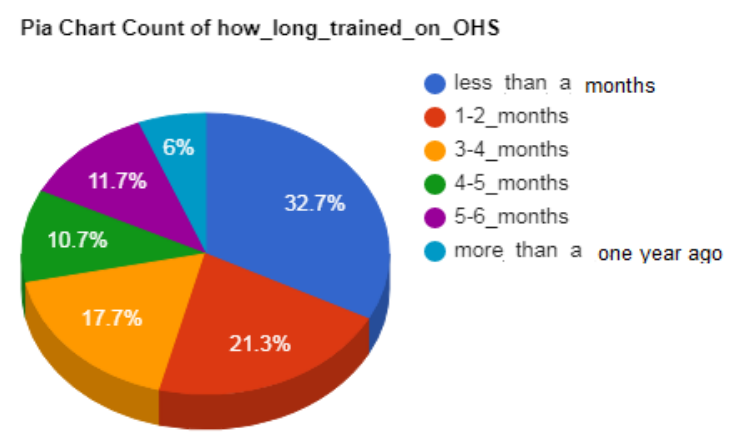

Figure 14. Distribution of workers according to most recent training on $\mathrm{OH} \& \mathrm{~S}$ they receive.

Figure 15 has been shown how the construction workers received the OH\&S related training have assessed the latest training. According to the survey obtained data, of the 201 trainers of OH\&S training, 16.7\% assessed the training as very good, 38.8\% assessed the training is good, $27.3 \%$ assessed the training is intermediate, $12.0 \%$ assessed the training is poor and $6.0 \%$ assessed the training is very poor.

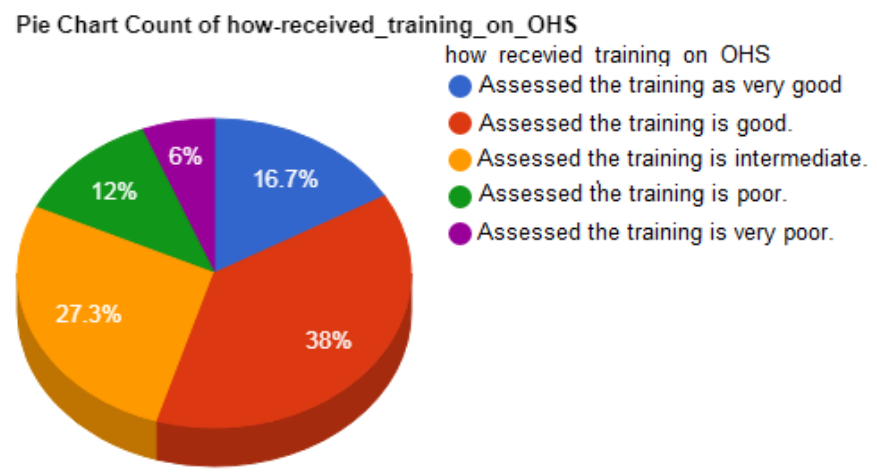

Figure 15. Illustrated the trainer assessment against the $\mathrm{OH} \& S$ related training.

Dissemination of whether the workers' idea about how the most recent training on OH\&S training should has been shown in Figure 16. According to the survey obtained data, $66.7 \%$ of the workers request to receive OH\&S training practically, $10.7 \%$ OH\&S training should be audio base and 22.7\% OH\&S training should be pictorial. Workers statements about the ideas of training content that, while surveys were being done are as follows; "must be taught the occupational hazards types and 
causes of these", "post-accident pictures of those who have a work accident should be exhibited", "must be given the regular and continuous training to the workers on the occupational health and safety", "the training on the occupational health and safety should be explained by shooting short film".

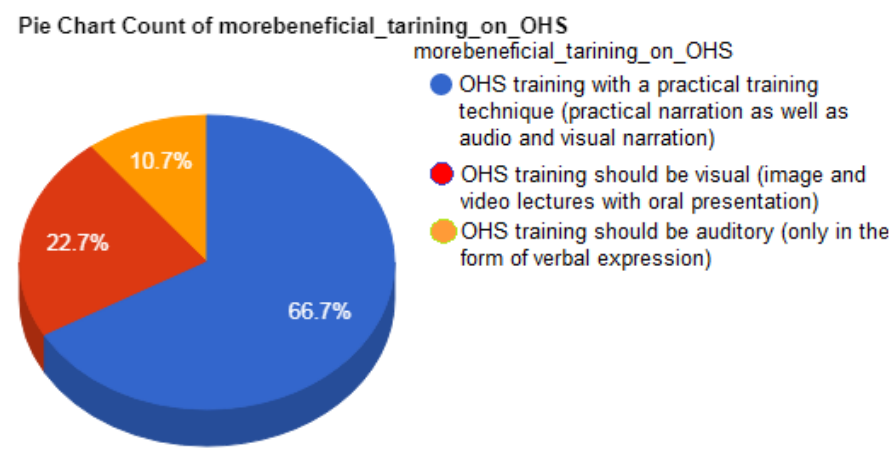

Figure 16. Construction workers' ideas about how OH\&S training.

Distribution of whether the consciousness of employees' tasks for the OH\&S has been shown in Figure 17. According to the survey obtained data, 16.7\% of the workers demanded to be aware of their responsibilities for the OH\&S, while $33.3 \%$ have chosen somewhat aware, and 50.0\% unaware possibilities. Of the 196 participants demanding to have a moral and reasonable level of information, $10.0 \%$ stated they learned their responsibilities from their friends, $45.2 \%$ learned their responsibilities from their $\mathrm{OH} \& \mathrm{~S}$ training, $16.6 \%$ learned their responsibilities from the internet, and $28.2 \%$ learned their responsibilities from their experiences.

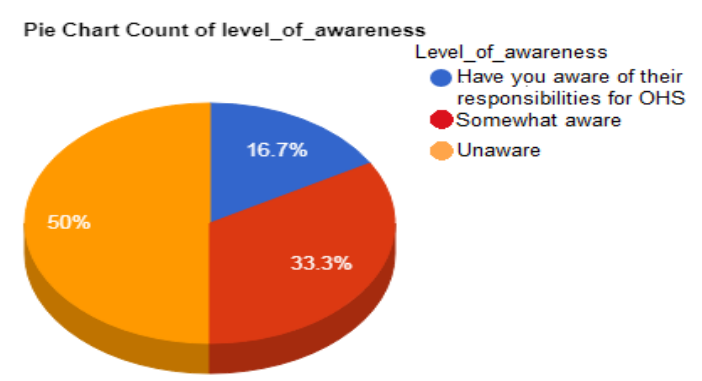

Figure 17. Level of consciousness of construction workers' responsibilities for $\mathrm{OH} \& \mathrm{~S}$. 
To define the connection between the binary variables from the survey, resultant the data Chi-square and Cross-tabulations were used and the important association between two variables is resolute. The obtained data given below that cannot be useful to the Chi-square tests are deduced only in the form of cross tables, while the appropriate chi-square data is presumed by execution Chi-square tests and cross tabulation.

Table 4 shows the association between the construction worker's age group and their satisfaction level. The Chi-square test results with respect to the age group of staff and the level of work gratification have not exposed an important relation $\left(p=0.313^{>0.05}\right)$. It has been analyzing that most of the workers in age groups are dissatisfied with job. The worker's ages go from 30-34 to the age group of over 50 are those who are un-satisfied. While the age group of 18-24 to 25-29, are those who are satisfied with their work. Nevertheless, the quantity of staff who are contented with their jobs, decreases related to the earlier group.

Table 4. The association between the age groups of the construction workers and their satisfaction level.

\begin{tabular}{|c|c|c|c|}
\hline & \multicolumn{3}{|c|}{ Satisfaction level } \\
\hline $\mathbf{A g e}$ & Satisfied & Neutral & Dissatisfied \\
\hline $\mathbf{1 8 - 2 4}$ & 66.250 & 18.750 & 15.000 \\
\hline $\mathbf{2 5 - 2 9}$ & 60.000 & 18.824 & 21.176 \\
\hline $\mathbf{3 0 - 3 4}$ & 58.974 & 30.769 & 10.256 \\
\hline $\mathbf{3 5 - 3 9}$ & 70.000 & 25.000 & 5.000 \\
\hline $\mathbf{4 0 - 4 4}$ & 66.667 & 33.333 & 0.000 \\
\hline $\mathbf{4 5 - 4 9}$ & 63.636 & 9.091 & 27.273 \\
\hline Over 50 & 58.824 & 23.529 & 17.647 \\
\hline Total & $\mathbf{2 0 4}$ & $\mathbf{6 4}$ & $\mathbf{3 2}$ \\
\hline
\end{tabular}

The relation between the construction worker's awareness level and the age group about OH\&S responsibility has shown in Table 6. The Chi-square test results in age groups of workers and the awareness level about OH\&S responsibility have not comprised a substantial relation $(\mathrm{p}=0.622>0.05)$. 
Table 6. Level of responsibilities for OH\&S?

\begin{tabular}{|c|c|c|c|}
\hline Age group & Below average & Average & Above average \\
\hline $\mathbf{1 8 - 2 4}$ & 54.000 & 32.000 & 14.000 \\
\hline $\mathbf{2 5 - 2 9}$ & 41.333 & 36.000 & 22.667 \\
\hline $\mathbf{3 0 - 3 4}$ & 56.410 & 30.769 & 12.821 \\
\hline $\mathbf{3 5 - 3 9}$ & 47.500 & 37.500 & 15.000 \\
\hline $\mathbf{4 0 - 4 4}$ & 66.667 & 16.667 & 16.667 \\
\hline $\mathbf{4 5 - 4 9}$ & 27.273 & 45.455 & 27.273 \\
\hline Over 50 & 52.941 & 35.294 & 11.765 \\
\hline Total & $\mathbf{1 5 0}$ & $\mathbf{1 0 0}$ & $\mathbf{5 0}$ \\
\hline
\end{tabular}

Table 7 has shown the relation between adoptions and the construction worker's age groups. The Chi-square test outcomes to the age group of workers and their approvals of following the technological development/innovations (materials, construction machinery, civil technology etc.) have not comprised a substantial relation $(\mathrm{p}=0.152$ $>0.05)$.

Table 7. The relation between adoptions and construction worker's age group.

\begin{tabular}{|c|c|c|}
\hline Age group & Yes & No \\
\hline $\mathbf{1 8 - 2 4}$ & 38.000 & 62.000 \\
\hline $\mathbf{2 5 - 2 9}$ & 33.333 & 66.667 \\
\hline $\mathbf{3 0 - 3 4}$ & 41.026 & 58.974 \\
\hline $\mathbf{3 5 - 3 9}$ & 50.000 & 50.000 \\
\hline $\mathbf{4 0 - 4 4}$ & 55.556 & 44.444 \\
\hline $\mathbf{4 5 - 4 9}$ & 9.091 & 90.909 \\
\hline Over 50 & 41.176 & 58.824 \\
\hline Total & $\mathbf{1 1 7}$ & $\mathbf{1 8 3}$ \\
\hline
\end{tabular}

Table 8 has shown the relationship between construction workers age groups and their books reading habit. The Chi-square test results with respect to construction workers age groups and their, books reading habit has not comprised a substantial relation $\left(\mathrm{p}=0.817^{>} 0.05\right)$. 
Table 8. The relation between the construction workers age groups and their books reading habit.

\begin{tabular}{|c|c|c|}
\hline & \multicolumn{2}{|c|}{ Books reading? } \\
\hline Age group & Yes & No \\
\hline $\mathbf{1 8 - 2 4}$ & 35.000 & 65.000 \\
\hline $\mathbf{2 5 - 2 9}$ & 38.667 & 61.333 \\
\hline $\mathbf{3 0 - 3 4}$ & 35.897 & 64.103 \\
\hline $\mathbf{3 5 - 3 9}$ & 27.500 & 72.500 \\
\hline $\mathbf{4 0 - 4 4}$ & 22.222 & 77.778 \\
\hline $\mathbf{4 5 - 4 9}$ & 27.273 & 72.727 \\
\hline Over 50 & 35.294 & 64.706 \\
\hline Total & $\mathbf{1 0 2}$ & 198 \\
\hline
\end{tabular}

Table 9 has shown the relation between construction workers age groups and their newspapers reading habit. The Chi-square test results with respect to the construction workers age groups and their newspapers reading habit has not comprised a substantial relation $\left(\mathrm{p}=0.767^{>} 0.05\right)$.

Table 9. The relationship of construction workers between age groups and their newspapers reading habit.

\begin{tabular}{|c|c|c|}
\hline & \multicolumn{2}{|c|}{ Newspapers reading? } \\
\hline Age group & Yes & No \\
\hline $\mathbf{1 8 - 2 4}$ & 78.000 & 22.000 \\
\hline $\mathbf{2 5 - 2 9}$ & 70.667 & 29.333 \\
\hline $\mathbf{3 0 - 3 4}$ & 79.487 & 20.513 \\
\hline $\mathbf{3 5 - 3 9}$ & 77.500 & 22.500 \\
\hline $\mathbf{4 0 - 4 4}$ & 88.889 & 11.111 \\
\hline $\mathbf{4 5 - 4 9}$ & 81.818 & 18.182 \\
\hline Over 50 & 70.588 & 29.412 \\
\hline Total & $\mathbf{2 3 0}$ & $\mathbf{7 0}$ \\
\hline
\end{tabular}

Table 10 has shown the relation between the educational ability of the workers and their books reading habit. The Chi-square test results with respect to the construction workers level of education and their, books reading habit has not comprised a substantial relation $\left(p=0.384^{>} 0.05\right)$. 
Table 10. The relation between the educational ability of the workers and their books reading habit.

\begin{tabular}{|c|c|c|}
\hline & \multicolumn{2}{|c|}{ Books reading? } \\
\hline Level of Education & Yes & No \\
\hline Grad 5 & 35.878 & 64.122 \\
\hline Grad 8 & 34.211 & 65.789 \\
\hline Grad 10 & 38.889 & 61.111 \\
\hline Diploma & 23.810 & 76.190 \\
\hline Bachelor's Degree & 16.667 & 83.333 \\
\hline Total & 102 & 198 \\
\hline
\end{tabular}

Table 14 has shown the relation between the educational ability of the workers and work-related accident rate. The Chi-square test results with respect to the level of education and work-related accident rate have not comprised a substantial relation $(\mathrm{p}$ $\left.=0.940^{>} 0.05\right)$. Moreover, according to the percentage given in the tables, the highest rate of having a work-related accident belongs to the Grad 5 school graduate with 24 , while the lowest rate is those with a bachelor's degree with 2.

Table 14. The relation between the educational ability of the workers and occupational accident rate of the workers.

\begin{tabular}{|c|c|c|}
\hline Level of Education & Have you ever had an occupational accident? \\
\hline Grad 5 & Yes & No \\
\hline Grad 8 & 18.321 & 81.679 \\
\hline Grad 10 & 15.789 & 84.211 \\
\hline Diploma & 16.667 & 83.333 \\
\hline Bachelor's Degree & 14.286 & 85.714 \\
\hline Total & 11.111 & 88.889 \\
\hline
\end{tabular}

Table 15 has shown the relation between the status of work-related accidents and the awareness level of responsibilities for the OH\&S. The Chi-square test results with respect to the level of awareness of workers duties for the OH\&S and the status of work-related accidents has comprised a substantial relation. $\left(p=0.001^{<} 0.05\right)$. 
Table 15. The relation between the awareness level of workers responsibilities for work-related health and safety.

\begin{tabular}{|c|c|c|}
\hline $\begin{array}{c}\text { The level } \\
\text { responsibilities for } \\
\text { OH\&S? }\end{array}$ & \multicolumn{2}{|c|}{ Have you ever had occupational accidents? } \\
\hline Above average & Yes & No \\
\hline Average & 0.000 & 100.000 \\
\hline Below average & 15.000 & 85.000 \\
\hline Total & 23.333 & 76.667 \\
\hline
\end{tabular}

Table 16 has shown the relation between the awareness ability of the workers and their working hours in the construction sector about OH\&S responsibilities. The Chi-square test results with respect to the awareness ability of the workers and their working hours in the construction sector about OH\&S responsibilities has not comprised a substantial relation. $\left(\mathrm{p}=0.887^{>} 0.05\right)$.

Table 16. The relation between the construction workers awareness level about OH\&S responsibilities and their working duration in the construction sector.

\begin{tabular}{|c|c|c|c|}
\hline & \multicolumn{3}{|c|}{ Level of responsibilities for OH\&S? } \\
\hline Duration & Above average & Average & Below average \\
\hline Less than a year & 8.333 & 38.889 & 52.778 \\
\hline $\mathbf{1 - 1 0}$ years & 16.190 & 30.476 & 53.333 \\
\hline $\mathbf{1 1 - 2 0}$ years & 20.225 & 32.584 & 47.191 \\
\hline $\mathbf{2 1 - 3 0}$ years & 16.667 & 37.037 & 46.296 \\
\hline Over 30 years & 18.750 & 31.250 & 50.000 \\
\hline Total & 50 & 100 & 150 \\
\hline
\end{tabular}

\section{DISCUSSIONS}

The comparison of the data found in a survey according to the Law in Pakistan. The current OH\&S training programs for the construction companies are not appropriately practices in Pakistan. Most of the recent research addressed only on safety issues irrespective of present health risks in the construction companies (Yiu, Sze, \& Chan, 2018). 
It was analyzed that $20.0 \%$ of the employees in the construction industry are not entitled to the relevant skilled certificate. The Technical Education Commission focus and National Vocational to grow work-related, skills values, programs, and employment testing certificate system for all sectors in which technical education and vocational training are conveyed. These trainings facilitate the professional education and vocational training to meet national and international demand for skilled workforce (Arthur-Mensah \& Alagaraja, 2018). Workers do not possess the relevant qualified certificate would not be able to work in the construction industry. Additionally, the workers do not have the proficiency certificate will not allow attaining any training and comprehensive particulars of his work.

Conferring to the survey information, $32.3 \%$ of the personnel were labor seven days. A large proportion of workers indicated that they work without any taking a day off and they absent from their duty only for specific reasons like sickness, heavy rain or to attend the funeral of close relatives. Hence, they are deprived of their rights provided by the Factories Act, 1934 (Section-34). Also, most of the workers (81\%) have been observed to work more than the maximum 56 hours limitations in the Shops and Establishments Ordinance 1969 and Mines Act 1923. The employee's health is affected, they are seen tedious, tired, an unmotivated, by the result of the workload and irregular sleep schedule. As an outcome of this circumstance emotional disturbances such as the inability to concentrate, training disparate attitudes that may happen through work become a threat to OH\&S of the employees.

According to the survey obtained data, it is perceived that $61.0 \%$ of the employees intricate the research are not attentive to bring the industrial development/ innovations related to the construction industry, $66.0 \%$ cannot read books; similarly $23.3 \%$ are not usually read newspapers, and $78.3 \%$ do not browse the internet. The factors above directed that training must be given to the employees under the Dock Labourers, Factories Act 1934. Those workers are essential for the industries which have habits of reading books or newspapers and take research into sympathy.

Furthermore, $84.3 \%$ of the employees engaged in the research survey that they watch television. It is examined that use the TV would be playing a significant role 
in determining the importance of $\mathrm{OH} \& \mathrm{~S}$ issues. Additionally, public opinion can be raised by fixing the advertisement billboard on "Public Spot".

$16.7 \%$ of the workers are reported to have occupational accidents, while $83.3 \%$ are not. It has been noted that among the primary school graduates with $43.7 \%$, the proportion of crashes amongst workers is considerably high.

$33.0 \%$ of the employees concerned with the survey quantified that they have not received training on OH\&S. Partially the employers have not satisfied their responsibilities to deliver workers training, stated in Provincial Factories Rules.

It is examined that $35.0 \%$ of the employees were accomplished the OH\&S training past year, which shows that they get an education of OH\&S at least once a year, so the directive on actions and codes of $\mathrm{OH} \& \mathrm{~S}$ training programs, has been desecrated.

The study has also been observed the rate of internet usage among different age groups and found inverse proportional between them. Likewise, the reading rate of the employees increases as the education level of the employee's increases. On the other hand, it has been examined that the price of internet use increases as the education level of the employees increases too.

Irrespectively the level of education of the employees and their age distribution, the overwhelming immense number of workers desire effective OH\&S training practices. Hence, according to the age and educational background of the workers, this demand did not differ.

According to the survey obtained data, $38.44 \%$ of the construction workers related to the study stated that they are under conscious of their duties connected to the OH\&S. According to the National Action Plan for Health Promotion in Pakistan; the worker's training program can be measured as a leading practice by which the present state of the construction company concerning the OH\&S standpoint, the construction companies can be categorized as precarious companies. Therefore, it is essential to approve a regular monitoring program to develop its condition in terms of OH\&S considerations. There must be workers are to be educated about the 
features of the OH\&S. The data of this survey clarified that OH\&S scheme had not been implemented according to its standard as per law.

\section{CONCLUSION AND SUGGESTION}

Ensure that for doing OH\&S education training that is compulsory to employees bestowing to Control and Health Promotion, the National Action Plan for Prevention in Pakistan, more pacifists; it is compulsory to have exact workers profile information who will receive $\mathrm{OH} \& \mathrm{~S}$ training. In this research, one-to-one interviews and questionnaires were directed with employees to find out the general opinion of workers and their general views on OH\&S in Pakistan. To find out the result for frequency analysis, cross-tabulation and Chi-square tests have been applied.

- According to Control and Health Promotion, the National Action Plan for Prevention in Pakistan, the planned significant change in OH\&S has not been wholly recognized in Pakistan.

- The worker's training which is the utmost essential foundation of info on $\mathrm{OH} \& \mathrm{~S}$ has not been accompanied efficiently and appropriately.

The data obtained from this research are beneficial following the recommendations are assumed to make the OH\&S training more accurate and useful. Whereas the worker's experience, education level, and their ages are quite diverse, it's compulsory when a group of workers was trained, and the education level is being formed must be these factors under consideration.

\section{REFERENCES}

Akhter, M. N., \& Deputy, R. (2011). A Comparative Study on Vocational Training Structure of Pakistan with British and German Model. International Journal of Business and Social Science, 2(1), 162-169. 
Arditi, D., \& Mochtar, K. (2000). Trends in productivity improvement in the US construction industry. Construction Management and Economics, 18(1), 15-27. doi: https://doi.org/10.1080/014461900370915

Arthur-Mensah, N., \& Alagaraja, M. (2018). Examining training and skills development of youth and young adults in the Ghanaian context: an HRD perspective. Human Resource Development International, 21(5), 493-508. doi: https:// doi.org/10.1080/13678868.2018.1468587

Awwad, R., El Souki, O., \& Jabbour, M. (2016). Construction safety practices and challenges in a Middle Eastern developing country. Safety Science, 83, 1-11. doi: https://doi.org/10.1016/J.SSCI.2015.10.016

By, P., Mushtaq, F., \& Khalid, M. (2015). Occupational Injuries in Pakistan: Incidences and Economic Impac, 72. Retrieved from: http://www.pide.org.pk/ pdf/HealthEconomics/Thesis_Faisal.pdf

Gheng, G.-W., Leu, S.-S., Gheng, Y.-M., Wu, T.-G., \& Lin, G.-G. (2012). Applying data mining techniques to explore factors contributing to occupational injuries in Taiwan's construction industry. Accident Analysis \& Prevention, 48, 214222. doi: https://doi.org/10.1016/J.AAP.2011.04.014

Friend, M. A., \& Kohn, J. P. (n.d.). Fundamentals of occupational safety and health.

Huang, X., \& Hinze, J. (2006). Owner's Role in Construction Safety: Guidance Model. Fournal of Construction Engineering and Management, 132(2), 174-181. doi: https://doi.org/10.1061/(ASCE)0733-9364(2006)132:2(174)

Hussain, J., Shabbir, F., Shamim, M. A., Naeem, U., Ejaz, N., Naeem, U. A., ... Farooq, Q. U. (2013). Assessment of most critical success factors for mega construction projects in Pakistan Carcinogenicity of pesticides in humans View project Effect of Addition of Nanomaterials on Engineering Properties of Asphalt Binder View project Assessment of most critical success factors for mega construction projects in Pakistan. Life Science Fournal, 10. Retrieved from: http:// www.lifesciencesite.comhttp//www.lifesciencesite.com.41 
Imriyas, K., Pheng, L. S., \& Teo, E. A. (2007). A framework for computing workers' compensation insurance premiums in construction. Construction Management and Economics, 25(6), 563-584. doi: https://doi.org/10.1080/01446190601110116

Jain, A., Leka, S., \& Zwetsloot, G. I. J. M. (2018). The Economic, Business and Value Case for Health, Safety and Well-Being, 67-98. Springer, Dordrecht. doi: https://doi. org/10.1007/978-94-024-1261-1_3

Jarullah, A. T., Abed, F.M., Ahmed, A.M., \& Mujtaba,I. M. (2019). Optimisation of several industrial and recently developed AJAM naphtha isomerization processes using model based techniques. Computers $\mathbb{E}$ Chemical Engineering, 126, 403-420. doi: https://doi.org/10.1016/J.COMPCHEMENG.2019.04.018

Kazaz, A., \& Acıkara, T. (2015). Comparison of Labor Productivity Perspectives of Project Managers and Craft Workers in Turkish Construction Industry. Procedia ComputerScience, 64,491-496. doi: https://doi.org/10.1016/J.PROCS.2015.08.548

Khan, M. W., Ali, Y., De Felice, F., \& Petrillo, A. (2019). Occupational health and safety in construction industry in Pakistan using modified-SIRA method. Safety Science, 118, 109-118. doi: https://doi.org/10.1016/J.SSCI.2019.05.001

Mahamid, I. (2013). Contractors perspective toward factors affecting labor productivity in building construction. Engineering, Construction and Architectural Management, 20(5), 446-460. doi: https://doi.org/10.1108/ECAM-08-2011-0074

Marcum, J. L., Foley, M., Adams, D., \& Bonauto, D. (2018). Characteristics of construction firms at risk for future workers' compensation claims using administrative data systems, Washington State. Fournal of Safety Research, 65, 5358. doi: https://doi.org/10.1016/J.JSR.2018.02.005

Mazlina Zaira, M., \& Hadikusumo, B. H. W. (2017). Structural equation model of integrated safety intervention practices affecting the safety behaviour of workers in the construction industry. Safety Science, 98, 124-135. doi: https://doi. org/10.1016/J.SSCI.2017.06.007 
Mohamed, S., Ali, T. H., \& Tam, W. Y. V. (2009). National culture and safe work behaviour of construction workers in Pakistan. Safety Science, 47(1), 29-35. doi: https://doi.org/10.1016/J.SSCI.2008.01.003

Mohd Kamar, I. F., Lop, N. S., Mat Salleh, N., Mamter, S., \& Suhaimi, H. A. (2014). Contractor's Awareness on Occupational Safety and Health (OSH) Management Systems in Construction Industry. E3S Web of Conferences, 3, 01019. doi: https://doi.org/10.1051/e3sconf/20140301019

Raheem, A. A., \& Issa, R. R. A. (2016). Safety implementation framework for Pakistani construction industry. Safety Science, 82, 301-314. doi: https://doi. org/10.1016/J.SSCI.2015.09.019

Riaño-Casallas, M. I., \& Tompa, E. (2018). Cost-benefit analysis of investment in occupational health and safety in Colombian companies. American fournal of Industrial Medicine, 61(11), 893-900. doi: https://doi.org/10.1002/ajim.22911

Sámano-ríos, M. L., Ijaz, S., Ruotsalainen, J., Breslin, F. G., Gummesson, K., \& Verbeek,J. (2019). Occupational safety and health interventions to protect young workers from hazardous work-A scoping review. Safety Science, 113, 389403. doi: https://doi.org/10.1016/j.ssci.2018.11.024

Seo, J., Han, S., Lee, S., \& Kim, H. (2015). Computer vision techniques for construction safety and health monitoring. Advanced Engineering Informatics, 29(2), 239-251. doi: https://doi.org/10.1016/J.AEI.2015.02.001

Shin, I., Oh, J.-B., \& Yi, K. H. (2011). Workers' Compensation Insurance and Occupational Injuries. Safety and Health at Work, 2(2), 148-157. doi: https://doi. org/10.5491/SHAW.2011.2.2.148

Singh, A. (1979). The 'Basic Needs' approach to development vs the new international economic order: The significance of Third World industrialization. World Development, 7(6), 585-606. doi: https://doi.org/10.1016/0305-750X(79)90095-0

Sørensen, O. H., Hasle, P., \& Bach, E. (2007). Working in small enterprises-Is there a special risk? Safety Science, 45(10), 1044-1059. doi: https://doi.org/10.1016/J. SSCI.2006.09.005 
Weissbrodt, R., \& Giauque, D. (2017). Labour inspections and the prevention of psychosocial risks at work: A realist synthesis. Safety Science, 100, 110-124. doi: https://doi.org/10.1016/J.SSCI.2017.02.012

Wu, G., Luo, X., Wang, T., Wang, Y., \& Sapkota, B. (2018). Safety challenges and improvement strategies of ethnic minority construction workers: a case study in Hong Kong. International Fournal of Occupational Safety and Ergonomics, 1-11. doi: https://doi.org/10.1080/10803548.2018.1466508

Yiu, N. S. N., Sze, N. N., \& Ghan, D. W. M. (2018). Implementation of safety management systems in Hong Kong construction industry-A safety practitioner's perspective. Fournal of Safety Research, 64, 1-9. doi: https://doi.org/10.1016/J. JSR.2017.12.011

Zaid, A. A., Jaaron, A. A. M., \& Talib Bon, A. (2018). The impact of green human resource management and green supply chain management practices on sustainable performance: An empirical study. Fournal of Cleaner Production, 204, 965-979. doi: https://doi.org/10.1016/JJCLEPRO.2018.09.062 
Edición Especial Special Issue Noviembre 2019

DOI: http://dx.doi.org/10.17993/3ctecno.2019.specialissue3.253-285 


$$
\text { /16/ }
$$




\section{AIRLINE DIGITAL CLICK STREAM EVENT PROCESSING FOR ENRICHING THE AIRLINE BUSINESS}

Md. Alauddin

Faculty of Computing and Informatics, Multimedia University, Cyberjaya, Selangor, Malaysia.

Ting Choo Yee

Faculty of Computing and Informatics, Multimedia University, Cyberjaya, Selangor, Malaysia.

Ian Tan Kim Teck

Faculty of Computing and Informatics, Multimedia University, Cyberjaya, Selangor, Malaysia. E-mail: alauddinm@gmail.com

Recepción: 02/08/2019 Aceptación: 24/09/2019 Publicación: 06/11/2019

\section{Citación sugerida:}

Alauddin, M., Choo Yee, T. y Kim Teck, I. T. (2019). Airline digital click stream event processing for enriching the airline business. 3C Tecnología. Glosas de innovación aplicadas a la pyme. Edición Especial, Noviembre 2019, 287-305. doi: http://dx.doi. org/10.17993/3ctecno.2019.specialissue3.287-305

\section{Suggested citation:}

Alauddin, M., Choo Yee, T. \& Kim Teck, I. T. (2019). Airline digital click stream event processing for enriching the airline business. 3C Tecnología. Glosas de innovación aplicadas a la pyme. Speciaal Issue, November 2019, 287-305. doi: http://dx.doi. org/10.17993/3ctecno.2019.specialissue3.287-305 


\section{ABSTRACT}

The new era of digital world with the rapid expansion of social network and mobile applications created wider scope to expand airline industry for new way of promoting their business. Due to several social media and other digital platforms, we need to emphasize on target marketing/customer profiling. Hence, to do target marketing, a new web technology is created to collect each of the raw events of their web data and mobile app data for tracking the way user is searching flights. In the proposed method BigQuery is used to process huge volume of online customers' data. The proposed method is to understand the airline ecommerce online visitors effectively by analysing the event data stream collected from various digital properties. The obtained raw digital data consists of lot information with a semi-structured and it needs to be cleansed before analysing it. So, the first stage of proposed system is to extract the data from various digital sources in real-time, then chose which data is appropriate for analysing and finally extract the key insights to improve the airline business. From the extracted variables, search patterns, the predictive models such as flight search forecast, seat sales forecast and digital channel attribution models can be developed.

\section{KEYWORDS}

Click stream processing, Big Query, Digital data processing, digital marketing, Data Cleansing and Enrichment. 


\section{INTRODUCTION}

In recent years, most of the Asian airlines prime focus is on digital transformation (O’Connell \& Williams, 2005). The prime objectives of digital transformation are to understand the online customer acquisition, digital channel attribution, online customer segmentation, and their search trend. These are the most important techniques to take right business action at right time to increase revenue. Most of the airline industries have their own online and mobile based ecommerce platform, it is possible to track and record their activities on the webpage as from which webpage they have entered, when and what they search, where they drop off, what they purchase, how frequently they book etc., (Klein \& Loebbecke, 2000). These visitor data can be for customer analytics like online customer profile, sales funnel to understand at which point visitors drop off, are they price sensitive or not.

However, tracking and processing visitors' raw events from the website logs data is complicated because of the large volume of hit level data (One of the major Asian airlines has about 15 million of online visitors per month, which generates roughly 3-5 billion events of unstructured or semi-structured web tracking data) (Ananthi, 2014). In this paper, the online digital click stream dataset is obtained from one of the major Asian Airline system with 50 destinations. Each route is tracked with one way and return flights for 30 days to 120 days. This paper mainly focus more on the real-time digital data collection and pre-processing of the dataset for flight sales prediction. The overall objective of the proposed work is that, the key variables are selected from the extracted digital click stream data is to improve the airline business.

\section{LITERATURE REVIEW}

The growth of Internet around the world made airline business to change their way of attracting the passengers (Singh \& Jain, 2014). Also this digital era made to buy tickets from anywhere in the globe at any time by comparing the different airlines. So it is becoming very difficult to predict the ticket prices and attracting the passengers becoming difficult with the influence of many factors (Gillen \& Lall, 2004). However, data science showed a way to progress in this type of scenarios to study the patterns 
and predict the behavior of the sales outcome. For example, it can be identifying the correlation between seat prices of particular airlines and air traffic delays. As per recent surveys of (Forbes, 2008), it is noticed that for every minute of flight delay it will affect the ticket prices about $\$ 1$.5. Low cost airlines offer ticket pricing without the baggage, food and beverages, which gives privileges to afford all common people (Groves \& Gini, 2013). Hofer, Windle and Dresner (2008) explained more details of the how low cost airlines are differ from the other airlines. Lazarev (2013) described in detailed how fare variations can be influenced in various time periods. Lazarev designed very good model to predict optimum prices for low cost airlines to generate almost $90 \%$ of the profit margin. In general, all the customers always think if earlier booking flight fares might be less prices.

Based on the various studies on the airline business, the most important aspects to buy tickets online in advance according to the user's observation and their risk (Etzioni, Tuchinda, Knoblock \& Yates, 2003). The user who purchases their tickets online should have a sense of control over the task they are performing over the Internet. This helps to reduce the feeling of risk or fear associated with the possibility of: making a mistake when making an airline booking online (that is, psychological risk); not receiving their ticket or the flight not even existing (performance risk) (Brons, Pels, Nijkamp \& Rietveld, 2002). Several research papers described the promotions on ticket prices, gift vouchers, airline points and upgrades, which playing indirectly to attract the customers (Barrett, 2004; Gillen, \& Lall, 2004). The majority of these studies conclude that the incentives employed have a positive effect on airline ticket purchase and repeat purchase and highlight that the effectiveness of the program depends to a large extent on the particular incentive offered (Aviasales, n.d.). The literature regarding the choice of Airlines has made it clear that both the benefits provided by frequent flyer programs and air fares significantly affect user's choices (Groves \& Gini, 2013). Users who travel for business perceive the frequent flyer programs as more useful than other users. These authors even guarantee that business travelers are willing to pay more in exchange for reducing access time, traveling with top-ranked airlines, and traveling in a better class (O'Connell \& Williams, 2005; Sabre, 2015). 


\section{IMPLEMENTATION OF DIGITAL EVENT DATA PROCESSING}

In recent years, most of the people in the world entered towards digital era, which increases the ecommerce transactions in a vast manner compared to the offline. Also the power of digital world made people to reach the world from anywhere any time through either social media, travel blogs or meta search engine. With these available resources, the traveller's can see different travel websites, travel blogs for price comparison before they book their flight tickets. This open lot of opportunity for the airlines to track the travellers search patterns and predict passengers' behaviour using predicting models. Besides, it is also possible to find which online channel is more effective for which airline routes and geo location for predicting the cost per acquisition, which in turn save lot of advertisement costs. Further, the successful tracking of all the digital data also enable the airlines to build sales funnel of digital products, customer life time value calculation and other predictive modelling for digital marketing.

\subsection{DATA COLLECTION}

To collect the online digital data and analyze its patterns, five types of variables are considered for better prediction of seat sales, which are:

- Visitor.

- Flight Search.

- Device.

- Channel.

- Transactions.

The transactional, operational data are extracted using various channels such as web, mobile and tablets in the year 2016. The collection of digital data in real-time is so complicated process, but with the evolution of Java scripts tagging framework, it is possible to track each web page and its components based on visitor status on the internet. The passenger activities such as which page they search, how much time 
they spent on each webpage, how many clicks and scrolls on each page etc. Also, the ecommerce related information such as add to cart, product related information and ecommerce transaction details etc. As the flight sales digital web data is very big and complex, the data collected, cleansed and processed using cloud technology. The implementation of digital analytics will help marketing to monitor the load factor $(\%)$ for future flights and how traveler is choosing origin hub to destination hub and other connecting hubs using fly through (transit). Figure 1 shows the detailed block diagram of the airline data collection from various sources and its predictive model.

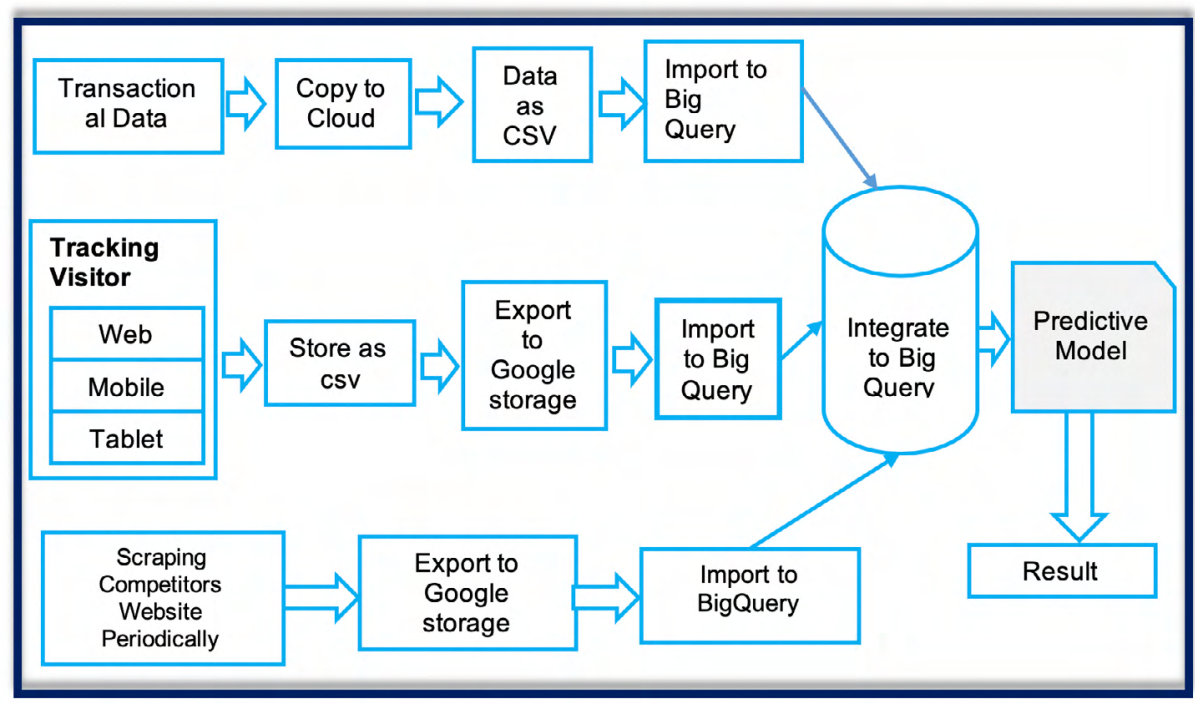

Figure 1. Airline digital data processing architecture.

Airline travel visitors search flight from different devices such as desktop, mobile devices and tablets. Therefore collecting the data from different devices is bit complicated, so it is necessary to consider each digital properties carefully. To collect the digital data (raw data) from various sources, a renowned tracking framework (The java script which is modification of Google tracking framework) is used. After collecting the data and tracking the gathered data, the user activity sends to the server for reporting and further analysis. The system uses different technologies to create data hits according to the types of digital properties. Hence, a new custom code is implemented for tracking web and mobile app users' activity. The proposed custom code also identifies the 
new users and returning users, which provides the more information to fix the seat price dynamically. Finally, the custom code is implemented for capturing the business specific information such as Flight Search Origin, Flight Search Destination, and Departure Date etc. Also, the web server is tracked to receive HTTP request, which gives the details of the airline customers searching patterns. From the webserver log the customers details (such as, computer info, the Location, hostname, the browser type, and language they are browsing etc.,) are extracted.

In the proposed research, BigQuery is used to process high volume of customers' digital data. BigQuery is a RESTful web service that enables interactive analysis of massively large datasets working in conjunction with Google Storage. It is an Infrastructure as a Service (IaaS) that may be used complementarily with Map Reduce. BigQuery is used to process the raw data to further level. After exporting each digital properties as raw tables, which are available in BigQuery as multiple daily tables. BigQuery uses SQL syntax to process the raw data. Figure 2 shows the airline flight search data processing flow. Figure 3 shows the airline online traffic and search data processing flow from all airline digital properties in a daily aggregation. After tracking for capturing the web and mobile digital properties and the listed attributes, the captured data is exported to BigQuery on a periodic basis.

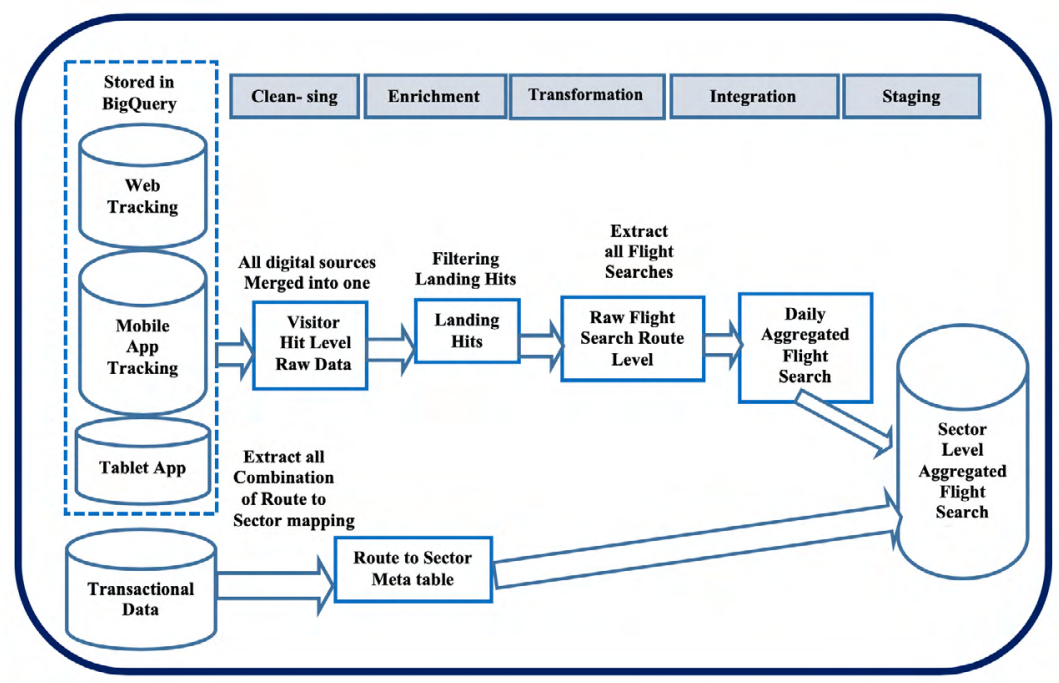

Figure 2. The block diagram of Airline Flight Search data processing flow. 
In general, the open source tracking code retrieves web page data as follows:

- A browser requests a web page that contains the tracking code.

- A JavaScript Array is created and tracking commands are pushed onto the array.

- A $<$ script $>$ element is created and enabled for asynchronous loading (loading in the background).

- The ga.js tracking code is fetched, with the appropriate protocol automatically detected. Once the code is fetched and loaded, the commands on the array are executed and the array is transformed into a tracking object. Subsequent tracking calls are made directly to the server.

- Loads the script element to the DOM.

- After the tracking code collects data, the GIF request is sent to the analytics database for logging and post-processing.

A GIF request can be classified into few types. Table 1 shows various types of GIF request. In each of these cases, the GIF request is identified by type in the utmt parameter. In addition, the type of the request also determines which data is sent to the Analytics servers. For example, transaction and item data are only sent to the Analytics servers when a purchase is made. User, page, and system information is only sent when an event is recorded or when a page loads and the user-defined value is only sent when the _setVar method is called.

Table 1. GIF request types.

\begin{tabular}{|c|c|c|}
\hline $\begin{array}{c}\text { Request Type } \\
\text { Page }\end{array}$ & $\begin{array}{c}\text { Description } \\
\text { A web page on your server is requested }\end{array}$ & $\begin{array}{c}\text { Class } \\
\text { Interaction }\end{array}$ \\
\hline Transaction & $\begin{array}{c}\text { An event is triggered through Event Tracking that } \\
\text { you set up on your site }\end{array}$ & Interaction \\
\hline Item & $\begin{array}{c}\text { A purchase transaction occurred on your site } \\
\text { Each in a transaction is recorded with a GIF } \\
\text { request }\end{array}$ & Interaction \\
\hline Var & A custom user segment is set and triggered by a & Interan \\
\hline
\end{tabular}




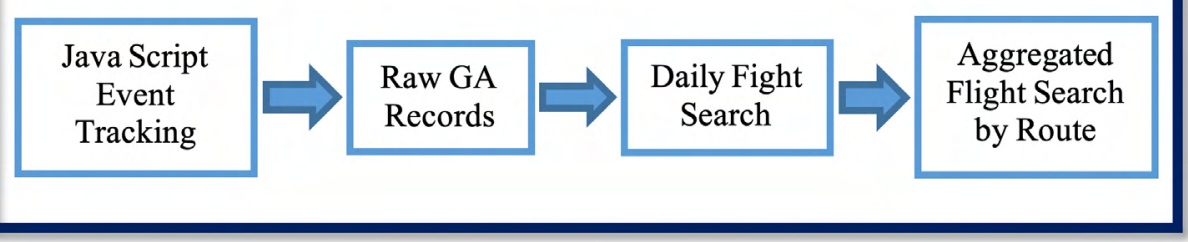

Figure 3. Airline online traffic and search data processing flow.

Raw web tracking data Processing: The volume of one year raw data is about six Terabyte. So, the first step used BQ SQL query to fetch the hits level data from BQ raw daily tables.

Data Cleansing and Enrichment: Raw tracking data have date format issues such as hit_timestmap in one format, the date extracted from page path URL has another format and custom dimension has different format. Therefore, all types of dates are converted in one standard format with same time zone. There are missing values of traffic information, flight search information, geo information, transaction information. To handle the missing values, first a metadata reference table have been created from other available attributes. Then the missing values are enriched using metadata tables. Also, the different digital properties captured with same information but different attributes name. Those need to be merged into one column. Figure 4 shows the BigQuery processing flow to predict the sector levels.

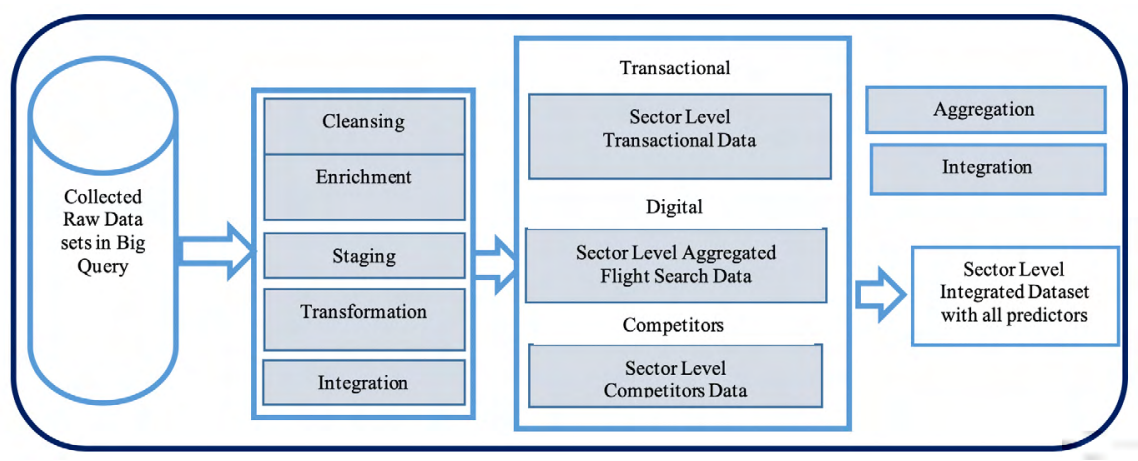

Figure 4. BigQuery processing flow to predict the different sectors data. 
All digital data is stored in google storage which contains all hit level records of the visitor's clickstream. This data has been filtered to get the hits which give user interactions of flight search. The 'hit-type' filter has been set to 'EVENT' or 'PAGE'. This will filter out all interaction hits of flight-search page view or flight-search event action such as click on search button. At the same time, hit-type equals APPVIEW filters all the hits from Mobile and Tablet App (iOS and Android). These filters exclude lots of impression and other irrelevant hits records. It also helps to reduce the data volume that we must process in next stage. After that, the landing hits for the web has been filtered. This provides first hit and search hits only. It also ensures the exclusion of all other activity hits after searches such as passenger details page, add-on page, confirmation page and payment page. After that next challenge is to filter only search hit pages from the web, mobile and tablet a The search page will be identified by page-path mapping for web and screen name for mobile and tablet a However, there are different versions of web application and mobile app release with a website revamp and new version release for a mobile a Thus, the page-path and mobile screen name are not constant. To overcome this limitation all different search identifier, need to be collected for each release over time to create a reference mapping table. This table could be used to identify all search hits from all devices.

Sometimes customer searches non-operational flight route. Thus, all flight search has been examined to verify the searched route by the customer. All non-operational flight route searched by the customer have been filtered to avoid any misleading data for the final training set.

\section{Digital data aggregation}

With the clean, structured and quality data produced after data cleansing, enrichment and transformation, aggregation can now be performed to get desired data set. Algorithm 1 shows the high-level process of aggregating the digital data. 


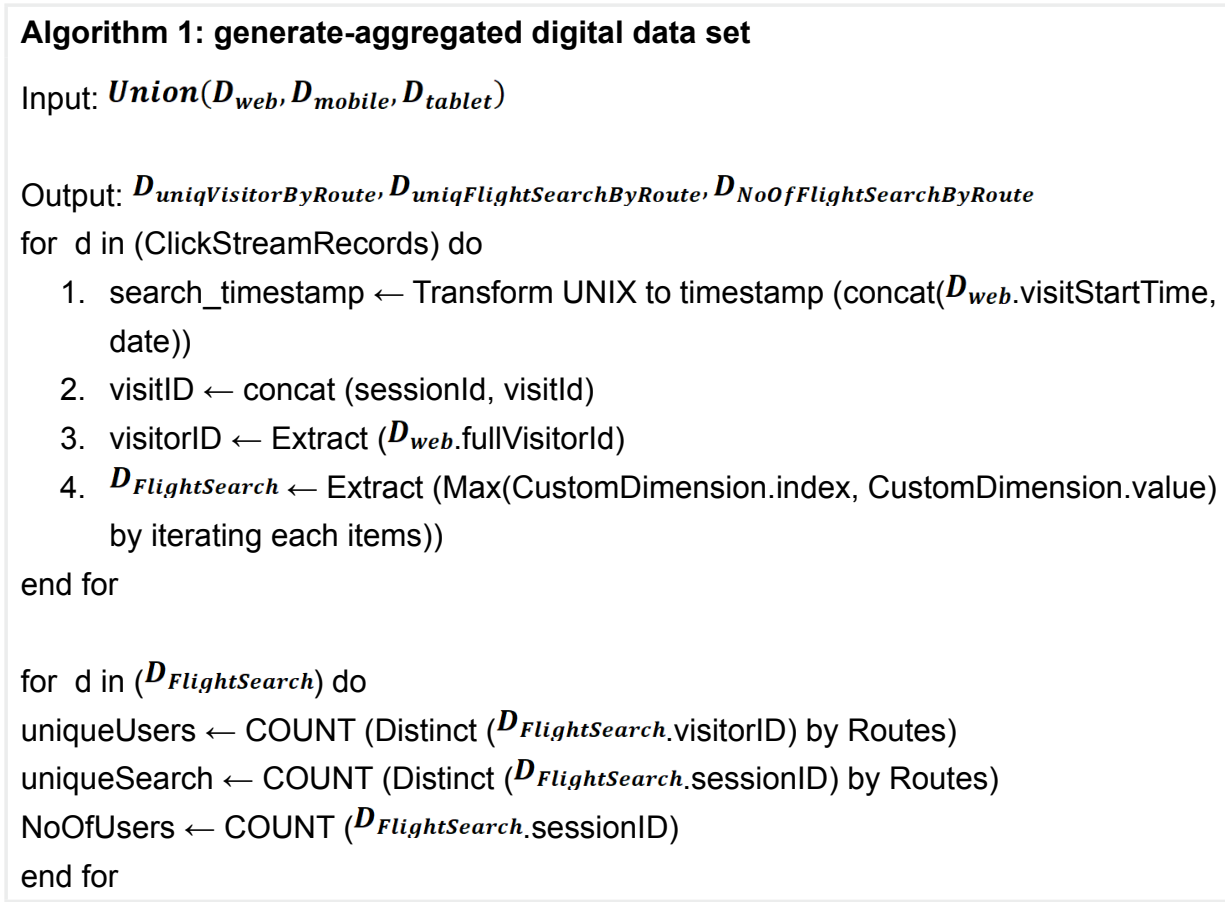

All digital platform (Web/Mobile/Tablet) data has been merged to make a one single data source. Since all the digital data are in the same structure, a UNION operation in BigQuery can merge multiple datasets of the same structure. This merged data table is named as 'clickStreamRecords'. Algorithm 3 takes this data as input. First step of the algorithm is to extract visitId and visitorId of the customer by hourly, daily, weekly and monthly basis and stored as $D_{\text {Flightsearch }}$.

After that, data has been aggregated to get the no. of flight, no. of unique user perform flight search and no. of total search as well as group by each selected route (origin and destination), search date and departure date. Furthermore, searchlead-days have been calculated by subtracting search-date from departure-date. This will compute how many days before the departure, customer searched for the flight. Output of this algorithm has been stored as $D_{\text {uniqVisitorByRoute }} D_{\text {uniqFightSearchyYRoute }}$ and $D_{\text {NoOfFlighSEarchByRoute }}$ Aggregated final dataset sample has been shown in Table 2. 
Table 2. Sample of digital data.

\begin{tabular}{|c|c|}
\hline Attributes name & Examples \\
\hline fullVisitorld & 1527445791 \\
\hline visitld & 1527445791 \\
\hline SearchedOrigin & DXB \\
\hline SearchedDestination & HKT \\
\hline SearchedDepartureDate & $2018-05-21$ \\
\hline SearchReturnDate & $2018-05-28$ \\
\hline unique_search & 6 \\
\hline NumberSearches & 10 \\
\hline
\end{tabular}

\section{RESULTS AND DISCUSSION}

The different datasets extracted from the total roll up are:

Visitor landing dataset with traffic source information: From which traffic source visitors performs the first hit at website and then what they do after landing to the website. Visitors can come from different types of online channel such as Paid Search, Organic Search, Paid Social, Meta Search, Direct etc. And after they renter into same airline webpage, it tracks the search flights as this increase the probability to purchase tickets. However, user might find irrelevant after landing to website hence drop off or visits web check-in, member sign off and other promotional pages.

Visitor Flight Search dataset: Fight Search dataset have multiple critical attributes such as Unique search visitors, Unique Search by Route, No of Total Search by Route, and other attributes

Ecommerce transaction dataset: which gives the money transactions on the seats bookings.

The reports produced from final stage of aggregated dataset is shown in Figure 5. 


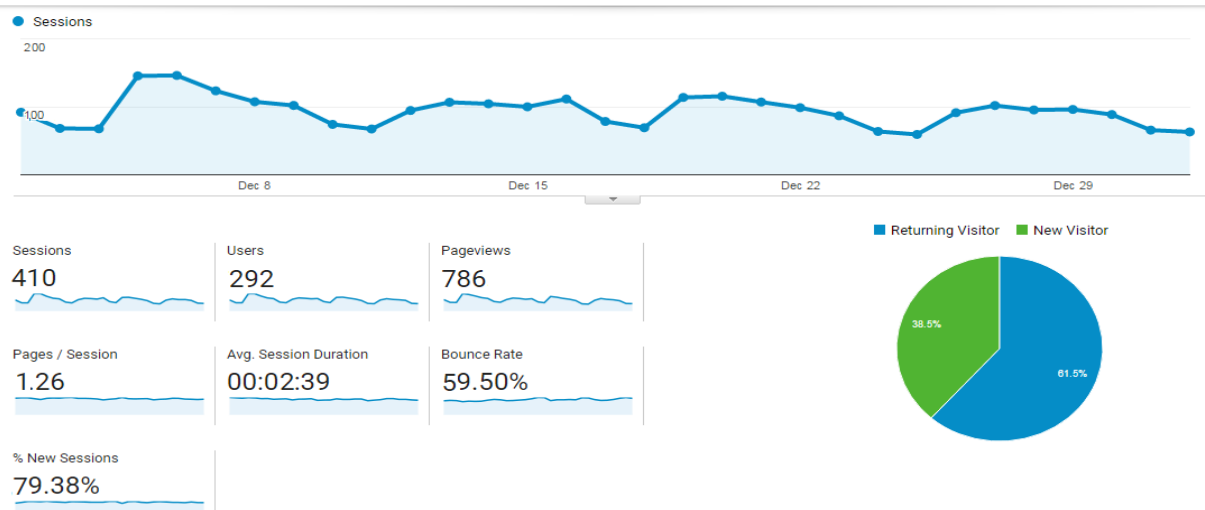

Figure 5. Digital airline Website tracking analysis report.

The digital airline website tracking analysis results shown in Figure 5 gives the summary of how many visitors visits each day and how many users log on to the website second time. Also, it shows how many numbers of sessions are in active, how long the user sessions were active. From these analysis, it is noticed that, based on the users searching patterns flight fares and seats could be decided. Few routes digital variable data have analyzed based on the seats sale using the correlation analysis and identified the best and worst routes, which is shown in Table 2.

Table 3. Correlation analysis results.

\begin{tabular}{|c|c|c|c|}
\hline \multicolumn{2}{|c|}{ Worst Case Route } & \multicolumn{2}{c|}{ Best Case Route } \\
\hline Total seats sold & 1.000 & Total seats sold & 1.000 \\
\hline Total unique visitors & 0.179 & Total unique visitors & 0.576 \\
\hline Total unique search & 0.216 & Total unique search & 0.609 \\
\hline $\begin{array}{c}\text { Total number of } \\
\text { search }\end{array}$ & 0.242 & $\begin{array}{c}\text { Total number of } \\
\text { search }\end{array}$ & 0.572 \\
\hline $\begin{array}{c}\text { Total unique } \\
\text { sessions }\end{array}$ & 0.198 & $\begin{array}{c}\text { Total unique } \\
\text { sessions }\end{array}$ & 0.593 \\
\hline
\end{tabular}


From the Table 3 results, it is observed that, digital variables can be a strong descriptor in some routes for seat sales. This shows the potential value in including these digital variables into the model in addition to the obvious transactional variable and operational variables to get more information. It is clearly noticed that users meta and paid search rates are higher compared to the direct search rates. It is also showed that meta search rate is higher in booking also. From these analysis it is observed that, users meta search is using to book flight seats. From all the digital variable data, transactional data and operational data, the seat sales have predicted, which is shown in Figure 6.

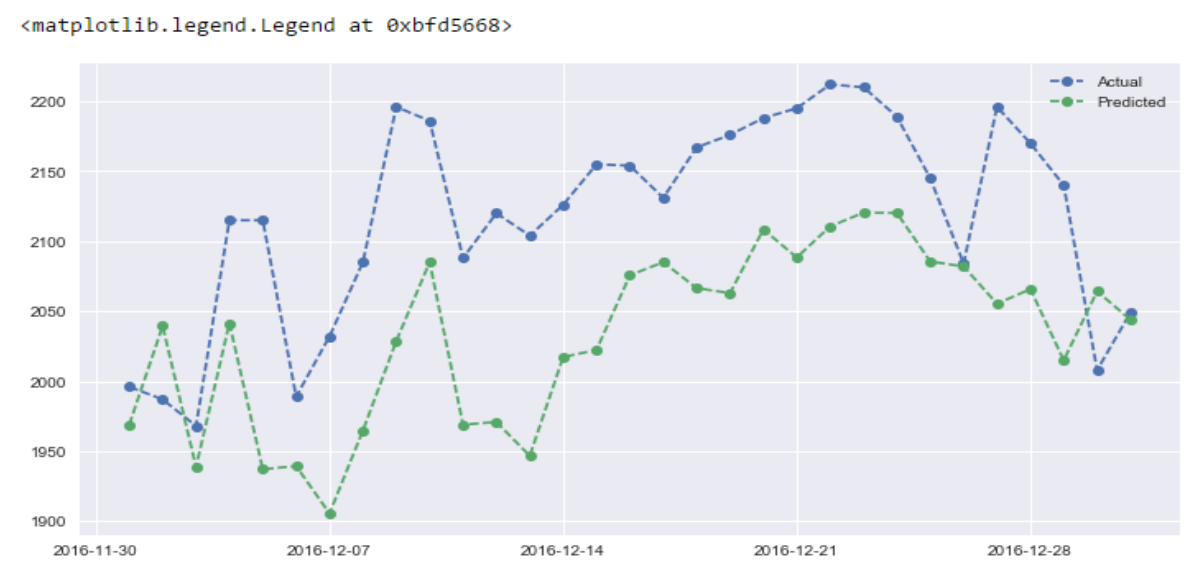

Figure 6. Seat sales forecast from various data variables data.

The forecast results showed in Figure 6 are part of the analysis. From the graph shown in Figure 6 that, the predicted values almost 6.5 to $9 \%$ deviation from the actual values. To predict accurately, hybrid models with ANN and ARIMA models are going to be implemented in further research works.

\section{CONCLUSION AND FUTURE WORK}

In this paper, the main approach used for selecting the important variables in flight sales forecast of each day on the route level. In this, for events tracking and web data tracking Java script is used. From the digital click stream data, the most prominent five selected variables were extracted to find visitors traffic, flight search transactions, 
device data and channel data. These five selected variables data will be used to build models for predictive analytics such as Seat Sales Prediction, Revenue Optimization with Digital and Transaction data, Channel Attribution Model, Customer Life time value, which could bring tremendous business value. The proposed correlation analysis of the extracted variables, the model produced around $7 \%$ and $9 \%$ error rate when forecasting 30 days and 60 days ahead respectively. This paper discussed only the requirements and design constraints of the dynamic models. In our next paper, the dynamic predictive models will be described in detail with the suitable analysis results to predict the seat sales forecast dynamically according to the extracted real time digital data.

\section{REFERENCES}

Singh, A. P., \& Jain, R.G. (2014). A Survey on Different Phases of Web Usage Mining for Anomaly User Behaviour Investigation. International fournal of Emerging Trends $\&$ Technology in Computer Science, 3(3), 70-75. Retrieved from: https://www. ijettcs.org/Volume3Issue3/IJETTCS-2014-06-03-066.pdf

Ananthi, J. (2014). A Survey Web Content Mining Methods and Applications for Information Extraction from Online Shopping Sites. International Fournal of Computer Science and Information Technologies, 5(3), 4091-4094. Retrieved from: https://www. semanticscholar.org/paper/A-Survey-Web-Content-Mining-Methods-and-forfrom-Ananthi/36613a9e89bf3efda507568b54295b92f2f8ad23

Aviasales. (n.d.). Aviasales API. Retrieved August 17, 2015, from: http://www. aviasales.ru/API

Barrett, S. D. (2004). How do the demands for airport services differ between fullservice carriers and low-cost carriers? Journal of Air Transport Management, 10(1), 33-39. Retrieved from: https://www.academia.edu/2422292/How_do_the_ demands_for_airport_services_differ_between_full-service_carriers_and_lowcost_carriers 
Brons, M. R., Pels, E., Nijkamp, P., \& Rietveld, P. (2002). Price elasticities of demand for passenger air travel: a meta-analysis. Journal of Air Transport Management, 8(3), 165-1 75. doi: https://doi.org/10.1016/S0969-6997(01)00050-3

Etzioni, O., Tuchinda, R., Knoblock, G. A., \& Yates, A. (2003). To buy or not to buy: mining airfare data to minimize ticket purchase price. Proceedings of the ninth ACM SIGKDD international conference on Knowledge discovery and data mining, 119-128. Retrieved from: https://www.isi.edu/integration/papers/etzioni03-kdd.pdf

Forbes, S.J. (2008). The effect of air traffic delays on airline prices. International journal of industrial organization, 26(5), 1218-1232. Retrieved from: http://recherche.enac.

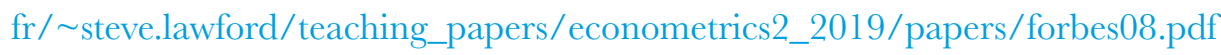

Francis, G., Fidato, A., \& Humphreys, I. (2003). Airport-airline interaction: the impact of low-cost carriers on two European airports. Fournal of Air Transport Management, 9(4), 267-273. doi: https://doi.org/10.1016/S0969-6997(03)000048

Gillen, D., \& Lall, A. (2004). Competitive advantage of low-cost carriers: some implications for airports. Fournal of Air Transport Management, 10(1), 41-50. doi: https://doi.org/10.1016/j.jairtraman.2003.10.009

Groves, W., \& Gini, M. (2013). An agent for optimizing airline ticket purchasing. Proceedings of the 2013 international conference on Autonomous agents and multiagent systems, 1341-1342. Retrieved from: https://www.researchgate.net/ publication/262172314_An_agent_for_optimizing_airline_ticket_purchasing

Hofer, G., Windle, R. J., \& Dresner, M. E. (2008). Price premiums and low cost carrier competition. Transportation Research Part E: Logistics and Transportation Review, 44(5), 864-882. doi: https://doi.org/10.10.1016/j.tre.2007.03.004

Klein, S., \& Loebbecke, G. (2000). The transformation of pricing models on the web: examples from the airline industry. 13th International Bled Electronic Commerce Conference, 19-21. Retrieved from: https://pdfs.semanticscholar. org/3112/430cbe6730d9c3eb559b83ab373bb913ec19.pdf 
Lazarev, J. (2013). The welfare effects of intertemporal price discrimination: an empirical analysis of airline pricing in US monopoly markets. Retrieved from: http://www.johnlazarev.com/Lazarev_JMP.pdf

O’Connell, J. F., \& Williams, G. (2005). Passengers' perceptions of low cost airlines and full service carriers: A case study involving Ryanair, Aer Lingus, Air Asia and Malaysia Airlines. Fournal of air transport management, 11(4), 259-272. doi: https://dx.doi.org/10.1016/j.jairtraman.2005.01.007

Sabre. (2015). APIs. Get travel information on demand with our REST and SOAP APIs. Retrieved August 17, 2015, from: https://developer.sabre.com/docs

\section{AUTHORS BIOGRAPHY}

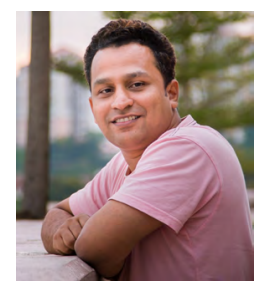

Md. Alauddin is currently Masters Student in the Faculty of Computing and Informatics, Multimedia University, Cyberjaya, Malaysia. He is a Computer Science and Engineering Graduate from Khulna University of Engineering and Technology with major of Software Engineering. His research interest mostly on BigData, Machine Learning and Data Engineering.

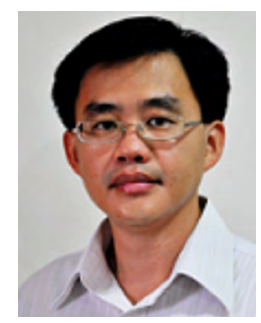

Dr. Choo-Yee Ting is currently holding Associate Professor in the Faculty of Computing and Informatics, Multimedia University, Cyberjaya, Malaysia. In the year 2002, Choo-Yee Ting is awarded the Fellow of Microsoft Research by Microsoft Research Asia, Beijing, China. In 2003, he received research fellowship from Rotary Research Foundation, Rotary Club of Kuala Lumpur Diraja, Malaysia. He has been involving himself in research projects funded by MOSTI, Malaysia and Industries. He is also certified in Microsoft Technology Associate (Database) and IBM DB2 CDA. 


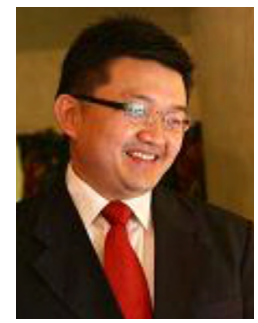

Dr. Ian Tan Kim Teck is currently holding senior lecturer in the Faculty of Computing and Informatics, Multimedia University, Cyberjaya, Malaysia. Ian Tan Kim Teck is graduated with a Doctor of Philosophy (Ph.D.) from Multimedia University, Malaysia in the area of Operating Systems' schedulers. He did his Master of Science Degree in Parallel Computers and Computation, from University of Warwick, United Kingdom in 1993 and a Bachelor of Engineering Degree and Associate of City and Guilds Institute in Information Systems Engineering, from Imperial College London, United Kingdom in 1992. He is also Novell Certified Linux Administrator (NCLA), Novell Certified Linux Professional (NCLP), member of IEEE and member of ACM. His area of research interest is primarily in systems; from operating systems process scheduling on multicore systems, efficient network data transfers, to systems and network security. 
Edición Especial Special Issue Noviembre 2019

DOI: http://dx.doi.org/10.17993/3ctecno.2019.specialissue3.287-305 


$$
\text { /17/ }
$$




\section{SOLAR ENERGY STATUS AND POTENTIAL ASSESSMENT ACROSS KARACHI, PAKISTAN}

\author{
Sabir Ali Kalhoro \\ Department of Electronics Engineering NED \\ University of Engineering and Technology \\ Karachi Pakistan. \\ E-mail: sabir13es66@gmail.com \\ Muhammad Shahid \\ Dawood University of Engineering \& \\ Technology, \\ Karachi, Pakistan. \\ E-mail: engr_shahid82@yahoo.com
}

\section{Rizwan Ali Lashari}

Department of Electronics Engineering NED

University of Engineering and Technology

Karachi Pakistan.

E-mail: rizwan.lashari71@yhoo.com
Muhammad Waleed

Indus University Karachi Pakistan.

E-mail: waleedyousuf12te91@gmail.com

Engr. Tufail Ahmed

Department of Electronics Engineering Mehran

University of Engineering and Technology Jamshoro, Pakistan.

E-mail: tufail.waseer@faculty.muet.edu.pk

Darakhshan Ara

Dawood University of Engineering \&

Technology, Karachi, Pakistan.

E-mail: ara.chemistry@yahoo.com

Recepción: 02/08/2019 Aceptación: 25/09/2019 Publicación: 06/11/2019

\section{Gitación sugerida:}

Ali Kalhoro, S., Shahid, M., Ali Lashari, R., Waleed, M., Ahmed, T. y Ara, D. (2019). Solar Energy Status and Potential Assessment across Karachi, Pakistan. 3C Tecnología. Glosas de innovación aplicadas a la pyme. Edición Especial, Noviembre 2019, 307-327. doi: http:/ / dx.doi.org/10.17993/3ctecno.2019.specialissue3.307-327

\section{Suggested citation:}

Ali Kalhoro, S., Shahid, M., Ali Lashari, R., Waleed, M., Ahmed, T. \& Ara, D. (2019). Solar Energy Status and Potential Assessment across Karachi, Pakistan. 3C Tecnología. Glosas de innovación aplicadas a la pyme. Speciaal Issue, November 2019, 307-327. doi: http:// dx.doi.org/10.17993/3ctecno.2019.specialissue3.307-327 


\section{ABSTRACT}

Renewable energy production in terms of solar irradiation comes is highly valuable for power generation. The World Bank Group (WB) investigated the quantity of intermittent renewable energy usage in regard to explore the existing solar power availability in Pakistan. The WB group put a strong effort to explore the renewable resources in the number of countries including Pakistan. The WB get the data available for all the observed countries. So the data obtained from WB sites located across Karachi. The solar data was studied by the WB group for the data sets in 20152017. In this paper, we have observed the solar irradiation trend and the fluctuation as for as the sunny day is concerned for the hourly, daily, monthly and yearly durations. The solar irradiations to be able to efficiently employ these renewable energy sources to meet the current and future power needs of Karachi of Pakistan. The Solar irradiation is available in the form of energy only need to explore it. We must use the python software for the solar irradiation trend observation for the Karachi.

\section{KEYWORDS}

Renewable energy, Solar energy, Solar irradiation, World bank observation. 


\section{INTRODUCTION}

Energy plays a biting role in socio-economic development by raising the level of the existing condition. The energy crisis is presently the foremost burning issue that is being faced by the whole world. Nowadays, Pakistan is facing an emerging energy crisis (Ashfaq \& Ianakiev, 2018; Kamran, 2018). Throughout the past decade, Pakistan's economy had shown positive growth and consequently, there was an increase in demand for energy however sadly no worthy steps are taken to put in new capability for generation of the desired energy sources. Currently, the demand exceeds the offer, by leading "load-shedding" that has become a standard development being round by the country (Sher, Murtaza, Addoweesh \& Chiaberge, 2015; Tahir \& Asim, 2018). The existing circumstances measure the results of lack of management. The faulty present energy management system, failure of forecast and future arrangement, put generating capability to transmit the load necessity. The grid stations and connected instrumentality unable to hold the load requirement and substantial distribution system of power provide the shortage (Best \& Burke, 2018; Wakeel, Chen \& Jahangir, 2016; Asif, 2009; K, 2009; Halacy, 1980; Ishaque, 2017 )

Pakistan incorporates a high potential for energy generation via a variety of native energy resource. Pakistan is the sixth richest nation due to coal manufacture. Additionally, the country is capable of manufacturing electricity by the atomic programs that were started by the Government in 1954. Despite the actual fact, Pakistan is gifted with the high potential of electricity generation from its available reserves. There are heavy reserves of fossil fuel principally within the southern and west part of Pakistan however because of the increase in usage, the country is facing a significant shortage of fossil fuel compromise. Pakistan has a good capability of power generation utilizing each commercially exploitable Hydel and geothermal resources. Although severe energy crisis, on the other hand, there's still hope that the country often strengthens the circumstance from the supplementary resources. The supplementary resources will satisfy the energy needs to adopt the varied short term and long run procedures. There is a variety of potential in Pakistan which is waiting for the green signal for the implementation to overcoming the increasing energy 
crisis (Ouria, 2019; Jung, Han \& Kim, 2019; Kabir et al., 2018; Prăvălie, Patriche \& Bandoc, 2019; Rauf, Wang, Yuan \& Tan, 2015; Zhang et al., 2019).

Fossil fuels remain the dominant energy supply within the international market. However, if consumption continues at its current rate, resources are going to be short among many decades attributable to their restricted provide. The fossil fuels based energy shows the emission of greenhouse gases and different other pollutants effect. To avoid the fast increase of greenhouse gases, the key lies within the improvement of energy potency on the buyer into renewable energy resources. Renewable energy is one of the foremost significant sources. This viable alternative source will exchange fossil fuels into vast pollution-free energy supply. Additionally, the environmental noticeable returns on the aspects will offer investment cherish by fossil fuels and might meet the stress of world energy consumption (Kamran, Fazal \& Mudassar, 2020; Ullah, Imran, Maqsood \& Butt, 2019; Lin \& Raza, 2019).

Over the past decade, Pakistan has been facing a shortage of between $3000 \mathrm{MW}$ and $6000 \mathrm{MW}$ within the supply and generation, resulting in many hours of loadshedding. The fundamental percentage of electricity generation is based on fossil fuels, resulting in price susceptibility. Where the geographical location and climate of the country tend to supply high alternative energy. The alternative resources signify the requirement for solar resource assessment for the look of alternative energy comes. The solar energy resource is highly supported by Pakistan due to the localization and topographical information carried out by the researchers. Numerous researchers have developed solar energy potential maps for the country's energy sector empowerment (Shah, Solangi \& Ikram, 2019; Wahab et al., 2019; Jung et al., 2019).

The solar irradiation is the most feasible source for the assessment of solar energy supply. The typical incident irradiance is needed to estimate the solar potential regionally. The solar irradiation works as freelance to upgrade the solar outcomes. Solar power produces the energy that gives the electricity and safe environment. The various hybrid, micro, nanogrid, urban block signifies the impact of solar electricity generation and potency. In addition, the economic profit in the reduction of utility values and environmental implication as $\mathrm{CO} 2$ emissions highlights the fundamental 
role of the solar system. So this alternative energy potential consequently fills the increasing demand-supply gap (Jung et al., 2019; Sadiqa, Gulagi \& Breyer, 2018;).

The solar system is capable to replace the fossil fuels at the location where high solar irradiation is available. The estimation of accessible solar power is the key to increasing energy generation as a result of sites with high available irradiation.

The solar resources give nice chances for energy production and use, thereby minimizing the loss by supply clean energy. Solar energy is one in every of the renewable energy resources with the best potential and will be the world's largest supplier of electricity by 2050 . The speedy increase within the use of solar energy in recent years highlights its nice development potential, and additional future energy source (Mirjat et al., 2017; Rafique \& Rehman, 2017; Dutta, 2019).

Solar energy has terribly obvious profit, particularly that the situation of the energy supply is usually constant because of the location of the energy use. The solar energy is applicable to build green energy capture through the "irradiation into electricity".

The basis of solar power is the sun irradiation supply which gives the limitless free energy all the time. Currently, new technologies are being used to get electricity by harvest solar energy. In Pakistan, the solar supply yield adequate power to exhibits the best potential to fulfill the growing gap of the demand and supply.

The solar energy is one in every of the most popular renewable resources that gives abundant energy in the replacement of minute investment. However, there is a lot of long gap in term of solar technology and solar power markets. The World Bank investigates the challenges for solar energy in Pakistan to identify the region-wise potential of solar energy. Pakistan opens the barriers to examine the solar power spectrum, policy problems, institutional roles and responsibilities to promote the solar power future (George et al., 2019; Badakhshan, Hajibandeh, Shafie-khan \& Catalão, 2019;).

The solar irradiation information measured by the Pakistan Meteorological Department (PMD) and the World Bank Group through the maps reported checking the solar availability within the region. The PMD compared the semi-permanent 
information from the World Radiation Data Centre (WRDG), and each information shows the valuable potential of solar energy.

The solar irradiation through the performance indicators of the World Bank provides insight as a location for establishing a solar system. The methodology and technical workflow as developed can support reliable and economical feasibleness studies, particularly within the early stage of discipline design.

Solar energy could be a key renewable supply for the decarbonization and therefore the future viable growth of social society. However, the success of the worldwide solar implementation depends on the in-depth information of irradiation distribution and intensity, which could upgrade the solar energy at the global perspective. This study primarily aims to analyze the solar supply and strength nationwide. The global horizontal irradiation $(\mathrm{GHI})$ and direct irradiation (DNI) are the key resources to gives the solar strength. The solar irradiation spatial information by the World Bank represents the reliable resolution for the solar power on the site of the selected region.

The World Bank group helps to choose the site that needed by many specialists to avoid subjective biases, usually wishing on rough estimations wherever the topography wasn't absolutely. Therefore, this study proposes a procedure methodology that estimates the potential of solar energy for prioritizing and choosing sites for power production from the PV system exploitation in public offered digital numerical maps (Reyes et al., 2019; Shahid, Kalhoro, Ara, Bano \& Perween, 2019; Kalhoro et al., 2019;).

\section{MODEL}

The Solar model is being responsible for the means of solar irradiation such as global irradiation, diffuse and direct normal solar irradiations established on the data of the World Bank assignment for Pakistan. The global horizontal irradiation (GHI) is the sum of diffuse and direct solar irradiation. It is best for the site chosen as the state in Eq.1. The diffuse horizontal irradiation (DHI) is dispersed by the sky as assumed by the World Bank in Eq.2. The direct normal irradiation (DNI) is the 
irradiation module of the solar that openly sticks the surface of the solar PV as presented in Eq.3. The zenith angle is defined as the angle vertical to the sun. The zenith angle is nighty degree with the elevation angle as given away in Eq.4. The elevation measured as the optimum selection for the site routine for the irradiation based solar power as described in Eq.5. The meteorological parameters are relative to the air temperature for solar irradiation power in the design system by the World Bank project. The meteorological parameters used to find the operating conditions and efficiency of the solar irradiation based project as specified in Eq.6. The Solar Atlas of the World Bank shows each parameter related to the generation of the solar power that evaluates the power generation from solar modules. The weather-related parameters verify the operation and performance of a solar energy project as defined in Eq.7. The air temperature determines the performance of the solar irradiation in the solar power system. Air temperature is used to determine the temperature of solar modules and uninterrupted impact on solar conversion efficiency in power damages. The World Bank gets the meteorological parameters for the solar project installation of the solar system. The solar electricity model algorithm incorporates the atlas which invariably provides an approximate for the electrical power that made at any site ruled by the interactive map as known in Eq. 8 to Eq. 11 .

$$
\begin{array}{cc}
G H I=D H I+D N I \cdot \cos (\theta) & \text { Eq. } 1 \\
\text { DHI }=\text { C. DNI } & \text { Eq. } 2 \\
\text { DNI }=\text { A. } \exp (-\mathrm{B} / \operatorname{Cos} \theta) & \text { Eq. } 3 \\
\zeta=90-\theta & \text { Eq. } 4 \\
\operatorname{Cos} \theta=\sin \delta \sin \varphi+\operatorname{Cos} \delta \operatorname{Cos} \varphi \cos \omega & \text { Eq. } 5 \\
\eta=\eta T r e f[1-\beta r e f(T c-\text { Tref })] & \text { Eq. } 6 \\
\eta_{p v g}=\eta_{r} \eta_{p c}\left[1-\beta\left(T_{c}-T_{r e f}\right)\right] & \text { Eq. } 7 \\
T_{c}=T_{a}+\left(\frac{N o c T-20}{800}\right) G_{t} & \text { Eq. } 8 \\
P_{p v}=\eta_{p v g} A_{p v g} & \text { Eq. } 9 \\
P_{M}=I_{s} V_{o c} & \text { Eq. } 10 \\
P_{\text {Array }}=N_{s} N_{s} P_{M} & \text { Eq. } 11
\end{array}
$$




\section{EXPERIMENTATION}

The World Bank has stabled a solar irradiation based project in order to evaluate the solar power in Pakistan. World Bank has set up solar staff through the number of countries including Pakistan. Pakistan has got so many number stations across the different coastal and non-coastal cities as a part of a global effort. The Karachi is the coastal city of the Pakistan and World Bank choose this city for the experimentation set up and site selection behind the data reported in this paper.

The meteorological station CSPS.MT.14.218 has been fitted on the rooftop of the Department of Industrial Management building of NED UET Karachi having the following direction $\left(24.9334^{\circ} \mathrm{N}, 67.1116^{\circ} \mathrm{E}\right)$ on April 22, 2015, as Figure 1.

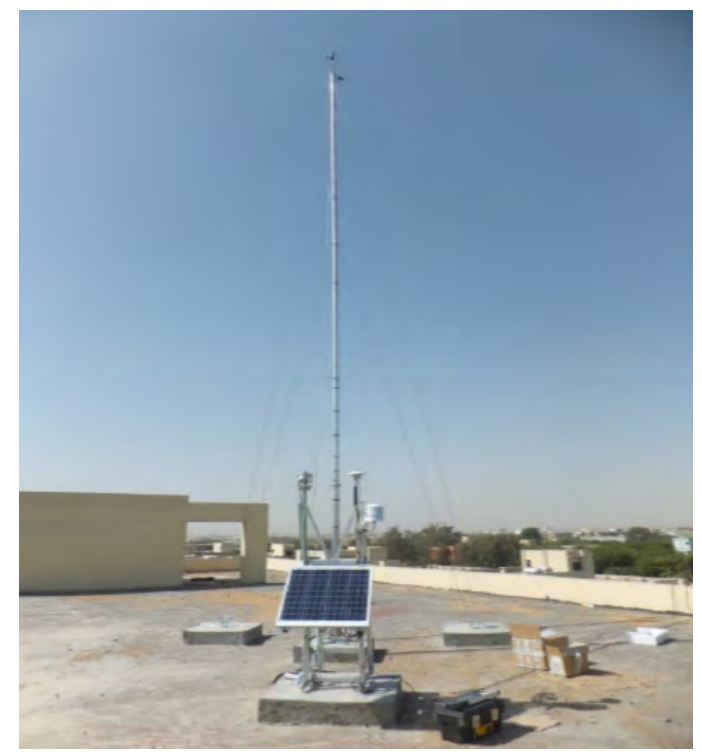

Figure 1. The Experimental setup for solar Station. Source: World Bank Site.

The World Bank set the solar station for the solar potential measurement in the whole scenario. The data of the different parameter is acquired in a period of every ten minutes. This data is continuously getting from 2015 to 2017 for solar power observation. 


\section{RESULTS}

The main results as regards the global horizontal irradiation (GHI) direct normal irradiation (DNI), direct horizontal irradiation (DHI), air temperature and the relative humidity are obtained by the active and passive solar systems. The solar irradiation result based on the conversion of the solar irradiation into the electric power in the hourly, daily, monthly and the yearly trend in the whole system as presented and discussed.

The Python indices the access information in a very essential Pandas measurement tools. Python information generally relates, and Pandas offers many supplementary detailed operations. As a result of Pandas was developed mostly in an exceedingly perspective, tools for monetary information. The related Pandas data packages are aware of the way to import monetary information from a variety of obtainable sources, together as "Yahoo" and "Google" Finance. In this way, Google's is used for the Program operation.

Pandas will make a date-time index which will be accustomed index information in an exceedingly series. The Pandas tools to repeat the demonstration from higher adaptably configured date and use codes to Process output. To make the formation of standard function for the sequences of convenient, Pandas offers some roles for this purpose.

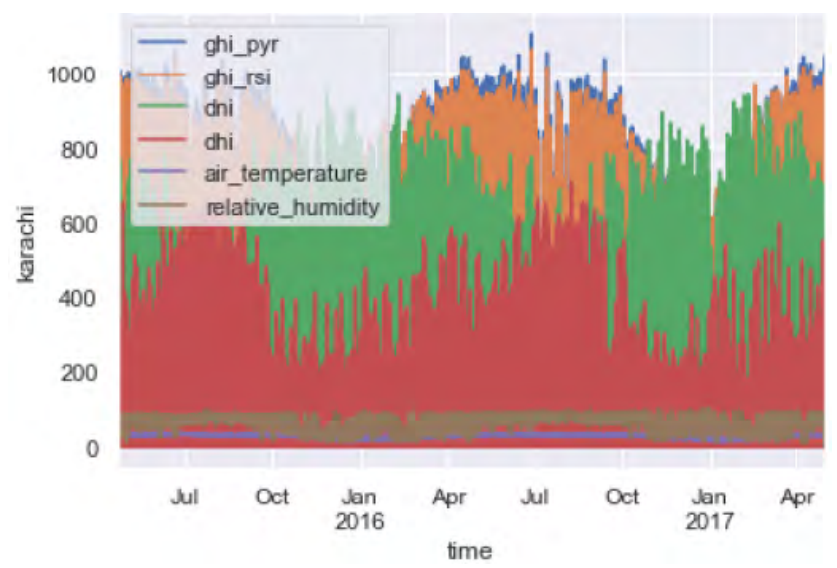

Figure 2. The weather parameter of solar irradiation for Karachi in each category of the solar data trendline is observed. 
The weather parameter of solar irradiation such as GHI, DNI, DHI, air temperature and relative humidity for Karachi in each category of the solar data trendline is observed. The python gain occurred by scheming the information. The software will gain a lot of comprehension by resampling the information to a rougher grid as shown in Figure 2. So we will resample it by the weekly, month and yearly trend.

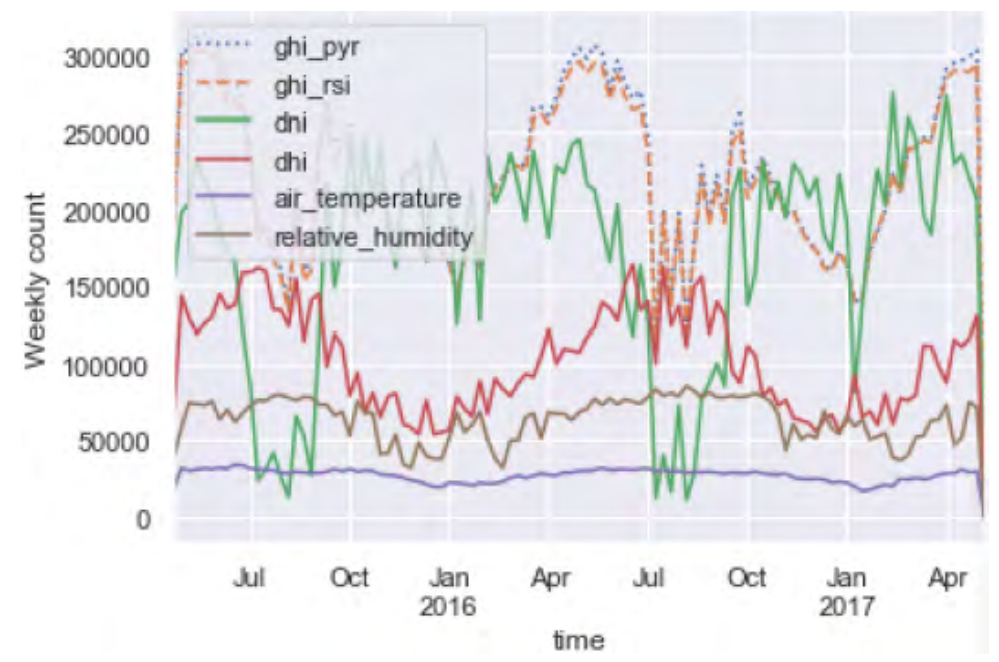

Figure 3. Solar Parameter for the Karachi are observed in a weekly count. The weekly count for the solar irradiation is examined for the period of Jan 2015 to April 2017.

The weekly count is done by the python in the very effective way now the python is ready for the monthly and the yearly trend as you may expect. The seasonal trend of the solar irradiation can be built to perform within the midsummer than within the winter, so among the selected seasonal fluctuation in a regression model. The all solar Parameter is again observed in a weekly count. The weekly count for the solar irradiation is examined for the period of 2015-2017. Wherever the python tends to explore further in a very minute period of time to gives the output as shown in Figure 3. 


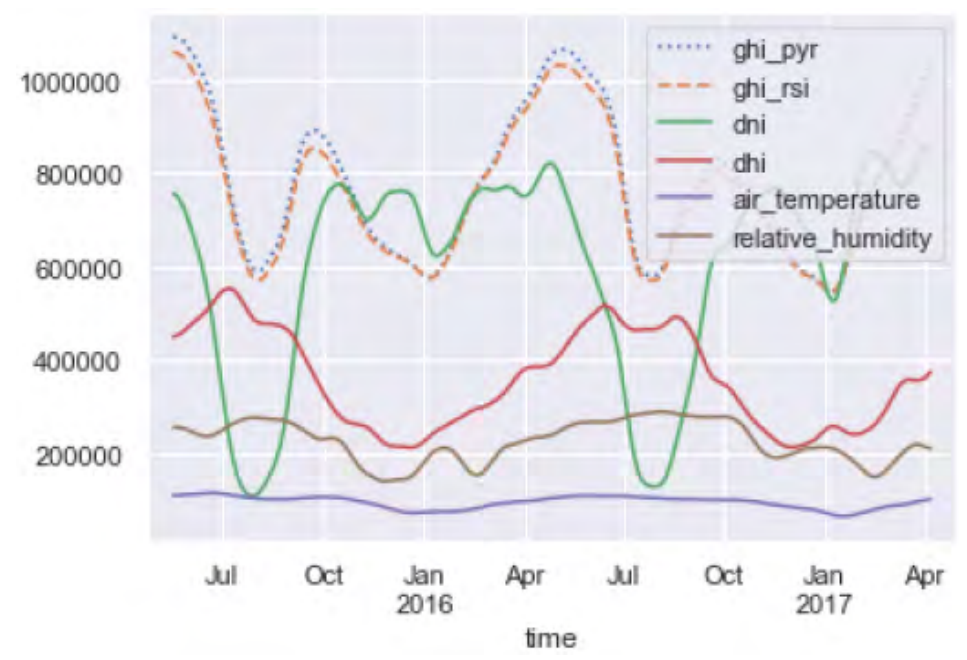

Figure 4. The periodic trend of solar parameter for the mean hourly count is experimented. The mean hourly count is investigated from Jan 2015 to April 2017.

The solar parameter trend for the mean hourly count is investigated. The mean hourly count has investigated the roughness in the results obtained by the arduous cutoff of the window in the yearly period is shown in Figure 4. The subsequent program requires a dimension of the window (selected fifty days) therefore the dimension of the Gaussian inside the frame.

The hourly trend of the bimodal distribution irradiation is given from the peaks around 00:00 to 24:00 within the morning and evening. This trend is often probably proof of a powerful part of crossing bridge for the solar irradiation in the system. The hourly trend of the model shows the limited variations between each hour of the observation. The irradiation generates the peaks power within the morning, and inadequately within the evening due to the irradiation strength. In this way, the python shows the trend of modification of the day of the week as consider Figure 5. 


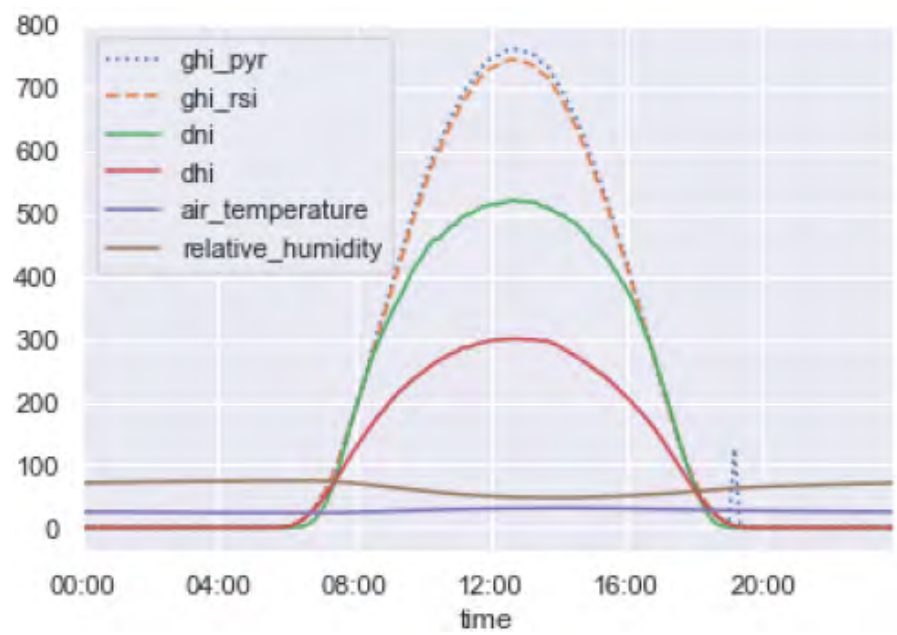

Figure 5. The hourly solar irradiation observation throughout the day. The different parameters are studied for the period of 25th April 2017.

While these information views measure the help to induce a plan of the overall irradiation trend within the information. Python gives a lot of fascinating structure for the solar irradiation based model in the selected way for the instance. The daily trend of solar irradiation is obtained for the time of day. The GHI and DNI show the trend of the day in the graph. The obtained victimization of the python is mentioned in Figure 6.

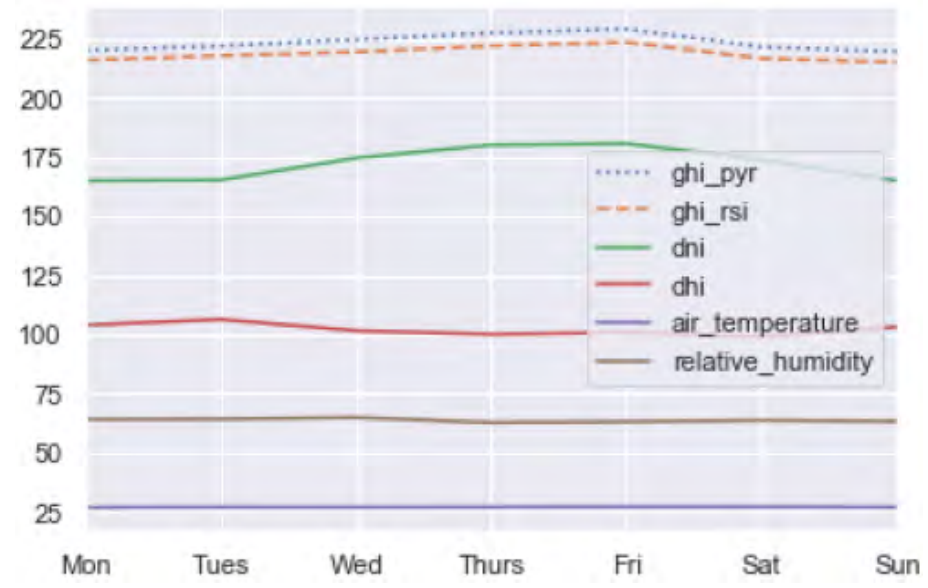

Figure 6. The daily observation of the solar irradiation with the consistent variations visible throughout the day. 
The weekday and the weekend trend of the irradiation are obtained to show the robust distinction between the output of the weekday and weekend totals. The day selection for the weekday and the weekend is Friday and Sunday. In the weekday and weekend, the hourly solar irradiation observation happens throughout the day. The different parameters are studied for the period of 25th April 2017. The irradiation for the appearance in the timely manner as presented in Figure 7.

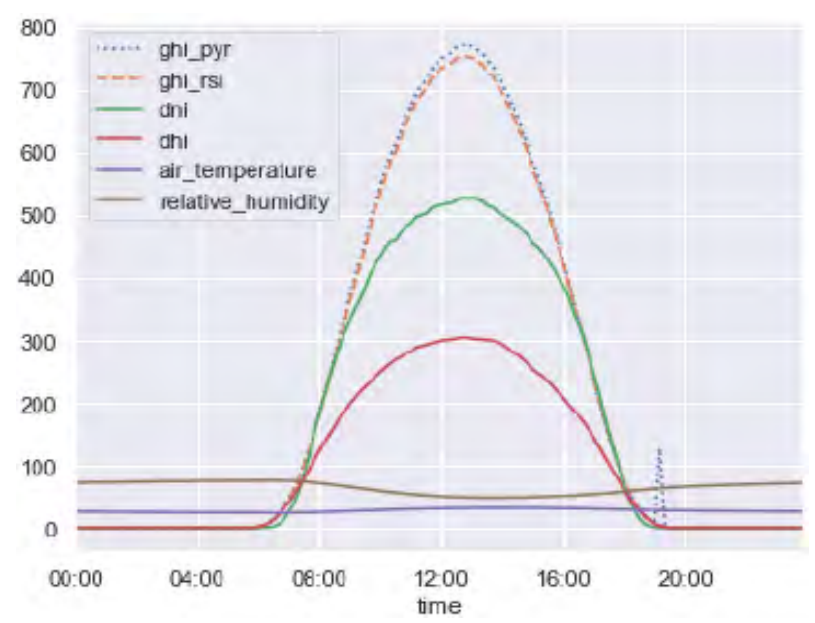

Figure 7. The hourly observation of the solar parameter that shows trend between the two days. The assessment shows the weekly basis Measurement for the Karachi.

The obtained result terribly interesting to see an irradiation modal commute pattern throughout the hourly, daily, monthly and yearly. The gained information gives the additional feature, that effect of weather parameter and different patterns which gives the best trend in the hourly, daily monthly and yearly result.

\section{ANALYSIS}

The World Bank aims to check the renewable energy potential across the different countries by fitted a project. The project will also be installed in Pakistan to evaluate the RE potential. The RE data is collected by the World Bank group in every 10 minutes from 2015-17. In this research, the World Bank data is being used to check solar availability in Pakistan. The available data is observed by daily, monthly and yearly trend to check solar irradiation for the solar power in Pakistan. The research 
points the consistent trend in weekly, daily, monthly and yearly data which gives the same trend for future use. Hence the research based on World Bank data proves the commendable solar accessibility that generates a huge amount of renewable energy in Pakistan. This data is observed by the Python software to check the solar irradiation obtainability as shown in Figure 2-7.

It is observed that the data for the daily trend from 22rd till 30th April show the highest trend in the irradiation also 23 April 2015, 23 April 2016 and 24 April of 2017 gives a similar trend. The days of 27 April 2015, 24 April 2016 and 23 April 2017 gives the lowest trend as refer Figure 2. The observed data have the irradiation availability in the April-May-June months from 2015 to 2017 and the lowest irradiation strength in the month of December-January 2015 to 2017 as shown in Figure 3-4.

The solar irradiation for the single day represents a high availability in the noon and the minimum from 8 am to 5 pm from 2015 to 2017 as presented in Figure 5 . The hourly observation of the solar parameter that shows the trend between the two days. The assessment shows the weekly basis measurement for the Karachi as in Figure 7. The irradiation is observed for a whole month of the year 2015-17 for the Karachi of Pakistan. The same resemblance of the result is observed all the time as solar radiations presence is highest in the months holding sunny days. Reliable with the summer, the solar irradiations are higher corresponding due to the solar angle. The whole analysis can be view by the solar atlas. In this atlas, the solar irradiation as GHI, DNI, and photovoltaic power potential prove the whole data analysis that is based on the World Bank calculation is shown in Figure 8. 

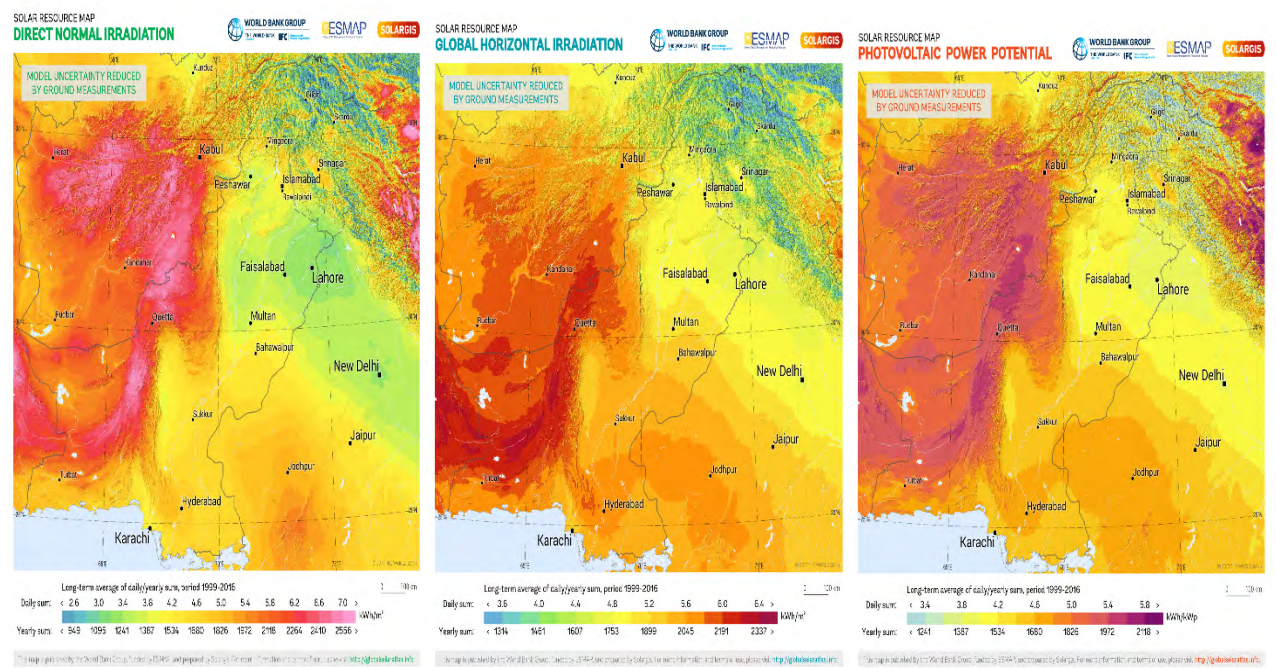

Figure 8. Global Horizontal irradiation, Direct Normal Irradiation, and photovoltaic power potential observation through Solar Atlas. Source: Solar Atlas World Bank Group.

\section{DISCUSSION}

The paper is based upon the solar energy potential offers by the World Bank in Pakistan. The World Bank group put a strong effort to explore the renewable resources in the number of countries including Pakistan. The World Bank group get the data available for all the observed countries. So the data obtained from World Bank sites located across Karachi. The solar data was studied by the World Bank Group for the data sets in 2015-2017. In this paper, we have observed the solar irradiation trend and the fluctuation as for as the sunny day is concerned for the hourly, daily, monthly and yearly durations. We must use the python software for the solar irradiation trend observation for the Karachi.

The Pandas, a package called in Python Software is employed for handling a large set of Python representing the dates, times, months, and timespans. The python was implemented as a framework of economic forming reasonably information. Time and day information arises in a very few senses, that are converse now for the irradiation based solar model. The reference explicit moments into the time intervals and periods of reference time between a specific starting and finish. The daily, 
monthly and yearly trend will be obtained by the typical reference of a special case in the time intervals in which uniform overlap between the time and value is obtained.

\section{CONCLUSION}

This paper is based upon the solar energy potential offers by the World Bank in Pakistan. The World Bank group put a strong effort to explore the renewable resources in the number of countries including Pakistan. The World Bank group get the data available for all the observed countries. So the data obtained from World Bank sites located across Karachi. The solar data was studied by the World Bank Group for the data sets in 2015-2017. In this paper, we have observed the solar irradiation trend and the fluctuation as for as the sunny day is concerned for the hourly, daily, monthly and yearly durations. We must use the python software for the solar irradiation trend observation for the Karachi.

\section{ACKNOWLEDGEMENTS}

Thanks World Bank for making the solar data available for Pakistan.

\section{REFERENCES}

Ashfaq, A., \& Ianakiev, A. (2018). Features of fully integrated renewable energy atlas for Pakistan; wind, solar and cooling. Renewable and Sustainable Energy Reviews, 97, 14-27. doi: https://doi.org/10.1016/j.rser.2018.08.011

Asif, M. (2009). Sustainable energy options for Pakistan. Renewable Sustainable Energy Review, 13, 903-909. doi: https://doi.org/10.1016/j.rser.2008.04.001

Badakhshan, S., Hajibandeh, N., Shafie-khan, M., \& Catalão, J.P.S. (2019). Impact of solar energy on the integrated operation of electricity-gas grids. Energy, 183, 844-853. doi: https://doi.org/10.1016/j.energy.2019.06.107 
Best, R., \& Burke, P. J. (2018). Adoption of solar and wind energy: The roles of carbon pricing and aggregate policy support. Energy Policy, 118, 404-417. doi: https://doi.org/10.1016/j.enpol.2018.03.050

Dutta, A. (2019). Impact of silver price uncertainty on solar energy firms. Journal of Cleaner Production, 225, 1044-105. doi: https://doi.org/10.1016/j. jclepro.2019.04.040

George, A., Boxiong, S., Arowo, M., Ndolo, P., Chebet, G., \& Shimmon, J. (2019). Review of solar energy development in Kenya: Opportunities and challenges. Renewable Energy Focus, 29, 123-140. doi: https://doi.org/10.1016/j. ref.2019.03.007

Halacy, J. D. S. (1980). Solar energy and the biosphere. Solar Energy Technology Handbook, Part A: Engineering Fundamentals, ed. W. C. and PN. Marcel. New York, 1-8.

Harijan, K., Uqaili, M.A., Memon, M., \& Mirza, U.K. (2009). Assessment of centralized grid connected wind power cost in coastal area of Pakistan. Renewable Energy, 34(2), 369-373. doi: https://doi.org/10.1016/j.renene.2008.05.001

Ishaque, H. (2017). Is it wise to compromise renewable energy future for the sake of expediency? An analysis of Pakistan's long-term electricity generation pathways. Energy Strategy Reviews, 17, 6-18. doi: https://doi.org/10.1016/j.esr.2017.05.002

Jung, J., Han, S.U., \& Kim, B. (2019). Digital numerical map-oriented estimation of solar energy potential for site selection of photovoltaic solar panels on national highway slopes. Applied Energy, 242, 57-68. doi: https://doi.org/10.1016/j. apenergy.2019.03.101

Kabir, E., Kumar, P., Kumar, S., Adelodun, A.A., \& Kim, K. H. (2018). Solar energy: Potential and future prospects. Renewable and Sustainable Energy Reviews, 82(1), 894-900. doi: https://doi.org/10.1016/j.rser.2017.09.094 
Kalhoro, S.A., Musvi, S.H.A., Ali, S., Rahoojo, S., \& Nawaz, A. (2019). An economical and relatively efficientimplementation of the Real-Time Solar Tracking System. 3C Tecnología, 68-99. doi: http://dx.doi.org/10.17993/3ctecno.2019. specialissue2.68-99

Kamran, M. (2018). Current status and future success of renewable energy in Pakistan. Renewable and Sustainable Energy Reviews, 82(1), 609-617. doi: https://doi. org/10.1016/j.rser.2017.09.049

Kamran, M., Fazal, M. R., \& Mudassar, M. (2020). Towards empowerment of the renewable energy sector in Pakistan for sustainable energy evolution: SWOT analysis. Renewable Energy, 146, 543-558. doi: https://doi.org/10.1016/j. renene.2019.06.165

Lin, B., \& Raza, M. Y. (2019). Analysis of energy related CO2 emissions in Pakistan. Journal of Cleaner Production, 219, 981-993. doi: https://doi.org/10.1016/j. jclepro.2019.02.112

Mirjat, N.H., Uqaili, M.A., Harijan, K., Valasai, G.D., Shaikh, F., \& Waris, M. (2017). A review of energy and power planning and policies of Pakistan. Renewable and Sustainable Energy Reviews, 79, 110-127. doi: https://doi. org/10.1016/j.rser.2017.05.040

Rafique, M.M., \& Rehman, S. (2017). National energy scenario of PakistanCurrent status, future alternatives, and institutional infrastructure: An overview. Renewable and Sustainable Energy Reviews, 69, 156-167. doi: https://doi. org/10.1016/j.rser.2016.11.057

Ouria, M. (2019). Solar energy potential according to climatic and geometrical parameters of cities and buildings: A case-study from Tabriz City- Iran. Urban Climate, 28, 100469. doi: https://doi.org/10.1016/j.uclim.2019.100469

Prăvălie, R., Patriche, G., \& Bandoc, G. (2019). Spatial assessment of solar energy potential at global scale. A geographical approach. Fournal of Cleaner Production, 209, 692-721. Doi: https://doi.org/10.1016/j.jclepro.2018.10.239 
Rauf, O., Wang, S., Yuan, P., \& Tan, J. (2015). An overview of energy status and development in Pakistan. Renewable and Sustainable Energy Reviews, 48, 892-931. doi: https://doi.org/10.1016/j.rser.2015.04.012

Reyes, A., Pailahueque, N., Henríquez-Vargas, L., Vásquez,J., \& Sepúlveda, F. (2019). Analysis of a multistage solar thermal energy accumulator. Renewable Energy, 136, 621-631. doi: https://doi.org/10.1016/j.renene.2018.12.103

Sadiqa, A., Gulagi, A., \& Breyer, C. (2018) Energy transition roadmap towards $100 \%$ renewable energy and role of storage technologies for Pakistan by 2050. Energy, 147, 518-533. doi: https://doi.org/10.1016/j.energy.2018.01.027

Shah, S. A. A., Solangi, Y. A., \& Ikram, M. (2019). Analysis of barriers to the adoption of cleaner energy technologies in Pakistan using Modified Delphi and Fuzzy Analytical Hierarchy Process. Journal of Cleaner Production, 235, 1037-1050. doi: https://doi.org/10.1016/j.jclepro.2019.07.020

Shahid, M., Kalhoro, S.A., Ara, D., Bano, N., \& Perween, R. (2019). Wind and solar energy Potentials around Southern Sindh \& Southern Baluchistan provinces, especially Karachi of Pakistan. 3C Tecnología, 116-141. doi: https:// doi.org/10.17993/3ctecno.2019.specialissue2.116-141

Sher, H. A., Murtaza, A. F., Addoweesh, K. E., \& Chiaberge, M. (2015). Pakistan's progress in solar PV based energy generation. Renewable and Sustainable Energy Reviewes, 47, 213-217. doi: https://doi.org/10.1016/j.rser.2015.03.017

Tahir, Z. R., \& Asim, M. (2018). Surface measured solar radiation data and solar energy resource assessment of Pakistan: A review. Renewable and Sustainable Energy Reviews, 81(2), 2839-2861. doi: https://doi.org/10.1016/j.rser.2017.06.090

Ullah, A., Imran, H., Maqsood, Z., \& Butt, N. Z. (2019). Investigation of optimal tilt angles and effects of soiling on PV energy production in Pakistan. Renewable Energy, 139, 830-843. doi: https://doi.org/10.1016/j.renene.2019.02.114

Wahab, A., Hassan, A., Arslan, M., Ali, H.M., Babar, H., \& Sajid, M. U. (2019) Solar energy systems-Potential of nanofluids. Fournal of Molecular Liquids, 289, 111049. doi: https://doi.org/10.1016/j.molliq.2019.111049 
Wakeel, M., Chen, B., \& Jahangir, S. (2016). Overview of Energy Portfolio in Pakistan. Energy Procedia, 88, 71-75. doi: https://doi.org/10.1016/j. egypro.2016.06.024

Zhang, J., Xu, L., Shabunko, V., Rong Tay, S.E., Sun, H., Yu Lau, S.S., \& Reindl, T. (2019). Impact of urban block typology on building solar potential and energy use efficiency in tropical high-density city. Applied Energy, 240, 513533. doi: https://doi.org/10.1016/j.apenergy.2019.02.033 
Edición Especial Special Issue Noviembre 2019

DOI: http://dx.doi.org/10.17993/3ctecno.2019.specialissue3.307-327 


$$
\text { /18/ }
$$




\section{STUDY ON ENHANCING THE ENERGY EFFICIENCYTHROUGHREAL-TIMESMART ENERGY MANAGEMENT SYSTEMS FOR ACHIEVING GREEN ICT CAMPUS}

Kesava Rao Alla Linton University College E-mail: alla@ieee.org

Zainuddin Hassan College of Information Technology, University Tenaga Nasional E-mail: zainuddin@uniten.edu.m

Soong Der Chen Graphics and Multimedia Dept., College of Information Technology, University Tenaga Nasional E-mail: chensoong@uniten.edu.my

\section{Citación sugerida:}

Rao Alla, K., Hassan, Z. y Der Chen, S. (2019). Study on Enhancing the Energy Efficiency through Real-Time Smart Energy Management Systems for Achieving Green ICT Campus. 3C Tecnología. Glosas de innovación aplicadas a la pyme. Edición Especial, Noviembre 2019, 329-347. doi: http://dx.doi.org/10.17993/3ctecno.2019.specialissue3.329-347

\section{Suggested citation:}

Rao Alla, K., Hassan, Z. \& Der Chen, S. (2019). Study on Enhancing the Energy Efficiency through Real-Time Smart Energy Management Systems for Achieving Green ICT Campus. 3 C Tecnología. Glosas de innovación aplicadas a la pyme. Speciaal Issue, November 2019, 329-347. doi: http://dx.doi.org/10.17993/3ctecno.2019.specialissue3.329-347 


\section{ABSTRACT}

Most Higher Education Institutions (HEI) are trying to achieve a Green ICT Campus as part of its responsibility for building a sustainable environment. Efficient energy distribution is one of the key factors to achieve the maximum benefits of producing clean and green energy. The importance of renewable energy generation and distribution synchronized by ICT for achieving a green campus in Malaysian Higher Education Institution (MHEI) are suggested and discussed here. This research paper focuses on studying the current practices in energy usage in MHEI and proposing various techniques to reduce the consumption of energy usage to achieve Green ICT Campus through the Smart Grid including suggesting for alternate energy production. The obtained results show that the energy consumption was reduced to a significant level of $30 \%$ when tested for one HEI, which plays a key role in fulfilling the green computing requirements and provides a pathway to realizing a green campus. With these findings, it is envisaged that this system optimizes energy usage and could be applicable for any MHEI.

\section{KEYWORDS}

Smart Grid, Energy optimization, Green ICT Campus, Green Computing. 


\section{INTRODUCTION}

Mankind is completely dependent on an uninterrupted supply of energy for living and working. It has become the key ingredient in all sectors of modern economies. Millions of years ago, fossil fuels were formed on planet earth gradually through the organisms that were buried in swamps. Fossil fuels continue to be consumed massively and are expected to reach its last drop within this century based on the projected consumption and growth rates which is as follows: It is predicted that oil will run out in 53 years, natural gas in 54 years, and coal in 110 years from 2015 (Singh, 2017). This study also indicated that renewable and clean energies are the only alternative to the impending destruction of the world's economies through climate changes that are caused by the consumption of fossil fuels. This destruction is also leading to the overall rise in temperature of the planet which is expected to rise by 2 degrees within this century. It is important that the policies that are made towards renewable energy production and climate change at national level to reach institutions and every home to make the implementation cycle complete for the benefit of our planet.

Hence, this research paper focuses on the study of the energy demands of Higher Education Institutions in Malaysia to conserve adequate resources that are essential in building a greener society. Higher Education Institutions are a replica of a mini society with higher energy demands mainly due to the nature of its academic activities like teaching and learning, research endeavors and residential energy needs. Energy consumption of academic activities could be improved by installing smart equipment or following smart strategies in energy production and distribution. According to Ministry of Higher Education, Malaysia has more than 600 higher education institutions in private, semi-government and public sectors and the population that is involved with these institutions represent a substantial segment of the society (Ministry of Higher Education Malaysia, 2017). Modern Higher Education Institutes are one of the biggest energy consumers along with their growing demand for sophisticated technical infrastructure. The staff, students and the total community in today's HEI matches a populated town and any policies and strategies implemented in HEI's has a direct and indirect impact on the society due to its reach and the involvement of stakeholders (Howlett, Ferreira \& Blomfield, 2016). As HEI resemble the same nature 
in terms of operation and functionality, one Malaysian Higher Education institution has been selected to study the real-time energy consumption and distribution methods to optimize energy consumption.

\section{SUSTAINABLE DEVELOPMENT}

Development which embraces the needs of the existing without conceding the ability of next generations in accomplishing their requirements was the first broadly agreed term on sustainable development in the history of mankind in the UN Conference on the Human Environment, Stockholm, 1972. The modern world since the industrial revolution has needed larger amounts of energy for its growth and development. Extraction of fossil fuels for energy and consuming the fossil fuels for growth and development has entered new heights from the 20th century. Fossil fuels formed in the crests of the earth since millions of years are being consumed daily for energy production. Fossil fuel extraction, production and consumption began through burning the coal around 4000BC in China and oil and gas from 1800AD onwards (Ritchie \& Roser, 2017). The global fuel consumption is shown in Figure 1.

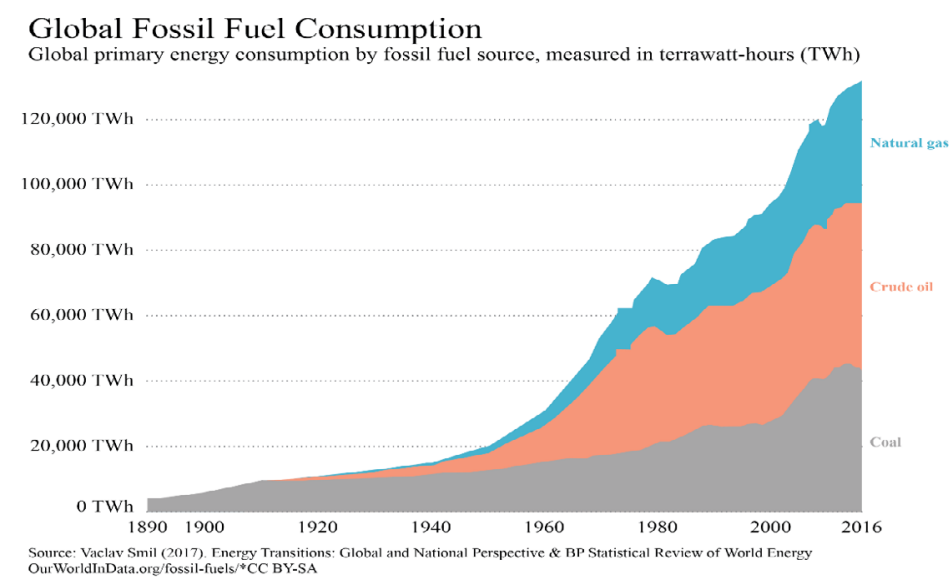

Figure 1. Fossil Fuel consumption chart.

It is surprising to see that these millions of year's fossil fuel reserves are being consumed within two centuries. The research analysis results show that, within another 50 years, the last drop of oil will be extracted from the earth at the present consumption 
ratio. But there is no concrete alternative that is equal and reliable to supplant this natural energy resource which is the fact as of today in 2017. Scientists have noticed this imminent disaster and started warning the mankind from the Nineteenth century (Du Pisani, 2006). The excessive urbanization and industrialization without maintaining an equilibrium with nature are leading mankind towards destruction. Whenever this symmetry is disturbed, there are consequences and at times, deadly consequences. The classic example of such an excessive usage of disturbing this ecological equipoise is visible in terms of natural disasters like unusual climatic conditions, global warming, disturbed patterns of el-Ninos, cyclones, and typhoons.

The scientific community has alerted this inhibiting danger and there are series of efforts by individuals, nations, social organizations and many other forms that joined hands together to overcome this melancholy. The first such major event was held in 1991 at Rio de Janeiro which gained a global reputation. Even though Brundtland Commission in 1987 was set up on studying the ecological disorders, it was the Rio declaration that provided the common guidelines and congregated the works of individuals and nations at the forefront in bringing up the efforts together. That noble task commenced in 1991, is still in progress and pleading our constant attention as of today. Rio declaration investigated major aspects of sustainable development and the causes of the environmental issues that are being faced by the mankind.

Energy generation is on one hand and the efficient distribution of the energy is on another hand which is equally important too. Energy distribution with smart grids and intelligent equipment that understands and performs the tasks with lesser human interaction without causing any inconvenience to the user are required to support the energy distribution. According to The Organisation for Economic Cooperation and Development (OECD) data, there are instances where energy distribution losses are recorded very high causing a daunt in the energy production. For example in India, energy distribution losses are recorded at 19\% in 2014 against the world's average of $8.24 \%$ which is one of the highest as per the Industry standards (The Organisation for Economic Cooperation and Development, 2017). India needs to address these challenges radically within a shorter period of time as every loss is contributed to extra energy generation and thus extra affliction to the sustainable development. 


\subsection{HEI ENERGY MANAGEMENT}

Higher Educational Institutions are more responsible in terms of generating awareness among the society for sustainable development. The nature and involvement of HEI's generally provide a closer association with the society as their involvement in research \& development and consultancy activities (Cabrera \& Zareipour, 2011). HEI's are more directly involved in developing cultural, social, ethical, economic and environmental knowledge that will, ultimately, assist stakeholders in handling the various issues of modern life effectively. At the same time, partnerships among various educational institutions provide multicultural contexts in establishing and understanding diversity, working closely with various stakeholders and the community reflects and improve their activities in relation to education for sustainable development (Wals \& Jickling, 2002).

HEI's are expected to arrange and engage debates, research activities, using smart equipment on sustainable development that could influence environmental and social outcomes (Nasibulina, 2015). There are many initiatives taken by some of the HEI's recently in this regard including offering courses and programs that are inbuilt with the values of SD that need to continue to develop these skills in new forms of learning including stakeholder interactions at various stages to produce SD ready graduates for the benefit of mankind (Vare \& Scott, 2007).

Higher Education Institutions (HEIs) need to engage themselves with the objective of building a sustainable society for the benefit of current and future generations (Suryawanshi \& Narkhede, 2014). While the HEI's focus on establishing social responsibility and accountability processes, HEI's eventually develop processes that could guide them towards establishing sustainable community within and outside campuses. HEIs are organizational forms that groom employment relationship and management responsibility from the primary levels (Ahola, Ahlqvist, Ermes, Myllyoka \& Savola, 2009). HEIs are the best places to face the challenges caused by unsustainable development clusters in the society and could be the best tools to inculcate the values and importance of sustainable development due to their nature and close relationship with all the levels society including intellectuals and scholars 
to the general public (Chai-Arayalert \& Nakata, 2011). Sustainable development can only flourish with the commitment of organisational accountability and responsibility where the concepts, theory, and practice could be initiated and implemented as primary test cases at HEIs. Alternate energy sources and using smart equipment to reduce the energy demand is another option too that motivated this study. Applying smart equipment with smart methods eventually, provide a smart solution through education for sustainable development (Fettweis \& Zimmermann, 2008).

Malaysia is an emerging economy in South Asia and dynamic accomplice in this global awareness process for renewable energy. From the1970 onwards, Malaysia has introduced a range of regulatory measures to balance the goals of surging socioeconomic development with sustainable environment. The annual report for the year 2010 from the Economic Planning Unit-EPU in the Malaysian Prime Minister's office stated that Malaysia is moving towards high-income society and aspiring for developed nation status by 2020 with a knowledge-based society. At the same time, Malaysia understands that knowledge-based and high-income society has the responsibility of maintaining sustainable environment through the renewable energy and reinforcing its policies towards this objective.

HEIs in Malaysia are requested to consider designing their own smart grids (SG) by bearing in mind that some of the current options such as optimized congestion control, reliability, and break down costs that would work best for them when they opted for smart grids. They can customize the options that best suit their demand based on the needs of the institution, and on the requirements and nature of the energy source that the institution depends on. Along with that, they need to be aware of the factors while implementing the smart grids such as initial investment, return on investment (ROI), security matters, period of obsolescence and privacy. The estimated energy optimization percentages by smart grid implementations across countries such as China, India, and others are above 20\% (El-hawary, 2014). Most recently, regulators and governments are forced to control the CO2 emissions which is moving towards producing clean and green renewable energy. This is an excellent move which should be appreciated without skepticism. The produced green energy needs to be connected to the distribution networks in an efficient mechanism to 
maximize the benefits (Pahwa \& Venkata, 2011). In the Smart Grid Projects today, these technologies are being adopted into electric grid applications, involving devices at the consumer level through the transmission stage in order to make the electric system more responsive and flexible (Zhao et al., 2014).

\subsection{SMART GRIDS}

Alternate energy sources such as Solar, Wind or any other forms such as from Tidal or Hydro resources availability need to be studied with the HEI's data in terms of energy availability and consumption. Each KWH produced for HEI could then be connected to the main supply (Aghasian, Pourtaheri \& Ahmadizadeh, 2013). The cost of energy per MW production from highest to lowest are listed as follows with an exception of location: thermal with coal, thermal with natural gas, bio mass, solar thermal, nuclear, solar PV and hydroelectric and onshore wind. The Annual Energy Outlook 2015, by the US Energy Information Administration for the year 2015 states this clearly (Webber et al., 2006). It is interesting to see all the renewable sources are listed at the lower side and Fossil fuels are on the higher side with the additional issue of limited availability and irreplaceability. Figure 2 shows the cost of production in USD for the renewable energy per KW.

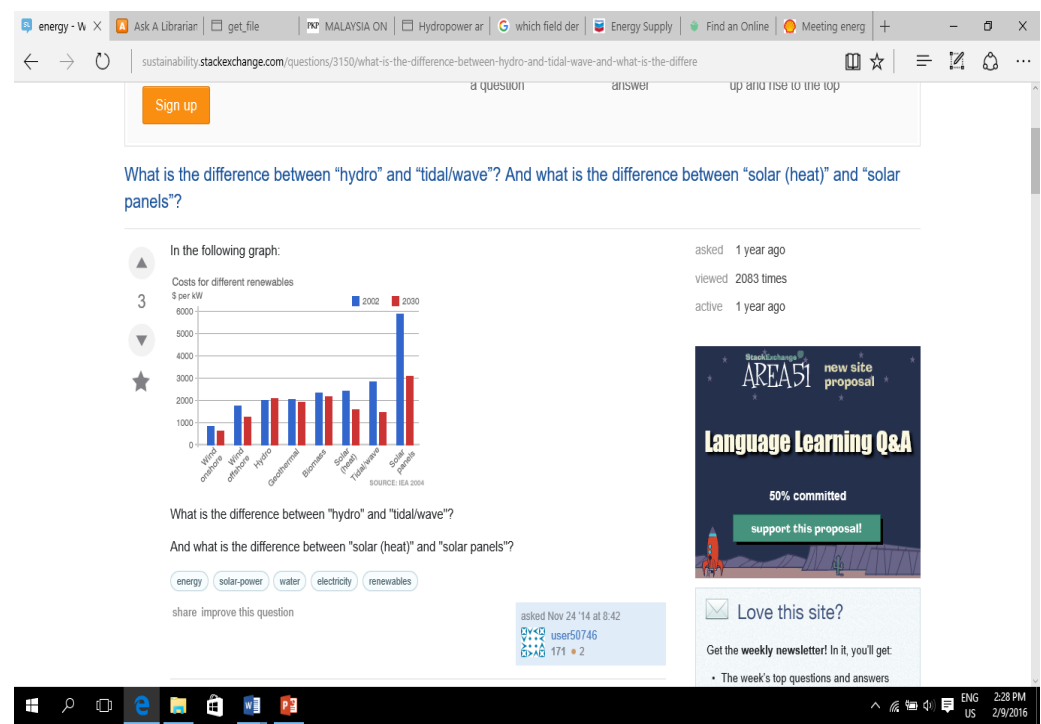

Figure 2. Cost of the production for Renewable Energy in USD per KW. 
Smart grid as defined by Electric Power Research Institute (EPRI) is "A Grid that incorporates information and communication technology into every aspect of electricity generation, delivery, and consumption in order to minimize environmental impact, enhance marketability, improve reliability, efficiency and service, and reduce costs." The main advantages of Smart Grids compared to previous traditional grids are its flexibility of allowing the consumers to play a role in optimizing the operation and provide a greater amount of information about the grid (Wakefield, 2011). It is obviously the appropriate time for HEIs to plan and switch their power supply systems to Smart Grids. Once they have started investing in the alternate energy source, they would reap the benefits it brings from the beginning as the cost of renewable energy generation such as the cost of solar panels are showing a consistent reduction since 1990. Figure 3 shows the cost reduction over the past 27 years and a projection for the coming decade-the graph clearly shows the great advantage of investing in alternative energy in terms of cost of energy production per watt.

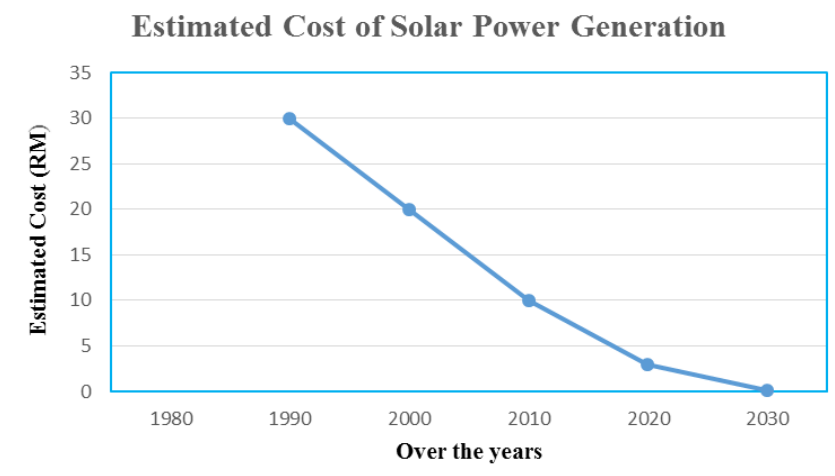

Figure 3. Solar power cost estimation over the years.

\section{IMPLEMENTATION METHODOLOGY}

The proposed research is being carried out in a private University College campus located in Mantin, Negeri Sembilan, Malaysia. The study details energy management within a campus that is built up area of 900,000 square feet with five academic blocks, one administration block, two blocks consisting 50 laboratories, nine lecture halls, and seven meeting rooms. The key factor in this study is to provide renewable 
energy that is suitable for the institution based on their scenario and opportunities available at its location and surroundings. Most importantly, it all depends on how this generated power is connected through a smart grid and to the distribution grid. To convert and maintain the campus as a green campus, a smart grid is proposed, as shown in Figure 4. The smart grid structure shown in Figure 4 could be used as a model Smart Grid for any HEI in Malaysia. In the proposed smart grid model, roof top solar panels and wind turbines are incorporated. The wind speed at the campus is recorded at an average of $5-10 \mathrm{~km} / \mathrm{h}$ throughout the year. This location is suitable for solar power generation as the average daily temperature ranges between 20-35c throughout the year that can easily produce 50W solar power (Mekhilef et al., 2012).

\subsection{THE REAL-TIME ENERGY MANAGEMENT EFFICIENCY}

Higher Education Campus' main energy consumptions are within the classrooms and laboratories. It is therefore crucial that these areas within a campus receive reliable and uninterrupted energy supply. The demands of the energy may vary between academic programmes depending on the nature of the programme and the equipment used to aid the teaching and learning processes. Technical and scientific programmes would require more energy particularly those with the use of heavy machinery for academic and research purposes (El-hawary, 2014).

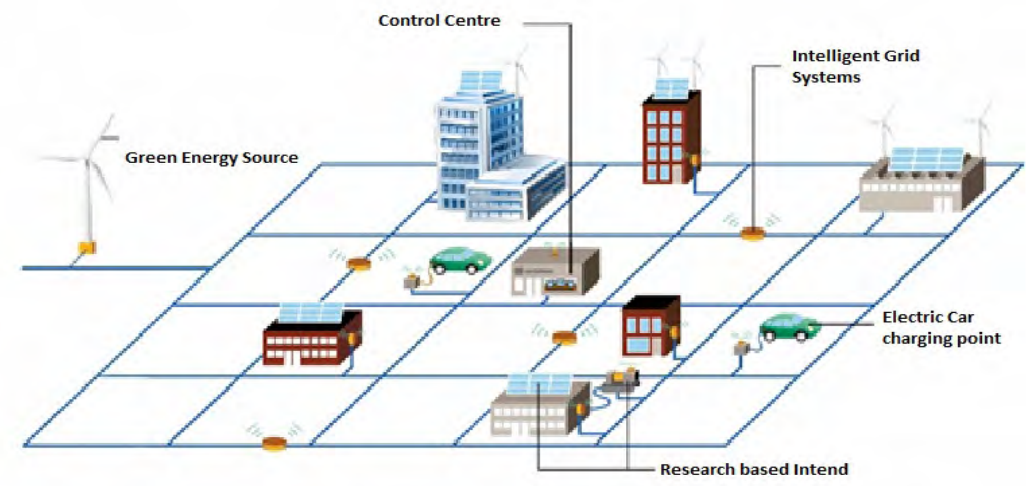

Figure 4. Typical structure of a smart grid for a HEI in Malaysia.

It is proposed that the particular HEI campus allocates Half-hour-ahead rolling optimization and a real-time control strategy are combined with fuzzy logic controller 
for surging optimization in producing high-efficiency energy distribution. A physical test platform has been established and was tested in an academic laboratory (a bench fitting lab) to observe the process in the campus.

\subsection{INTERNET OF THINGS (IOT) PROPOSAL FOR GRID OPERATION}

IoTs are also seen in the part of the total system that is operated in the smart grid system. Controlling the entire grid is possible from a remote location with IoT. Adjustments of power distributions from macro to micro is possible with IoT (Pahwa \& Venkata, 2011). The grid is evolving from the previous traditional one-way system, where power flows from centralized generation stations to consumers, to a platform that can detect, accept, manage, and control decentralized consumption and production resources. This allows power and information to flow as needed in multiple directions to keep the system in balance. As a result, utility executives are trying to determine which technologies merit precious capital resources (Zhao et al., 2014).

\subsection{TIMER CONTROLLED OPERATION FOR AIR-CONDITIONER}

The concept of the proposed circuit structure as shown in Figure 5 is to shut off the air conditioner every 1 hour after the unit is switched on.

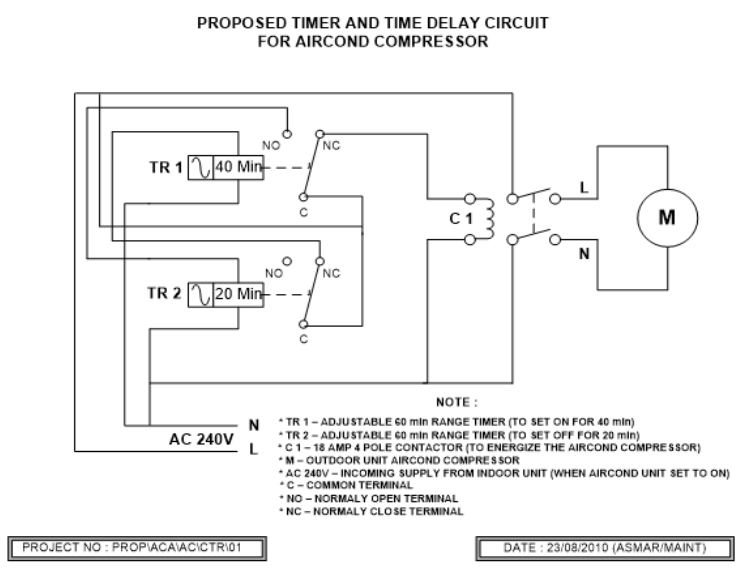

Figure 5. The proposed energy saver structure of an air-conditioner. 
Each time the air conditioner is switched back, the internal air conditioners IC board control will delay the outdoor unit (compressor) up to approximately 15 minutes in order to cool down the system. The user would have to switch on the air conditioner in order to continue its usage. As air conditioners have the highest energy consumption, this proposed method of smart timer structure in an air conditioning system would greatly save the HEI's energy consumption. The HEI's main energy consumption is for Air-conditioning which has been recorded at an average of $60 \%$ over the years.

\section{RESULTS AND DISCUSSIONS}

The two methods proposed for the ICT green campus are sensor controlled lighting arrangement in the laboratories and a timer-controlled air conditioner. These two techniques that were fixed at a nominal cost would fetch a lucrative ROI in less than a month while registering a commendable $40 \%$ in the laboratories, and $25 \%$ in air-conditioning energy optimization. The present HEI campus which is used in this study has a land area of about 200acres. The internal transport from the main entrance can be proposed into using bicycles for the students and for the staff using battery cars. This shows that ROI is expected within a year. There are many other possibilities such as fluorescent tubes could be replaced by LED lamps which can optimize a $30 \%$ reduction in the energy reduction.

\subsection{REAL TIME ENERGY MANAGEMENT LAYOUT}

The main power consumption for the month of May 2017 was $60 \%$ due to the air conditioning. 20\% were for lighting and desk stations, while laboratories were around $11 \%$. For the benefit of this research, each lab was fitted with a remote-controlled sensor that activates whenever there is a room in use. A motion sensor is fitted to each row of tables which controls the usage depending on its occupancy. This smart device is also able to differentiate a real user from a passerby as the motion detector is initiated 3 minutes after the machine is switched on. For lecture halls, the seat occupancy is controlled by the class management team that determines the allocation of the room and the seats inside the auditorium. The electricity consumption from the 
pre-and post-implementation for each of the venues are calculated on a daily basis. In the proposed study, it is assumed that in an 8-hour working day, 8 samples of data between a 15 minutes interval is collected which will result in at least 120 minutes or 2 hours of outdoor off-duty. This would mean no electricity consumption per 1 unit air conditioner per day. With this calculation record, the energy consumption of an air conditioner without a timer and with a timer is shown in Tables 1 and 2.

Table 1. HEl's Energy Consumption of an Air Conditioners without Timer.

\begin{tabular}{|c|c|c|c|c|c|c|c|}
\hline \multirow[b]{2}{*}{$\begin{array}{c}\text { AIRCOND } \\
\text { H/P }\end{array}$} & \multicolumn{7}{|c|}{ ELECTRICAL CONSUMPTION CHARGE CALCULATION FORMULA (NORMAL) } \\
\hline & KW & TARIFF & $\begin{array}{c}\text { RATE/ } \\
\text { HR } \\
\text { (RM) }\end{array}$ & $\begin{array}{c}X 8 \text { HRS } \\
\text { (RM) }\end{array}$ & $\begin{array}{c}\text { X } 20 \\
\text { DAYS } \\
\text { (RM) }\end{array}$ & $\begin{array}{l}\text { X TOTAL } \\
\text { (AC) }\end{array}$ & $\begin{array}{l}\text { AMOUNT } \\
\text { (RM) }\end{array}$ \\
\hline 1.0 & 0.746 & 0.43 & 0.32 & 2.56 & 51.20 & 9 NOS & 460.80 \\
\hline 1.5 & 1.118 & 0.43 & 0.48 & 3.84 & 76.80 & 4 NOS & 307.20 \\
\hline 1.8 & 1.342 & 0.43 & 0.58 & 4.64 & 92.80 & $16 \mathrm{NOS}$ & $1,484.80$ \\
\hline 2.0 & 1.491 & 0.43 & 0.64 & 5.12 & 102.40 & $50 \mathrm{NOS}$ & $5,120.00$ \\
\hline 2.5 & 1.864 & 0.43 & 0.80 & 6.40 & 128.00 & 265 NOS & $33,920.00$ \\
\hline 2.8 & 2.087 & 0.43 & 0.90 & 7.20 & 144.60 & 14 NOS & $2,016.00$ \\
\hline 3.0 & 2.237 & 0.43 & 0.96 & 7.68 & 153.60 & 258 NOS & $39,628.80$ \\
\hline 3.5 & 2.609 & 0.43 & 1.12 & 8.96 & 179.20 & $18 \mathrm{NOS}$ & $3,225.60$ \\
\hline \multirow[t]{2}{*}{5.0} & 3.725 & 0.43 & 1.60 & 12.80 & 256.00 & 64 NOS & $16,384.00$ \\
\hline & & & & & & $\begin{array}{l}\text { TOTAL } \\
\text { COST }\end{array}$ & $\begin{array}{c}\mathrm{RM} \\
102,547.20\end{array}$ \\
\hline
\end{tabular}

Table 2. HEl's Energy Consumption of an Air Conditioners using Timer.

\begin{tabular}{|c|c|c|c|c|c|c|c|}
\hline \multirow{2}{*}{$\begin{array}{l}\text { AIRCOND } \\
\quad \text { H/P }\end{array}$} & \multicolumn{7}{|c|}{$\begin{array}{l}\text { ELECTRICAL CONSUMPTION CHARGE CALCULATION FORMULA (TIMER } \\
\text { CIRCUIT) }\end{array}$} \\
\hline & KW & TARIFF & $\begin{array}{l}\text { RATE/ } \\
\text { HR (RM) }\end{array}$ & $\begin{array}{l}\text { X } 6 \text { HRS } \\
\text { (RM) }\end{array}$ & $\begin{array}{c}X 20 \\
\text { DAYS } \\
\text { (RM) }\end{array}$ & $\begin{array}{l}\text { X TOTAL } \\
\text { (AC) }\end{array}$ & $\begin{array}{l}\text { AMOUNT } \\
\text { (RM) }\end{array}$ \\
\hline 1.0 & 0.746 & 0.43 & 0.32 & 1.92 & 38.40 & 9 NOS & 345.60 \\
\hline 1.5 & 1.118 & 0.43 & 0.48 & 2.88 & 57.60 & 4 NOS & 230.40 \\
\hline 1.8 & 1.342 & 0.43 & 0.58 & 3.48 & 69.60 & 16 NOS & $1,113.60$ \\
\hline 2.0 & 1.491 & 0.43 & 0.64 & 3.84 & 76.80 & 50 NOS & $3,840.00$ \\
\hline 2.5 & 1.864 & 0.43 & 0.80 & 4.80 & 96.00 & $265 \mathrm{NOS}$ & $25,440.00$ \\
\hline 2.8 & 2.087 & 0.43 & 0.90 & 5.40 & 108.00 & 14 NOS & $1,512.00$ \\
\hline 3.0 & 2.237 & 0.43 & 0.96 & 5.76 & 115.20 & 258 NOS & $29,721.60$ \\
\hline
\end{tabular}




\begin{tabular}{|c|c|c|c|c|c|c|c|}
\hline \multicolumn{7}{|c|}{ ELECTRICAL CONSUMPTION CHARGE CALCULATION FORMULA (TIMER } \\
CIRCUIT) \\
$\begin{array}{c}\text { AIRCOND } \\
\text { H/P }\end{array}$
\end{tabular}

The Corridors are fitted with two 40W Fluorescent tubes within a distance of $15 \mathrm{ft}$. Each $(40 x 40) f t$ laboratory is fitted with 8 sets of fluorescent tube lights. There are two $100 \mathrm{~W}$ pedestal industrial fans that are connected along with two units of $2.5 \mathrm{hp}$ air-conditioners. Normal working hours are 8 AM to 4:30 PM. Average operating hours in a day are 5 hours. When a laboratory is in operation, the consumption within the laboratory totals up to 5700W (8X80W + 2X200 + 940X2.5X2). We have fitted the sensor control circuit shown in Figure 3 with an initial cost of RM700. This circuit is tested for an hour usage in the bench-fitting workshop and it does not draw any other energy other than lighting and air-conditioning.

From Tables 1 and 2, it is observed that a total of RM 25,636.80 can be saved. This is equivalent to $25 \%$ of savings every month by using this idea of delaying every single air conditioner for up to 2 hours daily in its operation. Table 3 shows the total airconditioners required and its costs for the entire academic operation. Table 4. Shows the electrical items that are purchased for constructing the control module in an air conditioner at the HEI.

Table 3. Total Air Conditioners required and its cost.

\begin{tabular}{|c|c|c|c|c|}
\hline PHASE & $\begin{array}{c}\text { AREA } \\
\text { COVERED }\end{array}$ & $\begin{array}{c}\text { TOTAL } \\
\text { AIRCOND }\end{array}$ & $\begin{array}{c}\text { COSTING in } \\
\text { RM }\end{array}$ & REMARKS \\
\hline 1 & Block A1 Till A5 & 296 Unit & $16,537.00$ & \\
\hline 2 & Admin Block & 226 Unit & $12,317.00$ & \\
\hline 3 & Block B1 \& B2 & 176 Unit & $9,592.00$ & \\
\hline & TOTAL & $\begin{array}{c}698 \text { Unit + } \\
\text { Extra }\end{array}$ & $38,446.00$ & + + RM 109.00 \\
\hline & GRAND TOTAL & 700 Unit & $38,555.00$ & \\
\hline
\end{tabular}


Table 4. Control modules cost for an Air Conditioners.

\begin{tabular}{|c|l|c|c|c|}
\hline NO & ITEM DESCRIPTION & $\begin{array}{c}\text { ESTIMATE } \\
\text { PRICE (RM) }\end{array}$ & QUANTITY & $\begin{array}{c}\text { TOTAL PRICE } \\
\text { (RM) }\end{array}$ \\
\hline 1. & 60 Minute Timer Relay (jkn) & $48.00 / \mathrm{Pc}$ & $700 \mathrm{nos}$ & $33,600.00$ \\
\hline 2. & 8 Pin Socket Base & $6.50 / \mathrm{Pc}$ & $700 \mathrm{nos}$ & $4,550.00$ \\
3. & Socket Railing (Alluminium) & $15.00 / \mathrm{Meter}$ & $15 \mathrm{pcs}$ & 225.00 \\
\hline 4. & Pvc Black Tape & $0.60 / \mathrm{Pc}$ & $50 \mathrm{rolls}$ & 30.00 \\
\hline 5. & Connector & $1.50 / \mathrm{Pc}$ & $100 \mathrm{pcs}$ & 150.00 \\
\hline & Grand Total & & & $\mathbf{R M ~ 3 8 , 5 5 5 . 0 0}$ \\
\hline
\end{tabular}

This simple mechanism and its installation worked extremely well for a period of 1 month with an average of $25 \%$ reduction in the energy usage and its direct cost. The graph shown in Figure 6 explains the monthly energy consumption distribution for the entire campus.

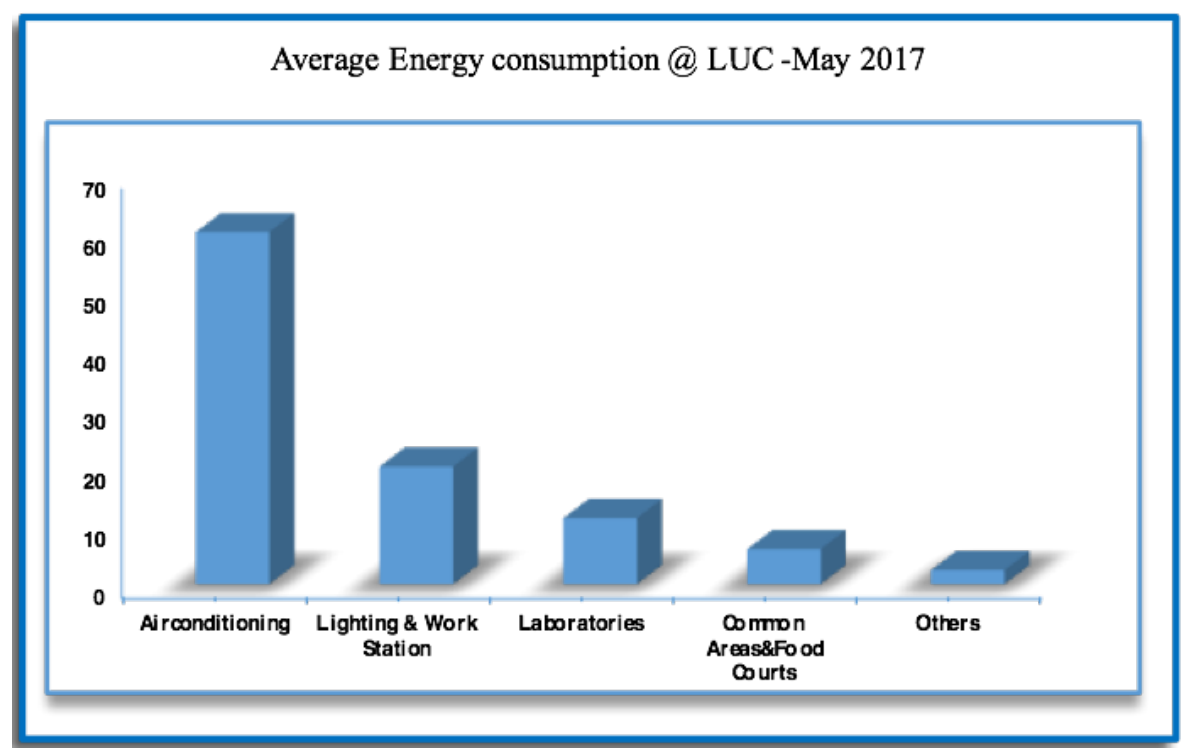

Figure 6. The monthly energy distribution of one HEI (Linton University College).

The motion detection sensors assisted in regulating and optimizing the usage as per classroom occupancy. This new technique proposed in the new circuit diagram has been used to continue observations for a period of one month with full capacity, partial capacity and within lower occupancy classrooms. The lower occupancies have a difference of up to $1700 \mathrm{~W}(70 \%)$ reduction and medium occupancy has $3130 \mathrm{~W}(45 \%)$ while the full occupancy has $600 \mathrm{~W}(10 \%)$. The difference from these 
three scenarios make an average of $40 \%$ reduced consumption. The same circuit setup holds good for a classroom and lecture halls with a difference in the number of equipment fitted. When ROI was calculated for the RM700 spent, the investment was returned within a month. The energy savings for the rest of the days in the year and in the future, will complement its usage. Further research is however needed especially in the areas of synchronizing with smart grid management and IoT. Such a paradigm change needs to begin from academic institutions in order to be forged by the society for the betterment of life and to fight against global warming.

\section{CONCLUSION}

Energy production and distribution are equally important and with the new technologies on board, the distribution with the help of smart grid has become resilient and efficient. The two methods proposed which are the timer-controlled air conditioner and motion-sensor-controlled lighting arrangements in the laboratories have proved that energy saving is $40 \%$ in average with the RoI within a month when compared to the previous energy costs. Similarly, Malaysian HEIs should focus on the possible ways to generate power, considering and incorporating the scale and technology that is convenient and available for the institution, and to integrate them with the distribution network with the help of smart grids that are monitored by ICT to realize the Green ICT Campus for better, greener world.

\section{REFERENCES}

Aghasian, E., Pourtaheri, H., \& Ahmadizadeh, E. (2013). An Investigation on Current Situation of Green ICT in University Technology Malaysia-Based on Stage of Growth and Monitoring Green Technology Standardization Criteria. Open International Fournal of Informatics (OIfI), 1(1), 18-28. Retrieved from: http:// apps.razak.utm.my/ojs/index.php/oiji/article/view/95

Ahola, J., Ahlqvist, T., Ermes, M., Myllyoka, J., \& Savola, J. (2009). ICT for Environmental Sustainability. VTT Research Notes. 
Gabrera, D.F., \& Zareipour, H. (2011). A Review of Energy Efficiency Initiatives in Post-Secondary Educational Institutes in Proceedings of the First International Conference on Smart Grids, Green Communications and IT Energy-aware Technologies. Paper presented at First International Conference on Smart Grids, Green Communications and IT Energy-aware Technologies.

Chai-Arayalert, S., \& Nakata, K. (2011) The Evolution of Green ICT Practice: UK Higher Education Institutions Case Study. In Proceedings of the 2011 IEEE/ ACM International Conference on Green Computing and Communications, 220-225. Paper presented at IEEE/ACM International Conference on Green Computing and Communications. IEEE Computer Society.

Du Pisani, J.A. (2006). Sustainable development-historical roots of the concept. Environmental Sciences, 3(2), 83-96. doi:https://doi. org/10.1080/15693430600688831

El-hawary, M.E. (2014). The Smart Grid - State-of-the-art and Future Trends. Electric Power Components and Systems, 42(3-4), 239-250. doi: https://doi. org/10.1109/MEPGON.2016.7836856

Fettweis, G. P., \& Zimmermann, E. (2008). ICT Energy Consumption-Trends and Challenges. In Proceedings of the 11th International Symposium on Wireless Personal Multimedia Communications (WPMC'08). Paper presented at 11 th International Symposium on Wireless Personal Multimedia Communications (WPMC'08). Lapland, Finland.

Howlett, G., Ferreira, J.A.L., \& Blomfield, J.M. (2016). Teaching Sustainable Development in Higher Education: Building Gritical Reflective Thinkers through an Interdisciplinary Approach. International Journal of Sustainability in Higher Education, 17(3), 305-321. doi: https://doi.org/10.1108/IJSHE-07-2014-0102

Mekhilef, S., Safari, A., Mustaffa, W.E.S., Saidur, R., Omar, R., \& Younis, M.A.A. (2012). Solar Energy in Malaysia: Current State and Prospects. Renewable and Sustainable Energy Reviews, 16(1), 386-396. doi: https://doi.org/10.1016/j. rser.2011.08.003 
Ministry of Higher Education Malaysia. (2016). Makro Institusi Pendidikan Tinggi, 1. Retrieved from: http://www.mohe.gov.my/en/download/awam/ statistik/2016-statistik

Nasibulina, A. (2015). Education for Sustainable Development and Environmental Ethics. Procedia-Social and Behavioral Sciences, 214, 1077-1082. doi: https://doi. org/10.1016/j.sbspro.2015.11.708

Pahwa, A., \& Venkata, S.S. (2011). Preparing the Workforce for Smart Distribution Systems. In Proceedings of IEEE PES Innovative Smart Grid Technologies Asia (ISGT). Presented at of IEEE PES Innovative Smart Grid Technologies Asia (ISGT), 1-3. Perth, Australia.

Ritchie, H., \& Roser, M. (2017). $\mathrm{CO}_{2}$ and other Greenhouse Gas Emissions. Retrieved from: https://ourworldindata.org/co2-and-other-greenhouse-gas-emissions

Singh, S. (2017). How long will fossil fuels last? Retrieved from: https:/ /www.businessstandard.com/article/punditry/how-long-will-fossil-fuels-last-115092201397_1. html

Suryawanshi, K.Y., \& Narkhede, S. (2014). Green ICT at Higher Education Institution: Solution for Sustenance of ICT in Future. International Fournal of Computer Applications, 107(14), 35-38. doi: https://doi.org/10.5120/18823-0237

The Organisation for Economic Gooperation and Development. (2018) OECD work on Climate Action. Retrieved from: http:/ /www.oecd.org/environment/ action-on-climate-change

Vare, P., \& Scott, W. (2007). Learning for a Change: Exploring the Relationship between Education and Sustainable Development. Fournal of Education for Sustainable Development, 1(2), 191-198. doi: https://doi.org/10.1177/097340820700100209

Wakefield, M.P. (2011). Smart Distribution System Research in EPRI's Smart Grid Demonstration Initiative. IEEE Power and Energy Society General Meeting, 1-4. doi: https://doi.org/10.1109/PES.2011.6039386 
Wals, A.E.J., \& Jickling, B. (2002). "Sustainability" in Higher Education: From Doublethink and Newspeak to Critical Thinking and Meaningful Learning. International Fournal of Sustainability in Higher Education, 3(3), 221-232. doi: https:// doi.org/10.1016/S0952-8733(02)00003-X

Webber, G.A., Roberson, J.A., McWhinney, M.G., Brown, R.E., Pinckard, M.J., \& Busch, J.F. (2006). After-hours Power Status of Office Equipment in the USA. Energy, 31, 2487-2502. doi: https://doi.org/10.1016/j.energy.2005.11.007

Zhao, J., Wang, C., Zhao, B., Lin, F., Zhou, Q., \& Wang, Y. (2014). A Review of Active Management for Distribution Networks: Current Status and Future Development Trends. Electric Power Components and Systems, 42(3-4), 280-293. doi: https://doi.org/10.1080/15325008.2013.862325 


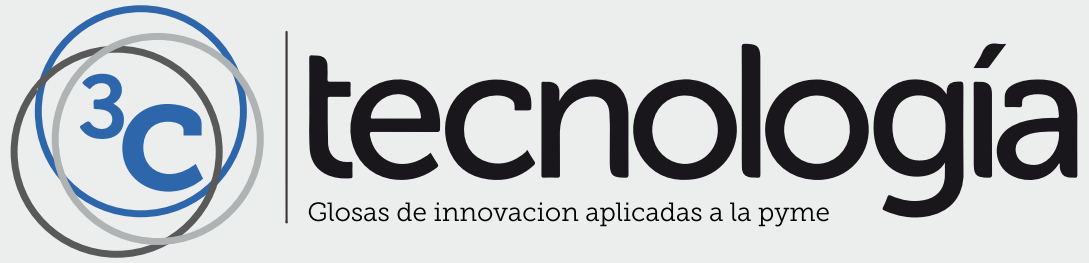

